University of Rhode Island

DigitalCommons@URI

Open Access Dissertations

2011

\title{
AN ANALYSIS OF MARINE RESERVE CO-MANAGEMENT WITHIN THE CARIBBEAN: FACTORS INFLUENCING STAKEHOLDER PARTICIPATION
}

Sarah Lindley Smith

University of Rhode Island, ssmith29@my.uri.edu

Follow this and additional works at: https://digitalcommons.uri.edu/oa_diss

\section{Recommended Citation}

Smith, Sarah Lindley, "AN ANALYSIS OF MARINE RESERVE CO-MANAGEMENT WITHIN THE CARIBBEAN: FACTORS INFLUENCING STAKEHOLDER PARTICIPATION" (2011). Open Access Dissertations. Paper 78. https://digitalcommons.uri.edu/oa_diss/78

This Dissertation is brought to you for free and open access by DigitalCommons@URI. It has been accepted for inclusion in Open Access Dissertations by an authorized administrator of DigitalCommons@URI. For more information, please contact digitalcommons-group@uri.edu. 


\title{
AN ANALYSIS OF MARINE RESERVE CO-MANAGEMENT WITHIN THE CARIBBEAN: FACTORS INFLUENCING STAKEHOLDER PARTICIPATION
}

SARAH LINDLEY SMITH

\begin{abstract}
A DISSERTATION SUBMITTED IN PARTIAL FULFILLMENT OF THE REQUIREMENTS FOR THE DEGREE OF

DOCTOR OF PHILOSOPHY
\end{abstract}

IN

MARINE AFFAIRS

UNIVERSITY OF RHODE ISLAND

2011 


\section{DOCTOR OF PHILOSOPHY DISSERTATION}

OF

SARAH LINDLEY SMITH

\section{APPROVED:}

Thesis Committee:

Major Professor __ Richard Pollnac

Tracey Dalton

Graham Forrester

Nasser H. Zawia

DEAN OF THE GRADUATE SCHOOL

\section{UNIVERSITY OF RHODE ISLAND}




\begin{abstract}
The goal of the research is to critically analyze co-management as a tool for sustainable marine resource management through improved understanding of stakeholder participation in co-management. This critique is based on the underlying hypothesis that co-management will lead to greater representation and participation of stakeholders in management and that successful co-management is that which encompasses a wide range of stakeholder perspectives in the decision-making process. This study investigates variability in the involvement of stakeholders in selected examples of existing co-management arrangements developed to manage marine reserves within the wider Caribbean. An understanding of the factors contributing to and dynamics of stakeholder participation is essential for promoting effective resource co-management. As a way of understanding the success of governance arrangements in reserve management, a comparative analysis of several sites has been conducted to ascertain some of the factors influencing the extent of stakeholder participation in comanagement arrangements, including the importance of social networks in fostering knowledge of and participation in management. A secondary objective of this dissertation is to use network analysis to determine what impact the underlying social network has on the co-management arrangement, and on stakeholder participation in comanagement.
\end{abstract}

This dissertation seeks to answer the following questions: 1) How do social networks affect participation?; 2) What is the relationship between successful comanagement and social networks?; 3) What does successful co-management look like? 
Additionally, management recommendations are provided to improve co-management processes at each of the MPAs included in this study.

This research includes six marine protected areas from around the Caribbean with some form of co-management in place selected as case studies. Residents of the communities adjacent to the marine protected areas were surveyed about their participation in management activities and about their knowledge of individuals responsible for making decisions about the marine protected area. Responses were analyzed to uncover factors that may influence participation by community members, and a social network analysis was conducted for each of the study sites based on the names provided by respondents. The effect of social network characteristics on participation is discussed, and the qualities of successful co-management are enumerated. 


\section{ACKNOWLEDGEMENTS}

I am sincerely indebted to a number of people, without whom this project, from conception to completion, would never have been possible. I wish to extend my deepest gratitude to Dr. Richard Pollnac, whose support and persistence made this all possible, and to Drs. Tracey Dalton and Graham Forrester, who allowed me to travel to the Caribbean as part of this project, and who provided invaluable guidance along the way. I would also like to offer my sincere thanks to Dr. Robert Pomeroy for providing me with comments and suggestions throughout the last few years as this dissertation took shape. I am grateful to Dr. Carlos Garcia-Quijano for his many thoughtful comments.

Much appreciation is owed to the many incredible friends I have made while in graduate school, from Marine Affairs and throughout the university, for providing inspiration and intellectual challenge. I am particularly indebted to Kate Mulvaney and Azure Westwood for their assistance with data collection, their company, and their humor. I owe a very special thanks to Dawn Kotowicz, who served as a research assistant and travel partner for much of this project, and an invaluable source of advice and encouragement for the rest of it. Much love and gratitude are due to Brennan Phillips for pushing me to finish the last pages and cheering me to the end. My sincerest thanks also extend to my family, who have supported and encouraged every dream, academic and otherwise, from the very beginning.

This work was supported by a Doctoral Dissertation Improvement Grant from the National Science Foundation, for which I am thankful. Finally, this work would not have been possible without the cooperation and generosity of the numerous individuals 
around the Caribbean who graciously answered my questions and provided the foundation for my research. 


\section{TABLE OF CONTENTS}

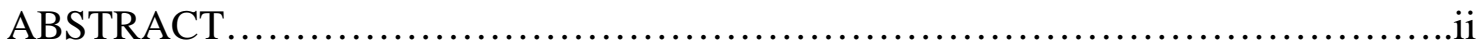

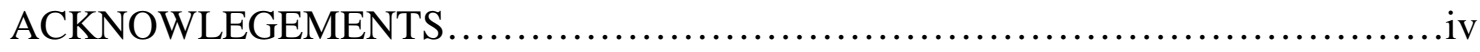

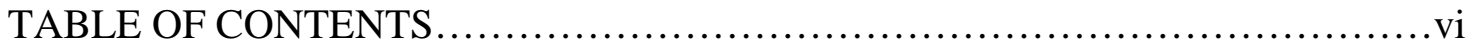

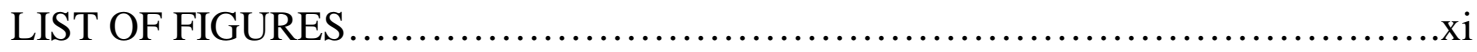

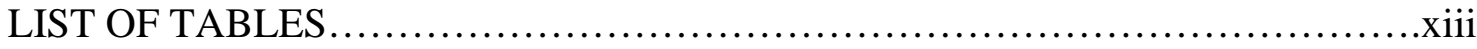

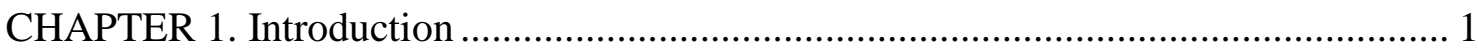

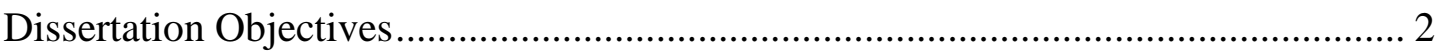

CHAPTER 2. LITERATURE REVIEW ........................................................... 7

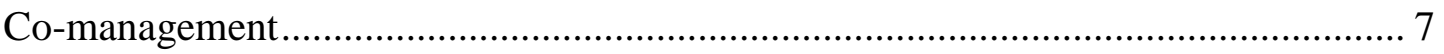

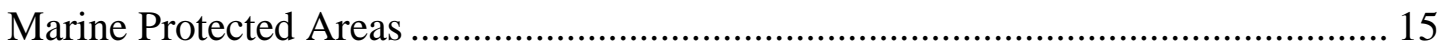

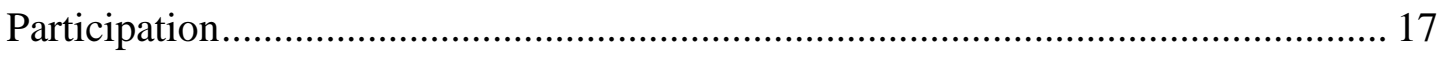

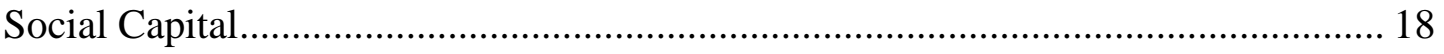

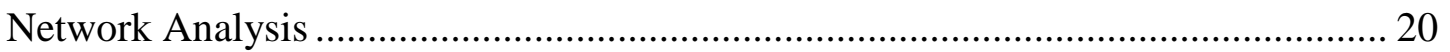

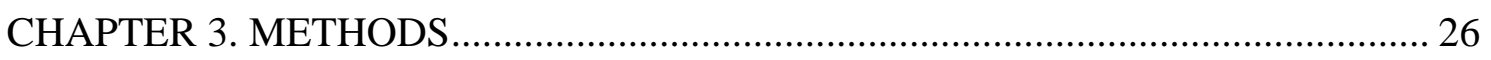

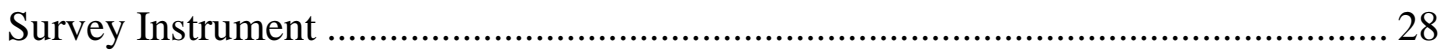

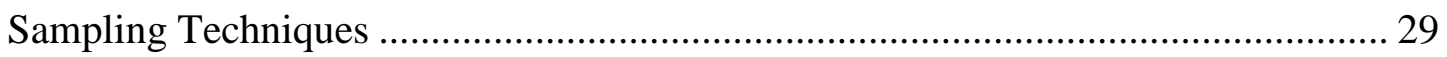

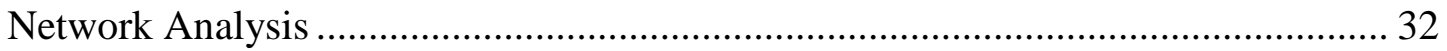

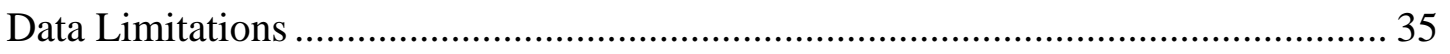

CHAPTER 4. SITE DESCRIPTIONS AND ANALYSIS ............................................ 38

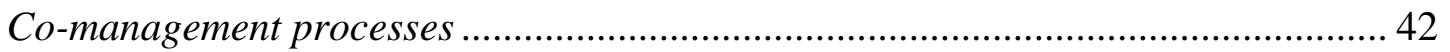

Participatory processes …………………………………............................. 43

Soufriere/Scotts Head Marine Reserve .................................................................. 46 


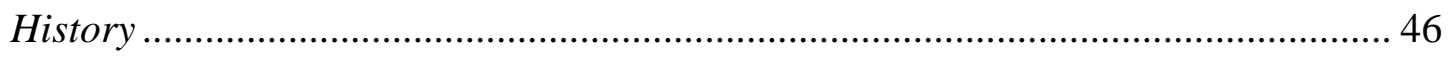

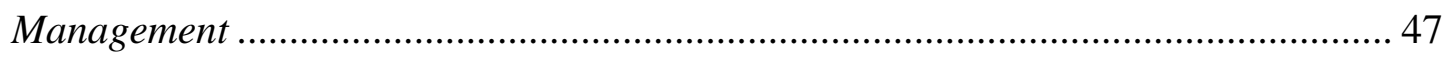

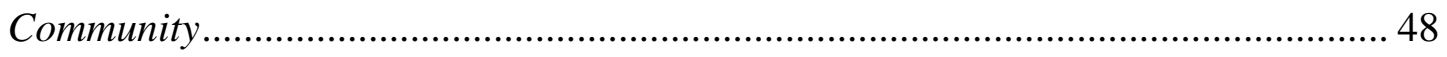

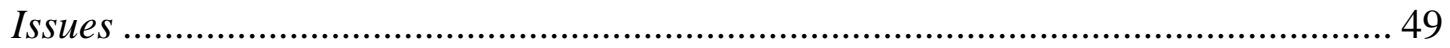

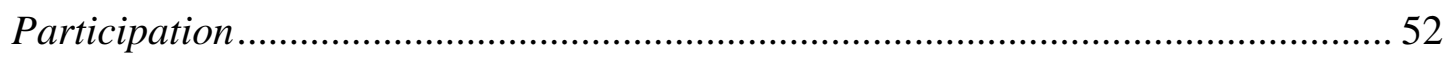

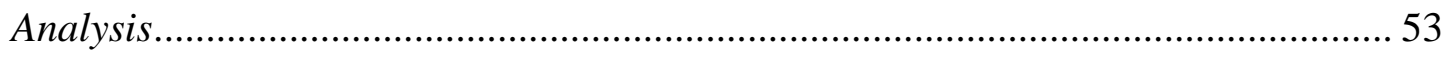

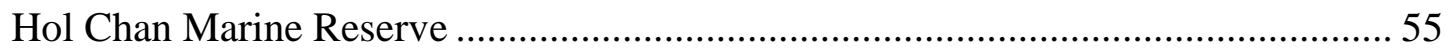

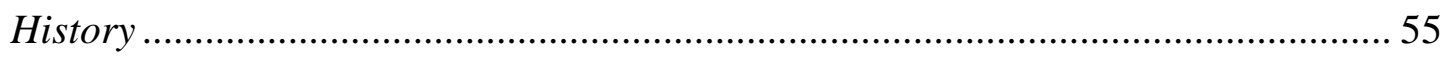

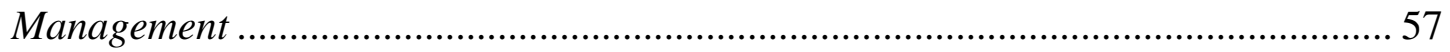

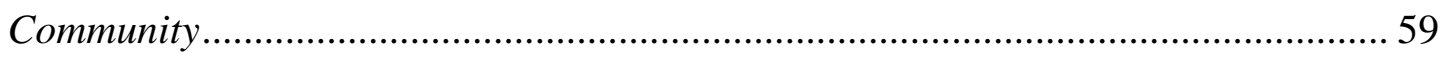

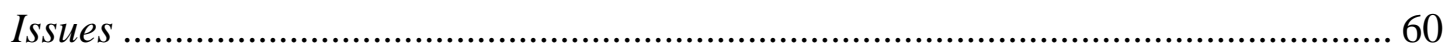

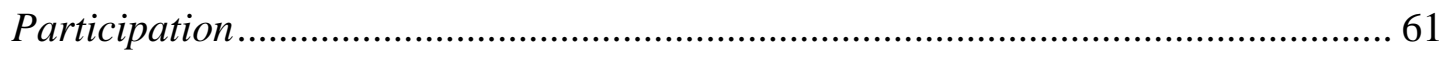

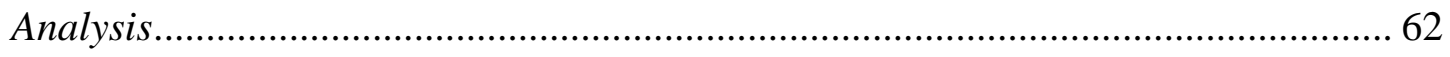

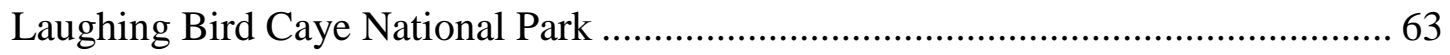

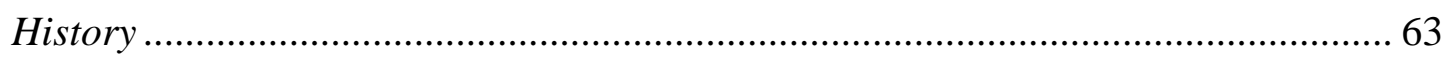

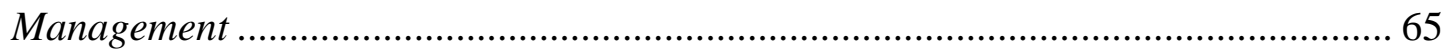

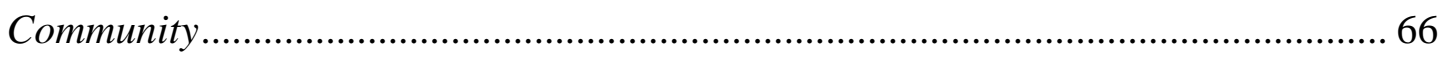

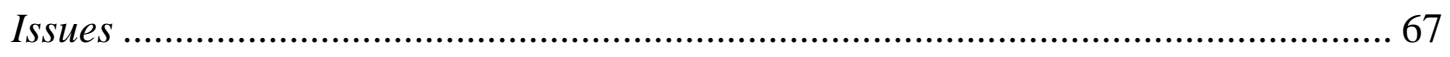

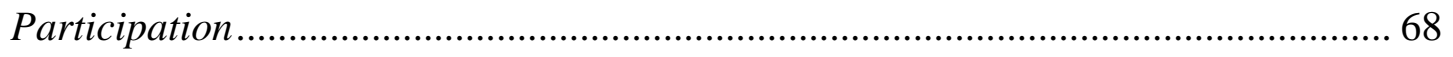

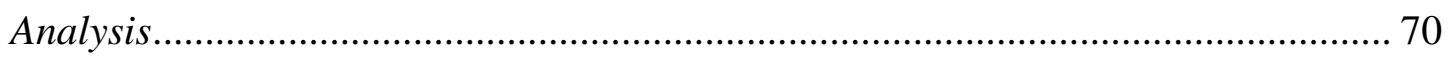

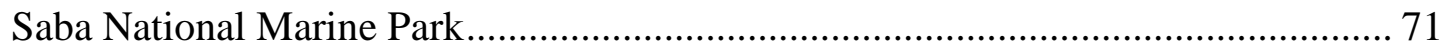

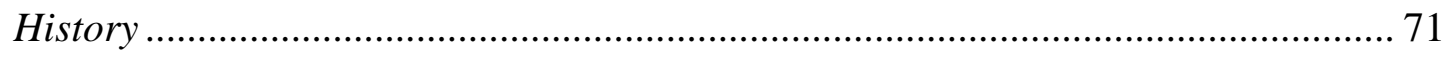

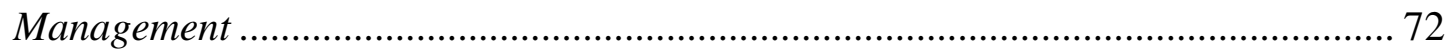




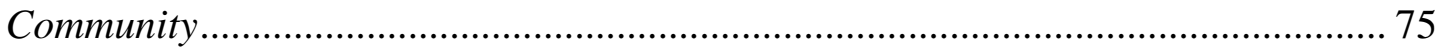

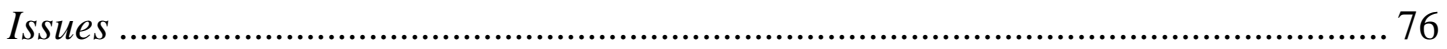

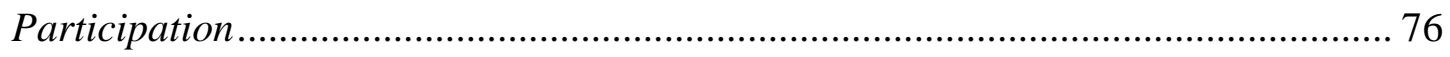

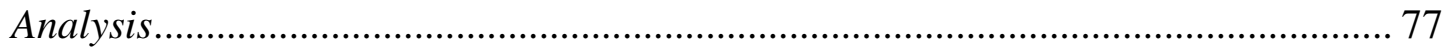

St. Eustatius National Marine Park .................................................................. 78

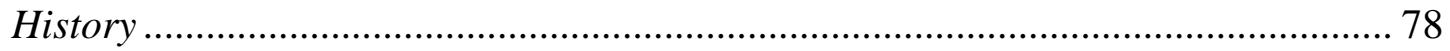

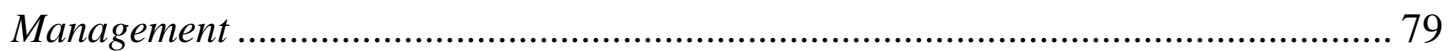

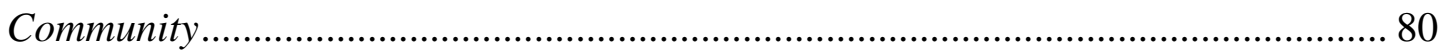

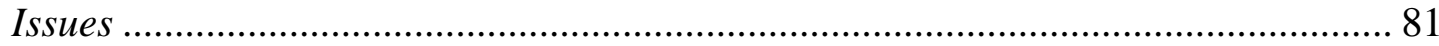

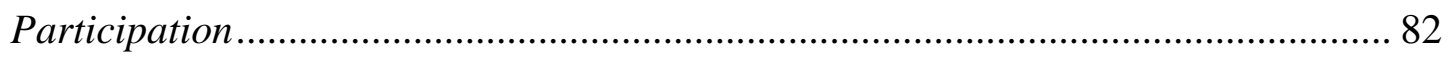

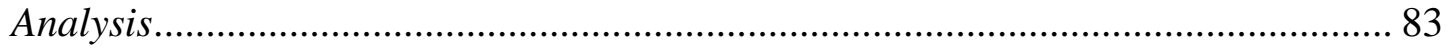

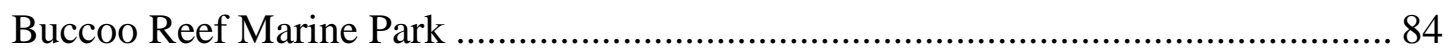

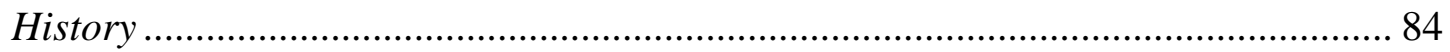

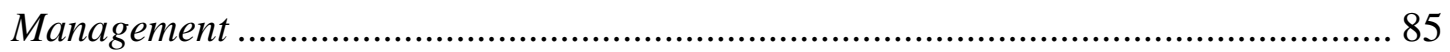

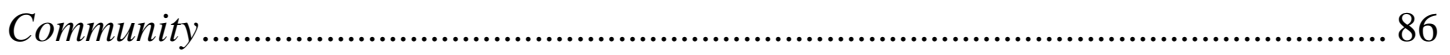

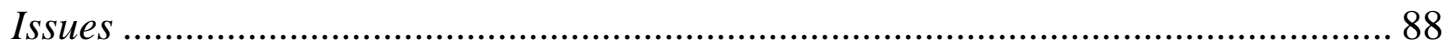

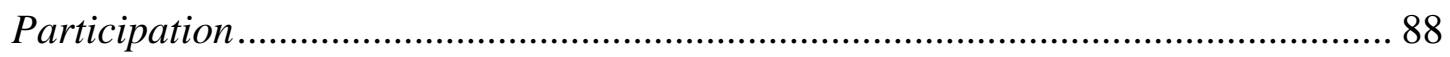

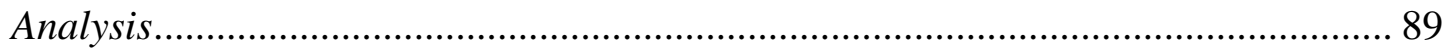

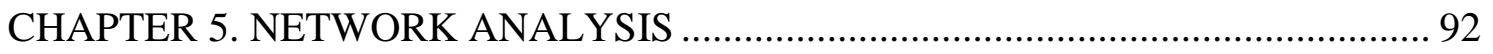

Communication Networks for Six Marine Protected Areas .................................. 92

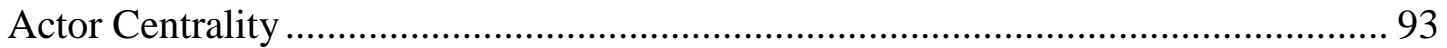

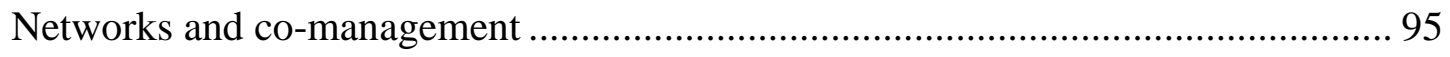

SCOTTS HEAD/SOUFRIERE MARINE RESERVE.......................................... 96 
Scotts Head/Soufriere Marine Reserve - Degree Centrality .................................... 101

ST. EUSTATIUS NATIONAL MARINE PARK................................................... 108

St. Eustatius National Marine Park.................................................................... 110

LAUGHING BIRD CAYE NATIONAL PARK ……………………................... 114

Laughing Bird Caye National Park- Degree Centrality .......................................... 116

HOL CHAN MARINE RESERVE …………………….................................... 123

Hol Chan Marine Reserve Degree Centrality ........................................................ 125

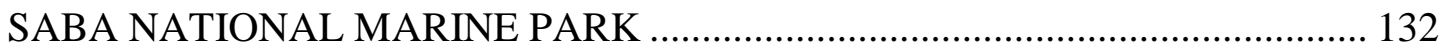

Saba National Marine Park Degree Centrality ..................................................... 134

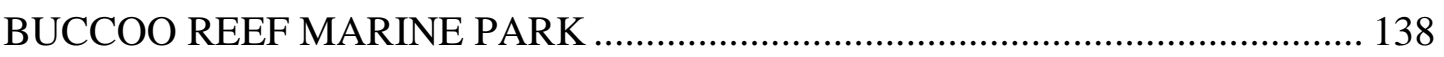

Buccoo Reef Marine Reserve - Degree Centrality .................................................. 140

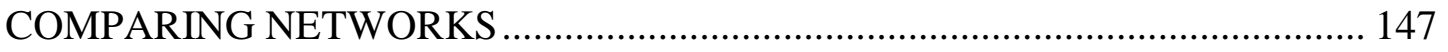

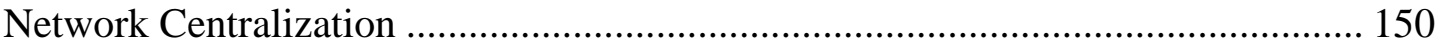

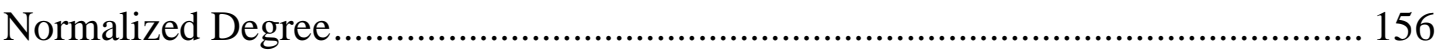

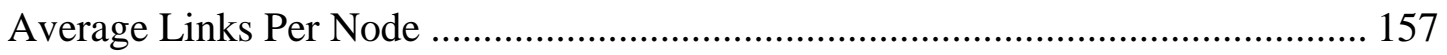

Networks and Co-Management Revisited ............................................................. 159

CHAPTER 6. ANALYZING PARTICIPATION IN CO-MANAGEMENT ............... 161

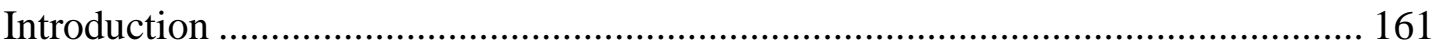

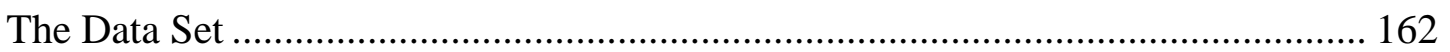

Comparison of Responses by Occupation .............................................................. 166

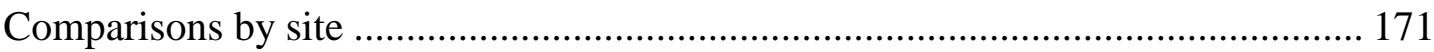

Comparing Participation by Site …………………………................................ 176

Attending meetings and having one's interests represented..................................... 179 
Logistic Regression to Predict Participation ........................................................ 182

Predictors of Naming Others Involved in Management............................................ 190

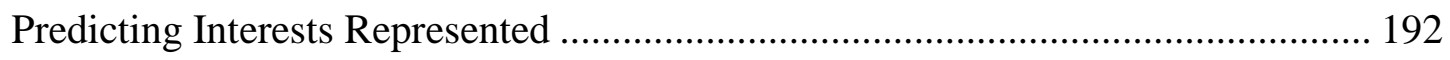

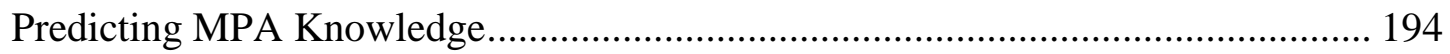

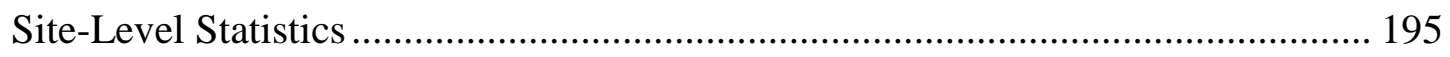

Comparison of Survey Data with Network Data................................................... 198

Comparing individual network measures by site ………....................................... 200

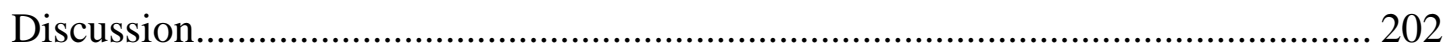

CHAPTER 7. DISCUSSION AND RECOMMENDATIONS ………….................... 205

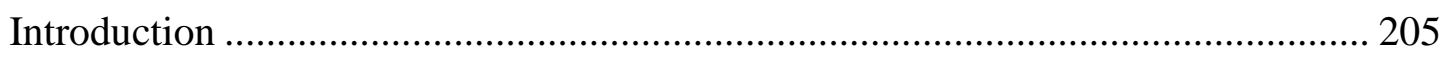

How do social networks affect participation? ......................................................... 206

What is the relationship between successful co-management and social networks?208

What does successful co-management look like? ................................................. 213

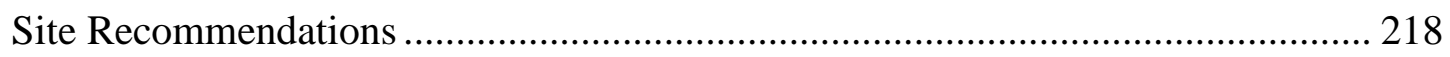

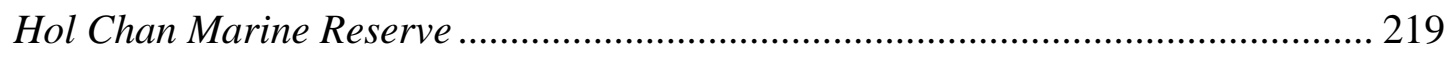

Scotts Head/Soufriere Marine Reserve ………………….................................... 219

St. Eustatius National Marine Park..................................................................... 220

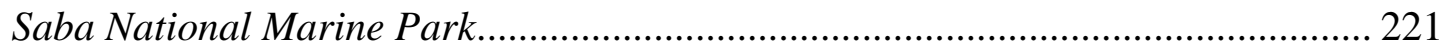

Laughing Bird Caye National Park...................................................................... 221

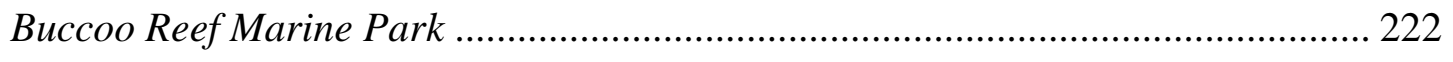

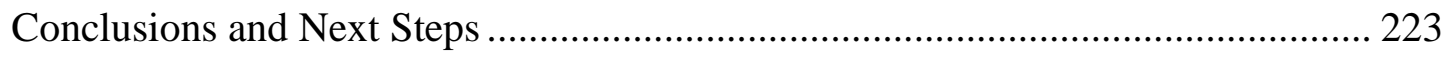

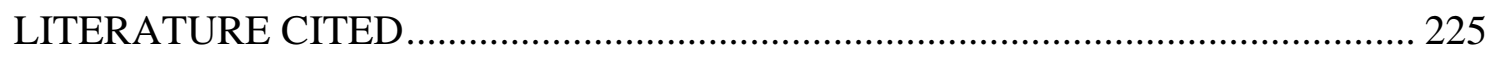




\section{LIST OF FIGURES}

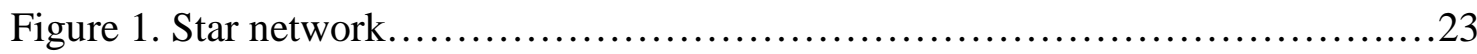

Figure 2. Relationship of social capital and agency to collective action................25

Figure 3. Arnstein's Ladder of Participation (1969) ………………............................. 44

Figure 4. Scotts Head/Soufriere Marine Reserve network graph .................................... 98

Figure 5. SSMR - Freeman Degree Centrality network graph. …….......................... 103

Figure 6. Scotts Head/Soufriere Marine Reserve network diagram with interests

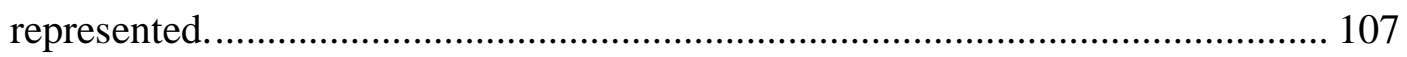

Figure 7. St. Eustatius National Marine Park - full network graph ............................... 109

Figure 8. St. Eustatius National Marine Park - Freeman Degree Centrality ................. 112

Figure 9. Laughing Bird Caye National Park - full network diagram ......................... 115

Figure 10. Laughing Bird Caye National Park - Freeman Degree Centrality .............. 118

Figure 11. Laughing Bird Caye National Park full network diagram with interests

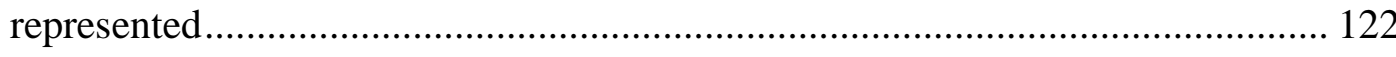

Figure 12. Hol Chan Marine Reserve full network graph ........................................... 124

Figure 13. Hol Chan Marine Reserve - Freeman Degree Centrality ………………..... 126

Figure 14. Hol Chan Marine Reserve - interests represented ..................................... 133

Figure 15. Saba National Marine Park network with occupation and participation .... 134

Figure 16. Saba National Marine Park - Freeman Degree Centrality ……………...... 136

Figure 17. Buccoo Reef Marine Park - full network diagram ...................................... 139

Figure 18. Buccoo Reef Marine Park - Freeman Degree Centrality ………….............. 142

Figure 19. Buccoo Reef Marine Park full network with interests represented ............ 146

Figure 20. Participation rate and network centralization measure by site.................... 197 


\section{LIST OF TABLES}

Table 1. Co-management spectrum (from Pomeroy et al. 2004)............................... 10

Table 2. MPAs selected for data collection .......................................................... 27

Table 3. Percentage of population surveyed............................................................. 32

Table 4. Summary of study sites and factors relevant to participation at each............ 40

Table 5. Summary of Stage of Implementation and Level of Co-Management of Sites 43

Table 6. Summary of Level and Extent of Participation at each site ........................... 45

Table 7. Definitions of key network analysis terms .............................................. 93

Table 8. SSMR Freeman Degree Centrality - Symmetric ....................................... 101

Table 9. Frequency of actors named by fishermen for SSMR ............................... 105

Table 10. Frequency of actors named by tour guides for SSMR ............................ 105

Table 11. Frequency of actors named by tourism workers for SSMR ....................... 106

Table 12. Freeman Degree Centrality for St. Eustatius National Marine Park network

Table 13. Frequency of actors named by tourism workers for St. Eustatius National Marine Park 113

Table 14. Laughing Bird Caye National Park Freeman Degree Centrality - Symmetric 116

Table 15. Frequency of actors named by fishermen for Laughing Bird Caye National

Park

Table 16. Frequency of actors named by tour guides for Laughing Bird Caye National

Park 120 
Table 17. Frequency of actors named by tourism workers for Laughing Bird Caye National Park

Table 18. Hol Chan Marine Reserve Freeman Degree Centrality - Symmetric 125

Table 19. Frequency of actors named by fishermen for the Hol Chan Marine Reserve 128

Table 20. Frequency of actors named by tour guides for the Hol Chan Marine Reserve 128

Table 21. Frequency of actors named by tourism workers for the Hol Chan Marine Reserve 128

Table 22. Saba National Marine Park Freeman Degree Centrality - Symmetric 134

Table 23. Frequency of actors named by tourism workers for Saba National Marine Park

Table 24. Buccoo Reef Marine Park - Freeman Degree Centrality..... 140

Table 25. Frequency of actors named by fishermen for Buccoo Reef Marine Park .... 144

Table 26. Frequency of actors named by tour guides for Buccoo Reef Marine Park .. 145

Table 27. Frequency of actors named by tourism workers for Buccoo Reef Marine Park

Table 28. Network measures 148

Table 29. Terms used to describe networks 148

Table 30. Average Links Per Node 157

Table 31. Number of surveys conducted at each site 162

Table 32. Comparison of respondents from each site 162

Table 33. Respondents by Gender. 163 
Table 34. Summary of respondents by occupation 165

Table 35. Coding of participation questions. 166

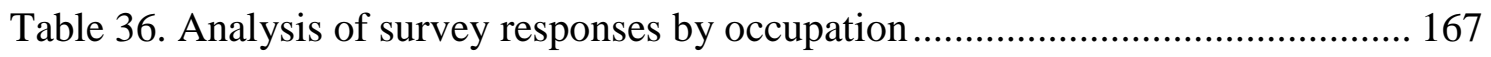

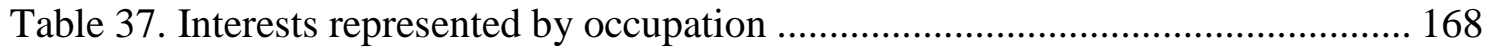

Table 38. Participation data by socioeconomic variables. ..................................... 169

Table 39. Hol Chan Marine Reserve ............................................................... 171

Table 40. St. Eustatius National Marine Park ....................................................... 173

Table 41. Scotts Head/Soufriere Marine Reserve .................................................. 173

Table 42. Saba National Marine Park..................................................................... 174

Table 43. Laughing Bird Caye National Park ....................................................... 174

Table 44. Buccoo Reef Marine Park ..................................................................... 175

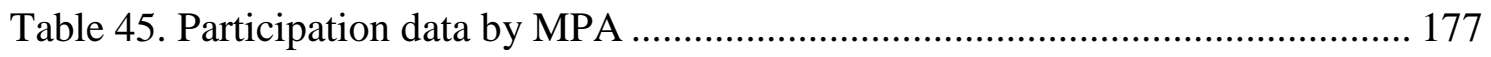

Table 46. Interests Represented and Meeting Attendance ................................... 181

Table 47. Results of Logistic Regression to predict Participation ............................ 183

Table 48. Results of Logistic Regression to predict Participation (with Fishermen, Tour

Guide, and Tourism used as predictor variables) ….................................... 186

Table 49. Results of Logistic Regression to predict participation for Hol Chan Marine

Reserve 189

Table 50. Results of Logistic Regression to predict naming someone involved in the MPA 190

Table 51. Results of Logistic Regression to predict whether respondents feel their interests are represented. 193

Table 52. Results of Logistic Regression to predict awareness of MPA. 194 
Table 53. Analysis of individual network measures

Table 54. Mean degree and betweenness centrality by meeting attendance for individual sites

Table 55. Mean degree and betweenness centrality by interests represented for

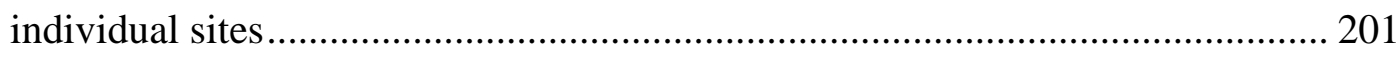




\section{CHAPTER 1. Introduction}

As natural resources worldwide have continued to decline from overexploitation and other anthropogenic stressors in spite of existing conventional management regimes, there is a growing recognition of the need to reconsider natural resource management approaches. Increasingly in the literature, there is a focus on linking social and ecological systems in order to promote sustainability (Carlsson and Berkes, 2005). This speaks to a more holistic system of management, where human and natural communities are viewed as inextricably linked and must be managed concomitantly. A logical progression from this shift in focus has been the movement toward integrating human communities into natural resource management, incorporating the resource users in management in an attempt to achieve more effective, equitable, and efficient management processes (e.g. Pomeroy and Berkes 1997).

Within natural resource management, there is increasing criticism of the traditional model of top-down management as a method of governance. Around the world, researchers and managers alike have recognized that resources can frequently be better managed when stakeholders, or those with an interest in the resource, are directly involved in management (Pomeroy 2001). The theory, simply stated, is that when responsibility for management is shared by resource users, stakeholders will have more incentive to use resources sustainably (Adger et al. 2005). It has been frequently asserted that participation by stakeholders who will be affected by management decisions will increase compliance, reducing the need for enforcement, and will increase effectiveness by incorporating local knowledge of resources (Pomeroy 2001). Cooperative management, or co-management, of resources is one way in which the call 
for stakeholder participation has been operationalized in a variety of resource management institutions.

Briefly, co-management is an approach to governance that involves some degree of power sharing between a government entity and a group or groups of stakeholders. Co-management should be viewed as a process, rather than an outcome (Carlsson and Berkes 2005). Participation and co-management are often spoken about concurrently, but they are not necessarily interchangeable. Co-management implies that the stakeholders involved in co-managing a natural resource are doing just that; they are involved in management, which usually means playing a role in decision-making. Participation, on the other hand, may refer to a broad range of activities, from attending meetings where community members are informed about the management activities, to sitting on an advisory council. While co-management necessitates the participation of stakeholders in some way, in no way does it mean all stakeholders are participating in management, or that all stakeholders are represented in management. In some cases, those stakeholders who are involved in co-managing a resource may not represent the interests of the community at large, or even the majority of stakeholders.

\section{Dissertation Objectives}

The goal of the research is to critically analyze co-management as a tool for sustainable marine resource management through improved understanding of stakeholder participation in co-management. This critique is based on the underlying hypothesis that co-management will lead to greater representation and participation of stakeholders in management and that successful co-management is that which 
encompasses a wide range of stakeholder perspectives in the decision-making process. This study investigates variability in the involvement of stakeholders in selected examples of existing co-management arrangements developed to manage marine reserves within the wider Caribbean. An understanding of the factors contributing to and dynamics of stakeholder participation is essential for promoting effective resource co-management. As a way of understanding the success of governance arrangements in reserve management, a comparative analysis of several sites has been conducted to ascertain some of the factors influencing the extent of stakeholder participation in comanagement arrangements, including the importance of social networks in fostering knowledge of and participation in management. A secondary objective of this dissertation is to use network analysis to determine what impact the underlying social network has on the co-management arrangement, and on stakeholder participation in comanagement.

This dissertation seeks to answer the following questions: 1) How do social networks affect participation?; 2) What is the relationship between successful comanagement and social networks?; 3) What does successful co-management look like? Additionally, management recommendations are provided to improve co-management processes at each of the MPAs included in this study.

Co-management is a term often discussed in the literature, and it is often implied that any co-management process involves stakeholders. Because stakeholder involvement is frequently regarded as a universal good in the literature, at least from the perspective of governance, co-management often escapes the lens of criticism. This research takes a closer look at the concepts of co-management and participation through 
a number of case studies of marine protected areas (MPAs) in the Caribbean. The goal of this research is to evaluate the co-management arrangement at each site from the perspectives of stakeholder participation and representation, with these two factors serving as proxies for social success in the realm of governance. This goal is addressed through determining which resource users and other stakeholders have been involved in managing the resource, what variables have influenced aspects of their involvement, and evaluating the extent of their participation at each site. A secondary objective of this research is to employ social network analysis to understand how the underlying social structure within each community created through the co-management process may predict participation by stakeholders. This research is intended to inform those involved in the planning and implementation of MPAs, including MPA managers and government officials, as well as those involved in other forms of coastal management projects. It will also bolster the existing literature on co-management through providing a novel approach of studying stakeholder participation in co-management.

The research was conducted in communities adjacent to six different marine protected areas in the wider Caribbean: Saba National Marine Park, Saba, Netherlands Antilles; St. Eustatius National Marine Park, St. Eustatius, Netherlands Antilles; Buccoo Reef Marine Park, Tobago; Scotts Head/Soufriere Marine Reserve, Dominica; Hol Chan Marine Reserve and Laughing Bird Caye National Park, Belize. All of these MPAs, at least nominally, have some form of co-management arrangement in place. Each of these sites varies considerably in a number of respects, including the objectives of the MPA, the way in which the MPA is managed, and the ways in which stakeholders have been incorporated into the management process, as well as the natural 
resources, history, and culture of each community. Some sites, such as Laughing Bird Caye National Park and Saba National Marine Park, have had extensive participation by stakeholders since their inception, and enjoy widespread support among the community members. Others, such as the Buccoo Reef Marine Park in Tobago, are just beginning the process of incorporating stakeholders. And others, like the Scotts Head/Soufriere Marine Reserve in Dominica, have been in existence for a number of years, but have little community support at present.

This study analyzes data collected from individuals living within the communities closest to or most affected by the MPAs, inquiring about their knowledge of MPA management, and their participation in activities related to management of the MPA. Individual-level variables are analyzed as predictors of participation and familiarity with management. Social network analysis is employed to understand the web of relationships between those individuals and groups directly involved in management and the rest of the community.

Social network analysis is a technique for evaluating the extent to which the individuals responsible for management are representative of the community as a whole, and how the co-management of an MPA by a small group of individuals may or may not translate to broader involvement by the rest of the community. This analysis is based upon the presumption that co-management arrangements will be more equitable if stakeholders know and can have their interests represented by those involved in management, and that an individual's likelihood of participating in activities related to the MPA will be determined in part by knowing others already involved. Social networks also provide a picture of the groups and sub-groups that exist within a 
community, and how information and resources diffuse among members of the community. Evaluation of networks can provide a measure of one type of social capital present within a community. Social capital is often considered a prerequisite for comanagement or other community-based management, because it is necessary for promoting collective action (Ostrom 2005), and social network analysis is a way of quantifying the ties between individuals that can lead to this collaboration. Social capital will be discussed in more detail in Chapter 2.

Chapter 2 provides further justification and context for this study by grounding it in the literature concerning co-management, stakeholder participation, and social network analysis. Chapter 3 describes the methods used to conduct this research. Chapter 4 provides a description of each of the MPAs in the research and their associated communities, with a discussion of the differences in and difficulties with comanagement at each site. Chapter 5 presents the network analysis conducted for each of the study sites, with descriptions of the network graphs and discussion of selected network measures. Chapter 6 integrates the network analyses with further analysis of factors influencing participation at each site, including comparison among sites. Finally, Chapter 7 presents conclusions and recommendations from the research. 


\section{CHAPTER 2. LITERATURE REVIEW}

There is a growing recognition within the literature of a need to address the indissoluble link between social and ecological systems in order to advance sustainability of natural resources (Carlsson and Berkes, 2005). It is understood that we must incorporate the interactions between human and natural systems in considering each of these, rather than simply viewing humans as 'stressors' on the natural world (Berkes 2004). As a result, managers and academics have sought ways to better link these two, often by incorporating natural resource users into decision-making.

\section{Co-management}

Increasingly, the traditional model of top-down natural resource management has come to be viewed as less than ideal, and often as ineffective, as resources have continued to decline under this governance model. There is growing recognition that resources can frequently be better managed when stakeholders are directly involved in management (Pomeroy, 2001). The term stakeholder is defined here as anyone who can influence, or can be affected by, the management process (Geoghegan and Renard 2002), whether directly or indirectly. When they share responsibility for management, the theory goes, stakeholders will have more incentive to use resources sustainably (Adger et al., 2005). Co-management has emerged as one way to address the incorporation of resource users and other stakeholders in management.

By definition, co-management involves cooperation among various groups or individuals in management, and it is often discussed in the context of common property 
theory. In the recent past, management of natural resources has often been approached from the perspective of Garrett Hardin's Tragedy of the Commons model (1968), based on the belief that resource users are "helpless individuals caught in an inexorable process of destroying their own resources" (Ostrom $1990 \mathrm{p}$ 8), unless the resources are in some way privatized or heavily regulated. Much recent study, however, focuses on promoting the concept that resource users have an incentive to conserve resources when provided with the opportunity to self-regulate. Numerous authors have claimed that when resource users and other stakeholders are involved in the decision-making process, management results improve, both from the perspective of stakeholder equity and sustainable use.

One of the fundamental bases of co-management is that it involves a claim to non-exclusive resources (Plummer and FitzGibbon 2004), as the concept of comanagement is derived from common-property theory (Pomeroy and Rivera-Guieb 2006). Common property resources have two fundamental characteristics in common: resource users cannot easily be excluded; and the supply of the resource is limited (or the use of the resource by one user limits the use by others) (Ostrom 1991 as cited in Pomeroy and Rivera-Guieb 2006). There has been considerable interest in studying examples of common-pool resources and other means of managing natural resources through collective action as an alternative to traditional management. In her seminal work on the subject, Ostrom (1990) lists having clearly defined boundaries, the ability of individuals affected by management decisions to participate in modifying the rules, monitoring, conflict resolution mechanisms, and the recognition of the rights of resource users to organize as some of the common underlying principles in successful 
examples of collective action. These are all themes that apply to co-management as well.

In particular, the concept of developing formalized cooperative management, or co-management, as it shall be known from here on, of natural resources, and particularly of fisheries and other marine resources, has emerged in the literature as a predominant way to think about community involvement in resource management (Noble, 2000). Definitions vary in the literature, but in simple terms co-management can be defined as an arrangement between the government and a group or groups of stakeholders for the management of natural resources (Pomeroy et al. 2004). Comanagement has often been defined broadly because of the variation in arrangements it can include (Plummer and FitzGibbon 2004). Like participation in general, comanagement can include a variety of arrangements such as consultation, advisory committees, and community control over resources (Pomeroy and Berkes 1997). Comanagement also does not exclusively occur at the local level; it may occur from the local up through the national level, and may include a broad spectrum of stakeholders or just immediate resource users (Berkes 2000).

Sen and Nielsen $(1996,406)$ define co-management as "an arrangement where responsibility for resource management is shared between the government and user groups". Similarly, McConney, Pomeroy, and Mahon $(2003,7)$ define it as "the sharing of responsibility and authority for the management of resources between government and stakeholders". Pinkerton $(1989,4)$, writing exclusively about the co-management of fisheries, describes the concept as "negotiated agreements and other legal or informal 
arrangements... between groups or communities of fishermen and various levels of government responsible for fisheries management".

Co-management is considered a promising solution for many problems of resource management (Pinkerton 1989). The ultimate goal of co-management is "more appropriate, more efficient, more equitable management" (Pinkerton 1989, 5). Rather than being a single, defined method for governing resource use, co-management can be viewed as continuum, from government-centralized management to community selfgovernance (Pomeroy et al. 2004). There is also no single characterization of how the management responsibility will be shared; co-management covers a wide variety of arrangements, with the degree of control by government or stakeholders varying. Pomeroy et al. (2004) describe a continuum with three broadly-defined levels of comanagement: consultative co-management, where the government interacts with stakeholders but makes all of the decisions; collaborative co-management, where the government and stakeholders work together closely; and delegated co-management, where the stakeholders are primarily responsible for making the decisions (see Table 1).

Table 1. Co-management spectrum (from Pomeroy et al. 2004).

\begin{tabular}{|c|c|c|c|c|}
\hline \multirow[b]{2}{*}{$\begin{array}{l}\text { Government has } \\
\text { most of the } \\
\text { control }\end{array}$} & $\begin{array}{l}\text { Consultative } \\
\text { co- } \\
\text { management }\end{array}$ & $\begin{array}{l}\text { Collaborative } \\
\text { co- } \\
\text { management }\end{array}$ & $\begin{array}{l}\text { Delegated co- } \\
\text { management }\end{array}$ & \multirow[b]{2}{*}{$\begin{array}{l}\text { People have } \\
\text { most of the } \\
\text { control }\end{array}$} \\
\hline & $\begin{array}{l}\text { Government } \\
\text { interacts often } \\
\text { with } \\
\text { stakeholders but } \\
\text { makes all the } \\
\text { decisions }\end{array}$ & $\begin{array}{l}\text { Government and } \\
\text { the stakeholders } \\
\text { work closely } \\
\text { and share } \\
\text { decisions }\end{array}$ & $\begin{array}{l}\text { Government lets } \\
\text { formally } \\
\text { organized } \\
\text { users/stakeholders } \\
\text { make decisions }\end{array}$ & \\
\hline
\end{tabular}

Co-management should be seen as a process rather than as a static arrangement. Often co-management is discussed in the context of adaptive management, an iterative 
process of management taking uncertainty into account, as successful co-management should have an adaptive component to it, including information sharing among partners that lead to changes and improvements (Pomeroy and Rivera-Guieb 2006). Pomeroy and Rivera-Guieb (2006) note that a healthy co-management process should change over time in response to factors such as changes in the level of trust, legitimacy, credibility, and success of the arrangement. Where the process falls on the spectrum of co-management may also change through the lifetime of the arrangement.

Co-management has the potential to increase the information and knowledge on which decisions are made by incorporating a variety of stakeholders in the process, and the hope is that this will increase both legitimacy and compliance (Sandersen and Koester 2000). Pinkerton (1989) lists three complementary goals to co-management: as a route to community-based management (or management conducted primarily by community members), as a way to decentralize decision-making to more effectively address problems, or as a means of reducing conflict through participatory democracy. Plummer and FitzGibbon (2004) cite equity and efficiency of decision-making, the legitimization of actors, and increased capacity at the local level as possible outcomes of co-management. Potential advantages to co-management cited by Pomeroy and Rivera-Guieb (2006) include: systems which are more democratic, transparent, accountable, economical, and participatory; improved or increased stewardship, enforcement, and communication; and a long-term perspective toward resource use, among other possible benefits.

While co-management is often described in the context of common property theory, as described above, there are a number of key aspects in which co-management, 
particularly when applied to an MPA, differs from the more traditional common property examples described in Ostrom (1990) and other common property literature. In Ostrom's examples and many of the other accounts of traditional collective action described within the literature, those involved in collective action are often users of single resource with similar intended outcomes, such as fishermen targeting one particular fish stock, or farmers sharing a single water source. Within MPAs the comanagement situation becomes more complicated, as there are numerous user groups and other stakeholders with varying interests, often using the MPA in different and sometimes contradictory ways. Some are direct users of the MPA, while others may derive indirect benefits from the MPA, such as tourism revenue or existence value. All of the MPAs analyzed within this project entail the exclusion of some users, including fishermen and sometimes others, from at least a portion of the resource. Ostrom (1990) has noted that the likelihood of adopting collective action depends in part on whether those doing the adoption will be affected similarly by the proposed rules, which for most MPAs is not the case. In this way, co-management does not completely resemble common property management, but is in fact a form of participatory governance. Comanagement, as noted above, refers to an agreement between the government and stakeholders; these agreements are embedded within a larger sociopolitical system where the government still plays a role as a co-management partner (McCay and Acheson 1987). Co-management as a method of governance lies somewhere between government control of resources and communal control of resources.

Co-management has the potential to encourage more effective management of natural resources by incorporating the interests of local stakeholders, yet there are 
numerous potential pitfalls in the process of community involvement. Co-management often assumes a dualism of management, with the government managing in concert with stakeholders, but in all likelihood numerous stakeholder groups, often with competing interests, exist. What is important for co-management is "not whether participation takes place, but how and among whom, and what differences it makes" (Rosenberg and Korsmo 2001, 284; see also Jentoft et al. 1998). While the benefits of co-management have often been touted, it is important to note that it is not a panacea for sustainable fisheries management, and it is necessary to constantly question who is benefiting, and consequently who is losing, in co-management agreements (Loucks et al. 2004).

Often co-management theory assumes a homogeneous community, which is very rarely the case; within a given community there are likely to be multiple interests and actors, political forces, and power struggles (Agrawal and Gibson 1999).

Stakeholders with low visibility and little power may be overlooked in this process; these same stakeholders may be the ones to whom the most attention needs to be paid to ensure an equitable outcome (Geoghegan and Renard 2002). Those participating in management may represent an especially vocal minority, or may represent a particularly powerful interest group (Geoghegan and Renard 2002). There exists a danger in comanagement structures that the community is being co-opted to support the interests of powerful stakeholder groups such as the tourism industry, or into supporting the government's objectives through meaningless participatory requirements. Jentoft (2005) defines co-management and community empowerment as the same thing; comanagement ideally brings previously excluded and disenfranchised user groups to the 
table to participate in the management process. Co-management may also sometimes serve to entrench existing power differentials and inequities that exist within communities (Jentoft 2000). Additionally, the community of stakeholders may be difficult to define, as there may be stakeholders outside of the geographically-defined community with an interest in the resource.

Co-management is a relatively new concept in most areas of the Caribbean (Brown and Pomeroy 1999), but it is quickly being implemented in numerous states to address a variety of problems. Numerous co-management projects in the Caribbean have been identified (e.g. Brown and Pomeroy 1999; Geoghegan et al. 2001); however, many of these projects are still at a relatively premature stage of development (Rosenberg and Korsmo 2001), and have yet to be thoroughly evaluated. Because of a long history of colonialism, the Caribbean region has few examples of traditional community-based management projects. Brown and Pomeroy (1999) describe Caribbean fishing communities in particular as having a low degree of social cohesion. The region generally has little experience with collective action (Brown and Pomeroy 1999), which serves as an impediment to starting co-management arrangements.

This research analyzes six co-management arrangements at marine protected areas in the Caribbean. For the purposes of this research, I considered an MPA to be comanaged if there existed either a formal or informal mechanism through which at least some stakeholders are able to participate in management decisions. In each of the comanagement situations analyzed within this paper (described in further detail in Chapter 4), there is a group of individuals, hypothetically representing the interests of other stakeholders, who sit on either a formal management committee or advisory board and 
have the ability to advise upon or make decisions about the MPA. While comanagement can refer to any situation where there is an arrangement for cooperative management between the government and some stakeholder group, and does not necessarily include participation by the larger community, all of these examples of comanagement involve a group of stakeholders who at least nominally represent the interests of the broader community. The inclusion of a broad range of stakeholders, including a range of user and non-user groups within the community, with the goal of having most community interests and viewpoints represented through the stakeholder participatory process, should in theory lead to greater engagement and involvement by the community at large.

\section{Marine Protected Areas}

Each of the research sites chosen for this study was selected for the presence of a marine protected area (MPA) that has some form of co-management arrangement in place. Simplistically, a marine protected area can be defined as a discrete geographic area created for the purpose of conserving marine and coastal resources (NRC 2001). Kelleher (1999) has defined an MPA as "any area of intertidal or subtidal terrain, together with its overlying water and associated flora, fauna, historical and cultural features, which has been reserved by law or other effective means to protect part or all of the enclosed environment". MPAs can have numerous objectives, and for those included within this study, each is designed with the promotion of certain human uses, whether fishing, diving, other tourism, or all of the above, among its objectives. Within this document, they are alternatively referred to as MPAs or marine reserves. Marine 
reserves are one type of MPA where some restrictions exist on the removal of biological resources (NRC 2001). Each of the MPAs included in this study is also a marine reserve, as each has restrictions on fishing in all or part of the area.

Many claims have been made about the benefits of marine reserves as a fisheries management tool, including that they lead to increases in abundance, size, biomass, and diversity of fish species (Roberts and Hawkins 2000). Marine reserves can protect ecosystem structure and function, which in the case studies used here, means protecting part of the coral reef from potentially destructive fishing activities. They may also enhance non-consumptive uses through enhancing recreational activities, such as diving and snorkeling, particularly through protecting the reef, and may promote ecotourism (Sobel and Dahlgren 2004). On the other hand, marine protected areas, and marine reserves in particular, can often be unpopular management tools as they may exclude some user groups, particularly fishermen, while promoting others, namely, tourism.

The nature of marine reserves means there can be many stakeholder groups with an interest in the MPA; because the MPA typically sets out rules for all uses of the particular area, promoting some and restricting others, multiple user groups are affected by the presence of an MPA. This makes co-management both suitable and challenging as a form of MPA governance. From the perspective of studying the role of social networks in co-management, MPAs are an interesting setting because of the diversity of stakeholders that often have an interest in the MPA. 


\section{Participation}

Participation is clearly a key component of co-management, but while the two overlap, it is important to distinguish them. Arnstein (1969) developed a ladder of participation to describe a hierarchy of various forms of participation from manipulation through information dissemination through delegated power and citizen control; others (Pretty 1995; Choguill 1996) have developed their own versions of the ladder to make the point that all participation is not equal. Co-management, as defined above, requires some stakeholders to be involved in making decisions about the resources in question in some capacity, and thus involves a level of participation from these individuals that falls high up on any of these participation ladders. However, the high level of participation from a small number of actors in a co-management scenario may be very different from broader participation by a larger number of stakeholders. Co-management has often been discussed in the literature as a process that induces community participation on a larger scale; ideally, those involved in the process of co-management represent, directly or indirectly, the interests of all key stakeholder groups. This research in part addresses whether co-management translates to broader participation on the part of stakeholders and other community members in MPAs.

Pretty (1995) describes two schools of thought on participation within the context of development. Some advocates for participation see it as a way to increase efficiency in natural resource management, by getting people to support a project through participating in it. Others view participation as a fundamental right. Within the international development world, it is often assumed that participation and social equity are interchangeable (Pretty 1995); while an important part of social equity, participation 
by itself does not achieve this goal (McShane and Wells 2004). Pretty (1995) notes the danger of assuming those who participate are representative of all views in the community; they rarely are, and those who are socially marginalized are in danger of being left out of participatory processes just as they are frequently left out of other processes.

Suárez de Vivero et al. (2008) have described what they term the participation paradox, where the greater the number of actors participating through co-management or any other means, the smaller the role of each group. This may be particularly problematic for fishing and other traditional activities; fishers may lose whatever decision-making capacity and political presence they may have, as they have to compete with other stakeholder groups within the participatory process. Suárez de Vivero et al. (2008) note that greater devolution does not necessarily lead to greater participation. Some consideration, they argue, should be given to who is actually included in participatory processes.

\section{Social Capital}

While there is general agreement about the importance of social capital in comanagement and other collective action to promote sustainability in natural resource management, there is a lack of agreement as to how to define social capital. Social capital, particularly as it concerns co-management, is viewed in part as the capacity of individuals to organize themselves (Bodin and Crona 2008). It is an important component of developing conservation at the community level (Bodin and Crona 2008). According to Pretty and Smith (2004), the concept includes the idea that social bonds 
can promote sustainability. Pretty and Ward (2001) identify what they see as four key aspects of social capital related to natural resource management: relations of trust; reciprocity and exchanges; common rules, norms, and sanctions; and connectedness, networks, and groups. Social capital facilitates cooperation among people and groups because it lowers the costs of working together; when there are shared rules and norms, as well as trust, individuals can more easily participate in collective activities for resource management (Pretty and Ward 2001). Thus social capital is an important component of co-management. Without some base level of social capital, stakeholders will find it difficult to collaborate in management and decision-making.

Social capital can be seen as either the result of institutional performance or as the driver of institutional performance; various theories found within the literature place it in both of these categories (Bodin and Crona 2008). The ability to solve conflicts may be one important outcome of social capital (Bodin and Crona 2008), particularly within the context of natural resource management. However, Bodin and Crona note (2008, 2765): "It is important to note that social capital is not the only factor explaining the success or failure of resource management in general and for fisheries in particular. Contextual differences among cases, such as culture, institutions, and type of fishery, will also play an important role".

Social capital has been defined as "the structure of relations between actors and among actors" (Pretty and Ward 2001). This structure, or social network, links community members, or actors, together; it is both the definition and product of social capital. Some scholars have suggested that social networks may be more important than the existence of formal institutions for fostering compliance with environmental 
regulations (Scholz and Wang 2006). Social networks, it has been argued, promote collective action by facilitating the diffusion of knowledge and information, the allocation of resources, and the resolution of conflicts, among others (e.g. Bodin and Crona 2009; Scholz and Wang 2006; Carlsson and Berkes 2005). However, the particular structure of the social network will affect how actors behave (Bodin and Crona 2009; Degenne and Forsé 1999; Wasserman and Faust 1994; and others). Social network analysis, discussed below, compares the structures of social networks and can evaluate which structures best promote effective cooperation in natural resource management.

\section{Network Analysis}

Social Network Analysis is a way of studying relationships among entities. Thus network analysis is an appropriate and informative tool for studying social capital among a particular group of actors - in this case, stakeholders of a particular MPA. Network analysis, as discussed below, is one method of attempting to describe and quantify social capital; the more ties there are among actors in a network, the more social capital there is within the community. This will be my operational definition of social capital.

Rather than being considered a particular technique, network analysis should be considered more of an approach (Wellman 1983). Unlike many traditional social science research methods, network analysis considers the relationship as the unit of analysis, rather than the individual. Network analysis, rather than assuming individuals to be independent of one another, as they are often considered to be for some types of 
statistical analysis, assumes individuals are interdependent. An individual's actions are influenced by not just who they are but by who they know and with whom they interact. Social networks provide both opportunities and constraints, because they affect one's access to knowledge and power. The tradition within social science research has been to treat the actions of individuals as the sum of their personal attributes (Wellman 1983). This approach disconnects individuals from the larger social structures of which they are a part, which as many in the network analysis literature would argue, disregards the primary predictor of behavior (e.g. Wellman 1983). "The network critique suggests that normative explanations overlook the ways in which structural access to scarce resources determines opportunities and constraints for behavior" (Wellman 1983, 162). Network analysis is concerned not so much with why people act, but with the structural constraints on their actions (Wellman 1983) that result from their personal network.

The basic unit of analysis in a social network analysis is the dyad, or the relationship between a pair of actors. At the most basic level, either a relationship exists between two individuals or organizations, or it does not. Network analysis is a method of conceptualizing, both graphically and mathematically, the structure of relations among actors (Wasserman and Faust 1994). The ability of an individual to have social influence will be closely related to the individual's structural position within a network (Wasserman and Faust 1994). In this research, the most powerful individuals within each network, or those who are the most central and have the most ties, are identified.

Using a network analysis approach to study participation is a logical choice, because whether an individual chooses to participate in management activities will be determined not just by their personal attributes such as gender or occupation, but by 
their position within a social network. Who they know will in large part determine what they know, in this case about the MPA, because relations in part serve as pathways to knowledge (Wasserman and Faust 1994). Networks affect people's access to information and power (Wellman 1983). Those who have a more central position in a social network are more likely to possess the ability to exert influence and power. One's network can provide opportunities, such as learning about a meeting being held or being able to express an opinion to someone more substantively involved in decision-making, or can provide a constraint. Those individuals who do not personally know anyone who is involved in the marine reserve are probably less likely to choose to participate themselves, in part because they may not be provided with the necessary information about formal opportunities to participate, or because they are not connected to the proper channels through which to make their opinion known.

"Network analysis treats social systems as networks of dependency relationships resulting from the differential possession of scarce resources at the nodes and the structured allocation of these resources at the ties" (Wellman 1983, 157). In this context, studying participation in marine reserve management, those 'scarce' resources include information about the marine reserve, the opportunity to participate, and the ear of the decision-makers to the concerns of stakeholders. In an equal network where everyone has access to the key individuals, the access to these resources is equal among all community members. This is the ultimate centralized network, known as the star network, and can be viewed in two ways; either the stakeholders are all equal, or the key individual in this case is the one holding all of the power (Figure 1). In most cases, though, the network will be less simplistic than this example, and stakeholders will vary 
in their connections to key actors. The network must be considered within the context of the relative power of the managers and the stakeholders.

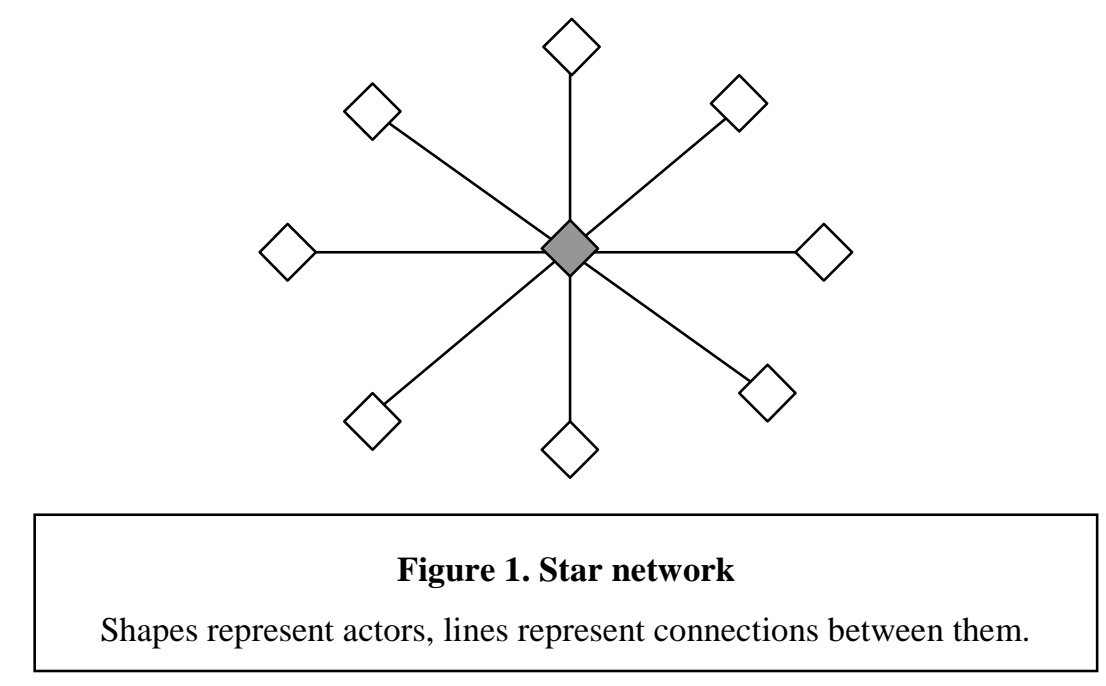

Within this research, both social network data and personal attributes are considered as factors influencing participation. After all, it is not possible to entirely separate the two, as an individual's personal attributes such as occupation will influence their network, and to some extent the network will influence personal attributes through providing opportunities and constraints. As Rogers and Kincaid (1981, 226) note, “network variables are approximately as important as individual characteristics in explaining the individual-level dependent variable". Both strongly influence individual behavior such as influence and participation.

The network within a particular community will determine in large part the extent to which community members can and do participate and have some influence over the co-management of the marine reserve. As with any other type of network, those individuals who are more central to the network, and have more connections to 
those making decisions about the marine reserve, are more likely to participate in activities and are more likely to be able to exert influence over the process of management. As discussed above, communities are rarely if ever homogeneous, and are instead made up of subgroups of individuals with different competencies, interests, perceptions, and levels of influence (Carlsson and Berkes 2005; Crona and Bodin 2006). Social network analysis can represent these complex community dynamics, and illustrate how different individuals of varying interests may relate to one another. Social network analysis can be used by agencies or other groups in designing co-management arrangements to ensure that the relevant representatives from various groups are being invited and engaged in participatory processes (Bodin and Crona 2009).

Some of the variables found to influence the outcomes of common-pool resource management include: the total number of decision makers; the similarities of interests; and the presence of participants who will serve as leaders (Ostrom 1990). Social network analysis is one way of analyzing these particular characteristics within a co-management arrangement. Figure 2, below, depicts how aspects of social networks influence both social capital and agency, or power, and how these can in turn lead to collective action. The literature on how social networks affect natural resource governance is limited (Bodin and Crona 2009), and this research attempts to increase that understanding. 


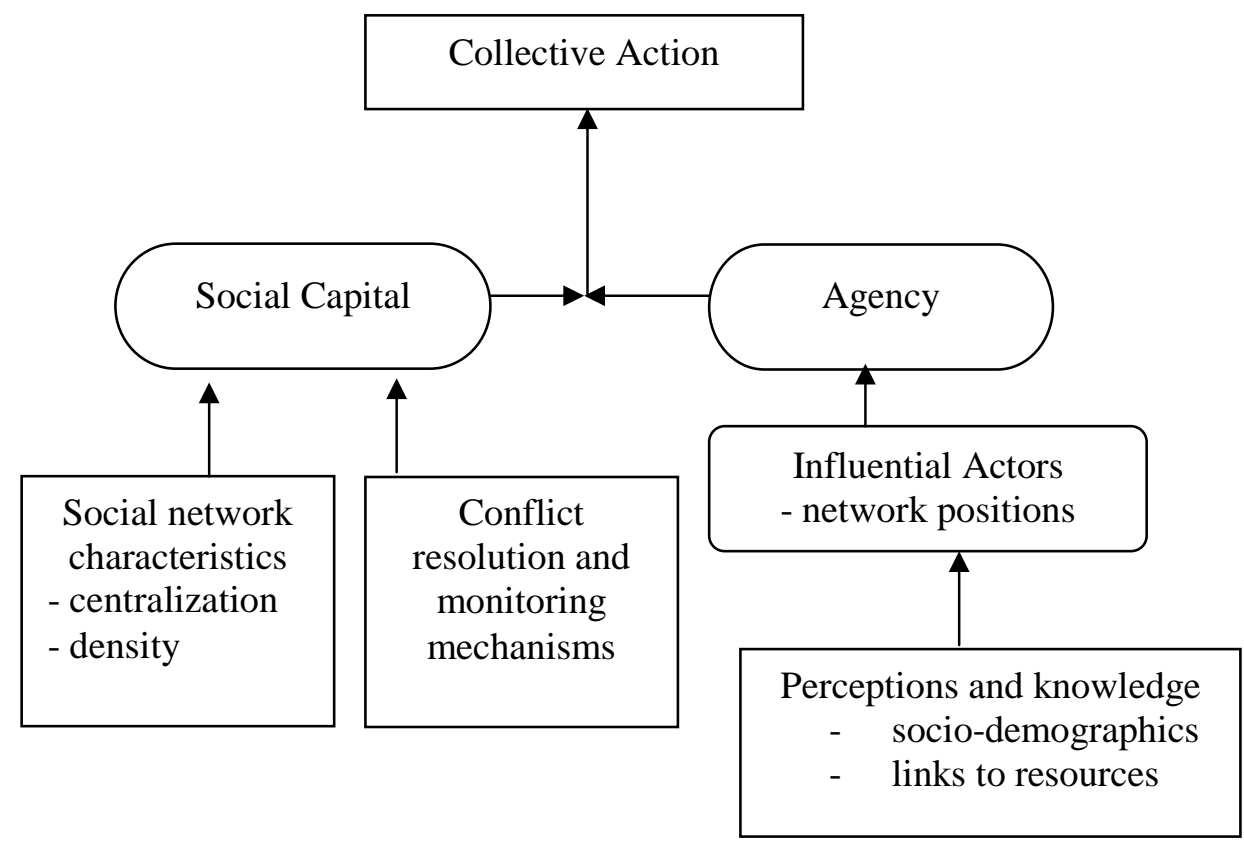

Figure 2. Relationship of social capital and agency to collective action (from Bodin and Crona 2008) 


\section{CHAPTER 3. METHODS}

Both qualitative and quantitative data collection on participation and social networks was conducted at six different locations in the wider Caribbean. Each site included in the study was selected from among the 32 marine reserves chosen for the National Science Foundation-funded project entitled, Understanding linkages among governance factors of linked social and ecological systems: an analysis of marine reserves in the wider Caribbean, under the direction of Drs. Tracey Dalton, Graham Forrester, and Richard Pollnac. Sites were selected from this project for ease of access and funding, and also for the sake of comparability to data collected from the larger project. This subset was chosen from marine reserves governed through some type of co-management arrangement, whether formally or informally. The determination of whether or not a site could be considered to be co-managed was made based on key informant interviews conducted as part of the research conducted for the Dalton et al. study and from analysis of management documents.

From this sub-group of co-managed marine reserves, six were selected for more in-depth study. These six were selected to maximize variation in such factors as culture and co-management arrangement, as well as on factors collected from the Dalton et al. study. To accomplish site selection, a principal component analysis was conducted of data collected from survey responses to questions about MPA success, participation in the MPA, knowledge of the MPA, and use of the MPA. A cluster analysis was then conducted based on the factor scores of each of the marine reserves with some form of co-management in place. Those sites selected for study were chosen from along the 
spectrum of the cluster analysis, with the goal of maximizing site variation. The sites involved in the study were the communities adjacent to marine protected areas where a majority of stakeholders using and affected by the MPA were likely to be found. Some of the MPAs had more than one associated community, while some had only one; data were analyzed at the MPA level, rather than at the community level, as the distinctions between some individual communities were vague.

The sites selected for data collection can be found in Table 2:

Table 2. MPAs selected for data collection

\begin{tabular}{|l|l|}
\hline MPA & Country \\
\hline Scotts Head/Soufriere Marine Reserve & Dominica \\
\hline Hol Chan Marine Reserve & Belize \\
\hline Laughing Bird Caye National Park & Belize \\
\hline St. Eustatius National Marine Park & St. Eustatius, Netherlands Antilles \\
\hline Saba National Marine Park & Saba, Netherlands Antilles \\
\hline Buccoo Reef Marine Park & Tobago, Trinidad and Tobago \\
\hline
\end{tabular}

For each site, data already existed from the research conducted by Dalton et al., including community surveys, key informant interviews, and collected documents. The author traveled to four of the six sites and conducted the initial key informant interviews personally. At two of the research sites (Saba and St. Eustatius), the data presented here were collected concurrently with the data for the Dalton et al. project. These two sites served as the pilot sites for the data collection. The survey instrument was tested at these two sites, and slightly modified for later sites. For the other four sites, data collection was conducted exclusively for this research project.

At each site, key informant interviews were conducted with several key informants including those involved in management and other important stakeholders. These interviews generally took the form of unstructured, open-ended interviews, and 
served both as a method of qualitative data collection and of ground-truthing the survey data collected from community members. Key informants were asked to describe the process of involving stakeholders in management, and about opportunities for stakeholders to participate in the marine reserve. These key informant interviews also served to determine which were the primary stakeholder groups that had been involved in management to this point, as well as serving as a starting point for the network analysis. Most key stakeholders served as nodes in the network analyses, and as someone was identified as important through the network analyses, they were selected for a key informant interview when possible.

Data on social networks and participation were collected through in-person surveys conducted at each of the research sites from June 2008 to February 2009. A total of 1496 surveys were collected during this period. The number of surveys collected ranged from 119 in Saba to 384 in San Pedro, Belize (see Table 3 for the numbers collected at each site). The time spent conducting research at each site varied as well, from six days in Saba to eleven days in Tobago.

\section{Survey Instrument}

The survey employed in field research was designed to be short, in order to conduct as many surveys as possible, and simple, to be easily employed by local community members hired to assist with data collection. All respondents were asked a series of basic demographic questions, including age, occupation, community of residence, years of residence, and years of education, and whether they had heard of the MPA. Those individuals who had not heard of the MPA were not asked any additional 
questions. Questions on participation asked respondents whether they had ever attended a meeting or otherwise been involved in the MPA in some way, and whether they believed their interests were being represented by those responsible for managing the MPA. For those respondents who had attended meetings or otherwise been involved, they were asked to provide details of what they had done, when, and how often.

Questions used for network analysis asked respondents to name anyone they could who was involved in the MPA, and to name who they would approach with an opinion about the MPA. Respondents were not limited in the number of individuals they could name, and were asked to name more than one person when possible. When respondents named a group or organization, they were asked to give the name of an individual at the organization where possible.

\section{Sampling Techniques}

As all potential actors in a social network were not known ahead of time for the sites, sampling techniques were used to select respondents to be included within the study (Wasserman and Faust 1994). At all sites, purposive sampling (Bernard 2006) was conducted in order to include in the sample as many groups and interests as could be identified through key informant interviews and observation. While the samples are not random, efforts were made to maximize variability in respondents by sampling from different locations on different days and at different times. An effort was made to include both groups identified as traditional stakeholders though key informant interviews, such as fishermen and tour guides, as well as other professions less likely to be engaged in the use of marine reserves. Those groups who relied more heavily on the 
marine reserves for their livelihoods, including fishers and those in the tourism industry, were deliberately overrepresented in the sample in order to ensure a broad range of responses from these groups. At sites where there were few fishermen or tour guides present in the community, these occupations make up only a small percentage of responses. In addition, an effort was made to include groups likely to be underrepresented, including women, the elderly, and ethnic minorities where applicable.

A random sample, while ideal, would have required considerably more time in order to identify community members selected randomly, and then track them down, possibly requiring several attempts to locate some community members. It would also be practically impossible, given the lack of information available for most of the communities on population sizes and addresses. The methods of respondent selection were comparable at all sites.

At each site, a certain percentage of individuals approached were unwilling to answer the survey, potentially introducing some bias into the sample. The response rate was generally high, varying from approximately 85 to $95 \%$ at each site of individuals approached who were willing to answer a survey. However, those unwilling to answer the surveys were often from underrepresented groups. Women were more likely than men to refuse to answer the survey, as were those who did not speak English as a first language. Frequently, those who were unwilling to answer the survey were those individuals who were unfamiliar with the marine reserve, or who felt they could not speak intelligently about the marine reserve because they claimed to know little about it. On a couple of occasions, individuals were unwilling to answer a survey because of a 
perceived injustice regarding the marine reserve, or because they were unwilling to speak to a foreigner. These types of reactions were atypical, however.

While Spanish language surveys were employed at the two Belize sites for those who did not speak English fluently, individuals who did not speak English as a first language could be found at all of the sites. At many of the sites, including both Belize sites and St. Eustatius, there was a small group of Chinese immigrants, some of whom were unable to answer the survey in English.

Where possible, local men and women were employed to conduct surveys after being trained by the researcher, and multiple interviewers were used at all sites. At all sites, the sample is composed of both surveys conducted by local assistants and by the author. Using local research assistants can have a number of advantages, including getting more honest responses (eliminating the bias of answering what the respondents believe the researcher wants to hear), and gaining access to individuals and areas which might otherwise be difficult to access. Local assistants when possible resided in the community where the surveys were being conducted, and thus had an intimate knowledge of the community and its residents. However, using local research assistants also introduced some problems into the data, including missing data, and concern about whether the questions were being asked consistently in the same way. At one site (Laughing Bird Caye National Park), a number of surveys had to be disregarded because of inconsistencies introduced by local research assistants. In addition, at one site a counter-accessibility problem was introduced, where community members were more likely to respond to an outsider (the researcher) than locals (the research assistants), whose motives they questioned. 
Using both local and foreign researchers ensures a more diverse sample, as locals may encounter different individuals than those encountered by the author. Local assistants are more likely to ask people they know, and have more access to private homes; these individuals may not have been included in a survey otherwise.

Table 3 below calculates the percentage of the population surveyed for each site. While the percentage varies considerably by site, at all sites but one (Hol Chan Marine Reserve), more than five percent of the population is accounted for in the surveys conducted within the communities.

Table 3. Percentage of population surveyed

\begin{tabular}{|l|l|l|l|}
\hline $\begin{array}{l}\text { Site (and associated } \\
\text { communities) }\end{array}$ & Population & $\begin{array}{l}\text { Number of } \\
\text { surveys }\end{array}$ & $\begin{array}{l}\text { Percentage of } \\
\text { population }\end{array}$ \\
\hline $\begin{array}{l}\text { Scotts Head/Soufriere Marine } \\
\text { Reserve } \\
\text { (Scotts Head and Soufriere) }\end{array}$ & 1757 & 300 & $17.1 \%$ \\
\hline $\begin{array}{l}\text { Hol Chan Marine Reserve } \\
\text { (San Pedro) }\end{array}$ & 8400 & 384 & $4.6 \%$ \\
\hline $\begin{array}{l}\text { Laughing Bird Caye National } \\
\text { Park } \\
\text { (Placencia and Seine Bight) }\end{array}$ & 1550 & 235 & $15.2 \%$ \\
\hline $\begin{array}{l}\text { Saba National Marine Park } \\
\text { (Saba) }\end{array}$ & 1349 & 119 & $8.8 \%$ \\
\hline $\begin{array}{l}\text { St. Eustatius National Marine } \\
\text { Park (St. Eustatius) }\end{array}$ & 2292 & 187 & $8.2 \%$ \\
\hline $\begin{array}{l}\text { Buccoo Reef Marine Park } \\
\text { (Buccoo, Bon } \\
\text { Accord/Canaan) }\end{array}$ & 4663 & 269 & $5.8 \%$ \\
\hline
\end{tabular}

\section{Network Analysis}

A subset of questions asked in the survey asked respondents to identify individuals involved in the MPA, as well as to name the individuals they would approach with questions or opinions about the MPA. These questions served as the basis of a social network analysis later developed for all sites. The network analysis 
questions were based on a free recall, where respondents were asked to name actors in response to questions, rather than providing them with a roster, or a list of pre-selected names. All actors must be known ahead of time in order to use a roster technique (Wasserman and Faust 1994), and this was not feasible for these sites. The disadvantage to using the free recall technique is that respondents do not always report accurately on their interactions with others, and often misrepresent their relationships by forgetting certain individuals, or over- or under-estimating their frequency of contact with others (Wasserman and Faust 1994). In this case, individuals are not asked specific information about their relationships, but may underreport their relationships because they forget to name someone they know who in actuality they might seek out regarding the marine reserve. It was also a common occurrence for individuals to forget the name of someone they may not interact with on a regular basis. Sometimes respondents would be able to describe someone to whom they would speak about the marine reserve, and who had a role in managing the marine reserve, but could not recall the individual's name. If the individual could not come up with a name, it was not considered to be a relation.

The network data was treated as asymmetrical, or directional, data, as the networks described in Chapter 5 generally flow in one direction. Wellman (1983) notes that the world is composed of asymmetric ties bound up in hierarchical structures. Within the real world, the relationship between two individuals is rarely symmetrical. Ties between two people are usually asymmetric in both content and intensity (Wellman 1983). Respondents are naming an actor to whom they would address an opinion or a question, but the actor named may or may not have the same relationship to the 
respondent. In the case of marine reserve management, this is unlikely, as most of the actors named at all sites played some role in managing the marine reserve, and are unlikely to have a personal relationship with everyone in the community.

Wasserman and Faust (1994) note that defining a group, or the collection of actors on which ties are to be measured, is problematic, as is specifying the network boundary. In some cases, the boundary may be determined by the actors themselves, or may be determined by the researcher's theoretical concerns. In the networks presented in this study, networks were defined by geo-political boundaries. However, some of these were more precise than others.

To determine the boundary of each network, I selected a geographicallybounded study area; in each case, a community or multiple communities, with natural or politically-defined boundaries. I included as community members, and as part of the network, anyone who lived or worked within the community, but not individuals who happened to be passing through. Three of my study sites had natural boundaries because they are islands (Saba, St. Eustatius, and San Pedro, Belize). The communities of Placencia and Seine Bight, Belize and Soufriere and Scotts Head, Dominica were easy to define because they all exist as geographically distinct villages. The communities of Tobago, however, were more difficult to define. While Buccoo is more or less geographically distinct, Bon Accord/Canaan and the surrounding communities are geographically indistinct, with each community distinguished mostly by road signs indicating one village or another, and adjacent to several other communities. While selecting this boundary for the network analysis is somewhat artificial, it was necessary to define limits to the network. 


\section{Data Limitations}

While ideally in social network analysis the networks would be complete, and include all possible actors, limitations to data collection required that the networks be incomplete and encompass only a sample of actors within each community. Efforts were made to find and survey every individual named by one of the respondents as someone they would speak to about the marine reserve. However, time and logistical constraints made it impossible to find and speak to all of these individuals for the purposes of this study. As a result, sub-groups are identified within the network where one or more respondents named an individual who is otherwise unconnected to the network. In most cases, this individual was named by only one respondent, and was not identified as someone connected to the marine reserve during key informant interviews. There is thus no conclusive evidence about whether these named individuals have any influence or power within the larger network, and thus whether they provide a conduit or a dead end to respondents in sharing and seeking information about the marine reserve. However, as an effort was made to include in the networks all individuals known to be actively involved in the MPA, it is unlikely that any of the networks missed any significant sub-groups of actors.

As Costenbader and Valente (2003) have noted, individuals who are not included in a network analysis study, particularly where the network is sampled, as it is here, are likely to be those individuals who are on the periphery and have fewer connections to the rest of the network. Individuals with fewer connections are more likely to be harder to find or contact when the survey is being conducted, or to refuse to participate in the survey. This may mean the data here are skewed slightly toward 
including respondents who have participated in the MPA, as they may be more visible within the network and more likely to respond to a survey.

One potential problem with survey data used to generate social networks is the problem of "noise" within the network, when respondents report links that do not actually exist (Rogers and Kincaid 1981). This is a particular hazard in this study, where individuals may report someone they know of who is involved in the marine reserve, but may not have a personal relation with that individual. However, while the data may be biased toward including more links with key individuals than actually exist, this information still demonstrates a knowledge of key individuals in the marine reserve, and the potential for information exchange.

The network analysis data required asking respondents about not only the names of other people, but also their own names, to be able to link them to the network in the case that they were named by someone else. While all of this data has been kept confidential, and the confidentiality of the data was expressed to respondents at the time of the survey, some were unwilling to provide their names. An additional difficulty was that as nicknames are very common in the Caribbean, it was sometimes difficult to match up the nicknames provided with the real names of individuals involved in the MPA. Commonly respondents knew those involved in the MPA only by their nickname, and not by their proper name.

There was sometimes reluctance on the part of respondents to provide personal data about themselves, particularly their age and years of education. This reticence was more common among women than men; women are more likely than men to have data missing in the data set. 
In a couple of the sites visited, there was a certain degree of survey fatigue present, where community members had been surveyed in the past about the MPA. At the Scotts Head/Soufriere Marine Reserve and the Laughing Bird Caye National Park in particular, many community members stated that they had already responded to a survey about the MPA; in only a few cases, however, did this lead to people being unwilling to respond to a new survey. 


\section{CHAPTER 4. SITE DESCRIPTIONS AND ANALYSIS}

What follows is a qualitative description of each of the six marine protected areas included in this study, with information about the current management and pressing issues gathered from discussions with key informants and from observations during visits to the communities. The co-management structure is described for each MPA, with discussion of which stakeholder groups are involved in the co-management process. A brief analysis of the representativeness of each arrangement is presented. Each site is also analyzed to determine the degree of co-management based on the scale developed by Pomeroy et al. (2004) (Table 1), and the stage of implementation of the co-management.

Of the six marine protected areas, all have been in existence for at least ten years. The St. Eustatius National Marine Park and the Laughing Bird Caye National Park, both established in 1996, are the newest MPAs, and Buccoo Reef Marine Park, created in 1973, is the oldest. The co-management arrangements at all but the Buccoo Reef Marine Park are in the post-implementation stage, and likewise, the comanagement arrangements at all but the Buccoo Reef Marine Park and Hol Chan Marine Reserve are delegated co-management arrangements, which Pomeroy et al. (2004) define as an arrangement where the government lets formally organized users or stakeholders make decisions. Stakeholder participation is also discussed at each of the sites based on two different models of participation.

Table 4 below presents a summary of the six sites selected as part of the study, and of some of the key factors influencing participation and co-management at each. 
The marine protected areas vary in such factors as their objectives and the population sizes of the communities that use the MPAs. One commonality amongst each of the sites is the existence of tourism as a significant economic driver in the community, and, consequently, each MPA has either the promotion or management of tourism activities as an objective. 
Table 4. Summary of study sites and factors relevant to participation at each.

\begin{tabular}{|c|c|c|c|c|c|c|c|}
\hline Site & Communities & Population & MPA Objectives & $\begin{array}{l}\text { Economy/ } \\
\text { Activities }\end{array}$ & $\begin{array}{l}\text { Year } \\
\text { Established }\end{array}$ & $\begin{array}{l}\text { Number of } \\
\text { Fishermen }\end{array}$ & Managed by \\
\hline \multirow{2}{*}{$\begin{array}{l}\text { Scotts Head/ } \\
\text { Soufriere Marine } \\
\text { Reserve, Dominica }\end{array}$} & Scotts Head & 721 & \multirow{2}{*}{$\begin{array}{l}\text { Reduce user } \\
\text { conflicts between } \\
\text { fishermen and } \\
\text { dive industry, and } \\
\text { protect traditional } \\
\text { fishing activities }\end{array}$} & \multirow[t]{2}{*}{$\begin{array}{l}\text { Fishing, } \\
\text { tourism }\end{array}$} & \multirow[t]{2}{*}{1987} & \multirow[t]{2}{*}{$\sim 250$} & \multirow{2}{*}{$\begin{array}{l}\text { Local Area Management } \\
\text { Authority (LAMA), } \\
\text { Fisheries Division }\end{array}$} \\
\hline & Soufriere & 1,036 & & & & & \\
\hline $\begin{array}{l}\text { Hol Chan Marine } \\
\text { Reserve, Belize }\end{array}$ & San Pedro & 8,400 & $\begin{array}{l}\text { Preserve coral } \\
\text { reef, promote } \\
\text { tourism }\end{array}$ & $\begin{array}{l}\text { Tourism, } \\
\text { construction }\end{array}$ & 1987 & 35 & $\begin{array}{l}\text { Board of Directors, } \\
\text { Fisheries Department }\end{array}$ \\
\hline \multirow{2}{*}{$\begin{array}{l}\text { Laughing Bird } \\
\text { Caye National } \\
\text { Park, Belize }\end{array}$} & Placencia & 750 & \multirow{2}{*}{$\begin{array}{l}\text { Protect island } \\
\text { from development } \\
\text { and fishing, } \\
\text { promote tourism } \\
\text { and local access }\end{array}$} & \multirow{2}{*}{$\begin{array}{l}\text { Tourism, } \\
\text { fishing }\end{array}$} & \multirow[t]{2}{*}{1991} & \multirow[t]{2}{*}{ N/A } & \multirow{2}{*}{$\begin{array}{l}\text { Friends of Nature, } \\
\text { Forestry Department }\end{array}$} \\
\hline & Seine Bight & 800 & & & & & \\
\hline $\begin{array}{l}\text { St. Eustatius } \\
\text { National Marine } \\
\text { Park, Netherlands } \\
\text { Antilles }\end{array}$ & St. Eustatius & 2,584 & $\begin{array}{l}\text { Manage and } \\
\text { conserve natural, } \\
\text { cultural and } \\
\text { historical marine } \\
\text { resources for } \\
\text { sustainable use }\end{array}$ & $\begin{array}{l}\text { Oil } \\
\text { transship- } \\
\text { ment, } \\
\text { tourism }\end{array}$ & 1996 & 18 & STENAPA \\
\hline $\begin{array}{l}\text { Saba National } \\
\text { Marine Park, } \\
\text { Netherlands } \\
\text { Antilles }\end{array}$ & Saba & 1,349 & $\begin{array}{l}\text { Protecting and } \\
\text { managing Saba's } \\
\text { natural resources }\end{array}$ & $\begin{array}{l}\text { Medical } \\
\text { school, } \\
\text { tourism }\end{array}$ & 1987 & $\sim 35$ & $\begin{array}{l}\text { Saba Conservation } \\
\text { Foundation }\end{array}$ \\
\hline \multirow{2}{*}{$\begin{array}{l}\text { Buccoo Reef } \\
\text { Marine Park, } \\
\text { Tobago }\end{array}$} & Buccoo & 1,090 & \multirow{2}{*}{$\begin{array}{l}\text { Protect coral reef, } \\
\text { promote tourism }\end{array}$} & \multirow{2}{*}{$\begin{array}{l}\text { Tourism, } \\
\text { commercial/ } \\
\text { retail }\end{array}$} & \multirow[t]{2}{*}{1973} & \multirow[t]{2}{*}{ N/A } & \multirow{2}{*}{$\begin{array}{l}\text { Fisheries Department, } \\
\text { Buccoo Reef } \\
\text { Management Committee, } \\
\text { Buccoo Reef Trust }\end{array}$} \\
\hline & $\begin{array}{l}\text { Bon Accord/ } \\
\text { Canaan }\end{array}$ & 3,571 & & & & & \\
\hline
\end{tabular}


The communities and countries where the MPAs are located differ in factors such as size, culture, and history, and these differences must be taken into account when attempting to explain differences in participation among sites. For example, the population sizes of the communities vary considerably, from San Pedro, Belize, a large island with a reported population of 8,400 , to the island of Saba with a population of just 1,349 . The population size of these communities will considerably influence some of the variables measured in this research, particularly as they relate to the network analysis. In smaller communities, residents are more likely to know each other and to know or know of the individuals responsible for managing the MPA.

The number of individuals working as fishermen in Scotts Head and Soufriere is much larger than at any of the other sites, and likewise the importance of fishing to the economy of these villages is much greater than elsewhere. On the other hand, fewer than one percent of residents in either St. Eustatius or San Pedro work as fishermen.

Cultural differences are also likely to be significant, particularly in fostering a culture of participation in these communities. All of the nations where these MPAs are located have a colonial history. Dominica, Belize, and Trinidad and Tobago were recently British colonies; Belize only gained its independence in 1981, while Dominica became independent in 1978 and Trinidad and Tobago in 1962. Saba and St. Eustatius, as part of the Netherlands Antilles, are considered autonomous states of the Netherlands. As such, they have a different system of government than the former British colonies. 
The two sites in Belize are highly ethnically diverse; the majority of residents in San Pedro are mestizos, with many Spanish-speaking recent immigrants from Honduras, Guatemala, and Mexico, while Placencia has a mix of Creoles, mestizos, and Maya, and Seine Bight is primarily a Garifuna community. ${ }^{1}$ Scotts Head and Soufriere, on the other hand, are very homogeneous communities, with nearly all residents of Afro-Caribbean descent. Saba is a community divided between the descendents of the few families originally on the island, descended from the Scotch and Irish, and newcomers, many of whom are white or Creole. The diversity of ethnicities and cultures between these various sites undoubtedly is responsible for some of the differences observed in the way co-management functions at each MPA. Each of the sites is discussed in further detail below.

\section{Co-management processes}

Each of the sites here is analyzed according to Pomeroy's scale of the stage of implementation and the degree of co-management (see Table 1 in Chapter 2). All of the sites selected for this study have been in place for at least a decade, most for much longer, and are in the post-implementation stage. The co-management of the Buccoo Reef Marine Park, however, is in a pre-implementation stage. Additionally, most function at the level of delegated co-management, where the government lets formally organized users or stakeholders make decisions (Pomeroy et al. 2004); in most cases there is a management body made up of stakeholders responsible for much of the

\footnotetext{
${ }^{1}$ Generally speaking, Creoles are individuals of mixed African and European heritage, Mestizos are of mixed Spanish and Native Indian heritage, Mayans are the native peoples of Belize. Garifuna are a distinct ethnic group on the coast of Belize descended from African slaves.
} 
management of the MPA.

Table 5. Summary of Stage of Implementation and Level of Co-Management of Sites

\begin{tabular}{|l|l|l|}
\hline Site & Stage of Implementation & Type of co-management \\
\hline $\begin{array}{l}\text { Scotts Head/Soufriere Marine } \\
\text { Reserve }\end{array}$ & Post-implementation & Delegated \\
\hline Hol Chan Marine Reserve & Post-implementation & Collaborative \\
\hline Laughing Bird Caye National Park & Post-implementation & Delegated \\
\hline St. Eustatius National Marine Park & Post-implementation & Delegated \\
\hline Saba National Marine Park & Post-implementation & Delegated \\
\hline Buccoo Reef Marine Park & Pre-implementation & Consultative \\
\hline
\end{tabular}

Participatory processes

Participation at each of these sites was highly variable. Participation can be regarded on two scales; the extent of participation, or how widespread participation is within the community (both in terms of the percentage of the community participating, and the number of stakeholder types participating), and the type of participation, or how people actually participated. It is important to underscore the obvious, that communities and stakeholder groups are not homogenous, and likewise, participation is not homogenous. As Arnstein (1969) argues, what is significant in participatory processes is not whether community members are able to attend a meeting and present their opinion, but whether they have the power to change the outcome of a decision. Data collected on participation are very basic, asking only about whether individuals had attended a meeting or participated in another activity, and if so, how they had participated. The questions of meaningful participation and power can only be inferred from the key informant interviews, which gathered additional information on how stakeholders had been participating in co-management or otherwise. 


\begin{tabular}{|c|c|c|}
\hline 8 & Citizen Control & \multirow{3}{*}{ Citizen Power } \\
\hline 7 & Delegated Power & \\
\hline 6 & Partnership & \\
\hline 5 & Placation & \multirow{3}{*}{ Tokenism } \\
\hline 4 & Consultation & \\
\hline 3 & Informing & \\
\hline 2 & Therapy & \multirow{2}{*}{ Nonparticipation } \\
\hline 1 & Manipulation & \\
\hline
\end{tabular}

Figure 3. Arnstein's Ladder of Participation (1969)

Arnstein's ladder of participation, widely discussed in the literature and used here as a model for evaluating participation, is focused on achieving citizen power through participation. While this model is somewhat useful in describing various levels of participation, it is also (necessarily) simplistic, as it is focused only on participation as a means of achieving citizen power. It has been criticized for, among other reasons, neglecting to explain differing levels of participation by different community members or groups (Tritter and McCallum 2006).

Choguill (1996) has developed another scale of participation more appropriate for evaluating participation in underdeveloped countries. She suggests using the term community participation instead of citizen participation, to imply that participation by individuals does not necessarily lead to benefits for the community as a whole. While this scale is geared toward development projects and focused on poverty alleviation, it is appropriate for discussing marine protected area management as well. Both Arnstein's and Choguill's models imply that the community has a single interest that can be achieved through participation; it is more often the case however that the interests of community members and groups are in conflict, and participation by one group may not be in the best interests of others. As Suárez de Vivero et al. (2008) have aptly noted, participation and devolution do not have a linear relationship, and more 
devolution does not necessarily lead to greater participation. The Arnstein and Choguill models can be more appropriately described as characterizing the stages of devolution, rather than participation.

Participation should thus be considered at both the community level and the individual level. For this analysis, however, it is not feasible to thoroughly discuss how each individual did or did not participate, as for the most part these processes were not observed. What is analyzed here is the opportunity for participation by stakeholders at each site, as well as the opportunity for representation, based on the structure of the co-management process as well as the extent to which participation has been invited or encouraged on a greater scale. The level of participation at each site mirrors the level of co-management at each site based on Pomeroy's scale, as the level at which stakeholders can participate will be related to the design of the comanagement structure.

Table 6. Summary of Level and Extent of Participation at each site

\begin{tabular}{|l|l|l|}
\hline Site & $\begin{array}{l}\text { Level of Participation } \\
\text { (devolution) }\end{array}$ & $\begin{array}{l}\text { Level of Community } \\
\text { Participation }\end{array}$ \\
\hline Scotts Head/Soufriere Marine Reserve & Delegated & Low \\
\hline Hol Chan Marine Reserve & Partnership & Medium \\
\hline Laughing Bird Caye National Park & Delegated & High \\
\hline St. Eustatius National Marine Park & Delegated & Medium \\
\hline Saba National Marine Park & Delegated & High \\
\hline Buccoo Reef Marine Park & Consultation & Low \\
\hline
\end{tabular}




\section{Soufriere/Scotts Head Marine Reserve}

History

The Soufriere/Scotts Head Marine Reserve (SSMR) is located along the southwestern coast of Dominica, and borders the communities of Scotts Head, Soufriere, and Pointe Michel. Work on establishing the marine reserve began in 1987, primarily by the Director of the Fisheries Division at the time, and it was officially codified under Fisheries Act No. 11 of 1987 (James et al. 2006). "The goal of the project is to minimize user conflicts, preserve traditional fishing cultures, cater to the trends in development and conserve a resource that is unique to the area." (SIDSnet n.d.) Dive tourism was just beginning in Dominica during the time at which the reserve was first conceived, but its founders were aware of the growing trends in tourism and anticipated future conflicts in this region. One of the goals of the reserve was to preserve access to traditional fishing grounds for the area's fishermen in the face of increased demand for recreational activities. As such, the reserve area was divided into four zones: the Fishing Priority, Recreational, Scuba Diving, and Fish Nursery zones. These zones were for the most part developed following existing traditional usage of these areas, and based on discussions with stakeholders in the planning stages. The Nursery zone was created based on scientific surveys of the area (Lawrence pers. comm.), and the only activities permitted are fisheries research and education (James et al. 2006). The Recreational zone is a small area set aside at a popular bathing beach for swimming and snorkeling, and the Fishing Priority and Scuba Diving zones are set aside for those activities respectively. 
By and large, the fishermen fishing out of this area have not traditionally fished within the confines of what is now the SSMR, but instead fish farther out to sea for pelagics including tuna and marlin. In exchange for their cooperation with the notake areas, the Fisheries Department promised to assist the fishermen in obtaining Fish Aggregation Devices (FADs) to enhance their fishing capacity. Some of the older fishermen who can no longer go very far out to sea to fish have traditionally used the nearshore area to set fish pots for balao and other small pelagics, primarily for subsistence fishing. Additionally, those fishermen who cannot afford an engine for their boats still fish using a rowboat, and thus fish close to shore. The Fishing Priority Area was designed to preserve these traditional fishing activities.

\section{Management}

The SSMR is co-managed by the Fisheries Department and the Local Area Management Authority (LAMA), formed in 1994 to implement the management of the marine reserve (James et al. 2006), and made up of representatives from various stakeholder groups. Groups with designated representation on LAMA include dive operators through the Dominica Water Sports Association, the Scotts Head-Soufriere Village Council, the fishing cooperative, the local youth group, and other members of the community. While fishermen had been consulted in the early stages of the SSMR, at present, there is no fisherman active with LAMA, in part because there has not been an active fishing cooperative in the community. During my research visits, one fisherman was trying to restart a fishing cooperative in Scotts Head. 
The local community was very active in the SSMR in its early days. SSMR Day is an annual celebration of the reserve put on by the Fisheries Department that includes a quiz competition between schools. In the early days, the Fisheries Department had a number of educational programs aimed at both the general public and at fishermen to develop awareness of and support for the SSMR. They held a number of public meetings in different fora, appeared on television and radio programs, and had students do skits for the public related to the SSMR. The Fisheries officers also met informally with the fishermen over rum to discuss the reserve and to garner their support. As a result of these efforts, many people within the community were aware of the presence of the reserve, but did not necessarily support it or know anything about it.

Many of these outreach activities have since fallen off, although SSMR Day is still celebrated each year. At present, LAMA employs four wardens and has an unpaid, acting manager. Between 2002-2006, they hired a full-time manager with funding from the EU, but no longer have the funding to pay a manager.

\section{Community}

As the name suggests, the marine reserve is adjacent to the two communities of Scotts Head and Soufriere, in the southwestern most point in Dominica. The two communities are separated by a road about a mile long. Scotts Head is a traditional fishing village, and fishing is the major economic activity (James et al. 2006); fishing is also important, although less so, in Soufriere. Roughly $90 \%$ of those who fish in this area reside in Scotts Head (James et al. 2006), whereas residents of Soufriere are more 
likely to be employed in trades such as construction, or to seek employment in Roseau, the capital. Scotts Head and Soufriere are poor villages by Dominica standards, and were more so at the time of inception of the SSMR. Scotts Head in particular is still known to be one of the poorest communities on the island. There is a small amount of tourism present in both communities; Scotts Head has a few small guest houses and restaurants, and Soufriere has a dive shop.

\section{Issues}

Despite the efforts to publicize the reserve and inform the community, public support for the reserve is mixed. Many fishermen believe they have been wrongly excluded from this area without consultation, especially younger fishermen who were not old enough to have been consulted during the planning stages. One of the outcomes of the zoning of the reserve was that anchoring was prohibited from the entire area. Prior to the creation of the reserve, yachts would sometimes anchor off the coast, and a small tourist industry developed providing services to the yachts. Some individuals, particularly those involved in tourism, continue to be upset about the loss of the yachts, and strongly oppose the decision by LAMA not to permit yachts to return to the area.

There is also a general lack of understanding by the public of the function of LAMA. Many residents of Scotts Head in particular are angry with the man who currently serves as the chairman of LAMA. This individual is a wealthy resident of Soufriere who owns the dive shop and a lot of land in Soufriere. Many respondents believe that he benefits financially from the SSMR, and some even believe that he 
personally created or owns the SSMR. There is also a good deal of conflict among the members of LAMA. Although, according to the acting manager of the reserve, the position of chairman within LAMA is only cosmetic, some of the members believe LAMA should hold elections and elect a new president. Those involved in the dive industry in particular believe LAMA is not functioning as it should, and that those at the top will not permit any changes. It appears LAMA has few if any meetings with the Board, and rarely with the general public. While fishermen were involved in LAMA and SSMR in the beginning, they are not involved today, in part it seems because they have lost interest in the reserve. Several key informants indicated that LAMA is supposed to be representative of the community and give everyone a venue to be involved and voice their opinions, but very few sectors of the communities actually sit on the board or are functionally involved in the marine reserve.

During my second research visit to Dominica, the acting reserve manager indicated he was planning to hold more meetings in the near future with members of the fishing community. It is evident that the LAMA board and the marine reserve manager do not necessarily function in coordination with one another. It is unclear whether these meetings were to be through LAMA or just held by the manager alone. The manager expressed a strong desire to keep fishermen engaged in the marine reserve and talked about how important it is for fishermen. However, he did not seem particularly concerned with involving other stakeholders in the process. This may be where a disconnect exists. At present, LAMA has no fishermen serving on the committee, and they are only represented through the Fisheries Department by way of the reserve manager. On the other hand, LAMA has representatives from other groups 
in the community, including the dive industry and the village council. The perception that LAMA was created to benefit the dive industry results from having two members of the dive tourism community (co-owners of the same dive shop) as the two most prominent members of LAMA, while in reality most of the decisions seem to come from the manager himself.

James et al. (2003) found in their survey of fishers in Scotts Head and Soufriere:

In terms of supporting the idea of the marine reserve when it was proposed, slightly more than half $(52 \%)$ of the fishers interviewed indicated that they did not support the idea. Twenty-eight percent supported the proposal for the SSMR, while the remaining 20 percent did not know whether they supported the idea or not. However, there is more support for the SSMR now (40\% of the fishers interviewed). Some stated their support on the condition that the SSMR does not affect the livelihood of fishers. Nevertheless, the remaining 60 percent do not support the SSMR. (37)

One particular impediment to receiving the cooperation and approval of the fishing industry in Scotts Head and Soufriere is a lack of coordination within the fishing industry. In late 2008, the fishermen in Scotts Head were in the process of forming a cooperative, which they have not had for several years. A prominent fishing boat owner was spearheading the process and serving as the president. However, he himself has never been to any meetings regarding the Scotts Head/Soufriere Marine Reserve or otherwise been involved in any way. Thus at the time of the research there was no connection between the burgeoning cooperative and the marine reserve, although perhaps once the cooperative becomes more active, they will have a representative serving on LAMA.

Another point of contention has been the finances of the reserve. User fees are supposed to be collected by all dive shops from divers who dive within the reserve and 
given to LAMA. A number of stakeholders reported there was no transparency regarding what happened with the funds, and argued that the reserve management must be taking the money. The reserve management claims the money goes towards funding SSMR Day, and that many of the dive shops collect the user fees but do not in turn give them to LAMA. The reserve has purchased a building in Soufriere with funds received from the European Union with the intention of creating a visitor's center. However, during my two research visits the building was shuttered, and LAMA reportedly did not possess the funds to open the visitor's center. Many residents in the community displayed much skepticism about whether anything would ever happen with this building, and in some residents' minds, the empty building was symbolic of a lack of management.

\section{Participation}

There are few opportunities for community members to substantively participate in the SSMR in any way. LAMA does not hold meetings with the general public at present. The reserve manager reported to have been holding meetings with fishermen, as did the Fisheries Department, but as there is not yet an active fishing cooperative, there is no organized group of fishermen and so these meetings were held with select individuals. Attendance at meetings or other participation by community members surveyed was low - only $14.3 \%$ - close to the lowest rate of participation among all sites in this study. LAMA is designed to have its members represent the two communities of Scotts Head and Soufriere as well as particular stakeholder groups within these communities, but when asked who was involved in management, few 
respondents named any individual other than the head of LAMA, about whom there was a great deal of disapproval. Only $37.0 \%$ of respondents stated they believed their interests were represented by those responsible for managing the MPA, the lowest of any of the sites where this question was asked. To become a member of LAMA, one must be voted on by other existing members of the group; thus it is unlikely that additional stakeholder representation on the board will be added anytime in the future. While LAMA is set up to represent community interests, few community members participate in any way or have the ability to have their interests represented.

Analysis

The Scotts Head/Soufriere Marine Reserve should be considered at the postimplementation stage of co-management. The reserve has been established since 1987, and while there are still numerous conflicts around the management of the reserve, both within the community and between members of the management committee, there is no serious discussion of changing the co-management arrangement or the rules of the reserve. This co-management arrangement should be considered a delegated management scenario based on Pomeroy's scale of co-management (Pomeroy et al. 2004), as LAMA has the primary responsibility for management. LAMA is relatively dysfunctional at present, but the few management activities that take place, such as patrolling the reserve, are coordinated by LAMA and not by the Fisheries Department. It was noted by key informants that for major changes to take place in reserve management, LAMA would need to be dissolved, as it was created by the statute that created the marine reserve. 
Following Arnstein's ladder of participation, LAMA should be considered delegated power, as a significant amount of decision-making about the marine reserve takes place at the community level. Choguill refers to this level as partnership (Arnstein has partnership as one level lower on the ladder), where decision-making is shared between outside interests and the community - in this case, the Fisheries Department and LAMA. However, the remainder of the community, those who are not on the board of LAMA, would probably be placed somewhere between informing and consultation on the Arnstein scale. Other interest groups, such as the dive industry operators, may theoretically be consulted by their representatives on the board, and those individuals representing the municipalities may seek the opinions of their constituents. However, there is no indication of whether the members of LAMA seek out the opinions of others in the community, and if they do, it does not appear other community members have any power over what takes place in the marine reserve. Thus while the level of devolution for LAMA is relatively high, in that those who participate on the management board and are thus responsible for management decisions, have a good deal of power, the extent of participation, or how much of the community participates, is low.

As a co-management organization, LAMA should be considered a success in its design, in that community members have delegated authority to manage the marine reserve. However, the lack of any fishing representation on the committee means a significant and important stakeholder group is not being represented in the comanagement process. The SSMR has also been unsuccessful from a participation standpoint, in that the co-management of the reserve has not led to greater 
participation by stakeholders in meetings and other management activities. LAMA should be considered an example of a co-management body arrangement that does not represent the interests of the community as a whole. It could be argued that this group has been co-opted to serve the interests of one particular stakeholder group (the dive industry), although the addition of one or more fishermen to the board could shift the balance of power back to something more representative of community interests at large.

\section{Hol Chan Marine Reserve}

History

The Hol Chan Marine Reserve was established in 1987, when local people in San Pedro lobbied for its designation to preserve and manage the reefs off Ambergris Caye. This came about in large part because a conflict had developed during the early 1980s between fishermen and tour guides over the use of the area, which was both a productive fishing ground and known for its coral reef formations. The reserve was developed through a public consultation process that also included an informal advisory committee of stakeholders (Garaway and Esteban 2002). Hol Chan was established as a multiple use MPA, and is made up of four zones. Zone A consists of the reef and a channel running through the reef; this is a popular area for diving and snorkeling, and these are the only activities permitted within this zone. Zone B is the sea grass habitat area; commercial and recreational fishing are permitted in this zone with a license. Zone $\mathrm{C}$ is made up of mangroves; sport fishing is also permitted here with a license. Zone D, known as Shark/Ray Alley, is another diving and snorkeling 
recreation zone; fishing is also permitted within this area (Garaway and Esteban 2002). The original reserve had a total area of 1320 hectares, of which 1224 hectares was marine, and 273 hectares made up the no-take zone. The Hol Chan Marine Reserve is self-funded through user fees. The reserve received 38,687 visitors in 2001 (Galaway and Esteban 2002).

The Hol Chan Marine Reserve is off the southern end of Ambergris Caye, an island consisting of the town of San Pedro. San Pedro is the top tourism destination in Belize. Because of its location on the south end of the caye, away from the main area of town, most residents of San Pedro do not use or see the marine reserve on a regular basis, although most are aware of its presence, if for no other reason than because there are dozens of tour operators in San Pedro, nearly all of whom sell snorkeling tours to Hol Chan. The Hol Chan Marine Reserve has an office in the center of San Pedro, and many of the residents surveyed mentioned the office when talking about the management of the reserve. The office, while small and set back a couple of blocks from the main tourist area, has a small interpretive center with displays about the ecology of the reserve along with other information about the reserve.

The Hol Chan Marine Reserve has been well studied, and has generally been considered a biological success in the literature. Increases in commercially valuable fish stocks have been demonstrated for the Hol Chan Marine Reserve (Cho 2005). Roberts (2000) found the Hol Chan Marine Reserve to be one of the most successful MPAs in the world in terms of increasing densities of large fish. 


\section{Management}

The Hol Chan marine reserve is managed by the Hol Chan Marine Reserve Board of Trustees, made up of the Fisheries Department, the Reserve Manager, a local NGO, a member of the business community (manager of a local bank), the Chair of the San Pedro Tour Guide Association, a member of the fishing community (the former head of the fisheries coop who is now the Minister of Tourism), a representative from the Coastal Zone Management Institute, the Financial Secretary from the Minister of Finance, and the chair of the Fisheries Advisory Board. These individuals are appointed by their various groups, and the groups represented on the board are chosen by the board. The board reportedly has quarterly meetings. The Board of Trustees is responsible for making decisions about the management of the reserve.

There is also a management organization directly responsible for the day-today management of the reserve run by the reserve manager, who also sits on the Board of Trustees. At the time of research, there were fourteen employees at the marine reserve including six rangers, a biologist, and educational and administrative staff. The Hol Chan Marine Reserve has a management plan, but according to the manager, the reserve is managed adaptively, and the management plan does not reflect current management strategies (M. Alamilla, pers. comm.). The organization is very active in the schools, holding Reef Week each spring, an educational program held with school children that celebrates the island's reefs, as well as additional education programs in the schools that take kids out to the reef. The reserve staff also does regular (at least 
yearly) training programs with the dive shops, through visits to the dive shops by the staff biologist and other staff members.

In 2007, the size of the Hold Chan Marine Reserve was tripled as the result of a community initiative from the tour guide association. The tour guides are the most visible and active stakeholders of the reserve, and they have the most to benefit from it. The Board of Trustees recently increased the user fee to the reserve and as a result decreased visitation to the reserve, an outcome desired by the reserve management as a way to limit overcrowding and resultant reef damage. This action was not supported by the tour guides. The tour guides generally have a high level of respect and trust for the head of the Tour Guide Association, who represents them on a number of issues. The tour guide association had an office until recently, but the office was closed in December 2008.

Fishing is minimal in the reserve; there are few fishermen still on the island. According to the coop manager, there are 20 active fishermen on the island, and 35 fishermen total. Some of the fishermen fish only during the first few weeks of conch and lobster seasons, and work other jobs the rest of the year. Many of the fishermen switched to being tour guides during the 1980s as the tourism industry on the island began to grow, and as the fishery was in decline (Gallaway and Esteban 2002). The park rangers mostly monitor tourist activities, as fishing is not a significant activity within the reserve. 


\section{Community}

San Pedro has a large tourism industry, but unlike many communities throughout the Caribbean with a significant tourism presence, the majority of businesses are owned by local residents, and the local community has greatly benefited economically from tourism (Garaway and Esteban 2002). Socially and economically, San Pedro is largely divided between those who were born there and those who were born elsewhere, either on the mainland of Belize or elsewhere in Central America. People born on San Pedro (San Pedrans) have a clear sense of pride about being from there, and appear to possess a strong sense of civic engagement. Many San Pedrans are middle class business and property owners, whereas many of the people who have come from elsewhere in Belize or Central America work in service jobs. The island has a very active Lion's Club, and regular community activities both with the schools and with adults, all of which are advertised in the local paper.

San Pedrans were for the most part well informed about the reserve and its management, and had strong opinions about the marine reserve and about other activities taking place in the coastal zone. Information about the reserve is frequently published in the local paper or on the local television show; respondents did not often report getting this information directly from the marine reserve office.

On the other hand, respondents not originally from San Pedro often expressed the opinion that the San Pedrans were the ones who made most decisions and excluded the rest of the community. In particular, those who have moved to San Pedro recently (a number of whom speak little English) are not generally well represented in decision 
making for the marine reserve, as most of the individuals involved in managing the marine reserve are long-term residents of San Pedro. Nor are these recent immigrants generally aware of who is involved in the marine reserve beyond knowing that it exists.

Issues

A common criticism from community members about the Hol Chan management was the belief that the marine reserve staff benefit financially from the reserve. A number of people reported that the rangers charge people for entrance fees and then pocket the money themselves. The reserve has historically had problems with financial accountability and transparency regarding the funds collected, and decisionmaking about the funds (Cho 2005). Some people also expressed concern that members of the staff, and particularly the manager, were not sufficiently personally invested in the success of the reserve.

The major ongoing issue in San Pedro is the South Beach development proposed for the south end of the island. This would be a massive high-end residential development built to resemble South Beach, Miami, and would be directly adjacent to the marine reserve. Most of the community is strongly opposed to the development, and the developer is an American in the process of completing an extensive development on the north of the island. There was widespread recognition that this development would impact the island's natural resources and thus tourism, although it was unclear whether community members were aware of its proximity to the marine reserve. 


\section{Participation}

Stakeholders are primarily represented in the Hol Chan Marine Reserve through its Board of Trustees, which has members selected to represent different stakeholder interests on Ambergris Caye. The management organization is very active in informing the community about developments related to the marine reserve and in organizing events related to outreach. They occasionally hold community-wide meetings about the reserve, and they regularly do trainings with dive shops and other tour guides. There are few opportunities for other community members to participate directly in marine reserve management. Of residents surveyed, only $16.6 \%$ said they had attended a meeting or otherwise participated in the marine reserve in some way. The reserve staff regularly hold trainings with dive operators and tour guides to educate them about the reserve and its management. These meetings serve more as an outreach activity than as a participatory activity. Some of the other activities mentioned in addition to meetings were clean-ups and school activities.

The individuals serving on the Board of Trustees were often named by respondents as people they knew who were involved in management, particularly the NGO representative and the head of the Tour Guide Association. A total of $64.6 \%$ of respondents said they believed their interests were represented by management, the highest percentage of any site where this question was asked. The groups represented on the board are specifically named in the legislation creating the board and the marine reserve, and the individuals representing these groups are appointed by their individual groups, most of which are formal organizations. Other community members do not have the opportunity to participate as part of the board without belonging to one 
of these organizations. Generally, the residents of San Pedro appear to be fairly well represented by the reserve management, but they have little direct involvement in the reserve. As mentioned above, however, many of the island residents who have moved there more recently, as opposed to being born in San Pedro, feel left out of the process. The members of the Board of Trustees are for the most part native San Pedrans and outsiders do not have representation on the board.

\section{Analysis}

The Hol Chan Marine Reserve is in the post-implementation phase of comanagement. The board of directors responsible for directing the management organization is well established, and the marine reserve is more or less accepted within the community. The reserve is managed through a process of adaptive management (Alamilla, pers. comm.), and thus the management plan is constantly being revised, but the co-management process and activities such as enforcement are stable and unlikely to undergo significant changes in the near future. This reserve can be considered managed through a collaborative co-management arrangement, where an organization responsible for management activities and a board of directors, drawn largely from the local community, is responsible for decision-making and for overseeing the management organization. However, the Belizean government still maintains considerable control and responsibility, as representatives from some government departments sit on the board of directors. Their role on the board is equal to that of the community members.

The Hol Chan Marine Reserve can be considered an example of partnership on 
Arnstein's ladder, where much of the power over managing the marine reserve has been granted to the management organization and its board of trustees, yet some control is still maintained by the Fisheries Department and the government, both directly and through the seats they maintain on the board of trustees. There is limited opportunity for the rest of the community to participate in management other than through the board of trustees. The staff of the marine reserve holds regular meetings with tour and dive guides on the island, but these meetings seem to be mostly for the purposes of informing the guides about the marine reserve, rather than encouraging their input.

The Hol Chan Marine Reserve can from one perspective be considered a successful co-management arrangement, in that the group of individuals responsible for managing the reserve seem to represent the interests of the greater community. The representation on the Board of Trustees is fairly diverse, and includes the major stakeholder interests of the community (tour guides, tourism, fishing, business, and the environmental community). However, the Hol Chan Marine Reserve has not been successful from the standpoint of promoting broader participation by stakeholders through the co-management body. While there appears to be general satisfaction with the marine reserve, greater participation should be a goal of the co-management board to ensure greater representation of community interests.

\section{Laughing Bird Caye National Park}

History

Laughing Bird Caye is a small, sandy caye of 0.56 hectares off the coast of 
Belize, located between the village of Placencia and the barrier reef. The island has reefs on either side, and the water adjacent to the island is protected as part of the park; the total area of the national park is 10,094 hectares (Cho 2005). Laughing Bird Caye is located about 12 miles from Placencia, and cannot be seen from the mainland because of the island's low profile. The island has a ranger station, a small interpretive center, and a few moorings. In addition to the significant numbers of tourists who come to snorkel or dive around the island during the tourism high season, some charter boats from elsewhere stop at the island for a picnic, and many locals from Placencia and other communities come to Laughing Bird Caye to picnic and bathe.

In 1991, a group of fishermen and other residents of the communities of Placencia, Seine Bight, and Independence formed the Friends of Laughing Bird Caye and petitioned the government to declare Laughing Bird Caye a national park. At the time, Laughing Bird Caye was used by local residents, who would travel to the island to picnic, by local fishermen, and by an emerging tourism industry. A developer was attempting to purchase the island, generating great concern among local residents about the loss of access to the island and its resources, and so they convinced the government to purchase the island instead and declare it a national park. Many of the individuals first involved in this effort are still actively involved with the organization, with a couple of them presently serving on the Board of Directors. In 1996, Laughing Bird Caye and several other sites on the Belize Barrier Reef were declared a World Heritage Site by the IUCN.

In 2001, the Friends of Laughing Bird Caye signed a co-management agreement with the Department of Forestry to co-manage the park. The organization 
later changed its name Friends of Nature, as its purview increased to include the Gladden Spit and Silk Cayes Marine Reserve. Today, the group is formally known as SEA, or the Southern Environmental Association ${ }^{2}$, having merged in late 2008 with a group known as TASTE out of the town of Toledo, and is additionally responsible for the Sapodilla Cayes Marine Reserve.

Initially, the newly-formed Friends of Laughing Bird Caye conducted consultations with the fishermen in the communities as part of the creation of the national park. These consultations did not all go smoothly in the beginning, but according to key informants, more recently fishermen have been approaching the Friends of Nature and asking them to protect more areas.

\section{Management}

Today, Friends of Nature works with the six main communities in the region to ensure representation from each of them. These include Placencia, Seine Bight, Monkey River, Independence/Mango Creek, Sittee River, and Hopkins. The chairperson (head of the local government) from each community, or another individual appointed by the chairperson, sits on the Board of Directors of Friends of Nature. The Board of Directors also includes a representative from the tour guide association, the fishermen's cooperative, the Belize Tourism Board, the regional high school in Independence, the dive industry, a local businessman, and the owner of the local shrimp farm. The individual groups forming the Board of Directors were selected

\footnotetext{
${ }^{2}$ However, the group will be referred to Friends of Nature throughout this document, as that is the name community members and even staff members were still using to refer to the organization at the time of data collection, as the name change had just taken place.
} 
by Friends of Nature, and representatives are selected by their respective groups. The Board is supposed to meet every two months.

During the time field work was being undertaken, Friends of Nature was conducting a dive master training program designed as an alternative livelihood project for fishermen from the southern region of Belize. They trained 31 new dive masters to work in the tourism industry in 2008. Many of the fishermen work as tour guides during the tourism season and fish during the off-season. Friends of Nature has also been involved in taking local fishermen on field trips to other countries, including Mexico, Cuba, and Guatemala, to teach them about alternative fishing techniques and methods. Many of these projects have been funded by the UNDP.

Friends of Nature has an office in Placencia, and many people in Placencia were aware of the presence of the office. Unlike on San Pedro, the Friends of Nature office is not designed for visitors and does not have an interpretive center. However, a number of people from the community were passing through the office while I was there. Rangers patrol Laughing Bird Caye and the other areas managed by Friends of Nature 24 hours a day, seven days a week. Additionally, there is a ranger patrol station on Laughing Bird Caye and a small interpretive display.

\section{Community}

Because of its location offshore, Laughing Bird Caye is not directly associated with any one particular community. There are six communities in the region represented on the board of Friends of Nature, each considered to have a stake in the marine park. Of these, the community of Placencia has probably the strongest ties to 
the marine park. This is where the office for Friends of Nature is located. In addition to being geographically closest to the caye, the area's tourism industry is primarily based in Placencia, so many of the tours to Laughing Bird Caye depart from here (although the tour guides sometimes live in other communities and travel to Placencia). Because of the tourism industry, Placencia, a small community of less than a thousand people, has a diverse population, with a number of Creoles, some Mestizos, and a significant expatriate community. ${ }^{3}$ There are also a number of Mayans who work in Placencia or come to the community to sell crafts, but few of them reside in the community full-time.

Seine Bight, on the other hand, to the north of Placencia, is primarily a Garifuna $^{4}$ community, in which many of the residents make a living fishing. Unlike Placencia, Seine Bight is largely a poor community. Independence is a larger community and the area's population center. The regional high school is located there, and many of the individuals who work in Placencia reside in Independence. There is a small ferry connecting the two communities across the lagoon.

Issues

A number of residents complained of being deterred from visiting the Laughing Bird Caye by the entrance fee that they did not want to have to pay; however, key informant interviews revealed that Belizeans do not actually need to pay an entrance fee to visit the caye. This fact seems to have been poorly communicated to

\footnotetext{
${ }^{3}$ Generally speaking, Creoles are individuals of mixed African and European heritage, Mestizos are of mixed Spanish and Native Indian heritage, Mayans are the native peoples of Belize.

${ }^{4}$ Garifuna are a distinct ethnic group on the coast of Belize descended from African slaves.
} 
the community.

During my research visit to Laughing Bird Caye, a sailboat attempted to anchor on the reef, and while the tour guides who were on the island at the time were very concerned and eventually directed the sailboat to a mooring, the two rangers present on the island at the time took no action to prevent the vessel from anchoring. Some community members had complained about a lack of enforcement by the rangers.

\section{Participation}

The Friends of Nature provides several opportunities for community members to be involved in the marine reserve at different levels. According to key informants, they hold yearly community consultations, where stakeholders can learn about developments in the park and express their interests, and they hold quarterly informative meetings about the park through the education department. Each of the six communities in the region of the Laughing Bird Caye National Park has its community chairperson or another formal representative on the board. These individuals are tasked with relaying information and issues regarding the park at their community meetings, and receiving community input to bring back to the board. In this way, all stakeholders of the park should have some degree of representation, and each has some opportunity for participation. The Board of Directors of Friends of Nature is also designed to be representative of various stakeholder groups, and many respondents within the communities named these individuals as being involved in the park.

The group least represented is newcomers to the communities or part-time 
residents who live in Placencia or the surrounding communities part of the year to work in the tourism industry. Many of these individuals were unaware of the park, or of the management of the park. Parsram and McConney (2004) note that Creoles in the communities do not generally attend meetings, while Mayans and Garifuna are more likely to attend meetings and be involved in what is happening with the national park. I found a number of Garifuna in Seine Bight who had attended meetings, but also found many Creoles who had been involved. In my own field work I encountered few Mayans who had attended meetings. In their analysis of this MPA from 2004, Parsram and McConney also noted:

Friends of Nature is seen by many as merely an extension of government rather than a true representative of the people and resource users in the community. There is little transparency and accountability of Friends of Nature, especially concerning funds and decision-making that affects key user groups (fishers and tour guides). $(2004,9)$

In my experience, the majority of people within the communities seemed to be accepting of the MPA and of the role of Friends of Nature, so perhaps the issue of representativeness has been counteracted by overall satisfaction with the MPA and the organization. However, there were some stakeholders who addressed concerns about transparency and accountability of some of the staff.

The day before I arrived in Placencia, Friends of Nature held a consultation with fishermen in the area to solicit their opinion about banning net fishing from certain areas. The organization also holds numerous outreach and training programs with tour guides and through the schools, as well as meetings and workshops with fishermen, and many community members responded that they have participated in these. In all, 25.2\% of community members surveyed said they had attended meetings 
or participated in the MPA in some way, the highest percentage among MPAs in the study after the Saba Marine Park.

Analysis

Both Pomeroy et al. (2004) and Parsram and McConney (2004) suggested the co-management of the Laughing Bird Caye National Park was in the implementation stage. At the time the fieldwork was conducted in late 2008, however, the comanagement arrangement for this MPA could be considered in the postimplementation stage. Many of the conflicts regarding the park had been resolved, and there is active and ongoing management and enforcement of the park. Pomeroy et al. (2004) further suggested that the Laughing Bird Caye reserve is managed through a form of delegated co-management. My fieldwork confirms this; while the park is comanaged with the Department of Forestry, decisions regarding management as well as management actions are all made by Friends of Nature.

Friends of Nature, responsible for managing the Laughing Bird Caye National Park, is another example of delegated power. In this case, the co-management organization has most of the responsibility for managing, but the government still retains a certain degree of authority. The level of devolution at this site is similar to that at SSMR, but the extent of participation within the communities is higher.

Overall, the co-management of the Laughing Bird Caye National Park should be considered a success from the perspective of representation. The board of Friends of Nature is large and diverse, with a wide variety of stakeholders represented. For the most part, the primary stakeholders of the marine park are well represented on the co- 
management body, and there are no significant groups of stakeholders completely left out of the process. This MPA should also be considered successful from a participation perspective, based on the large percentage of respondents who have attended meetings compared with most of the other sites.

\section{Saba National Marine Park}

\section{History}

The Saba National Marine Park was founded in 1987 as a means of protecting and managing Saba's natural resources. The park is comprised of about 1300 hectares surrounding the island out to a depth of 60 meters, and is zoned for various activities, with a focus on recreational diving. The marine park began when the island government wanted to promote dive tourism and protect the island's unique and relatively pristine coral formations, so they looked to the work STINAPA ${ }^{5}$ had done in establishing the highly successful Bonaire National Marine Park (Saba Conservation Foundation 1999). Members of the island government contacted Tom van't Hof, who had been instrumental in Bonaire's park, to work with them, and together he and the lieutenant governor of Saba began the process of creating a park. According to informants, there was extensive consultation and participation when the park began. The government and van't Hof did surveys with fishermen at the outset, and held the first public consultation in 1984. They provided free beer at the meetings to get people to attend and had public meetings with fishermen. Fishermen were generally

\footnotetext{
${ }^{5}$ The management organization of the Bonaire National Marine Park, often held up as a standard of a successful MPA
} 
supportive to begin with, largely because there was little subsistence fishing on Saba. Most of the fishermen fish out on Saba Bank, well beyond the boundaries of the marine park. The zones developed for the park were based largely on existing uses. The government held open houses and presented different scenarios to the public based on possible rules and zones, and they deliberately sought the participation of fishermen, divers, and yachters in this process.

According to one informant, there was a lag time of about a year and a half between when the consultations took place and when the park opened, and this provided time for rumors to start and conflict to develop. Once the ordinance was passed creating the park, most people lost interest in what was taking place and stopped showing up for meetings. There have been no stakeholder consultations since the park was opened because, according to one informant, there have been no contentious issues.

\section{Management}

The park is currently managed by the Saba Conservation Foundation, which has a seven-member Board of Directors. Members of the Board of Directors are chosen by other members of the Board, who select individuals they believe are appropriate. There is no maximum number of board members. Currently, of existing board members, two are Saban, two are Antillean, two are American, and one is Dutch. Of these individuals, two serve as part of the island government, one runs a hotel, one owns a restaurant, and the other three are in non-tourism-related industries. The Saba Conservation Foundation is overseen by the Dutch Caribbean Nature 
Alliance (DCNA), an umbrella organization responsible for financial and management oversight of the national parks organizations on each of the Dutch Antilles.

The Saba Conservation Foundation holds a general meeting open to the public every year, which informants say is usually sparsely attended by the same individuals each year, usually the expatriate community. They also hold public meetings whenever there is research to present. The organization has an office located alongside the island's only port. The office has a gift shop for tourists and has educational information about the marine park.

The Saba Conservation Foundation manages the marine park as well as a terrestrial park, and runs environmental education programs on the island. The organization has a manager responsible for both parks and the organization, a ranger for the marine park, an educator, an administrator, and a few individuals responsible for maintaining the trails for the terrestrial park. The organization has an extensive educational program where the education staff visits the local schools once a month to work with all students between the ages of six and twelve. This program is focused primarily on the marine park and teaching the students about the marine life around Saba. For older children, the foundation runs a snorkel club, a sea scout program, and a junior ranger program, all focused on educating the local youth about the marine environment and getting them involved in the marine park. Additionally, the foundation has an article in the local newspaper once a week about something related to the marine park or the organization. As a result, awareness of the marine park on the island was very high (greater than 95\%), certainly amongst young people, but also amongst their parents. The organization runs an island clean-up twice a year in which 
numerous locals participate. All of the dive shops (of which there are three, and one live-aboard yacht that visits Saba frequently) are required to have their staff participate in an orientation by the Saba Conservation Foundation.

The marine park has a management plan, but it is out of date, and according to the manager, the rules are continuously being negotiated with the stakeholders. The original ordinance creating the marine park doesn't make the rules clear, so the rules in place are left open to interpretation. The park boundaries extend out to a depth of 60 meters, and there are four different zones within the park. Approximately one third of the park's area is zoned primarily for diving, and there are dive moorings in place throughout the park. Fishing is not permitted within the diving zones. The park contains an anchoring zone where visiting yachts can anchor. The remaining areas are the multiple use zone, which is restricted to fishing and some diving, and the allpurpose recreational zone, in which snorkeling, diving, fishing, boating, and swimming are all permitted (Saba Conservation Foundation 1999). Saba residents only are allowed to troll for pelagic fish or fish with a line from a boat within all zones of the park other than the diving zone. Spearfishing is technically allowed within the park, although the transportation of spear guns is illegal, and the collection of turtles within the park is prohibited. Fishermen are not allowed to place their pots in the recreational zone. Nets are also prohibited throughout the MPA. Fishing within the marine park is primarily for recreational or subsistence purposes, mostly by hook and line, and commercial fishing rarely takes place in this area, as the prime fishing grounds are on Saba Bank, several miles from the island (Saba Conservation Foundation 1999). Reportedly, compliance by fishermen with the rules of the park is 
very good, and fishermen are rarely ever found fishing within the park. According to the manager, the rules are very rarely broken, but when they are no penalties are ever issued, and he doubted whether they would ever be successful in prosecuting anyone for breaking the laws. There are a few artisanal fishermen who fish illegally within the park, although these are mostly teenagers with fish pots.

\section{Community}

Saba is a very small, volcanic island of roughly 13 square kilometers and a reported population of 1349. The island has four separate communities:

Windwardside, The Bottom, Hell's Gate, and St. Johns. Each of these villages is located in the hills, as opposed to along the coast, so none is actually on the water. Tourism is important to the island, but because of its shape, Saba has no beach, limiting tourism to primarily diving and hiking. The island has a medical school, serving as an important driver for the local economy. The medical school brings a significant foreign-born population to the island, primarily American students, as does the tourism industry, which attracts a largely European crowd.

Tangible benefits to the community from the marine park are primarily in the form of dive tourism, although few local Sabans benefit directly from tourism. Foreigners own all of the dive shops, only one of the hotels is owned by a Saban, and only one or two of about a dozen restaurants on the island are owned by Sabans. Local Sabans benefit more from the medical school on the island, by renting out apartments to students, than they do from the marine park. Those individuals on the island involved in the tourism industry are frequently also involved in the marine park; those 
not involved in tourism are less involved in what goes on with the park.

Issues

One prominent issue at the time of the data collection was the issue of park fees. The organization had recently raised the fees for accessing the park, upsetting some individuals involved in tourism, because they believed it might affect their business. Informants claimed the dive industry and the tourism industry were not consulted about the decision, and that the decision was made by a couple of individuals rather than the board as a whole. Some informants were generally concerned that the park was not involving the public enough overall, while others believed the Saba Conservation Foundation was doing a sufficient job of involving the public. Generally, few complaints about the marine park were heard from the general public, but there was also a sense that many of the local Sabans were not concerned in any way about what went on regarding the park. A few informants had complained that the existing manager was not doing enough to involve the community and had ceased a number of programs; at the time this is being written, the manager has left and a new manager has just started.

\section{Participation}

According to most key informants, there was extensive stakeholder consultation when the park was first put in place. Since then, however, participation by the public has largely dropped off. The park holds public meetings at least yearly, 
but attendance is said to be low. The board of the Saba Conservation Foundation is small, with only seven members, two of whom are from the island government. There was no indication of how representative of the rest of the community the other board members might be; in general, when asked about who was involved in the marine park, respondents very rarely named members of the board. The Saba Conservation Foundation does have a very active outreach program in the schools; many of the respondents who said they had participated in the marine park in some way had attended the park's educational programs in previous years. For the most part, there are currently few issues of contention with the park, and no changes to the park regulations, so there are rarely occasions where consultations are deemed necessary, and many stakeholders have lost interest. Still, $26.9 \%$ of respondents to the survey say they have attended a meeting or otherwise participated in the marine park in some way, the highest percentage of any site included in the study.

\section{Analysis}

Like the other MPAs discussed above, the Saba National Marine Park is in a post-implementation phase. The park is well established within the community, and other than staff turnover, there have been few changes in management since the park was first founded. The park can also be considered to have delegated co-management. The Saba Conservation Foundation (SCF) is entrusted with all day-to-day management activities, and the government is involved through participating on the board of the SCF. The government of Saba created the park through a statute, and would also be responsible for changing any of the park regulations through amending 
the legislation governing the park.

The Saba Conservation Foundation is another example of delegated power, or partnership on the Choguill scale. The level of community representation on the boards of directors of the SCF is high, and the government also participates on the board of directors. The overall level of community participation has also been fairly high.

The co-management of the Saba National Marine Park should be considered relatively successful. The board of the organization represents the community as a whole to a limited degree; the board is fairly small, but represents several segments of the community. There was no clear indication of whether these individuals are representative of broader community interests, but nor were there complaints that individuals were left out of the process. Participation has been high in the past, but the organization has not sustained a high level of participation, in part because of a lack of contention surrounding the marine park.

\section{St. Eustatius National Marine Park}

History

The St. Eustatius National Marine Park was established in 1996. The park encompasses all of the waters around the island of St. Eustatius from the high water mark out to a depth of 30 meters, and has a total area of 27.5 square kilometers. The park includes two marine reserve areas, the southern reserve $\left(3.29 \mathrm{~km}^{2}\right)$ and the northern reserve $\left(1.61 \mathrm{~km}^{2}\right)$, which are no-take areas. 


\section{Management}

The St. Eustatius National Marine Park is managed by STENAPA, the St. Eustatius National Marine Parks Foundation. STENAPA is also responsible for managing a terrestrial park on the island and the island's botanical garden. Like the Saba Conservation Foundation, the organization is overseen by the Dutch Caribbean Nature Alliance (DCNA). STENAPA has a board made up of stakeholders from the island, and a staff drawn mostly from local residents responsible for managing the marine and terrestrial parks. The members of the board include representatives from the oil terminal, the dive industry, the government, the local youth organization, and several other community members. There is a spot on the board of directors reserved for a fisherman; however, this position had not been filled at the time of data collection. The mission of the marine park is to: "manage and conserve natural, cultural and historical marine resources of St. Eustatius for sustainable use with continued stakeholder participation, for the benefit of current and future generations" (STENAPA 2007, 10).

The marine park has a management plan, designed to be a living document to be used in line with the principles of adaptive management. STENAPA conducted an extensive stakeholder consultation process in 2007 when the new management plan was being developed, which included holding meetings with the fishermen and individuals within the tourism industry and using questionnaires to gather the opinions of the general public (STENAPA 2007).

There are two marine reserves within the park where fishing and anchoring are not permitted. The reserves were created through consultations with the fishermen at 
the early stages of the marine park planning. The stated goals of the marine reserves are to conserve biodiversity, protect fish stocks, and promote sustainable tourism (STENAPA 2007). The park maintains 30 dive moorings, three snorkel moorings, and twelve yacht moorings. There are two rangers in the park, one of whom is a former fisherman, a park manager, and an educational and administrative staff at STENAPA who run programs related to the marine park. Outreach programs for the park include meetings with fishermen and other stakeholder groups, TV and radio programs, flyers, and presentations. They also hold summer camps, snorkel clubs, and junior ranger programs with kids, and organize activities in the schools each year.

\section{Community}

The island of St. Eustatius is part of the Netherlands Antilles, and is considered a Dutch municipality. The island is small, with an area of $21 \mathrm{~km}^{2}$, much of which is taken up by two volcanic peaks, and a population of 2,584 according to the 2005 census (STENAPA 2007). There are two primary communities on the island, Oranjestad and Golden Rock.

The largest employer on St. Eustatius is Statia Terminals, an oil transshipment facility employing over $10 \%$ of the island's population either directly or indirectly through a contractor. Tourism-related industries employ about $29 \%$ of the workforce (STENAPA 2007). Like on Saba, most of the tourism businesses are owned by nonlocals, including all of the dive shops and most of the hotels. The dive shops do not generally hire locals. There are roughly eighteen active fishermen on the island (Esteban pers. comm. June 25, 2008), of which only three can be considered full-time 
professional fishermen. Most of these fishermen only fish part-time and have other sources of income (Dilrosun 2004). Spiny lobster is by far the most important fishery on the island. Although the fishery is small, because of the small size of the island, it remains an important activity from a socio-economic perspective, contributing money directly into the island's economy (Dilrosun 2004). Most of the fishermen fish along the narrow shelf surrounding the island (Dilrosun 2004), as opposed to traveling to Saba Bank like the fishermen from Saba do, and so there is more conflict with the marine park.

Issues

Financing the marine reserve has been an issue for St. Eustatius National Marine Park. In 2003, STENAPA was forced to close for a few weeks because of financing, and reportedly, without the presence of rangers, illegal fishing took place within the marine reserves during this period. There have been some ongoing conflicts between fishers and the park and between fishers and other park users. There is a perception amongst many community members that fishers continue to poach in the park during the hours when the rangers are not patrolling, including fishers from neighboring St. Kitts. There are also conflicts over artisanal fishing activity, especially fish traps, which are permitted outside of the marine reserve areas. Divers are concerned about the effect of fishing on fish populations in the park, and divers have sometimes cut fish traps, fueling ongoing conflicts between fishermen and the dive industry.

Overall, fishermen have not been very engaged in activities of the park, 
although in the past efforts have been made to include them. The island's fishermen do not have a cooperative or any other sort of process for organizing themselves (STENAPA 2007). According to one study conducted in 2004, the fishermen asserted that STENAPA converted the best fishing grounds around the island into the marine reserves, and their catches had been declining since the marine reserves were created. Additionally, the fishermen found the marine reserve boundaries to be poorly defined (Dilrosun 2004). These factors have created considerable resentment among the fishermen over the marine reserve. However, in 2008 when this research was conducted, the manager of STENAPA claimed the fishermen were now generally happy with marine park management (Esteban pers. comm. 2008). There is also a concern among fishermen and other community members about oil tankers anchoring within the marine park and destroying fish habitat with their anchors, as well as cutting the lines to fish traps with their anchors (Dilrosun 2004).

\section{Participation}

The STENAPA board generally meets once per month, and membership on the board is pre-determined through selecting which stakeholder groups are to be represented on the board. In 2007, there were consultations held with key stakeholder groups, including fishermen and individuals involved in the tourism industry, about a new management plan, allowing them to participate through providing input to the plan. STENAPA also has an extensive outreach program, much like the park on Saba, involving young people in the park through camps and junior ranger programs, and informing the general public through various media as well as visits to churches and 
other groups. However, in spite of these efforts, only $15.5 \%$ of respondents to the survey said they had attended a meeting or otherwise been involved in the marine park in some way. Many of the consultations and other attempts at involving the public are directed at fishermen and those involved in the tourism industry, yet these two groups make up a very small percentage of individuals on the island, as these are not prominent industries here.

Because the island is very small, well over half of the individuals surveyed $(60.4 \%)$ could correctly name someone involved in the marine park. STENAPA has a fairly large staff and board, so a number of people on the island work or have worked for STENAPA or served on the board, or have family members who have been directly involved. This seems to be a strength of STENAPA; participation is not extensive within the community, but a fair percentage of the community is directly involved in some way.

\section{Analysis}

The St. Eustatius National Marine Park is in the post-implementation phase of management. STENAPA, which manages the park, is well established as the managing entity and a management plan and practices are in place for the park. Like the Saba National Marine Park, the St. Eustatius National Marine Park has individuals from the government on the board of directors of the managing organization. It can be considered a delegated co-management scenario because most of the management is done by STENAPA.

Similar to the Saba Conservation Foundation, STENAPA can also be 
considered delegated power, or partnership on the Choguill scale. As with the Saba National Marine Park, the level of community representation on the boards of directors is high, and for each the government also participates on the board of directors. Participation among the rest of the community has in not been as high for the St. Eustatius National Marine Park as for the Saba National Marine Park.

From a co-management perspective, the St. Eustatius National Marine Park should be considered a success. The board of STENAPA is diverse and represents a number of stakeholder groups, as well as some individuals from the community who do not represent any particular group. Many of the community members surveyed named individuals on the board as well as the staff of STENAPA, and thus the comanagement body is well-known to and can be representative of the community. However, the fact that fishing interests, while small within the community, are not represented on the board should be remedied if possible. From a participation perspective, this MPA should be considered moderately successful - ideally, the participation rate would be higher, although it seems like there are numerous opportunities for individuals to participate.

\section{Buccoo Reef Marine Park}

\section{History}

The Buccoo Reef Marine Park was created in 1973 when the reef was formally protected as a restricted area, and remains the only marine protected area on Tobago. The site includes Buccoo Reef and the Bon Accord lagoon, and contains coral reef, seagrass beds, and mangrove habitats. The marine park encompasses 150 hectares of 
marine area and another 300 hectares of land (Brown et al. 2001). It is Tobago's most popular tourist attraction, receiving 75,000 visitors per year (Buccoo Reef Trust n.d.). Located on the southwestern tip of the island, the marine park is adjacent to the communities of Buccoo and Bon Accord, and is located in close proximity to much of the island's tourism infrastructure, including much ongoing development. As a result, the quality of the reef has been declining, even after being declared a marine park.

\section{Management}

Despite having been in existence for more than 35 years, the Buccoo Reef Marine Park is still at an early stage of co-management. The park is managed by the Department of Marine Resources and Fisheries, with input from the Buccoo Reef Management Committee, an advisory group made up of stakeholders from Tobago, mostly drawn from various government and non-governmental agencies. Representatives on the committee include the Department of Fisheries, which chairs the committee, the Department of Natural Resources, the Institute of Marine Affairs for Tobago, the Tourism Department, the Environmental Management Authority for Trinidad and Tobago, the municipal governments for Buccoo and Bon Accord, two NGOs (Environment Tobago and the Buccoo Reef Trust), and a member of the reef tour operators association. Fishermen are not represented on the committee, other than through the Department of Fisheries. The Department of Fisheries has been the group to decide who is invited to participate on the committee. In 1999, there was a group formed called the Buccoo Reef Action Group with a similar advisory role; this group disbanded in 2000 . 
The Buccoo Reef Trust, while not directly responsible for managing the marine park, is very active on the island in research, monitoring, and outreach projects, many of which involve the marine park. They have also been instrumental in putting together and organizing the management committee. This organization more or less co-manages the park with the Department of Fisheries, partly by default. When community members were asked about who was responsible for the marine park, they frequently named Buccoo Reef Trust or one of its staff. Likewise, most of the meetings attended by respondents were meetings organized by the Buccoo Reef Trust.

The Department of Fisheries employs four patrol officers, based out of Buccoo, who are responsible for monitoring activities within the marine reserve and enforcing regulations, although they do not have powers of arrest. Fishermen seldom use the marine reserve area other than to pass through it on the way from Buccoo to their fishing grounds. Some illegal fishing for conch takes place here, and sometimes fishermen set nets on the reef, but there are few conch left in the area. The park does not presently have a management plan in place, although the management committee has a work plan for the park, which includes hiring a park manager. Legislation prohibits anchoring or walking on the reef within the marine park. There is no real structure in place for community members to express their opinions about the marine park, and the community has not really been involved in the marine park up until this point (Armstrong, pers. comm.).

\section{Community}

As noted above, the Buccoo Reef Marine Park is adjacent to the communities 
of Buccoo and Bon Accord/Canaan. Buccoo is a small fishing village with some tourism as well. There is one reef tour operator based in Buccoo who takes tourists snorkeling and to view the reef; the majority of reef tour operators are located elsewhere. Buccoo is a fairly self-contained village located on a point, and with a small harbor filled with a couple dozen small, wooden fishing boats. As a fishing community, where many of the residents are employed as fishermen, this community is poorer than many on Tobago. There are a couple of guesthouses and restaurants located in the village, as well as a beach, attracting a small number of tourists.

Bon Accord and Canaan are two communities located inside the Bon Accord lagoon, which forms part of the marine park. These two communities are treated as one; they have a single municipal government, and there are few distinguishing features between the two other than a street sign delineating the boundary between the two communities. This area, along with neighboring Crown Point, makes up the commercial and tourism center of Tobago, with a large number of markets, shops, and other retail facilities, as well as some hotels and other tourism facilities. Because of the extensive tourism here and in the surrounding communities, many of the individuals who work in these communities live elsewhere on the island. These villages are separated from the reef by an extensive mangrove system, and so while the communities have a direct impact on the reef, particularly through wastewater, residents of the communities cannot see the reef area.

Most of the reef tour operators operate out of Pigeon Point, a terrestrial park located along the point making up the southern boundary of the marine park, or from Store Bay, a beach just outside of the marine park area. Pigeon Point is not necessarily 
a community in the sense that for the most part people do not live here, but it is the hub of much tourism activity on the island, and a number of island residents work on Pigeon Point, either as tour guides or in the cluster of shops and restaurants found here. There are also a number of fishermen who keep their boats on Pigeon Point.

Issues

The Buccoo Reef Marine Park, including the Bon Accord lagoon, has been heavily impacted by human activity over the years. The reef is frequently visited by snorkelers and glass bottom boats; many of the boats until recently had provided shoes for passengers to get out of the boat and walk around on the reef, causing extensive damage. The neighboring communities have limited sewage treatment facilities, and nutrient runoff poses a serious threat to the health of the reefs. The large-scale development of a high-end resort in an area adjacent to the marine park is ongoing, and has been a source of considerable controversy in the area.

The Buccoo Reef Marine Park has not had a park manager since around 2003, and the Department of Fisheries has had a difficult time in filling this position. The park manager would serve an important role as the public face of the park and generate awareness of regulations.

\section{Participation}

There are few opportunities for public participation in the Buccoo Reef Marine Park. The advisory board is made up of stakeholders from the island, but these are 
mostly representatives of branches of the island government, the governments of the local communities, and two local NGOs. There is one board member who represents the reef tour operators association, although reportedly many of the area's reef tour operators are not members of the association, hence not directly represented on the board. The primary means for community members to have some involvement in the marine park is though the NGOs or the municipal governments, rather than directly; thus, they have little opportunity for direct input or influence over the process. There have been meetings held in the communities regarding the marine park, most of these organized by Buccoo Reef Trust, although some have been held by the Fisheries Department. Only $13.2 \%$ of community members surveyed had attended a meeting or otherwise participated in the marine park in some way, the lowest of any of the study sites, although not far below the participation rates for the SSMR.

\section{Analysis}

Unlike the other sites included in the research, the Buccoo Reef Marine Park is presently in the pre-implementation stage of the co-management arrangement. While the park has been in place for decades longer than most others in the Caribbean, there was no community involvement at its creation, and attempts to bring stakeholders into the management process are relatively new. The Buccoo Reef Management Committee is an advisory committee established more than ten years ago to comanage the park with the Department of Fisheries and Marine Resources, but at the time of fieldwork, the committee was still implementing a work plan and establishing their role. The committee has never been legally established. Thus, while the overall 
management of the park itself is at a post-implementation phase, the co-management of the park through the management committee is still at a pre-implementation phase.

The Buccoo Reef Marine Park can be considered a consultative comanagement arrangement; the advisory committee does not possess the authority to make decisions regarding management, but only to advise the Department of Fisheries on how to manage the marine park. In addition to the management committee, the Buccoo Reef Trust serves as a de facto co-management partner. Although a representative from the organization is on the management committee, the Buccoo Reef Trust plays a much bigger role in the marine park through providing education, outreach, research, and logistical support to the park. This should also be considered a consultative co-management arrangement.

The Buccoo Reef Marine Park differs from the others in the level of devolution. This co-management arrangement can be considered at the consultation level of devolution; decisions are being made by the government (via the Fisheries Department), with some consultation of the public through meetings and other means, but there is no guarantee the public's ideas or interests will be taken into account. The advisory board can also provide input but does not have decision-making authority, nor can the greater public participate directly on this board.

From a co-management perspective, this site is not yet successful. The advisory committee, made up mostly of government agencies, represents the interests of Tobago, but not necessarily user groups. Reef tour operators are represented to some extent, but fishermen and other groups who rely on the marine park for tourism do not have direct representation. The Buccoo Reef Trust has been de facto co- 
managing this MPA for some time. The interests of this group are thus represented in management; while they do not necessarily represent the community as a whole, they have provided more opportunities for community participation and input than the advisory committee. 


\section{CHAPTER 5. NETWORK ANALYSIS}

Social Network Analysis was applied to the data collected at all six of the marine protected areas in a variety of ways in order to describe the data and to quantify measures meaningful to evaluating the success of the co-management arrangement. These measures related to how centralized the social networks are, and whether stakeholders are likely to be connected directly to those responsible for making decisions. Network analysis graphs are presented below for each of the six marine protected areas, with a description of the graph and what it indicates about participation and representation for stakeholders at that particular site. Centrality measures, or the importance each actor has to the network, are discussed for each network. Finally, the six networks are compared on a number of measures collected from the network graphs.

\section{Communication Networks for Six Marine Protected Areas}

For each marine reserve, several network analysis graphs were developed based on the data collected at each site. It should be emphasized that these network graphs do not represent the entirety of the social network for each community, but rather are an attempt at constructing a network based only around communicating about the marine reserve. The point of this network analysis is to develop a graphical representation for how information and opinions are likely to move among members

of the community. The networks represented by the graphs are not the only means by which community members can learn about or become involved in the marine reserve, nor are they by any means a definitive and complete network of all possible linkages 
among community members with regards to the marine reserve. They are simply constructed in response to questions asked of community members about who they are likely to speak to about the marine reserve. It is also important to note that these network graphs represent only a snapshot in time, and whom each respondent was thinking about on that particular day. These networks are variable and will change, especially as the MPAs encourage additional participation or stop seeking stakeholder participation as the process continues.

Table 7. Definitions of key network analysis terms

\begin{tabular}{|l|l|}
\hline Term & Description \\
\hline Node & $\begin{array}{l}\text { Each node within the network represents a single actor, whether an } \\
\text { individual or group. Actors represent either the individuals surveyed } \\
\text { within the community or individuals or groups named by those who } \\
\text { were surveyed }\end{array}$ \\
\hline Tie & $\begin{array}{l}\text { The lines between nodes in the network graphs represent a } \\
\text { connection between the two nodes, where one named the other in the } \\
\text { survey }\end{array}$ \\
\hline Degree centrality & $\begin{array}{l}\text { The number of direct links each actor has to others within the } \\
\text { network }\end{array}$ \\
\hline Isolate & $\begin{array}{l}\text { A node not connected to the rest of the network, because the actor } \\
\text { did not name another individual }\end{array}$ \\
\hline
\end{tabular}

\section{Actor Centrality}

All of the complete network graphs displayed below can be described as having a core-periphery structure. This term refers to a network that cannot easily be divided into subgroups (Borgatti and Everett 1999). The networks can all be described as having a core of actors in the center who are connected to one another, and a periphery of actors who are connected to the core actors, but not necessarily to one another. Because of the nature of the survey design in combination with the nature of the subject (asking individuals about others who are involved in the marine reserve), 
this kind of structure is to be expected. In considering the impact of network structure on collective action, this type of structure is well suited for certain tasks, such as gathering and distributing information, which can be done by a small subset of key actors (Leavitt 1951 in Ernston et al. 2008).

Degree centrality is a more precise measure of how often each actor has been named by others within the network; it is the number of direct links each actor has to others within the network. In a core-periphery network, the core actors will by definition have a high level of centrality. The measures of degree centrality provided here are symmetric measures of degree, meaning they do not take into account the direction of the relationship, but nonetheless the vast majority of ties making up each actor's degree centrality will be from being named by others in the network because of the nature of the data. Actors who receive many ties, and thus have a high degree centrality, are often referred to as being prominent, or as having high prestige (Hanneman and Riddle 2005). This is logical, because those actors named most often as someone who others would approach regarding the marine reserve will by definition be the most prominent actors.

Degree centrality is one of many different measures of centrality that can be used to talk about a network, but here it is the most straightforward measure to identify which individuals are viewed to be the most important actors in the network. Degenne and Forsé (1999) define degree centrality as an individual's capacity to develop communication within a network. Those actors who speak to the greatest number of individuals about the marine reserve have the greatest capacity to develop communication, by both receiving and passing information to others. As would be 
expected, in each network the key actors identified as being most involved in the marine reserves also had the highest levels of degree centrality compared with individuals who are not directly involved in the marine reserve, although the most central actors are not necessarily those who have the most authority with relation to the marine reserve. Degree centrality is one means of identifying the most central individuals within the community with regards to the marine reserve, without necessarily having to rely on the opinions of a few informants about who the key actors are (Bodin and Crona 2008).

\section{Networks and co-management}

One explanatory element that can be derived from looking at the network graphs is how well the co-management structure of each MPA represents the interests of large segments of the community. For a well-functioning co-management arrangement, most of the actors should be connected to the network (they should each have a connection, whether direct or indirect, to those in charge), and those directly responsible for co-management should all be central within the network. Ideally, no actors should be more than a step or two away from the core of the network (the decision-makers). There should also be a relatively even distribution of ties among those doing the co-managing, and they should be connected to other stakeholders who are like them, or to those whose interests they theoretically represent. This means that the level of degree centrality should be relatively evenly distributed among those responsible for managing the MPA, which would prevent one individual or group from being disproportionately powerful. In an idealized network representation of a 
well-functioning co-management arrangement, those individuals who are part of the co-management arrangement will be connected in the middle of the graph, with other stakeholders radiating out and evenly distributed through the rest of the network. The structure of the network graphs for each of the MPAs will now be investigated and discussed.

\section{SCOTTS HEAD/SOUFRIERE MARINE RESERVE}

The individuals surveyed in Dominica about the Scotts Head/Soufriere Marine Reserve (SSMR) are represented in the network graph below (Figure 1). This graph identifies key individuals based on their importance within the network. Those who are located toward the center of the graph and have the most connections to other individuals are the most central actors in this network and in the marine reserve. This network has a total of 326 nodes, of which 92 , or $28.2 \%$, are isolates, or individuals who did not name someone else within the network. Most of the respondents in the SSMR network are connected to the main component, meaning they are either directly or indirectly connected to the reserve manager and the Local Area Management Authority (LAMA), the group responsible for managing the reserve.

This network graph depicts select occupations (fishermen in red, tour/dive guides in green, other tourism-related professions in blue), with other occupations in gray. The members of LAMA, the management board, are in orange, the individuals employed to manage the reserve are in yellow, and members of the government or government agencies are in pink. Community is depicted by shape, with residents of Scotts Head as circles, residents of Soufriere as diamonds, and other individuals as 
squares. Node size corresponds to whether or not these individuals have attended meetings; those who have attended meetings are represented by larger nodes. 




Figure 4. Scotts Head/Soufriere Marine Reserve network graph

The key actors in the marine reserve are circled

Fishermen=red; tour/dive guides=green; other tourism-related industries=blue; LAMA=yellow; reserve employees=orange; government=pink Scotts Head resident=circle; Soufriere resident=diamond; other=square

Larger nodes=attended meeting 
In looking at the Scotts Head/Soufriere Marine Reserve network diagram to assess which actor each individual is most likely to approach with an opinion, some general patterns emerge. As those individuals who have attended meetings are indicated in the graph by larger nodes, participation can be compared with who these individuals named, to match up whether they have participated with who they cite as someone they would speak with about the marine reserve. It is obvious from this graph that some of the key players, or those with formal roles in the co-management of the MPA, were referenced much more frequently than others. It can also be seen by comparing the connections in the network graph with those nodes that have been circled that respondents within the community did not always cite those with the authority to make decisions about the marine reserve.

One slightly surprising outcome of the network analysis for SSMR is the frequency with which respondents cited the chairman of LAMA, node 280, as fieldwork revealed this individual is much reviled within the community. He is very prominent within the community and also very wealthy by community standards, and so is well known, even if he is not well liked by everyone. This result begs the question of whether people would actually seek him out to express an opinion, or whether they cite him just because of his position within the community (see Figure 7 for whether the individuals included in the network graph believe their interests are being represented). Several of the actors who named node 280 , the chairman of LAMA, have attended meetings or otherwise been involved in the marine reserve. The importance of particular individuals within the network is further illuminated by degree centrality, discussed below. 
Only one of the individuals who named node number 209 has ever been involved in the marine reserve. Node 209 is a member of the village council, and is therefore an influential person in the community. Node 209 is also employed by the chair of the management authority in his dive shop, and thus has direct access to those involved in making decisions about the marine reserve, as well as access to information about the marine reserve. While not involved in co-management himself, this individual has the capacity to serve as an intermediary to those co-managing the marine reserve. Those who named node 209 may not be aware that he is not directly involved in making decisions about the marine reserve, because they have never attended a meeting so may not know who is responsible for making decisions. While Node 209 may have the ability to provide members of the community with information about being involved in the marine reserve, such as when meetings are being held, as he is not part of the co-management group himself he cannot represent those who claimed they would go to him with an opinion in a decision-making capacity.

By comparison, the head warden of the SSMR, node 210 , is frequently named by individuals who have attended meetings or otherwise been involved in the SSMR, but by very few who have not attended meetings, despite the fact that the warden is based in Soufriere. This suggests the presence of a warden may not be known to individuals who have not had some involvement in the reserve. Alternatively, the warden may be very effective at disseminating information about the reserve, and therefore engaging others in participating in meetings. 
A few of the individuals who are isolates, or did not name any individuals or groups who they would speak to about the marine reserve, also responded that they had participated in the marine reserve. It seems unusual if they have attended meetings that they would not be able to name any other actors involved in the marine reserve, but this could be because either they could not remember the names of other actors involved at the time, or in some cases, they stated they would not speak to anyone about the marine reserve because they believed those in charge did not represent their interests.

\section{Scotts Head/Soufriere Marine Reserve - Degree Centrality}

Table 8 and Figure 6 below demonstrate Freeman degree centrality for the Scotts Head/Soufriere Marine Reserve, one particular measure of centrality used within network analysis (Freeman 1979). Each actor's degree centrality is a measure of how many ties that actor has, and corresponds to how often the actor was named by others within the network, and thus how central they are to the network. The node numbers are also marked with whether these individuals and groups named through the network analysis are actually involved in the co-management of the MPA.

Table 8. SSMR Freeman Degree Centrality - Symmetric

\begin{tabular}{|l|l|l|l|}
\hline Node & Description & Degree & $\begin{array}{l}\text { Normalized } \\
\text { Degree }\end{array}$ \\
\hline $280^{*}$ & LAMA Chairman/ Dive Shop owner & 66.000 & 20.122 \\
\hline $281^{*}$ & LAMA member/ Dive Shop owner & 46.000 & 14.024 \\
\hline 209 & $\begin{array}{l}\text { Village Council member/Dive shop } \\
\text { employee }\end{array}$ & 25.000 & 7.622 \\
\hline $210^{\#}$ & SSMR head warden & 25.000 & 7.622 \\
\hline
\end{tabular}




\begin{tabular}{|l|l|l|l|}
\hline $282^{\#}$ & SSMR manager & 16.000 & 4.878 \\
\hline 301 & Fisheries Chief & 13.000 & 3.963 \\
\hline 302 & Fisheries Division & 11.000 & 3.354 \\
\hline $298^{*}$ & LAMA member/Village Council member & 11.000 & 3.354 \\
\hline 47 & Head of Fishermen's Coop & 6.000 & 1.829 \\
\hline $300^{*}$ & LAMA & 6.000 & 1.829 \\
\hline
\end{tabular}

* - on co-management committee

\#- MPA staff 


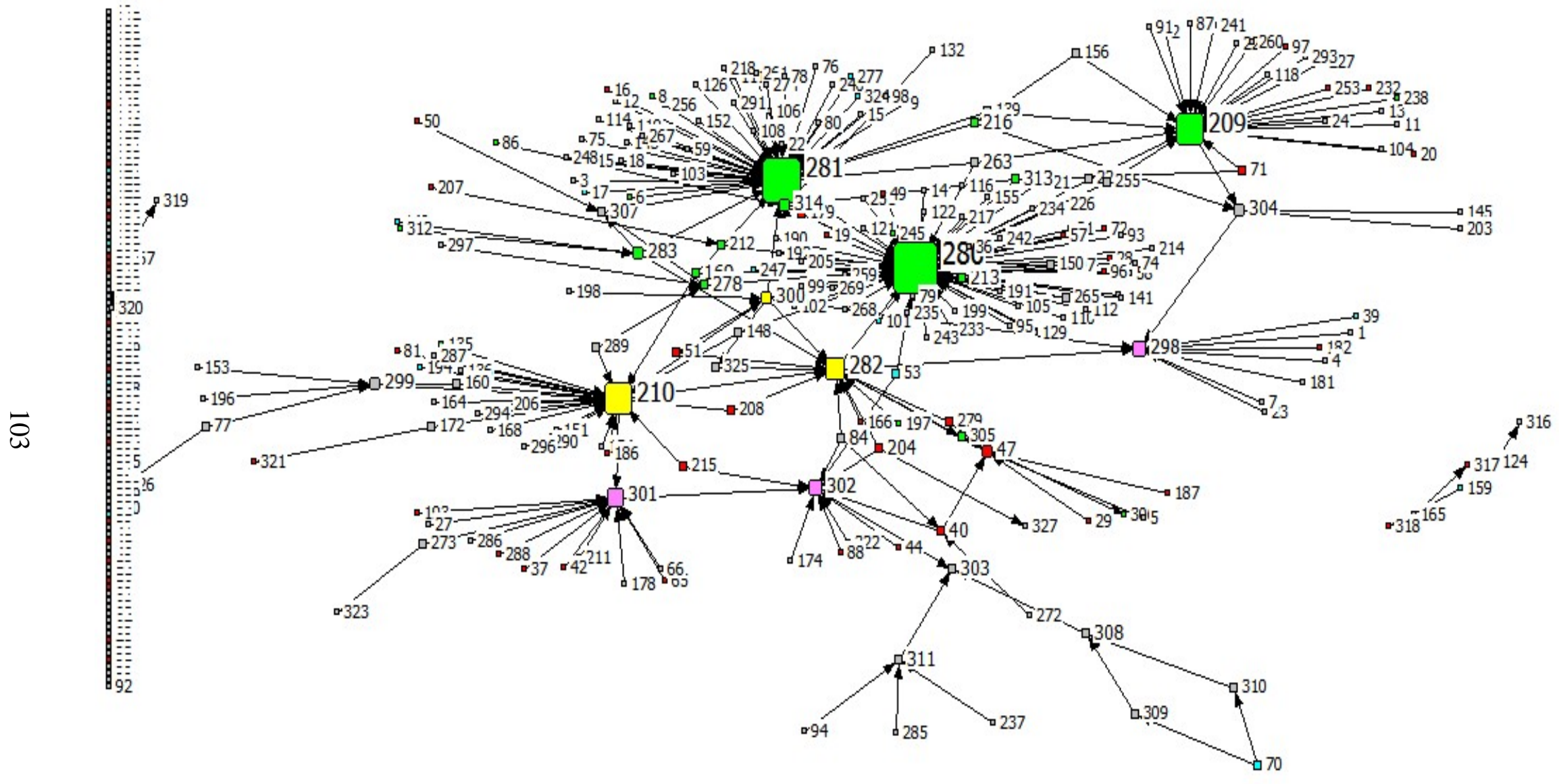

Figure 5. SSMR - Freeman degree centrality network graph.

Fishermen=red; tour/dive guides=green; other tourism-related industries=blue; LAMA=yellow; reserve employees=orange; government=pink Node size corresponds to degree centrality 
Table 8 shows the ten most central individuals in the Scotts Head Soufriere Marine Reserve (SSMR) network based on using Freeman Degree centrality, one particular centrality measure used as a criterion for determining the centrality of each member of the network. Figure 6 is a representation of degree centrality within the network, with the size of the nodes determined by degree centrality. Many, but not all, of the most central individuals play a decision-making role in the co-management of the marine reserve. Those individuals who either serve as a member of LAMA or work for the Fisheries Division as part of the staff responsible for managing the reserve are indicated.

The most prominent individual, node number 280 , is the chairman of the Local Area Management Committee, the board responsible for co-management of the marine reserve. Nodes 281 and 298 are members of LAMA, while number 300 is LAMA itself. Number 282 is the manager of the marine reserve, and numbers 301 and 302 are the chief of the Fisheries Division and the Fisheries Division itself, respectively.

Most of those with the highest centrality measures are all, whether directly or indirectly, involved in the marine reserve. The current SSMR manager, who established the marine reserve and arguably has the greatest role in managing the marine reserve, was not found to be as central as some other individuals. This may be because he does not reside within either of the communities (Scotts Head or Soufriere) and thus is not as well known to the community members, or may not have established a great deal of trust with the community, perhaps because of the fact that he does not reside there. 
While most of the individuals or groups appearing in this list of the most central actors are directly involved in the reserve, two have no direct involvement at all with the marine reserve, yet are still among the most highly central actors. Node 47 is a prominent fisherman who had just restarted the fishermen's cooperative; however, he himself had never attended a meeting regarding the marine reserve or otherwise been involved at the time the surveys were conducted, although he said he planned to become more involved in the reserve. Node 209 is a member of the village council, but is not directly responsible for making decisions about the marine reserve.

However, as a member of the village council, this individual is very active in the community, and he is also employed at the local dive shop, which has been very involved in the marine reserve. Because of their prominence within the community, efforts should be made to engage these individuals in the marine reserve.

Table 9. Frequency of actors named by fishermen for $\operatorname{SSMR}(n=50)$.

\begin{tabular}{|l|r|l|}
\hline Description & Node & Percent \\
\hline Chair of LAMA & 280 & $16.0 \%$ \\
\hline SSMR manager & 282 & $10.0 \%$ \\
\hline Dive shop employee/village council member & 209 & $10.0 \%$ \\
\hline Fisheries Division & 302 & $8.0 \%$ \\
\hline Fisheries Chief & 301 & $8.0 \%$ \\
\hline Head of fishermen's coop & 47 & $8.0 \%$ \\
\hline SSMR Head warden & 210 & $8.0 \%$ \\
\hline
\end{tabular}

Table 10. Frequency of actors named by tour guides for SSMR (n=17).

\begin{tabular}{|l|r|r|}
\hline Description & Node & Percent \\
\hline Chair of LAMA & 280 & $30.4 \%$ \\
\hline LAMA member/dive shop owner & 281 & $30.4 \%$ \\
\hline Former SSMR manager & 307 & $11.8 \%$ \\
\hline SSMR manager & 282 & $11.8 \%$ \\
\hline SSMR Head warden & 210 & $11.8 \%$ \\
\hline
\end{tabular}


Table 11. Frequency of actors named by tourism workers for $\operatorname{SSMR}(n=15)$.

\begin{tabular}{|l|r|r|}
\hline Description & Node & Percent \\
\hline Chair of LAMA & 280 & $20.0 \%$ \\
\hline LAMA member/dive shop owner & 281 & $20.0 \%$ \\
\hline
\end{tabular}

Tables 9, 10, and 11 list the frequency of actors named by respondents of various occupations as a means of understanding whether respondents are likely to name actors in similar occupations to themselves who may be more likely to represent their interests in the co-management of the MPA. Only those actors named by more than one respondent are included in the tables. For the SSMR, the Chair of LAMA was the top actor named by all three of the occupation groups investigated here (fishermen, tour guides, tourism workers). However, fishermen did differ somewhat from the rest of the respondents in the other actors they were likely to name. Several named the park manager, node 282 , who reportedly has been engaged in many outreach programs with the fishermen. None of the fishermen named node 281, who had the second highest degree centrality and was named often by both tour guides and those working in tourism. This particular actor, node 281 , works in tourism as a coowner of the dive shop and is an outsider not originally from Dominica. The fishermen generally seemed to have a lack of trust of this individual. These tables highlight that, while there is considerable overlap, there is a difference by occupation in which actors various stakeholders trust for information and therefore are likely to speak with about the reserve. 


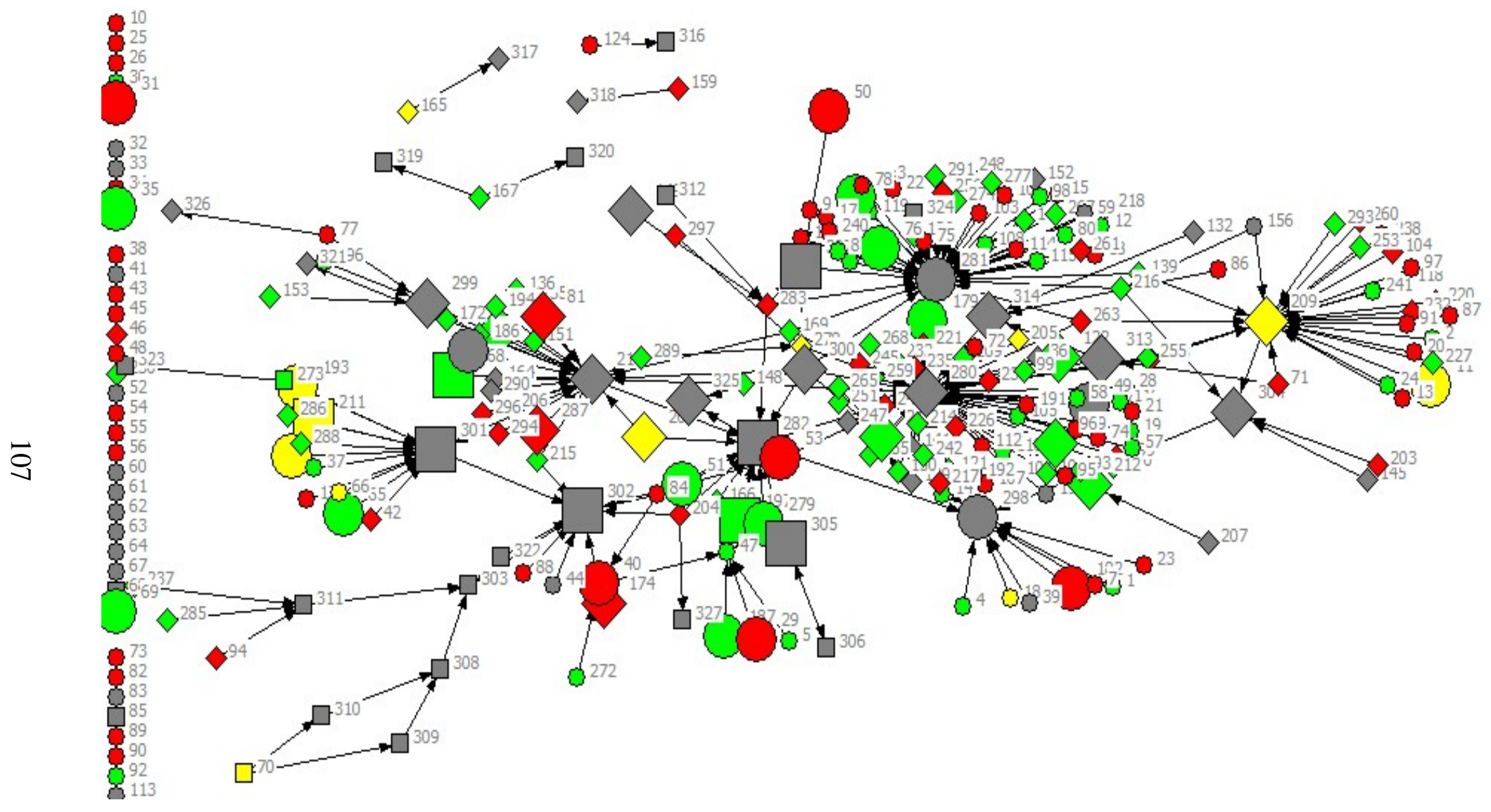

Figure 6. Scotts Head/Soufriere Marine Reserve network diagram with interests represented.

Interests represented: Yes=Green; No=Red; Maybe=Yellow; Don't know/no answer Larger nodes $=$ attended meeting

Diamond=Soufriere residents; Circle=Scotts Head resident 
The network diagram above (Figure 7) indicates whether the respondents surveyed believed their interests were being represented by those in charge of the marine reserve. Those who answered yes are in green, those who answered no are in red, those who replied maybe are in yellow, and those who responded they did not know, or did not answer the question (because they had not heard of the marine reserve or otherwise) are in gray. Once again, the enlarged nodes indicated individuals who have attended a meeting or otherwise participated in the marine reserve. This diagram illustrates considerable discontent with the management of the marine reserve, both amongst individuals who have been involved in the marine reserve and individuals who have not, although there are also a large number of respondents who believed their interests were represented. Individuals who believed their interests were not being represented, as well as individuals who believed their interests were represented, are fairly evenly distributed throughout the network, meaning that those individuals believing their interests are not represented were not restricted to naming particular key individuals who are involved in making decisions.

\section{ST. EUSTATIUS NATIONAL MARINE PARK}

The network graph for the St. Eustatius National Marine Park (Figure 4) has 203 nodes, of which 42 , or $20.7 \%$, are isolates. Once again, occupation is depicted by color, and those who have attended meetings are represented by larger nodes in the diagram. 


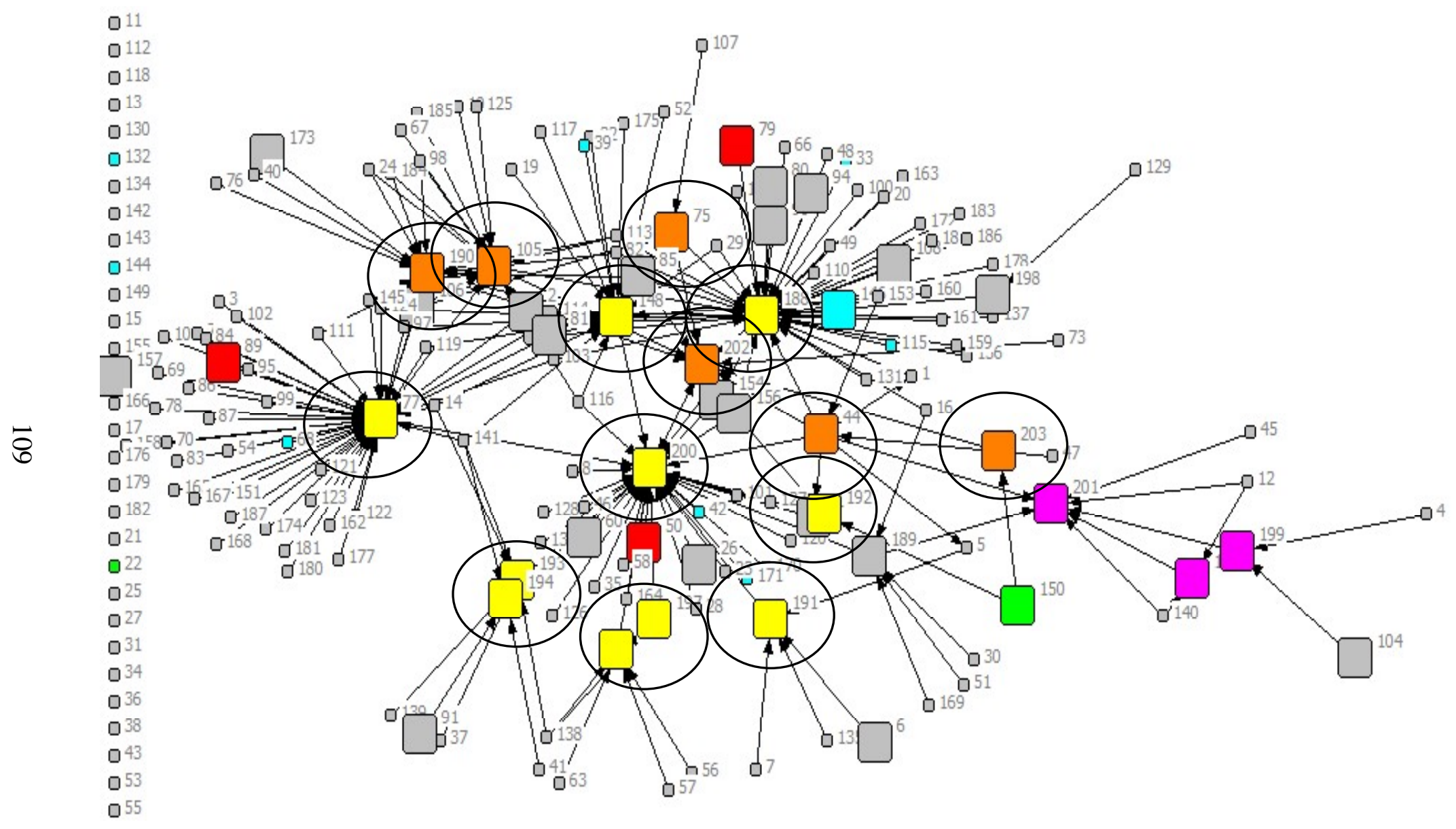

Figure 7. St. Eustatius National Marine Park - full network graph

Circled nodes are key actors (staff and board of directors of STENAPA)

Red=fishermen; green=tour guide; blue=tourism industry; STENAPA staff=yellow; STENAPA board members=orange; government=pink Larger nodes=attended meeting 
Few of the individuals surveyed about the St. Eustatius National Marine Park work as fishermen or tour guides, or are otherwise employed in the tourism industry. St. Eustatius has a relatively small tourism industry, and there are very few fishermen on the island. A large majority of the individuals who have attended meetings or otherwise participated in the marine reserve are employed in other occupations. It is interesting to note that all of the fishermen surveyed in St. Eustatius had attended meetings, although this includes only three individuals. Most of the actors who responded that they had participated in the marine reserve are directly linked to one or more of the staff members of STENAPA, the management organization for the park; many of them named the director of STENAPA (node 188) as someone they know and would speak to about the marine park. Additionally, of the rest of the actors who have not participated in the marine park, the vast majority who correctly named someone involved in the marine park named a member of the staff of STENAPA or named one of the board members of the organization (in orange).

\section{St. Eustatius National Marine Park}

Table 12. Freeman Degree Centrality for St. Eustatius National Marine Park network

\begin{tabular}{|l|l|l|l|}
\hline Node & Description & Degree & $\begin{array}{l}\text { Normalized } \\
\text { Degree }\end{array}$ \\
\hline $188^{\# *}$ & Marine reserve manager & 46.000 & 22.772 \\
\hline $77^{\#}$ & $\begin{array}{l}\text { Management organization employee - } \\
\text { administration }\end{array}$ & 45.000 & 22.277 \\
\hline $200^{\#}$ & Management organization & 35.000 & 17.327 \\
\hline $148^{\#}$ & $\begin{array}{l}\text { Management organization employee - } \\
\text { administration }\end{array}$ & 19.000 & 9.406 \\
\hline $190^{*}$ & Chair of the Board of Directors & 15.000 & 7.426 \\
\hline $105^{*}$ & Serves on the board, former chair & 14.000 & 6.931 \\
\hline $202^{*}$ & Board of Directors for STENAPA & 9.000 & 4.455 \\
\hline $44^{*}$ & $\begin{array}{l}\text { Serves on Board of Directors, works for } \\
\text { Department of Planning }\end{array}$ & 9.000 & 4.455 \\
\hline
\end{tabular}




\begin{tabular}{|c|c|c|c|}
\hline 201 & Island government & 7.000 & 3.465 \\
\hline $193^{\#}$ & Park warden & 6.000 & 2.970 \\
\hline
\end{tabular}




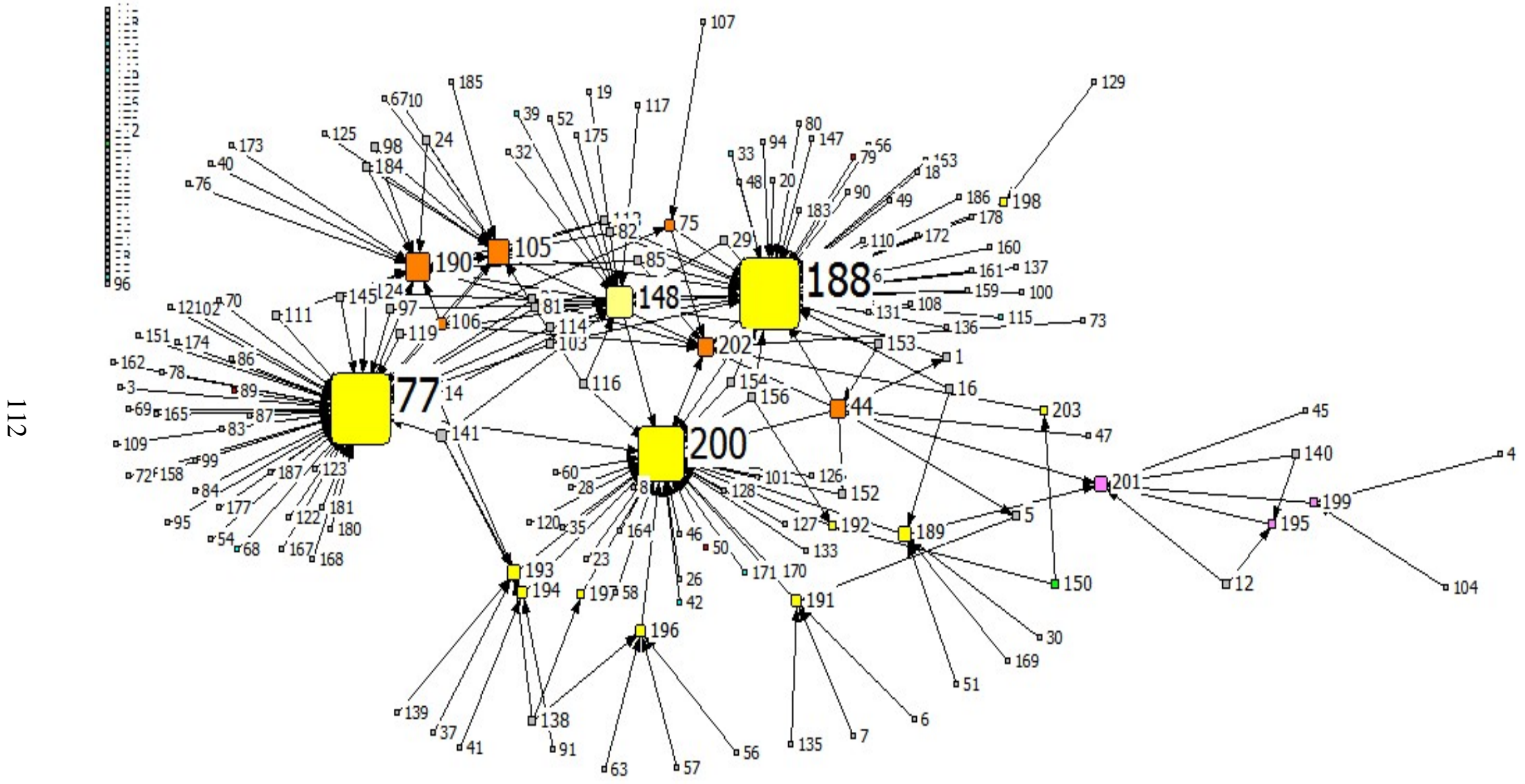

Figure 8. St. Eustatius National Marine Park - Freeman degree centrality network graph

Red=fishermen; green=tour guide; blue=tourism industry; STENAPA staff=yellow; STENAPA board members=orange; government=pink Node size corresponds to degree centrality 
All of the most central actors named for the St. Eustatius National Marine Park correspond with the staff or board of STENAPA with the exception of the island government, which many people named, although representatives from the government do sit on the board of STENAPA. The individual most often cited as someone people would go to about the marine reserve was the marine reserve manager (node 188), followed by an administrative employee of the organization (node 77). The management organization itself with no specific employee named (node 200), followed by another employee (node 148), were also at the top of the list. This indicates that STENAPA is highly identified with the marine park, and that the organization and its employees are known and visible within the community. The fifth, sixth, and eighth most central individuals (nodes 190, 105, and 44) are all members of the Board of Directors, with the sixth most central being the Board of Directors itself (node 202).

Table 13. Frequency of actors named by tourism workers for St. Eustatius National Marine Park (n=10).

\begin{tabular}{|c|c|c|}
\hline Description & Node & Percent \\
\hline Marine Reserve Manager & 188 & $30.0 \%$ \\
\hline
\end{tabular}

Of the three occupation groups, both fishermen and tour guides had very small sample sizes (three and two, respectively). Of these two groups and individuals working in tourism, only one actor was named more than once - the marine reserve manager was named by $30 \%$ of respondents, or three individuals, employed in tourism. 


\section{LAUGHING BIRD CAYE NATIONAL PARK}

The network for Laughing Bird Caye National Park in Belize has 268 actors, of which $23.5 \%$, or 63, were isolates. The individuals sampled for the Laughing Bird Caye National Park were from a variety of communities, although data collection was focused on the communities of Placencia and Seine Bight. Friends of Nature, the group responsible for managing the park, draws on stakeholders from six communities Placencia, Seine Bight, Independence/Mango Creek, Monkey River, Sittee, and Hopkins - for their board of directors and when consulting with community members. Individuals sampled for the network analysis include residents of all of these communities, but are drawn primarily from Placencia, which is where the management organization is based, and where the vast majority of tourism activity related to the marine reserve takes place.

In this diagram, as with the others occupation is represented by color, with green representing tour and dive guides, blue representing individuals working in other aspects of the tourism industry (hotels and restaurants), red representing fishermen, yellow representing government and public service, including the Friends of Nature staff, and gray representing other occupations. 


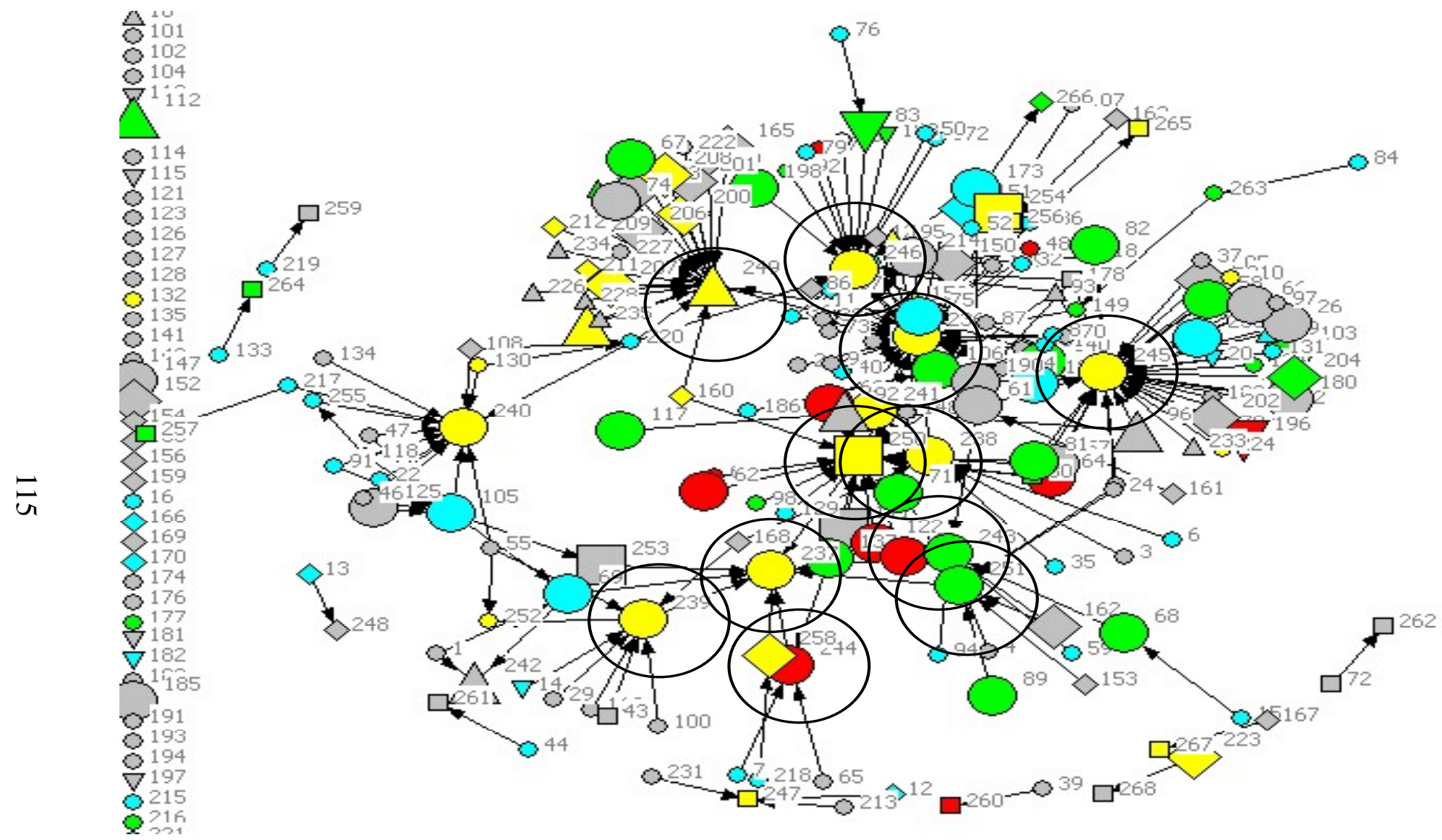

Figure 9. Laughing Bird Caye National Park - full network diagram

Nodes in circles are key actors (Staff of Friends of Nature, Board of Friends of Nature)

Red=fisherman; green=tour guide; blue=tourism industry; yellow=government/public service/Friends of Nature staff; gray=other Placencia residents=circle; Independence=triangle; Seine Bight=diamond

Larger nodes=attended meeting 
The above diagram shows the entire network for Laughing Bird Caye National Park, with individuals who have participated in the park by attending a meeting or otherwise shown as larger nodes. It is possible to visually compare actors' participation with those whom they cited as individuals they would speak to about the marine reserve. Node 236 at the center of the graph is the Friends of Nature, the organization responsible for managing the reserve. Many respondents named the organization, or named people who are affiliated with the organization, placing it at the center of the graph. A significant number of individuals who named node 249 (11 of 24 individuals) have participated in the marine park. This individual is the director of the outreach program for Friends of Nature, so he may have contacted stakeholders prior to their participation. Variation also exists among the staff members of Friends of Nature listed - more individuals who named nodes 245 and 250 have been involved in the marine park than those individuals who named node 246, another staff member.

\section{Laughing Bird Caye National Park- Degree Centrality}

Table 14 presents the top actors by degree centrality for the Laughing Bird Caye National Park.

Table 14. Laughing Bird Caye National Park Freeman Degree Centrality - Symmetric

\begin{tabular}{|l|l|l|l|}
\hline Node & Description & Degree & $\begin{array}{l}\text { Normalized } \\
\text { Degree }\end{array}$ \\
\hline $245^{\#}$ & FoN administrative staff member & 52.000 & 19.476 \\
\hline $236^{\#}$ & Friends of Nature (FoN) & 47.000 & 17.603 \\
\hline $246^{\#}$ & FoN administrative staff member & 26.000 & 9.738 \\
\hline $249^{\#}$ & FoN Outreach/Education staff member & 25.000 & 9.363 \\
\hline $250^{\#}$ & Friends of Nature Executive Director & 19.000 & 7.116 \\
\hline 240 & Tourism Center & 14.000 & 5.243 \\
\hline
\end{tabular}




\begin{tabular}{|l|l|l|l|}
\hline 105 & Tourism Center staff & 9.000 & 3.371 \\
\hline $239 *$ & $\begin{array}{l}\text { Chair of Placencia village council/ member } \\
\text { of FoN Board of Directors }\end{array}$ & 9.000 & 3.371 \\
\hline $243 *$ & $\begin{array}{l}\text { Head of Tour Guide Association/ member } \\
\text { of FoN Board of Directors/ founding } \\
\text { member of FoN }\end{array}$ & 8.000 & 2.996 \\
\hline $237 *$ & Friends of Nature Board & 8.000 & 2.996 \\
\hline
\end{tabular}

* - on co-management committee

\#- MPA staff 


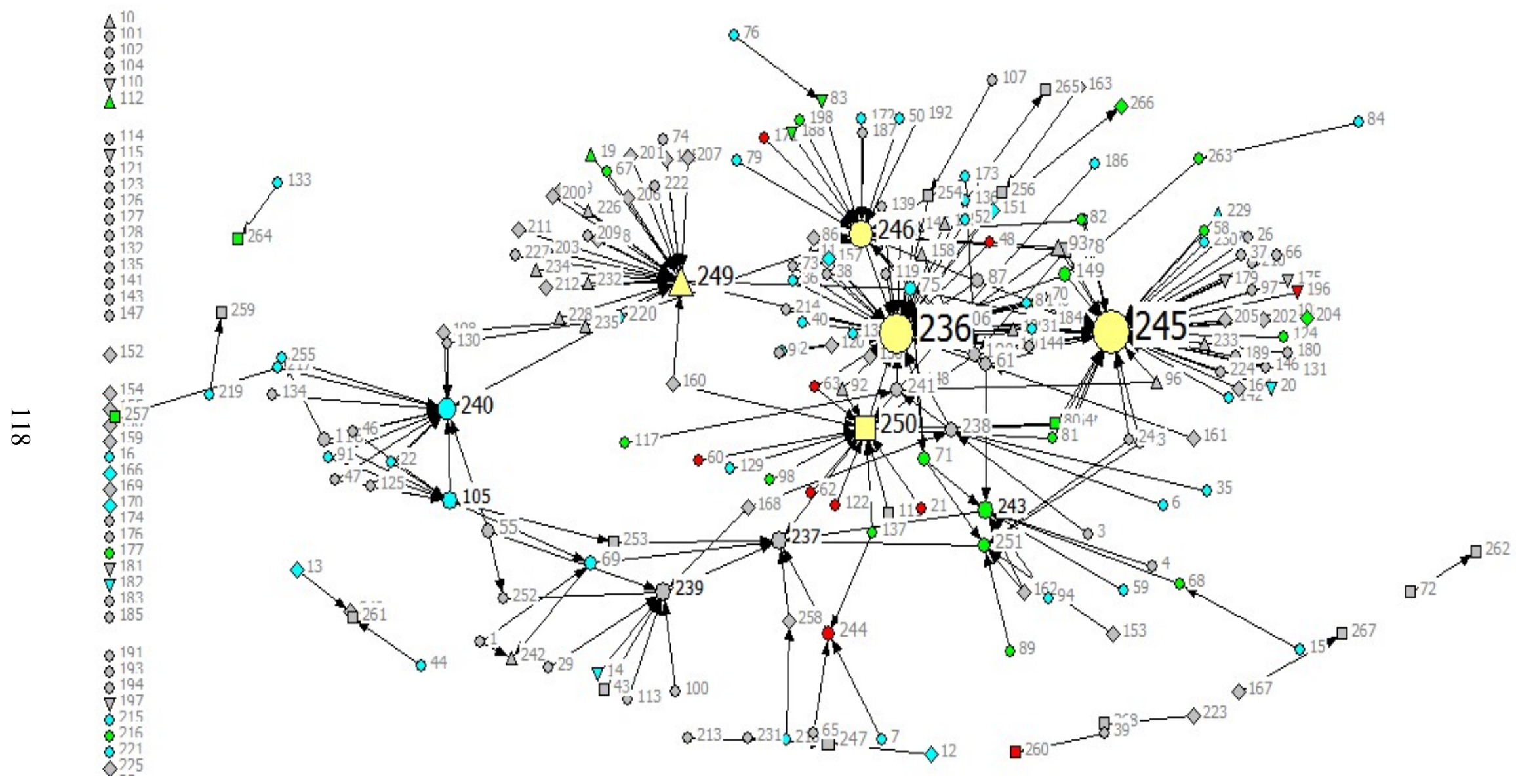

\section{Figure 10. Laughing Bird Caye National Park - Freeman Degree Centrality}

Red=fisherman; green=tour guide; blue=tourism industry; yellow=government/public service/Friends of Nature staff; gray=other Placencia residents=circle; Independence=triangle; Seine Bight=diamond

Larger nodes $=$ attended meeting 
Most of the actors found to be most central to the Laughing Bird Caye National Park network are associated with Friends of Nature (FoN), the organization responsible for co-managing the park. All but two of the most central actors named are either staff of the organization or sit on the board. The individual with the highest degree centrality for the Laughing Bird Caye National Park network, node 245, is an individual who works for Friends of Nature and is from Placencia, where many of the surveys were conducted. The organization itself, node 236 , has the second highest degree centrality, followed by three more individuals who make up the Friends of Nature staff. One of these individuals, node 249 , is responsible for education and outreach for the organization, and conducts visits with the local schools. Node 243 serves on the Board of Directors, and was a founding member of the organization. He is also the head of the local tour guide association.

Node 240, the sixth ranked actor for degree centrality, is the Tourism Center, an information center located in Placencia directed at tourists, and the next highest ranked actor, node 105 , is an employee of the tourism center. This is indicative of the fact that Laughing Bird Caye National Park is primarily a tourist destination, and many residents of the community clearly see the marine reserve as being tied to the tourism industry. Few people who cited node 240, the Tourism Center, have attended meetings. There are two non-exclusive explanations for this: those individuals who have been involved know who the key decision makers are, and are more likely to cite them; and because the Tourism Center is not directly involved in decision making for the marine park, they do not provide information for individuals about opportunities to participate with the marine reserve. 
Although community members from the other communities were surveyed as well about whom they would speak to about the marine reserve, all of the top actors for degree centrality either reside or work in the village of Placencia. The community of Placencia appears to have stronger ties to the marine reserve than the surrounding communities, both because of the presence of the management organization and because of the importance of the park to the tourism industry based in Placencia. Most of the tours to Laughing Bird Caye depart from Placencia.

Table 15. Frequency of actors named by fishermen for Laughing Bird Caye National Park (n=9)

\begin{tabular}{|l|r|r|}
\hline Description & Node & Percentage \\
\hline FoN Executive Director & 250 & $66.7 \%$ \\
\hline FoN Administrative staff member & 245 & $22.2 \%$ \\
\hline Friends of Nature & 236 & $22.2 \%$ \\
\hline
\end{tabular}

Table 16. Frequency of actors named by tour guides for Laughing Bird Caye National Park $(n=26)$

\begin{tabular}{|l|r|r|}
\hline Description & Node & Percentage \\
\hline FoN Administrative staff member & 246 & $23.1 \%$ \\
\hline FoN Executive Director & 250 & $19.2 \%$ \\
\hline $\begin{array}{l}\text { Head of Dive Guide assoc./FoN } \\
\text { Board member }\end{array}$ & 251 & $7.7 \%$ \\
\hline $\begin{array}{l}\text { Head of tour guide assoc./FoN } \\
\text { Board member }\end{array}$ & 243 & $7.7 \%$ \\
\hline FoN Education/Outreach & 249 & $7.7 \%$ \\
\hline
\end{tabular}

Table 17. Frequency of actors named by tourism workers for Laughing Bird Caye National Park $(n=37)$

\begin{tabular}{|l|r|r|}
\hline Description & Node & Percentage \\
\hline FoN Administrative staff member & 245 & $29.7 \%$ \\
\hline FoN Administrative staff member & 246 & $24.3 \%$ \\
\hline FoN Ranger & 238 & $5.4 \%$ \\
\hline FoN Executive Director & 250 & $5.4 \%$ \\
\hline $\begin{array}{l}\text { Head of tour guide assoc./FoN } \\
\text { board member }\end{array}$ & 243 & $5.4 \%$ \\
\hline FoN Education/Outreach & 249 & $5.4 \%$ \\
\hline Tourism Center & 240 & $5.4 \%$ \\
\hline Tourism Center staff & 105 & $5.4 \%$ \\
\hline
\end{tabular}


The actors named by fishing and tourism stakeholders do not differ considerably from the list of the most central actors. One difference worth noting is that as many tour guides named the head of the dive guide association (and many of the tour guides are likely to be employed as dive guides) as named the head of the tour guide association, with just two tour guides naming each individual. This perhaps indicates that these individuals are not as prominent as they should be; while they both serve on the board of Friends of Nature, perhaps their association with the organization, and hence with the reserve, is not known to their constituents in these organizations. It is also possible that many tour and dive guides surveyed do not belong to these respective organizations. 


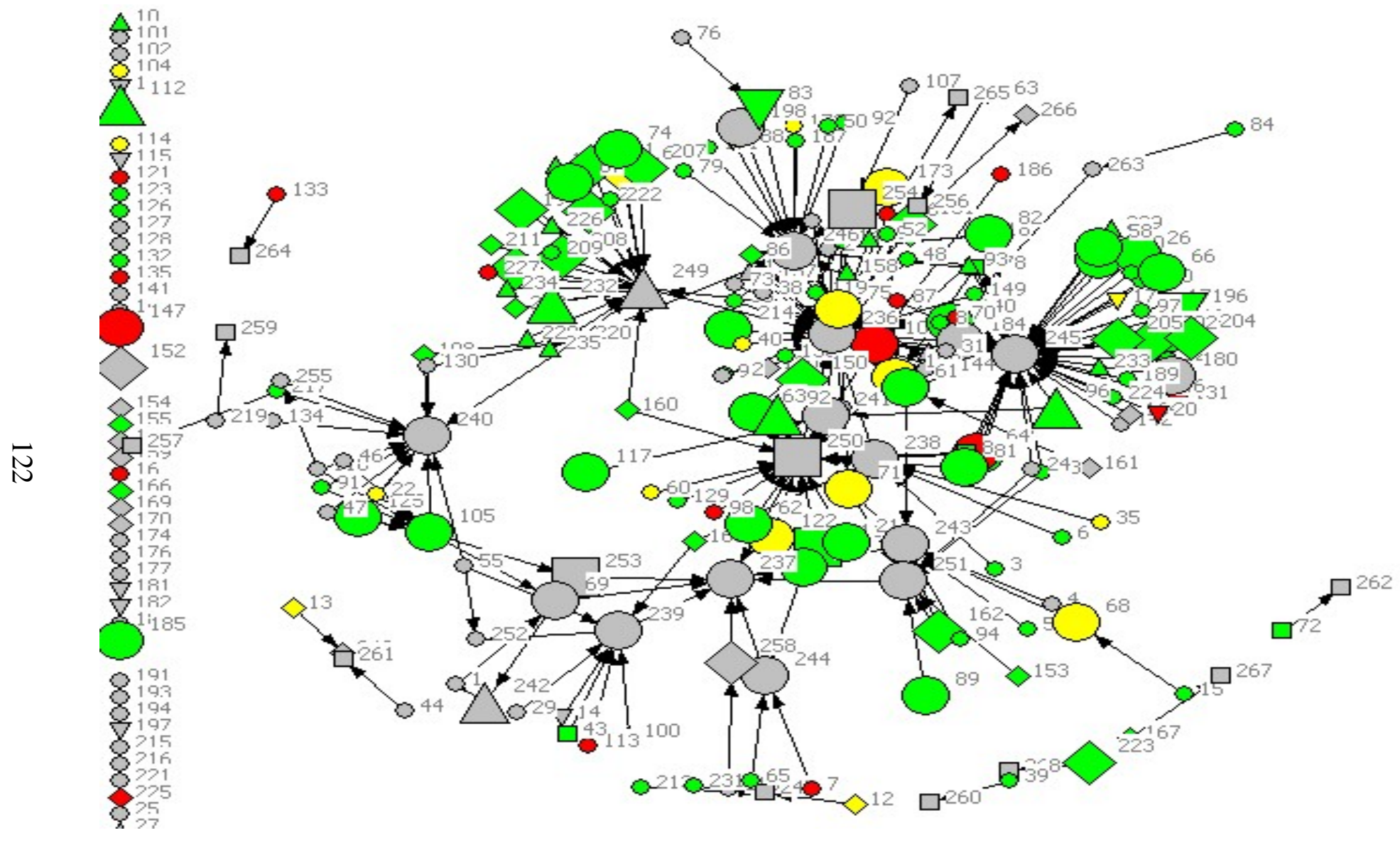

Figure 4. Laughing Bird Caye National Park full network diagram with interests represented

Interests represented: Green=yes; Red=No; Maybe=Yellow; Don't know/no answer=gray

Placencia residents=circle; Independence=triangle; Seine Bight=diamond

Larger nodes=attended meeting 
This network diagram (Figure 11) again shows the entire network for the Laughing Bird Caye National Park, with the nodes for those who have attended a meeting or been involved enlarged. Additionally, the nodes are color-coded by response to the question "do those responsible for making decisions about the marine park represent your interests?" Those who answered yes are represented in green, those who said no are in red, and those who answered 'somewhat' are represented in yellow. Those who said they did not know, or did not answer the question, are in gray. Overall, the vast majority of respondents for the Laughing Bird Caye National Park said they believed those in charge to represent their interests. The respondents who cited nodes 245 and 249 (both staff of Friends of Nature) overwhelmingly believed their interests were represented, while those who cited node 239 (chairman of the village council) or 240 (Tourism Center) were less consistently positive. Generally, it appears as if those individuals who cited Friends of Nature or its staff (most of the nodes in the upper right half of the diagram) believed their interests were well represented, while those respondents who named other individuals less involved in Friends of Nature (such as along the lower half of the diagram) often said they did not know whether their interests were represented. Those same individuals were also less often involved in meetings regarding the marine reserve.

\section{HOL CHAN MARINE RESERVE}

The network for the Hol Chan Marine Reserve has 441 nodes, of which 30.6\% are isolates. 


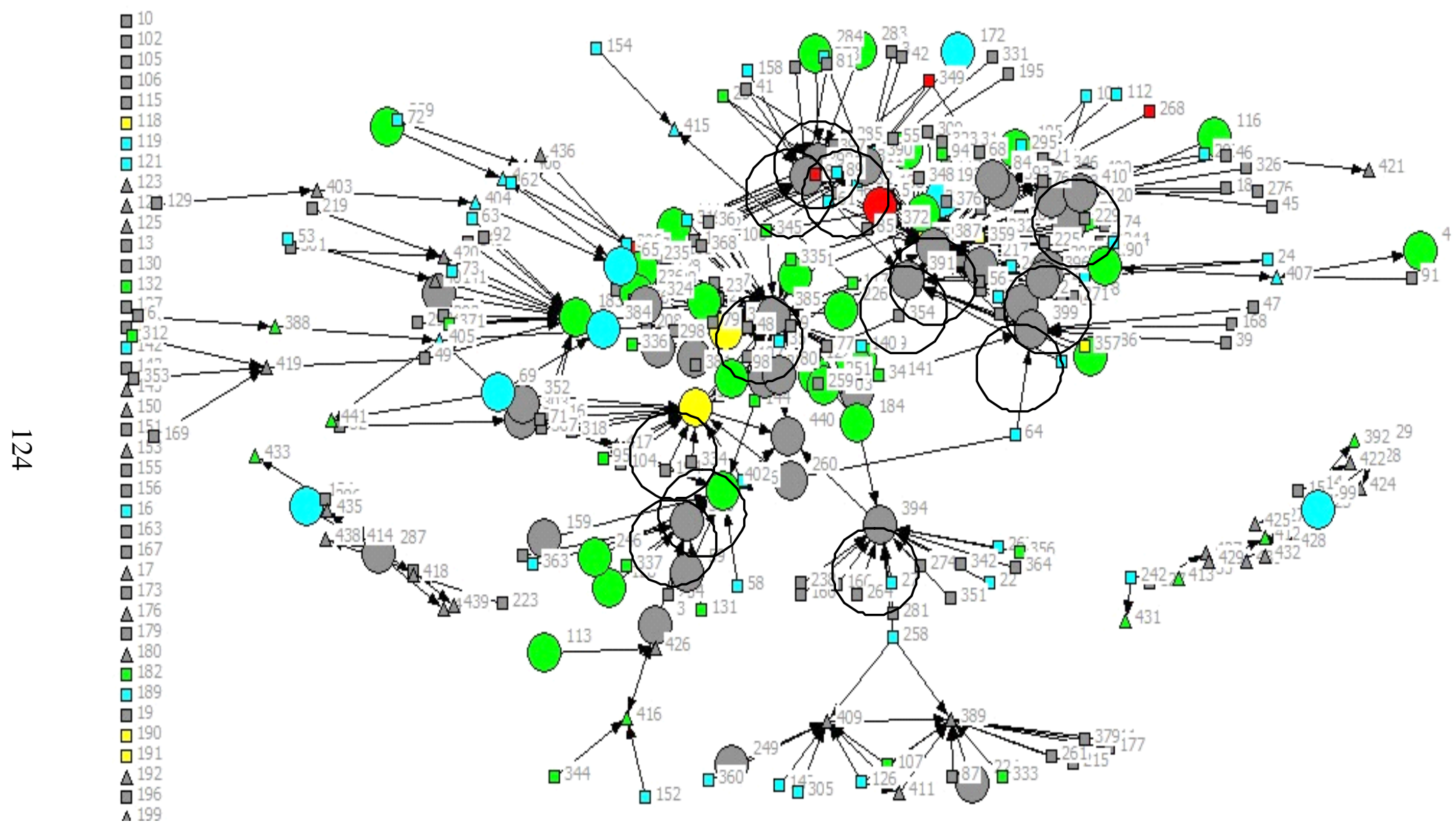

\section{Figure 5. Hol Chan Marine Reserve full network graph}

Key actors are circled (Hol Chan Marine Reserve staff and board)

Red=fishermen; Green=tour guides; Blue=tourism industry; Yellow=government; Gray=other

Larger nodes=attended meeting 
The network above (Figure 12) shows the entire sampled network for the Hol Chan Marine Reserve, with tour guides demarcated in green. Tour guides are important stakeholders for the reserve, as the area is used primarily for tourism purposes. It can be seen from this diagram that most tour guides are connected to the central network, with a few part of a smaller, disconnected network. Many of the tour guides are in the middle of the network, indicating that they are directly connected to the Hol Chan management staff and other actors responsible for making decisions about the marine reserve. A large number of the tour guides have been involved in the marine reserve as well. Some of the individuals involved in tourism, those nodes in blue, also have attended meetings or otherwise been involved, but most of these are either not connected to the central network, or connected to the reserve management only via an intermediary.

\section{Hol Chan Marine Reserve Degree Centrality}

Table 18. Hol Chan Marine Reserve Freeman Degree Centrality - Symmetric

\begin{tabular}{|l|l|l|l|}
\hline Node & Description & Degree & $\begin{array}{l}\text { Normalized } \\
\text { Degree }\end{array}$ \\
\hline $387^{\#}$ & Hol Chan Office & 76.000 & 17.273 \\
\hline $385^{\#}$ & Hol Chan manager & 62.000 & 14.091 \\
\hline $394^{*}$ & Minister of Tourism/ Board of Directors of Hol Chan & 16.000 & 3.636 \\
\hline $308^{*}$ & President of local NGO/ Board of Directors of Hol Chan & 16.000 & 3.636 \\
\hline $391^{\#}$ & Hol Chan Rangers & 14.000 & 3.182 \\
\hline $390^{\#}$ & Ranger & 14.000 & 3.182 \\
\hline 183 & Head of local business association & 14.000 & 3.182 \\
\hline $398^{\#}$ & Ranger & 13.000 & 2.955 \\
\hline 389 & Mayor of San Pedro & 13.000 & 2.955 \\
\hline $393^{\#}$ & Ranger & 12.000 & 2.727 \\
\hline $\begin{array}{l}*-\text { on co-management committee } \\
\text { \#- MPA staff }\end{array}$ & \\
\hline
\end{tabular}




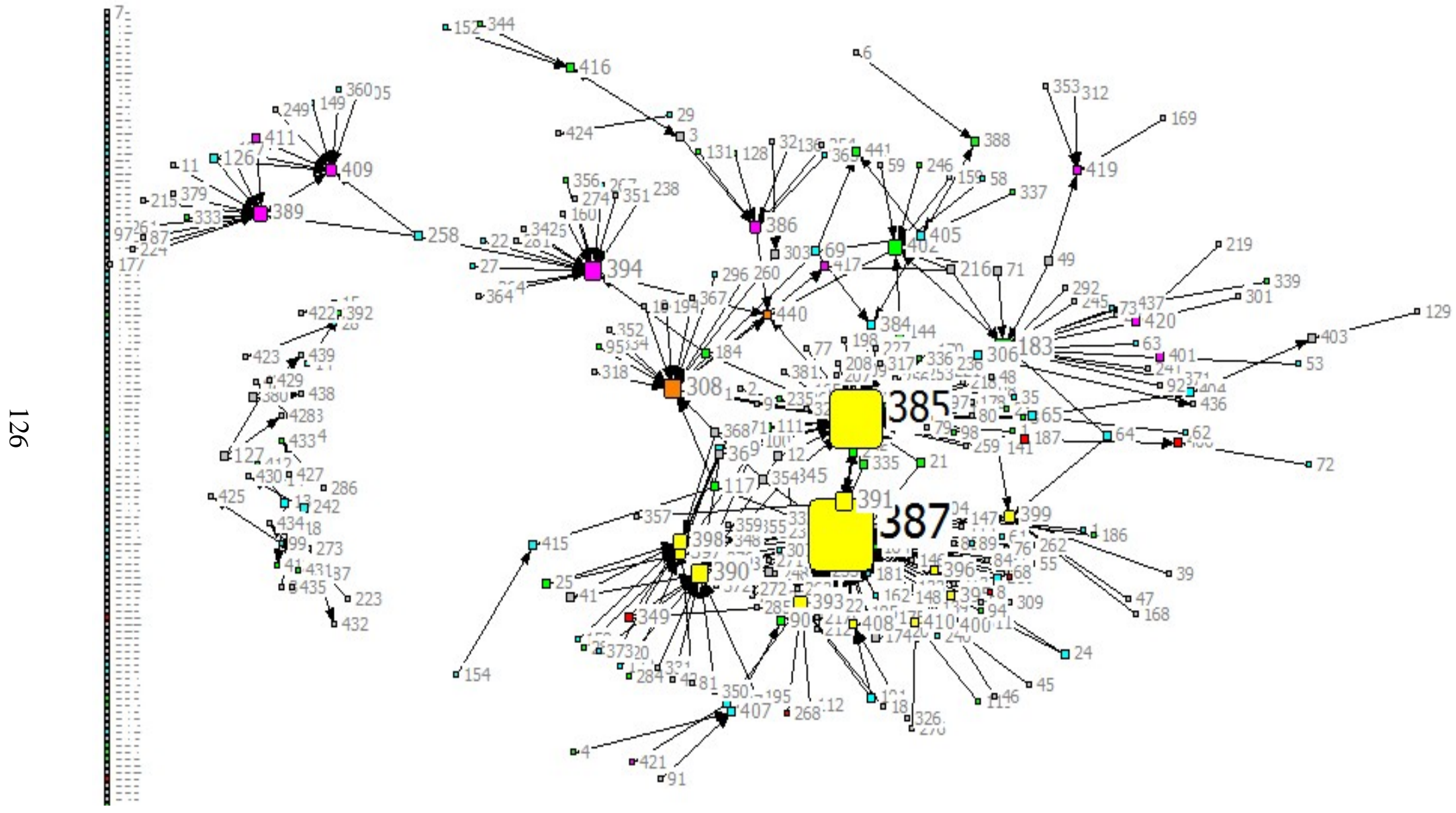

Figure 6. Hol Chan Marine Reserve - Freeman Degree Centrality

Red=fishermen; Green=tour guides; Blue=tourism industry; Yellow=government; Gray=other Node size corresponds to degree centrality 
The most central actor in the Hol Chan Marine Reserve network according to the Freeman Degree centrality measure is the Hol Chan office itself, node 387. A large number of individuals within the community knew the reserve had an office and named this as where they would go to share an opinion, even if they could not name anyone working there. The second most central actor is the manager of the Hol Chan reserve, node 385, whose name at least was well known to the residents of San Pedro. Tied for third, and significantly less central than either the Hol Chan office or the Hol Chan manager, are the Minister of Tourism, node 394, who is a resident of San Pedro and serves on the Board of Directors for the reserve, and the president of the local environmental group, node 308, who also serves on the Board of Directors. Number five ranked for centrality were the Hol Chan marine reserve rangers who patrol the reserve (with no name given), tied with one particular ranger, node 390. Two other rangers, nodes 398 and 393, also made the list of top ten most central actors. Tied with the rangers is the head of the local business owners' association, node 183, who is also a prominent member of the community. The mayor of San Pedro (node 389) was also listed frequently and is one of the most central actors in the Hol Chan reserve according to the network analysis, although the mayor is not directly involved in the marine reserve in any way.

Clearly those actors named for the Hol Chan Marine Reserve network are all actors who either play a role in the management of the reserve, or otherwise are prominent individuals within the community. Compared with the other networks, the Hol Chan office and the Hol Chan manager have higher degree centrality measures than other central actors, in part because the Hol Chan network is larger than any of 
the other networks. At the same time, the centrality of the other actors in the network who rank near the top is relatively low, especially when compared with the top two actors. This indicates that power within the Hol Chan Marine Reserve network is more highly focused around just these two key actors than may be seen in some of the other networks described in this chapter.

Table 19. Frequency of actors named by fishermen for the Hol Chan Marine Reserve $(\mathbf{n}=7)$

\begin{tabular}{|l|r|r|}
\hline Description & Node & Percentage \\
\hline Hol Chan office & 387 & $28.6 \%$ \\
\hline Ranger & 393 & $28.6 \%$ \\
\hline
\end{tabular}

Table 20. Frequency of actors named by tour guides for the Hol Chan Marine Reserve $(\mathbf{n}=55)$

\begin{tabular}{|l|r|r|}
\hline Description & Node & Percentage \\
\hline Hol Chan manager & 385 & $34.5 \%$ \\
\hline Hol Chan office & 387 & $7.3 \%$ \\
\hline Biologist for Hol Chan & 397 & $7.3 \%$ \\
\hline Ranger & 393 & $5.4 \%$ \\
\hline Head of tour guide association & 402 & $5.4 \%$ \\
\hline Mayor & 389 & $3.6 \%$ \\
\hline Fisheries Department & 386 & $3.6 \%$ \\
\hline Rangers & 391 & $3.6 \%$ \\
\hline Minister of Tourism & 394 & $3.6 \%$ \\
\hline Head of local NGO & 308 & $3.6 \%$ \\
\hline
\end{tabular}

Table 21. Frequency of actors named by tourism workers for the Hol Chan Marine Reserve $(\mathbf{n}=75)$

\begin{tabular}{|l|r|r|}
\hline Description & Node & Percentage \\
\hline Hol Chan office & 387 & $13.3 \%$ \\
\hline Hol Chan manager & 385 & $8.0 \%$ \\
\hline Town Board & 409 & $6.7 \%$ \\
\hline Minister of Tourism & 394 & $5.3 \%$ \\
\hline Ranger & 393 & $4.0 \%$ \\
\hline Ranger & 390 & $2.7 \%$ \\
\hline Head of tour guide association & 402 & $2.7 \%$ \\
\hline Head of local business association & 183 & $2.7 \%$ \\
\hline Mayor & 389 & $2.7 \%$ \\
\hline Ranger & 398 & $2.7 \%$ \\
\hline
\end{tabular}


The actors named most frequently by the various stakeholder groups for the Hol Chan Marine Reserve do not differ substantially from the most central actors overall. One notable difference is the biologist on the marine reserve staff, who was named by several tour guides. This individual is responsible for an outreach program with tour guides around the island, where she visits dive shops and informs dive guides and other tour guides about ongoing management activities in the marine reserve, and thus is personally known to many of the dive guides around the island. It is also worth noting that while the sample size for both tour guides and tourism workers is large for this site, there are very few individuals or groups named by more than three or four respondents from these stakeholder categories. The diversity of actors named speaks to a lack of consistency in the individuals with whom these groups associate, and perhaps to a lack of direct representation for these stakeholders within management, although most stakeholders do feel nonetheless that their interests are represented. For example, even the head of the tour guide association, who also sits on the Hol Chan board, was only named by five percent of the tour guides, or three individuals, as the person to whom they would speak. 


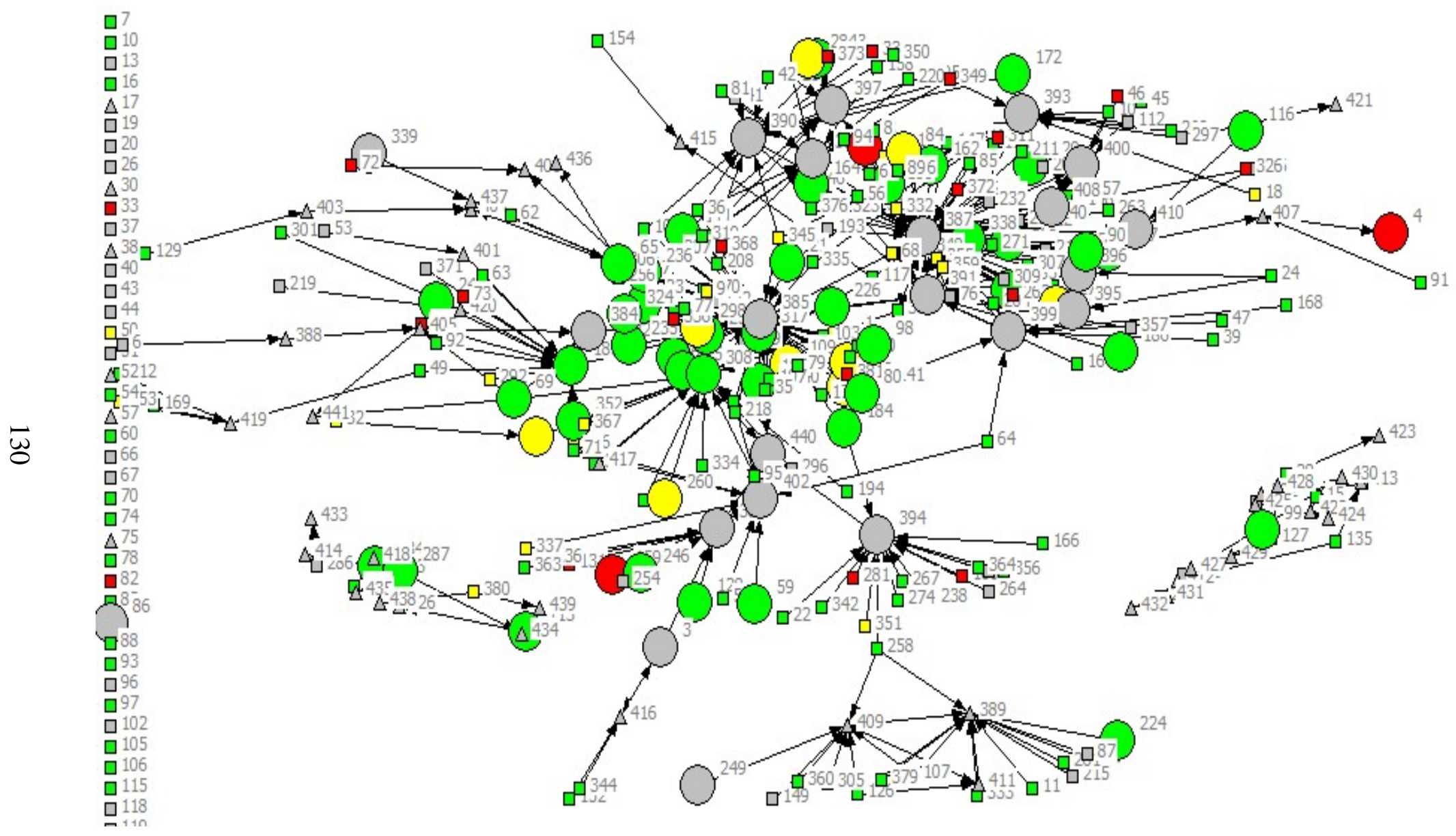

Figure 7. Hol Chan Marine Reserve - interests represented

Interests represented: Green=yes; Red=No; Maybe=Yellow; Don't know/no answer=gray Larger nodes=attended meeting 
The network depicted in Figure 14 shows the Hol Chan network with colorcoding for responses to the question about whether or not the actors feel those involved represent their interests. Those who felt their interests are being represented are in green, and make up the vast majority of respondents. Those individuals who have participated in the marine reserve are enlarged; the majority of individuals who have participated felt their interests were being represented, or either didn't respond or said they didn't know if their interests were represented (nodes in gray). The greatest discontent with the reserve management appears to be with those who named the Hol Chan Office (node 387) as where they would go to express an opinion about the reserve, followed by the manager of the reserve (node 385); an unsurprising finding, as these are the two most central actors within the network.

However, of the individuals who had cited the manager or the office and responded they did not believe those in charge represented their interests, only one of them had actually participated in the marine reserve. To some extent, it appears that the further removed the actors responding to the question are from the core of the network and the management of the reserve, the more satisfied they are that their interests are represented by the management, and are also less likely to have been involved in the marine reserve. This could be because these individuals are less concerned about having their interests represented, and thus less involved or less aware of what takes place within the management of the reserve. They could also feel their interests are being represented, so don't feel the need to be involved. The majority of isolates believe their interests were well represented, although they did not know who it was managing the marine reserve and thus representing their interests. 
This finding is contrary to the network for the Laughing Bird Caye National Park, where the respondents who were closer to the key actors in the network were more likely to say their interests were represented.

\section{SABA NATIONAL MARINE PARK}

The Saba National Marine Park sampled network is the smallest of the six sites, with 135 nodes. It also has the fewest isolates of any site, with only $18.5 \%$ of the respondents appearing as isolates. 


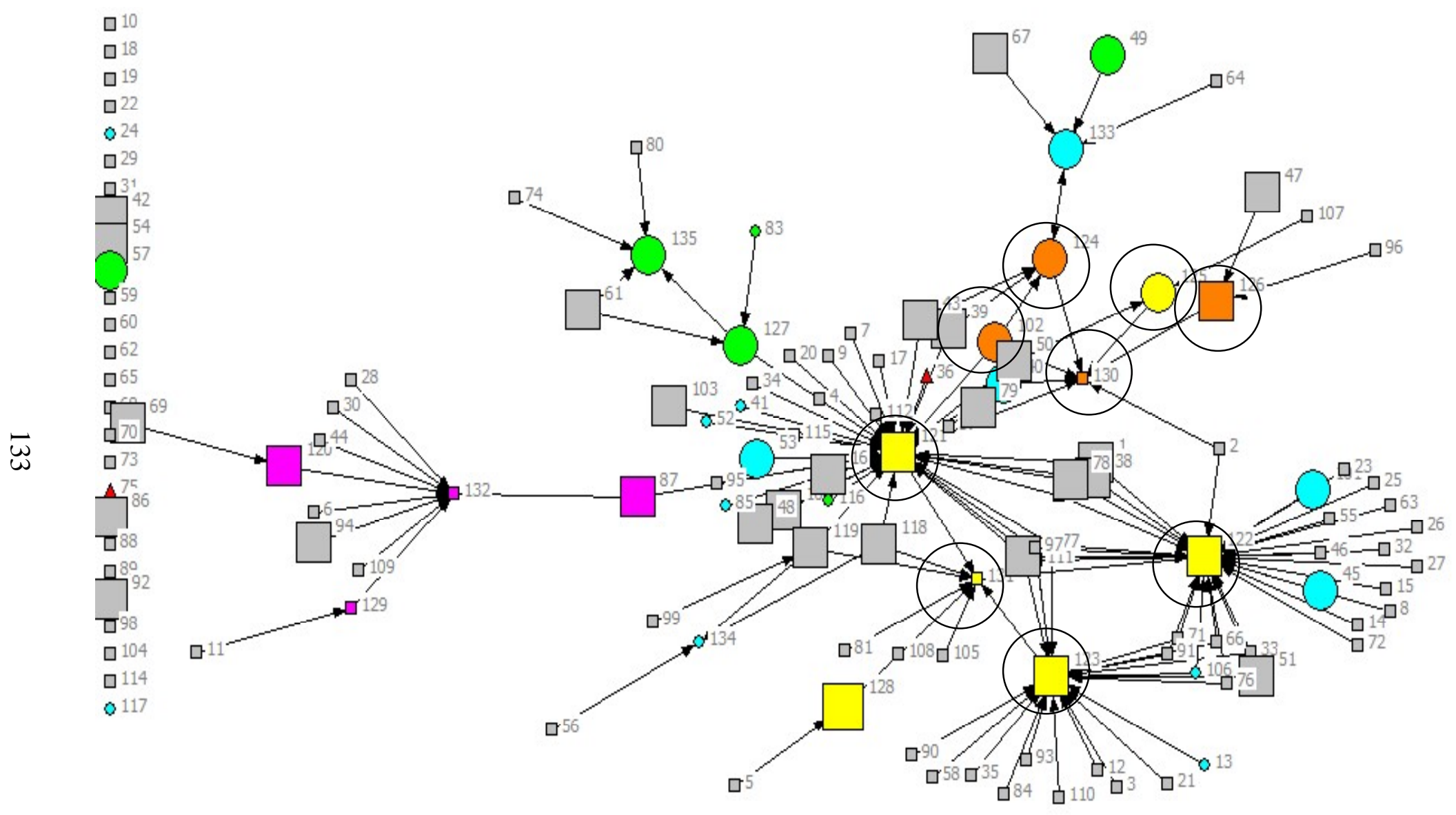

Figure 8. Saba National Marine Park network with occupation and participation

Key actors are circled (SCF staff and board)

Green=tour guide; Blue=tourism industry; Yellow=SCF staff; Orange=SCF board members; pink=government Larger nodes=attended meeting 
The above network diagram shows the sampled network for the Saba National Marine Park, with actors who have attended meetings or otherwise participated enlarged, and occupation indicated by color and shape. The Saba network shows relatively extensive participation compared with other sites, and relatively few central nodes. This is likely because this network is smaller than the others, but also because Saba itself is a smaller community than the other sites, and has fewer people directly involved in the marine park than at any other site.

Many of those actors involved in tourism, shown as blue circles, reported to have participated in management of the marine park. Tour guides, including dive shops, are those actors depicted in green. There are few tour guides within the Saba network, but most have participated in the marine park in the past. Fishermen are depicted in red; there are only two fishermen in the network, neither of whom has attended meetings. Many of the actors who have attended meetings or otherwise been involved work for the government or in the public service sector (which includes the Saba Conservation Foundation, which manages the park); these actors are depicted as yellow squares. Gray squares are other occupations; a number of actors from these other occupations have been involved in the marine park as well.

Saba National Marine Park Degree Centrality

Table 22. Saba National Marine Park Freeman Degree Centrality - Symmetric

\begin{tabular}{|l|l|l|l|}
\hline Node & Description & Degree & $\begin{array}{l}\text { Normalized } \\
\text { degree }\end{array}$ \\
\hline $121^{\#}$ & $\begin{array}{l}\text { Manager of Saba Conservation } \\
\text { Foundation/Marine Park }\end{array}$ & 40.000 & 29.851 \\
\hline $122^{\#}$ & $\begin{array}{l}\text { Saba Conservation Foundation Education } \\
\text { Director }\end{array}$ & 31.000 & 23.134 \\
\hline
\end{tabular}




\begin{tabular}{|l|l|l|l|}
\hline $123^{\#}$ & $\begin{array}{l}\text { Saba Conservation Foundation } \\
\text { Administrative Staff }\end{array}$ & 22.000 & 16.418 \\
\hline $131^{\#}$ & Saba Conservation Foundation (SCF) & 11.000 & 8.209 \\
\hline 132 & Island government & 9.000 & 6.713 \\
\hline $130^{*}$ & SCF Board of Directors & 5.000 & 3.731 \\
\hline $124^{*}$ & Chair of the SCF Board of Directors & 5.000 & 3.731 \\
\hline 127 & Local dive shop owner & 4.000 & 2.985 \\
\hline 135 & Local dive shop owner & 4.000 & 2.985 \\
\hline $119^{\#}$ & $\begin{array}{l}\text { Saba Conservation Foundation staff } \\
\text { terrestrial programs) }\end{array}$ & 4.000 & 2.985 \\
\hline 133 & $\begin{array}{l}\text { Founder of Saba Marine Park/local hotel } \\
\text { owner }\end{array}$ & 4.000 & 2.985 \\
\hline
\end{tabular}

* - on co-management committee

\#- MPA staff 


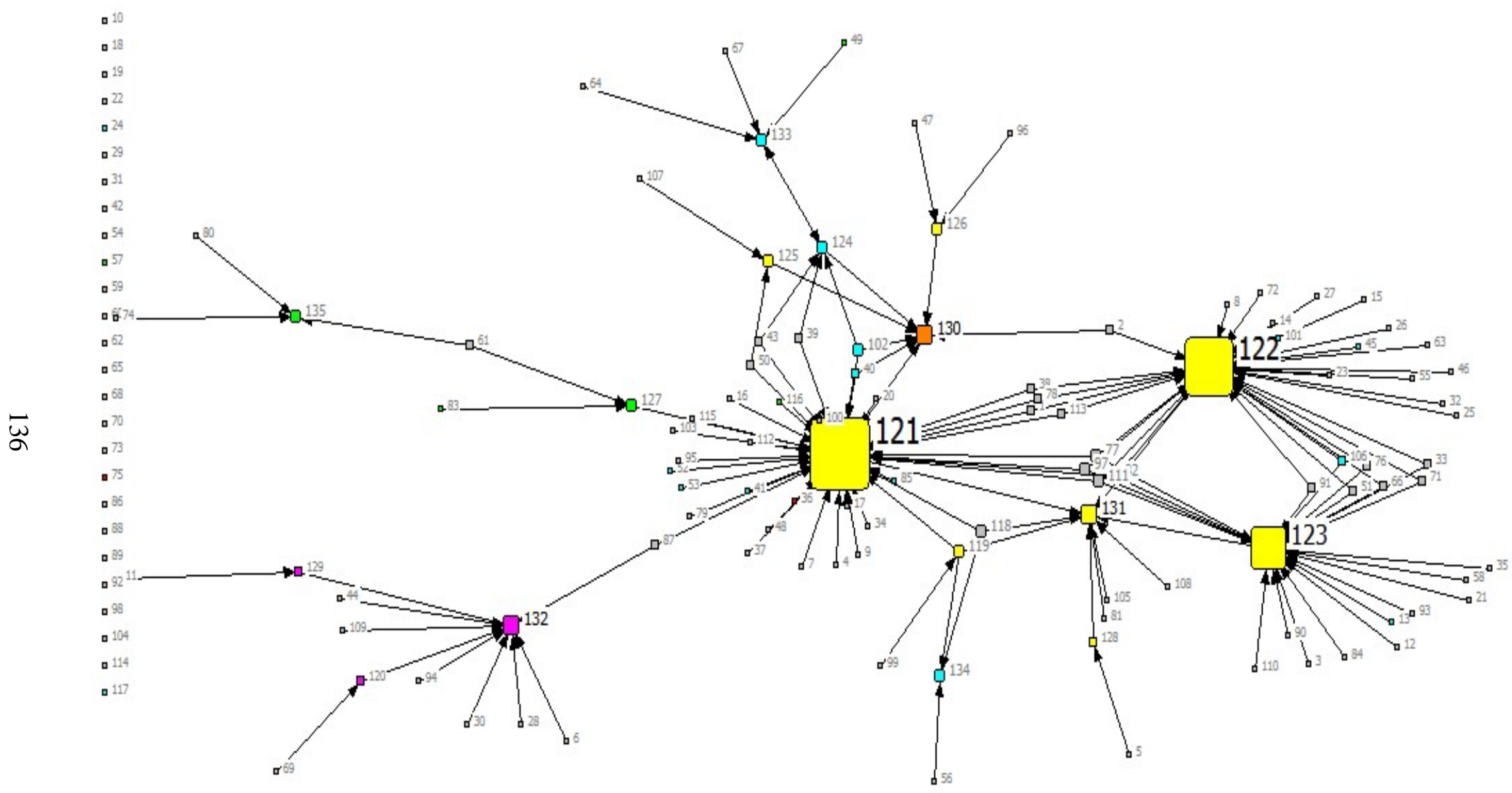

Figure 9. Saba National Marine Park - Freeman Degree Centrality

Green=tour guide; Blue=tourism industry; Yellow=SCF staff; Orange=SCF board members; pink=government Node size corresponds to degree centrality 
The actor with the highest centrality in the Saba National Marine Park network is node 121 , the manager of the marine park and the local foundation responsible for managing the park. The second and third most central actors (nodes 122 and 123) are also employees of the Saba Conservation Foundation. The next most influential actor is the Saba Conservation Foundation (SCF) itself (node 131), followed by the island government (node 132) and the Saba Conservation Foundation's Board of Directors (node 130). Tied with the Board of Directors for centrality is the chairperson of the Board of Directors (node 124). There were four actors tied for being the eighth-most central actors; two co-owners of a local dive shop (nodes 127 and 135), a staff member of the Saba Conservation Foundation who works on the terrestrial hiking programs (node 119), and the original founder of the marine park, who runs a hotel on the island (node 133). By looking at the network diagram, it can be seen that many linkages among most of these actors exist, and many respondents named more than one of these actors, with the exception of the island government, which is linked to the rest of the network only by one link. The island government is responsible for comanaging the marine park with the Saba Conservation Foundation, and the island government has a seat on the Board of Directors of the organization. However, none of the actors responding to the survey named both the island government and any member of the Saba Conservation Foundation; the actors only named one or the other.

Table 23. Frequency of actors named by tourism workers for Saba National Marine Park $(n=12)$

\begin{tabular}{|l|r|r|}
\hline Description & Node & Percentage \\
\hline Park manager & 121 & $50.0 \%$ \\
\hline Education director & 122 & $25.0 \%$ \\
\hline Administrative staff & 123 & $16.7 \%$ \\
\hline
\end{tabular}


The actors named by those individuals working in tourism (the sample size of fishermen and tour guides was too small to calculate the frequency of named actors) exactly mirrors the order of the top three most central actors. This is reflective of the high degree centrality of each of these individuals in the network as a whole; the community members interviewed frequently knew exactly who the individuals were responsible for managing the reserve, partly because of the small size of the community.

\section{BUCCOO REEF MARINE PARK}

The Buccoo Reef Marine Park network has 329 nodes, making it just slightly larger than the Scotts Head/Soufriere Marine Reserve network. The Buccoo Reef network has the most isolates, with $31.6 \%$ of all respondents saying they did not know to whom they would speak about the marine reserve, or never having heard of the marine reserve at all. 


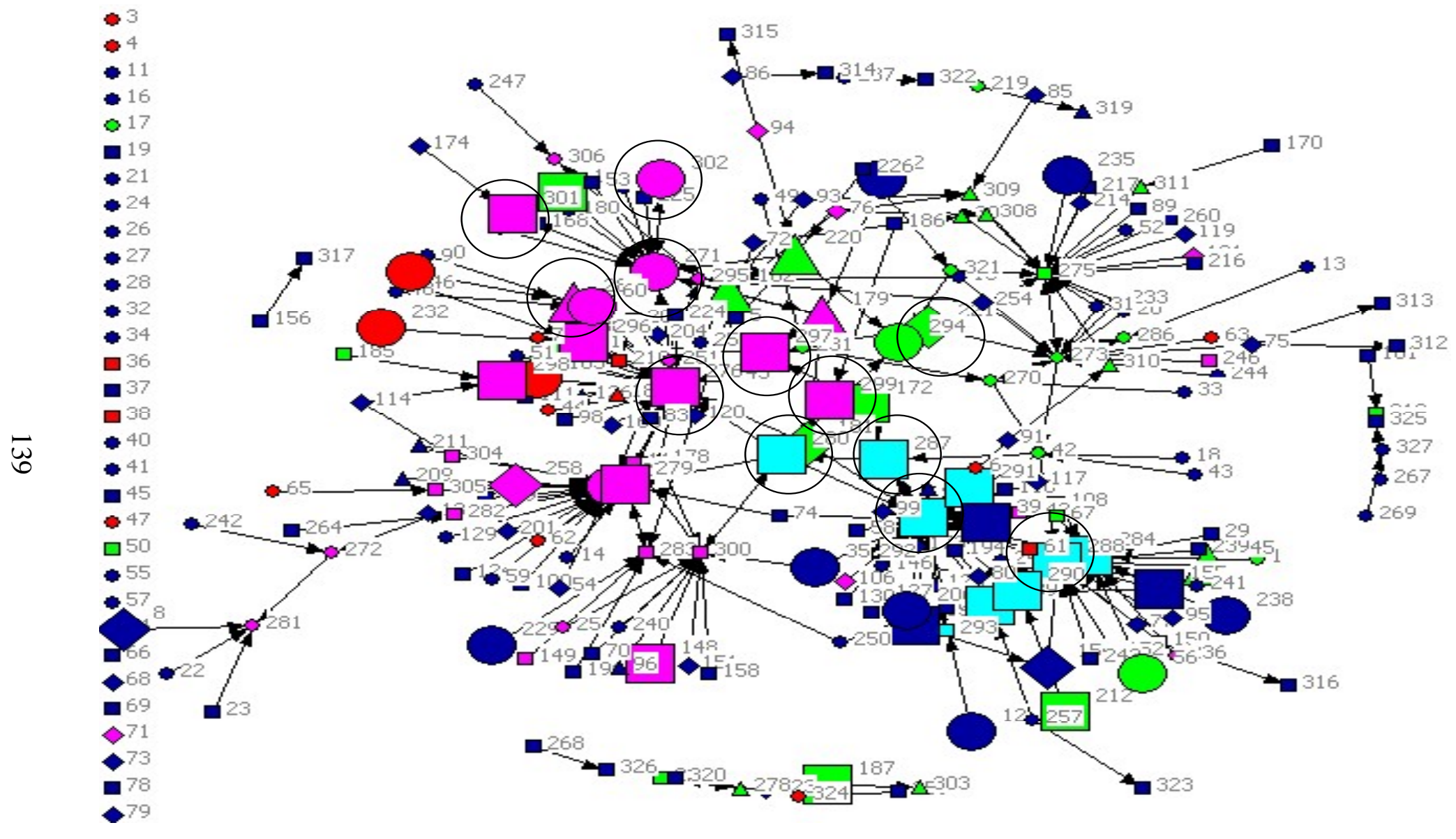

Figure 10. Buccoo Reef Marine Park - full network diagram

Key actors are circled (members of management committee, staff of Fisheries Department working with marine park) Red=fisherman; Green=tour guide; Light blue=tourism industry; Pink=government/public service; Dark blue=other Larger nodes=attended meeting 
This diagram shows participation by occupation (color), with those who have attended meetings enlarged. The nodes who have been involved in the marine park are mostly centered on an axis through the middle of the network. A large number of network actors that have attended meetings are in pink, meaning they work in the public sector, including for the government or for Buccoo Reef Trust. A large number of these actors are individuals or agencies who were named by those surveyed, but who did not necessarily participate in the survey. The advisory committee of the marine park is made up of a large number of individuals and agencies, most of them part of the island government. These agencies and the individuals working for them were often cited by respondents.

A significant number of the nodes that are shown as participating in the marine reserve are green, meaning they are tour guides. Interestingly, more than for most other networks, nodes are highly clustered by occupation, with many of the tour guides linked together, with the individuals working in tourism clustered together, and with fishermen, shown as red, highly clustered on the left side of the network diagram. Government officials, staff of Buccoo Reef Trust, and other public servants are also heavily clustered, in part because of their involvement with the marine park advisory committee.

\section{Buccoo Reef Marine Reserve - Degree Centrality}

Table 24. Buccoo Reef Marine Park - Freeman Degree Centrality

\begin{tabular}{|l|l|l|l|}
\hline Node & Description & Degree & $\begin{array}{l}\text { Normalized } \\
\text { degree }\end{array}$ \\
\hline $274^{*}$ & Buccoo Reef Trust & 38.000 & 11.621 \\
\hline
\end{tabular}




\begin{tabular}{|l|l|l|l|}
\hline $276^{\#}$ & $\begin{array}{l}\text { Department of Fisheries and Marine } \\
\text { Resources }\end{array}$ & 33.000 & 10.092 \\
\hline $271^{\#}$ & Reef patrol & 15.000 & 4.587 \\
\hline 288 & Director of Buccoo Reef Trust & 15.000 & 4.587 \\
\hline 275 & Reef tour operators & 14.000 & 4.281 \\
\hline 273 & $\begin{array}{l}\text { Prominent family in Buccoo involved in } \\
\text { reef tours }\end{array}$ & 13.000 & 3.976 \\
\hline $300^{*}$ & Tourism Department & 11.000 & 3.364 \\
\hline $277^{*}$ & Buccoo Village Council & 11.000 & 3.364 \\
\hline $279^{*}$ & Tobago House of Assembly & 10.000 & 3.058 \\
\hline
\end{tabular}

* - on co-management committee

\#- MPA staff 


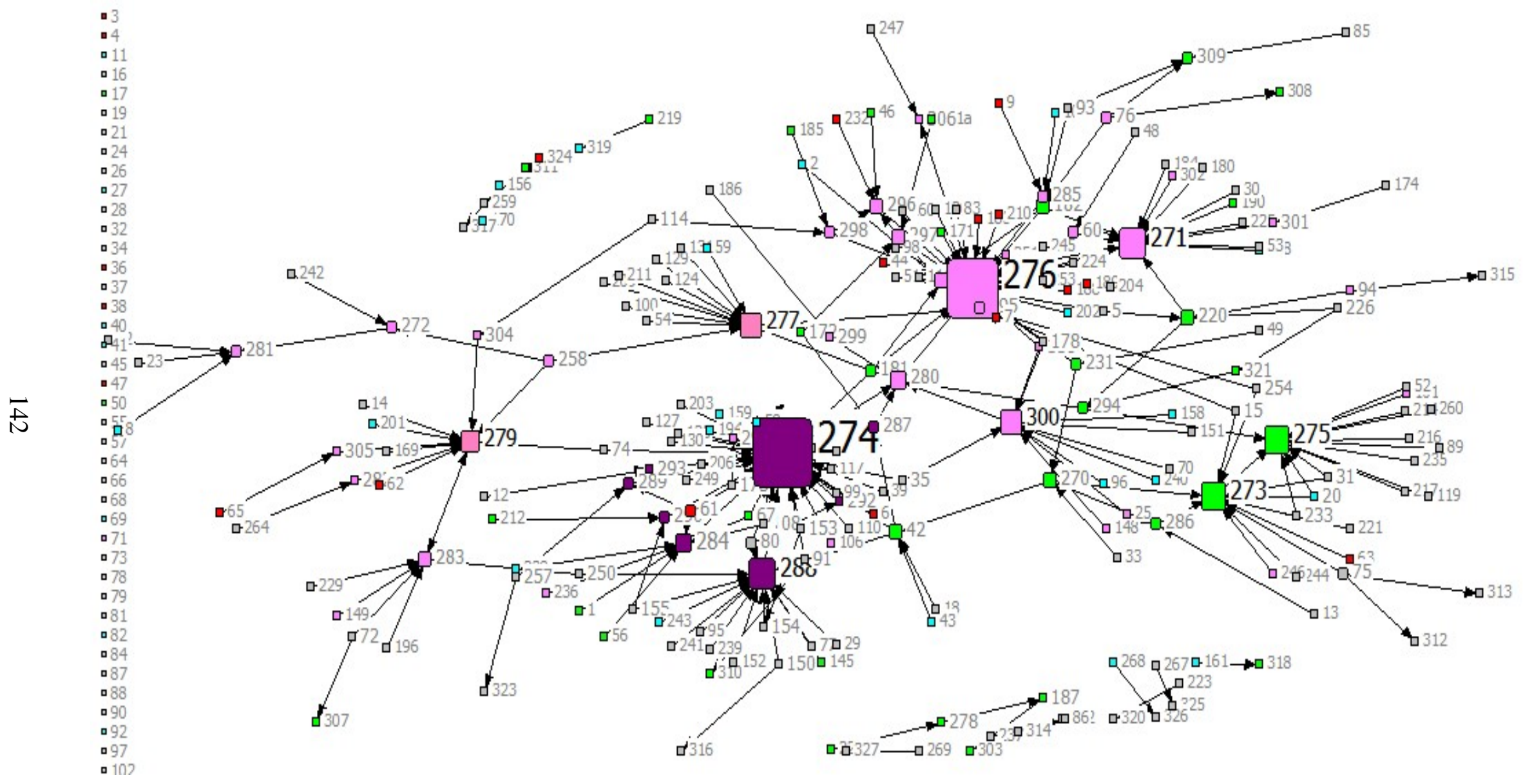

Figure 18. Buccoo Reef Marine Park - Freeman degree centrality

Red=fisherman; Green=tour guide; Light blue=tourism industry; Pink=government/public service; Purple=Buccoo Reef Trust; Gray=other Node size corresponds to degree centrality 
The network for the Buccoo Reef Marine Park differs from the other networks, because community members cited government agencies or other entities, as opposed to individuals, much more frequently than respondents from other networks. This could indicate that these respondents do not actually know personally anyone who has been involved in the marine park, or it could be related to the relatively high level (within the Tobago government) at which decisions about the marine park are being made. Most of the actors found to be most central to the Buccoo Reef Marine Park network are not individuals but groups or government entities.

The most central actor, node 274, was Buccoo Reef Trust, which has led the efforts at co-managing the marine park, and involves the public in its work in a number of ways, even if not directly in the marine park management. The Buccoo Reef Trust is not directly responsible for making decisions about the marine park, but has nonetheless been involved in many other aspects of the park. The next most central actor was found to be the Department of Fisheries and Marine Resources for Tobago (node 276), which is directly responsible for managing the park.

The next most central actor is node 271 , the reef patrol for the marine park. Again, some respondents named individuals who serve on the reef patrol, but many just named the reef patrol as a group and were unable to name anyone in particular. Node 288, tied for third in centrality, is one of the directors of Buccoo Reef Trust; node 284 , tied for tenth in the centrality ranking, is another director at the organization.

Node 275, fifth in the measure of Freeman Degree centrality, is actually a group of individuals, the reef tour operators. Many respondents named the reef tour 
operators, the actors who use Buccoo Reef the most, as a group, without naming any of the tour operators in particular. In fact, the reef tour operators do have an association, although it was unclear how many of the reef tour operators are members of the reef tour operator association. Many of the respondents instead, or in addition, named a number of individual reef tour operators. The sixth most prominent actor, node 273 , is again a group of individuals, in this case a prominent family in the village of Buccoo, who runs a reef tour business. Most respondents who listed this family provided the family name, and some, when pressed, provided names of individuals within the family. Following this, tied for eighth are the Tourism Department, node 300, and the Buccoo Village Council, node 277. While both of these groups sit on the marine park advisory committee, respondents generally did not name any individuals involved in these organizations. The tenth ranked node for centrality is the Tobago House of Assembly, node 279. The Tobago House of Assembly is the group of representatives responsible for governing the island, and while Tobago is relatively small, it seems unlikely that most of the individuals who said they would go straight to the House of Assembly with a concern have the contacts within the government to have their opinions heard through the proper channels.

Table 25. Frequency of actors named by fishermen for Buccoo Reef Marine Park (n=21).

\begin{tabular}{|l|r|r|}
\hline Description & Node & Percent \\
\hline Department of Fisheries & 276 & $19.0 \%$ \\
\hline Buccoo Reef Trust & 274 & $9.5 \%$ \\
\hline Tobago House of Assembly & 279 & $9.5 \%$ \\
\hline $\begin{array}{l}\text { Prominent family in Buccoo } \\
\text { involved in reef tours }\end{array}$ & 273 & $9.5 \%$ \\
\hline
\end{tabular}


Table 26. Frequency of actors named by tour guides for Buccoo Reef Marine Park $(\mathbf{n}=\mathbf{2 7})$

\begin{tabular}{|l|r|r|}
\hline Description & Node & \multicolumn{1}{|l|}{ Percent } \\
\hline Department of Fisheries & 276 & $14.8 \%$ \\
\hline Buccoo Reef Trust & 274 & $11.1 \%$ \\
\hline Director of BRT & 284 & $11.1 \%$ \\
\hline Director of BRT & 288 & $7.4 \%$ \\
\hline BRT reserve project coordinator & 287 & $7.4 \%$ \\
\hline
\end{tabular}

Table 27. Frequency of actors named by tourism workers for Buccoo Reef Marine Park $(\mathbf{n}=38)$

\begin{tabular}{|l|l|l|}
\hline Description & Node & Percent \\
\hline Buccoo Reef Trust & 274 & $7.9 \%$ \\
\hline Tourism department & 300 & $7.9 \%$ \\
\hline $\begin{array}{l}\text { Prominent family in Buccoo } \\
\text { involved in reef tours }\end{array}$ & 273 & $5.3 \%$ \\
\hline
\end{tabular}

As was the case for the complete network, these three stakeholder groups largely named groups and organizations, rather than individuals, as the actors to whom they would speak about the marine park. Some tour guides named individual employees at Buccoo Reef Trust, and both fishermen and tourism workers named a family of individuals tied to the reef tour industry, but generally few individuals were named. There were also a large number of actors or groups named by just one respondent (not listed in the tables), indicating a lack of consensus among these stakeholders of who are the individuals and groups in charge of the Buccoo Reef Marine Park. The responses provided by these particular stakeholder groups are representative of the responses of the community as a whole, and of the fact that the community at large is not directly represented in the co-management of the MPA. 


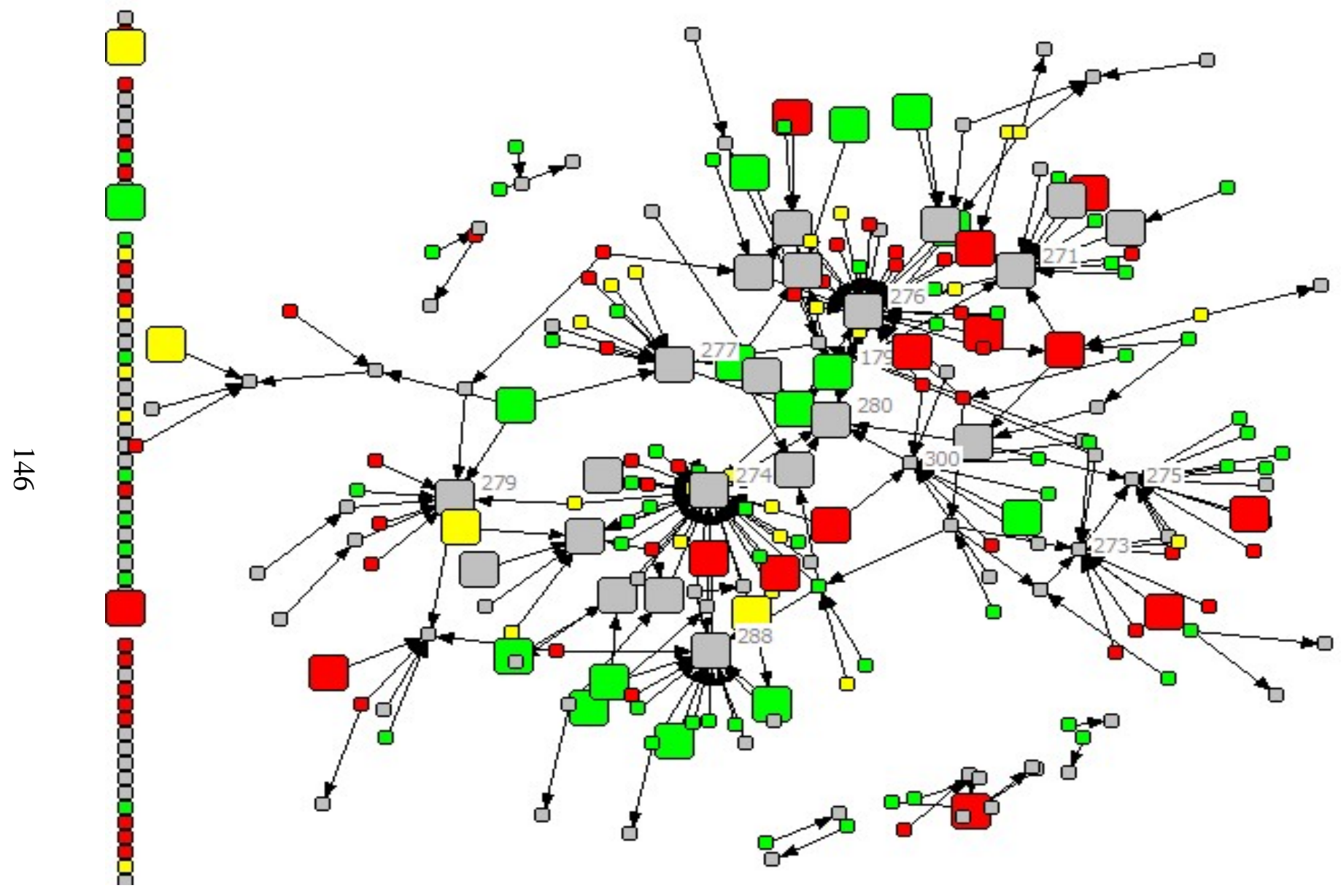

Figure 19. Buccoo Reef Marine Park full network with interests represented

Interests represented: Green=yes; Red=No; Maybe=Yellow; Don't know/no answer=gray Larger nodes=attended meeting 
The above network graph (Figure 19) illustrates the actors' responses to the question of whether they believe their interests are being represented. There is clearly considerable dissatisfaction among respondents with how they feel their interests are being represented, with a large number of respondents answering they do not feel those in charge are representing their interests (nodes in red). This includes both individuals who have attended meetings regarding the marine park and individuals who have not. Many of the individuals who named the Buccoo Reef Trust and the Department of Fisheries Marine Resources, the two primary organizations involved in the marine park, also said they had participated in meetings about the marine park, including many who said they did not feel their interests were represented. In fact, most of the individuals who had participated and named the organizations as where they would go with an opinion about the park said they did not feel their interests were represented, whereas many of the other individuals who had attended meetings and named other key actors claimed their interests were represented. This includes, for example, respondents who named node 288, the director of Buccoo Reef Trust. Most felt their interests were represented by this individual.

\section{COMPARING NETWORKS}

Overall, the networks that included the greatest numbers of actors also had the greatest numbers of isolates. The smaller networks, those for Saba and St. Eustatius,

were developed from small, geographically contained communities, so the likelihood that an individual could name someone involved in management of the marine reserve was higher. These networks had the fewest actors and the fewest isolates. The 
exception to this is the network for the Buccoo Reef Marine Park, which had the greatest percentage of isolates, despite being smaller than the network for the Hol Chan Marine Reserve. This is indicative of little participation and less active management for the Buccoo Reef Marine Park site, as well as a community that is more fluid and not well defined geographically.

Table 28 below lists a number of different metrics created for each of these network graphs that can be compared across sites.

Table 28. Network measures

\begin{tabular}{|l|l|l|l|l|l|l|}
\hline & $\begin{array}{l}\text { Buccoo } \\
\text { Reef } \\
\text { Marine } \\
\text { Park }\end{array}$ & $\begin{array}{l}\text { Hol Chan } \\
\text { Marine } \\
\text { Reserve }\end{array}$ & $\begin{array}{l}\text { Laughing } \\
\text { Bird Caye } \\
\text { National } \\
\text { Park }\end{array}$ & $\begin{array}{l}\text { Saba } \\
\text { Marine } \\
\text { Park }\end{array}$ & $\begin{array}{l}\text { St. Eustatius } \\
\text { National } \\
\text { Marine Park }\end{array}$ & $\begin{array}{l}\text { Scotts Head/ } \\
\text { Soufriere } \\
\text { Marine } \\
\text { Reserve }\end{array}$ \\
\hline $\begin{array}{l}\text { Number of } \\
\text { Nodes }\end{array}$ & 329 & 441 & 268 & 135 & 203 & 326 \\
\hline $\begin{array}{l}\text { Network } \\
\text { centralization } \\
\text { (degree } \\
\text { centrality - } \\
\text { symmetric) }\end{array}$ & $11.22 \%$ & $17.00 \%$ & $18.89 \%$ & $28.76 \%$ & $21.94 \%$ & $19.76 \%$ \\
\hline Density & 0.0024 & 0.0018 & 0.0036 & 0.0078 & 0.0052 & 0.0024 \\
\hline Mean degree & 1.54 & 1.56 & 1.95 & 2.04 & 2.11 & 1.57 \\
\hline $\begin{array}{l}\text { Mean } \\
\text { betweenness } \\
\text { centrality }\end{array}$ & 214.6 & 247.6 & 163.3 & 115.3 & 137.6 & 199.9 \\
\hline $\begin{array}{l}\text { Percentage } \\
\text { Isolates }\end{array}$ & $31.6 \%$ & $30.6 \%$ & $23.5 \%$ & $18.5 \%$ & $20.7 \%$ & $28.2 \%$ \\
\hline
\end{tabular}

Table 29. Terms used to describe networks

\begin{tabular}{|l|l|}
\hline Term & Definition \\
\hline Network density & $\begin{array}{l}\text { A measure of how many links exist within a network compared } \\
\text { to the total number of possible links (Wasserman and Faust } \\
1994)\end{array}$ \\
\hline Network centralization & $\begin{array}{l}\text { The extent to which the network is centered around one or a } \\
\text { few highly central nodes }\end{array}$ \\
\hline Mean degree & $\begin{array}{l}\text { Mean number of connections each actor has to others within the } \\
\text { network }\end{array}$ \\
\hline $\begin{array}{l}\text { Mean betweenness } \\
\text { centrality }\end{array}$ & $\begin{array}{l}\text { The degree to which an actor has indirect connections to others } \\
\text { within the network via other nodes }\end{array}$ \\
\hline
\end{tabular}


Network density is a measure of how many links exist within a network compared to the total number of possible links (Wasserman and Faust 1994). With these six networks, the ranking of density corresponded almost exactly to network size. Costenbader and Valente (2003) note that network density is a result of network size, the number of nominations permitted, and the type of questions asked. As they note, all other factors being equal, network size will decrease network density. Bodin and Crona (2009) hypothesize that the greater the network density, the higher the possibility of collective action, as actors have more possibilities to collaborate. There is also the possibility that a very high network density can lead to homogenization, where new innovations are not being brought into the network (Bodin and Crona 2009; see also Rogers 1983). This does not appear to be a problem for the case studies here, as densities are relatively low and there are a high number of isolated individuals excluded from the networks.

Network size amongst the sites varies from 135 (Saba) to 441 (Hol Chan). As the smallest network, Saba has the highest density, and Hol Chan has the lowest. As respondents were somewhat limited in their responses (they were naming only individuals they would speak to about the marine reserve, and not everyone they knew in the community), the network densities of each site are very low, because the number of ties provided by the survey data compared to the total number of possible ties is low. Because actors are not being asked about their ties to everyone in the network, but rather only to specific individuals within the network, it makes logical sense that the smaller networks are denser, because there are fewer possible ties. 
Saba has the highest network density (0.0082) and the smallest population of the sites included in the study (Placencia is actually a smaller community, but the network data for Laughing Bird Caye National Park includes some residents of neighboring Seine Bight and Independence as well). Because the community is so small, residents have a greater likelihood of personally knowing the individuals responsible for management. For the same reason, Saba has the smallest percentage of isolates of any of the networks.

The exception to the finding about network density and network size is the network for the Buccoo Reef Marine Park in Tobago, which has the same density as the network for the SSMR in Dominica, despite being slightly larger. This statistic seems somewhat misleading, however. The number of different individuals and groups named by respondents for the Buccoo Reef Marine Park is much higher than that for the Scotts Head/Soufriere Marine Reserve (54 versus 45), and many of these individuals are affiliated through groups (for example, people named many different employees of Buccoo Reef Trust, one of the groups sitting on the management committee). In other words, respondents for the SSMR were much more consistent in which actors they named. This somewhat artificially inflates the network density for Buccoo.

\section{Network Centralization}

Density may not be the most informative measure for comparing these particular networks, because the size of these networks varies greatly. A potentially more appropriate measure by which to compare these networks is network 
centralization, which, as defined in Table 29, measures the extent to which the network is centered around one or a few highly central nodes. Symmetric centralization, which does not take the direction of the ties into account, is used here, because for this purpose the direction of the ties is without import. A network with 100 percent centralization would be one in which all actors had ties to one central actor (e.g. a star configuration), and a network with zero centralization would be one in which no one actor had more ties to other individuals than any other actor (e.g. a circle graph).

Saba National Marine Park is the smallest network and has the highest centralization, at $28.76 \%$ (Table 28). In part, this is again because it has the fewest actors, so the data set is smaller and fewer individuals are named overall in the network analysis survey, but this is also related to the fact that Saba itself is a small and insular community. Respondents repeatedly named the same individuals as those who they would speak to about the marine reserve, and they named few intermediaries. Almost everyone named someone who either worked for the Saba Conservation Foundation (SCF), responsible for managing the Saba National Marine Park, or someone who serves on the board of the SCF. A large percentage of the individuals surveyed personally know those involved in the marine park simply because of the small size of the island, so they are likely to name those individuals instead of naming intermediaries from whom they would seek information who may or may not be involved in the park. Also, in part because the island is so small, Saba National Marine Park has fewer individuals directly responsible for managing the park than some of the other marine reserves. The staff of the organization is small, and only 
a subset of the staff (four individuals) are involved with the marine park. The Board of Directors for the organization is also relatively small. The island does not have any organized groups of stakeholders with an interest in the marine park, such as a fishermen's cooperative or a tour guide association, and many of the individuals with a direct connection to the marine park or tourism in general, such as hotel owners or dive shop owners, are part of the Board of Directors. Most of those individuals were named as key actors in the marine park. Thus, Saba residents consistently named the same few individuals as those they would speak to about the marine park, making the network highly centralized.

Because of both the high network density and the high network centralization, it can be hypothesized based on the literature that residents in Saba will have the greatest opportunity for collective action, because they have the greatest likelihood of interacting with others in the community about the marine park. Indeed, as will be discussed in Chapter 6, the Saba National Marine Park has the highest rate of participation of all the sites discussed here. This dense network can contribute to greater social capital, which may be a factor leading to greater participation in marine park management.

At the other end of the spectrum, with the least network centralization, is Buccoo Reef Marine Park, with a centralization measure of only $11.22 \%$. Network centralization is not entirely related to size or network density; the centralization for Hol Chan Marine Reserve network, which is a larger network, is $17.00 \%$, greater than that for the Buccoo Reef Marine Park (BRMP) network. There are a few explanations for this. BRMP has a large number of agencies, and consequently, a large number of 
individuals, involved in the co-management of the park, between the Fisheries Department, the Buccoo Reef Trust, and all of the other government agencies who sit on the BRMP Advisory Committee. Many of the respondents surveyed named individuals who are not directly involved in the marine park in any way, such as various reef tour operators, who may or may not have a direct connection to decisionmakers involved with the park. This increases the number of different actors named by respondents within the network, and decreases the centrality.

An additional and related explanation is that the communities in which surveys were conducted for the BRMP are less geographically bounded than some of the other sites, and so respondents are less limited in the actors they are likely to name. Many of the actors named are part of the Tobago government and are thus found in Scarborough, the capital, rather than in any of the communities bordering the marine park. This can be contrasted with Hol Chan, in which all survey participants reside on Ambergris Caye, a geographically bounded community, and almost all of them named someone else on Ambergris Caye, increasing the odds that the actor named would also be named by another respondent.

Finally, the effect of co-management on network centrality should be considered. Unlike the other sites, co-management of the Buccoo Reef Marine Park is relatively new, and the group responsible for co-managing the marine park (the BRMP Advisory Committee) is made up primarily of government agencies, rather than stakeholders from the communities (see Chapter 4). The lack of direct representation on the advisory committee leads to a less centralized network, in which stakeholders do not have a clear idea of who is doing the co-managing and with whom they should 
share their opinions. A lack of participation by community members (Buccoo Reef Marine Park has the lowest rates of participation, as discussed in Chapter 6) will also lead to a low network centralization, as stakeholders do not have the opportunity to interact over the marine park and develop the social capital of which centralization is indicative. Likewise, having low centralization within the social network here could mean fewer opportunities for community members to participate in the MPA, as the mechanisms by which participation is promoted are not in place and fewer residents are likely to be aware of opportunities for participation.

Two networks that are interesting to compare on measures of centrality are that for Laughing Bird Caye National Park, with a centrality of 18.89\%, and Scotts Head/Soufriere Marine Reserve, with a centrality of $19.76 \%$. Although the network for the SSMR is larger, it is somewhat more centralized. These networks both involve multiple communities - two in the case of SSMR, and three primary communities for the Laughing Bird Caye National Park (LBCNP), although one of these was more heavily sampled than the others. In both cases, the communities in question are not entirely isolated, but have highly defined geographical and natural boundaries, unlike the communities in Tobago. In this case, the explanation for why the network for the LBCNP is less centralized than that for SSMR is likely that more individuals are involved in the co-management of LBCNP, and this was reflected in survey responses. The Friends of Nature, responsible for co-managing the park, has a large staff, many of whom are well-known to the community, and a large Board of Directors made up of prominent individuals from all of the surrounding communities. The community of Placencia has an active tourism industry, and many of the individuals employed in the 
tourism industry have attended meetings or otherwise been involved. By contrast, the SSMR is co-managed by the Department of Fisheries and LAMA, but a few key individuals, who also were those most commonly named by respondents, are more or less the only individuals responsible for managing the reserve. LAMA has few active members, and there are few individuals outside of LAMA or the Fisheries Department who have been involved in managing the reserve. There was greater consistency, and thus greater centrality, in the responses of community members for SSMR.

As a means of comparing the networks, and consequently the extent to which stakeholders are connected to each marine reserve, there are two ways of regarding centrality. Within the literature (Hanneman and Riddle 2005), centrality is equated with power. In the Saba Marine Park, for example, as respondents named mostly individuals who are part of staff of the Saba Conservation Foundation (SCF), this instills this group with a lot of power. Respondents, it seems, would speak almost exclusively with them about the marine reserve, as opposed to with other nonemployees or board members. This gives the SCF more control over the flow of information within the network. This may mean that individuals who do not personally know the staff of the SCF do not have the ability to make their opinions known regarding the marine park, and may not receive information regarding the marine park if there are fewer intermediaries within the network.

On the other hand, because the staff of the SCF are actually the people making these decisions, it is perhaps a sign of a more effective system of management when community members can speak directly with those making the decisions, rather than 
having to speak through a group representative or other intermediary, in which case an individual's interests and opinions might be misrepresented or distorted.

The further an individual is removed from those at the top, the less influence s/he has. Additionally, because in this survey respondents frequently did not know who was responsible for managing the marine reserve, in a network like that for the Buccoo Reef Marine Park, the low degree of centralization is in part a measure of uncertainty about who the key actors are, as the individual or group named in many cases has little to do with the marine park. The individual with whom they might share an opinion might be a dead end, with no direct route to the decision-makers. In Saba, by contrast, the high degree of centralization is indirectly a measure of the degree of knowledge of the respondents about the management of the marine park; many of them knew precisely who is responsible for the marine park. Another way of looking at this network, however, is that more individuals are connected to the decision makers for the marine reserve, and thus can make their opinions known to them. Hence, a more centralized network may be more efficient.

\section{Normalized Degree}

Additionally, along with individual measures of centrality provided for the most prominent actors in each of the networks, the normalized degree is provided. The normalized degree measure is standardized to be comparable across all network sizes, so this can be used to compare the relative degree centrality of the key actors in all of these networks. The actor with the highest normalized degree centrality of all the networks is the manager of the Saba National Marine Park (with a normalized degree 
centrality of 29.851), followed by the education director of the Saba National Marine Park (normalized degree centrality of 23.134). This score indicates that if all six networks were of the same size, these two central figures for the Saba National Marine Park would have been named more often than the central figures for any other marine reserve. The Saba Marine Park network is considerably smaller than the networks for any of the other sites, and these two figures are highly central to this network. The St. Eustatius National Marine Park, next in overall network size, has the next two actors with the highest normalized degree centrality measures, the director (normalized degree centrality of 22.772) and a member of the administrative staff (normalized degree centrality of 22.277).

Arguably, this means these actors are the most powerful of all actors cited within this study. There is validity to positing that the directors of the organizations co-managing these two marine parks have the most power. The co-management structures of the Saba National Marine Park and the St. Eustatius National Marine Park are very similar. In each case, the individual directing the co-management organization is part of the board of directors for the organization and also manages the staff of the organization, and thus has considerable authority over the marine park. That these individuals are well-known to their respective communities may also instill them with additional authority over the co-management process.

\section{Average Links Per Node}

Table 30. Average Links Per Node

\begin{tabular}{|l|l|l|l|}
\hline Site & Links & Nodes & $\begin{array}{l}\text { Avg. links } \\
\text { per node }\end{array}$ \\
\hline
\end{tabular}




\begin{tabular}{|l|l|l|r|}
\hline Buccoo Reef Marine Park & 255 & 328 & 0.777 \\
\hline Scotts Head/Soufriere Marine Reserve & 260 & 329 & 0.790 \\
\hline Hol Chan Marine Reserve & 358 & 441 & 0.812 \\
\hline Laughing Bird Caye National Park & 261 & 268 & 0.974 \\
\hline Saba National Marine Park & 138 & 135 & 1.022 \\
\hline St. Eustatius National Marine Park & 215 & 203 & 1.059 \\
\hline
\end{tabular}

As density is a measure dependent partly on network size, another way of comparing networks of different sizes is through using the average links per node (e.g., Bodin and Crona 2008). The number of links within each network is a way of assessing the level of cohesiveness of the community with regards to the marine reserve. The average links per node allows comparison between these networks. The outcome of this measure is different than the measure of centralization, which is a measure of the extent to which the respondents named the same individuals. The lowest average links per node of all the sites is at the Buccoo Reef Marine Park, which also has the highest percentage of isolates, and the lowest centralization. Buccoo Reef Marine Park is followed closely by the Scotts Head/Soufriere Marine Reserve in the average links per node; this site also had a high number of isolates, and a large number of respondents named only one individual involved in the marine reserve. At the other end of the spectrum, the site with the highest average links per node is the St.

Eustatius National Marine Park. This may be indicative of a higher level of social capital within the community, at least with regards to the marine reserve, because community residents on average have more connections to the marine reserve, indicating that community members in St. Eustatius may have greater potential to act cooperatively in managing the marine reserve. 


\section{Networks and Co-Management Revisited}

The social networks and their associated measures presented here represent the ways in which, at the time of the surveys, various stakeholders are connected to the management of the MPA. These network graphs demonstrate how well the comanagement of the site is or is not working by indicating on one level whether those doing the co-managing are representing the community as a whole. At a basic level, stakeholders must know how it is they can voice their opinions to feel as if they have any representation at all, and co-management should be a medium for representing the viewpoints of a variety of stakeholders. Thus the networks representing the most successful co-management arrangements are also likely to be the most centralized, as more stakeholders will be connected to those key actors doing the decision-making. They are also likely to be the densest, having the greatest number of connections between actors to create the social capital necessary for co-management. However, as the Scotts Head/Soufriere Marine Reserve demonstrates, it is not enough for the stakeholders to simply know who is in charge, but must also feel that those individuals in fact represent their interests.

Of the network graphs presented, those for the St. Eustatius National Marine Park and the Laughing Bird Caye National Park probably come closest to an idealized representation of a co-managed MPA and the social network related to it. Each has several core actors in the middle of the graph who are also those responsible for comanaging the MPA, meaning respondents primarily named the co-managers when asked. There are several key actors with high degree centrality, meaning the degree centrality is not strongly weighted toward any one particular individual, and 
stakeholders are fairly well distributed throughout the network, meaning there is a diversity in who they choose to speak to. These factors are likely to contribute to better and more diverse representation of stakeholder interests from a variety of different sectors for these two MPAs. The Laughing Bird Caye National Park has a lower network centralization than some of the other sites; this is partly a reflection of the high percentage of isolates, and partly a reflection of the large number of individuals involved in the co-management of the MPA. The Saba National Marine Park is also representative of a well-functioning co-management structure, but has less diversity in stakeholder representation, as there are a few highly centralized actors responsible for managing the MPA. 


\section{CHAPTER 6. ANALYZING PARTICIPATION IN CO-MANAGEMENT}

\section{Introduction}

This chapter looks more closely at participation in co-management by community members, based on analyses of the data collected. The reasons for and means of participating are many and varied, and depend a great deal on the particular community, the resources involved, and the means by which participation is facilitated or encouraged. Nevertheless, there are doubtless underlying social and demographic factors that are related to participatory activities, and the subsequent analyses are directed at identifying these factors.

As discussed in Chapter 3, in addition to data on participation and to the data collected for the purposes of the network analysis, data were collected from each participant on their occupation, age, gender, years of education, and in most cases, years of residence within the community. These data provide a picture of the residents

of each community where research was conducted, as well as providing an opportunity to investigate how these factors may be important in participation. Data analyzed below also include questions asked of residents about whether they have participated in the MPA in any way, including attending meetings and other activities, and whether they can name any individuals responsible for management, an indicator of their ability to participate.

Descriptive and inferential statistics were both used to analyze and summarize the data collected at each site, and across all sites. Logistic regression was employed 
to look at some of the factors affecting participation. Data were analyzed using SPSS Versions 9.0 and 17.0.

\section{The Data Set}

A total of 1,496 surveys were conducted between the six sites, with the largest number of surveys collected from the community adjacent to the Hol Chan Marine Reserve (384), and the fewest surveys collected from the Saba National Marine Park

Table 31. Number of surveys conducted at each site

\begin{tabular}{|l|l|l|}
\hline Site & N & Percentage \\
\hline Hol Chan Marine Reserve & 384 & $25.67 \%$ \\
\hline $\begin{array}{l}\text { Scotts Head/Soufriere } \\
\text { Marine Reserve }\end{array}$ & 300 & $20.05 \%$ \\
\hline $\begin{array}{l}\text { Laughing Bird Caye } \\
\text { National Park }\end{array}$ & 235 & $15.71 \%$ \\
\hline Buccoo Reef Marine Park & 271 & $18.11 \%$ \\
\hline $\begin{array}{l}\text { Saba National Marine } \\
\text { Park }\end{array}$ & 119 & $7.95 \%$ \\
\hline $\begin{array}{l}\text { St. Eustatius National } \\
\text { Marine Park }\end{array}$ & 187 & $12.50 \%$ \\
\hline Total & $\mathbf{1 , 4 9 6}$ & \\
\hline
\end{tabular}

As Table 32 shows, the samples from each site were fairly similar in terms of factors such as age and years of education, although there is some variation in each of these. Years of residence, although not collected at all sites, is more variable. The mean years of residence for the communities in Dominica adjacent to the SSMR is more than twice the mean years of residence for respondents from the communities associated with the Hol Chan and Laughing Bird Caye MPAs ( $\mathrm{F}=125.680, \mathrm{p}<.001)$.

Table 32. Comparison of respondents from each site

\begin{tabular}{|l|l|l|l|l|l|}
\hline Variable & Site & N & Mean & Maximum & Minimum \\
\hline Years Residence & Hol Chan & 375 & 15.32 & 79 & 0 \\
\hline
\end{tabular}




\begin{tabular}{|l|l|l|l|l|l|}
\hline \multirow{5}{*}{} & SSMR & 251 & 33.56 & 83 & 0 \\
\cline { 2 - 6 } & LBC & 232 & 15.01 & 68 & 0 \\
\cline { 2 - 6 } & Buccoo Reef & 246 & 22.12 & 74 & 0 \\
\cline { 2 - 6 } & & & & & \\
\hline Years Education & Hol Chan & 368 & 11.75 & 34 & 0 \\
\hline \multirow{5}{*}{ Age } & SSMR & 233 & 11.46 & 31 & 0 \\
\hline & LBC & 227 & 12.07 & 27 & 0 \\
\cline { 2 - 6 } & Saba & 114 & 12.26 & 29 & 5 \\
\cline { 2 - 6 } & St. Eustatius & 178 & 13.13 & 40 & 5 \\
\cline { 2 - 6 } & Buccoo Reef & 234 & 12.05 & 36 & 3 \\
\cline { 2 - 6 } & & & & & 18 \\
\hline \multirow{5}{*}{} & Hol Chan & 380 & 33.24 & 73 & 18 \\
\hline & SSMR & 284 & 38.60 & 83 & 18 \\
\cline { 2 - 6 } & LBC & 231 & 33.42 & 73 & 18 \\
\cline { 2 - 6 } & Saba & 115 & 42.62 & 85 & 18 \\
\cline { 2 - 6 } & St. Eustatius & 181 & 41.64 & 96 & 18 \\
\cline { 2 - 6 } & Buccoo Reef & 263 & 39.35 & 80 & 18 \\
\hline
\end{tabular}

Table 33. Respondents by Gender

\begin{tabular}{|l|l|l|l|l|l|}
\hline Gender & Site & Male & Pct & Female & Pct \\
\hline \multirow{7}{*}{ Hol Chan } & 253 & $66.1 \%$ & 130 & $33.9 \%$ \\
\cline { 2 - 6 } & SSMR & 187 & $62.3 \%$ & 113 & $36.7 \%$ \\
\cline { 2 - 6 } & LBC & 153 & $65.1 \%$ & 82 & $34.9 \%$ \\
\cline { 2 - 6 } & Saba & 50 & $52.1 \%$ & 46 & $47.9 \%$ \\
\cline { 2 - 6 } & St. Eustatius & 91 & $52.9 \%$ & 81 & $47.1 \%$ \\
\cline { 2 - 6 } & Buccoo Reef & 173 & $63.8 \%$ & 98 & $36.2 \%$ \\
\hline Total & & 907 & $62.3 \%$ & 550 & $37.7 \%$ \\
\hline
\end{tabular}

Table 33 gives a breakdown of the sample by gender. While efforts to include

female respondents were made at all sites, the portion of males is higher at every site, with males making up $62.3 \%$ of the total sample.

Table 34 provides a breakdown of respondents by occupation. Occupation was broken down into eleven categories. Each occupation category has at least 100 responses, with the exception of student and self-employed, for which there were few responses, and fisherman, with 92 . The percentages within each category vary greatly from site to site, particularly fishing, which makes up a large percentage of responses in the SSMR and a much smaller number at other sites, and tour guides, which are more heavily represented in the Hol Chan Marine Reserve and the Laughing Bird 
Caye National Park. The most common occupation type in the survey was retail/sales, followed by trades (construction) and by tourism-related businesses. 
Table 34. Summary of respondents by occupation

\begin{tabular}{|c|c|c|c|c|c|c|c|c|c|c|c|}
\hline & \multicolumn{11}{|c|}{ OCCUPATION } \\
\hline MPA & Fisherman & $\begin{array}{l}\text { Tour } \\
\text { guide }\end{array}$ & Tourism & Retail & Trades & $\begin{array}{l}\text { Public } \\
\text { sector }\end{array}$ & $\begin{array}{l}\text { Professio } \\
\text { nal }\end{array}$ & Student & $\begin{array}{l}\text { Self } \\
\text { employed }\end{array}$ & None & Other \\
\hline \multirow[t]{2}{*}{ SSMR } & 50 & 17 & 15 & 15 & 47 & 19 & 26 & 6 & 7 & 64 & 33 \\
\hline & $16.7 \%$ & $5.7 \%$ & $5.0 \%$ & $5.0 \%$ & $15.7 \%$ & $6.3 \%$ & $8.7 \%$ & $2.0 \%$ & $2.3 \%$ & $21.3 \%$ & $11.0 \%$ \\
\hline St. Eustatius & 3 & 2 & 10 & 12 & 32 & 33 & 39 & 9 & 2 & 19 & 26 \\
\hline Marine Park & $1.6 \%$ & $1.1 \%$ & $5.3 \%$ & $6.4 \%$ & $17.1 \%$ & $17.6 \%$ & $20.9 \%$ & $4.8 \%$ & $1.1 \%$ & $10.2 \%$ & $13.9 \%$ \\
\hline Hol Chan & 7 & 55 & 75 & 93 & 46 & 10 & 50 & 1 & 2 & 15 & 28 \\
\hline Mar. Reserve & $1.8 \%$ & $14.3 \%$ & $19.5 \%$ & $24.2 \%$ & $12.0 \%$ & $2.6 \%$ & $13.0 \%$ & $0.3 \%$ & $50.0 \%$ & $3.9 \%$ & $7.3 \%$ \\
\hline LBC National & 9 & 26 & 57 & 34 & 30 & 9 & 16 & 6 & 0 & 11 & 24 \\
\hline Park & $4.1 \%$ & $11.7 \%$ & $25.7 \%$ & $15.3 \%$ & $13.5 \%$ & $4.1 \%$ & $7.2 \%$ & $2.7 \%$ & $0.0 \%$ & $5.0 \%$ & $10.8 \%$ \\
\hline Buccoo Reef & 21 & 27 & 38 & 52 & 43 & 19 & 20 & 1 & 3 & 26 & 19 \\
\hline Marine Park & $7.7 \%$ & $9.9 \%$ & $14.0 \%$ & $19.1 \%$ & $15.8 \%$ & $7.0 \%$ & $7.4 \%$ & $0.4 \%$ & $1.1 \%$ & $9.6 \%$ & $7.0 \%$ \\
\hline Saba Marine & 2 & 4 & 12 & 17 & 15 & 24 & 9 & 3 & 1 & 22 & 10 \\
\hline Park & $1.7 \%$ & $3.4 \%$ & $10.1 \%$ & $14.3 \%$ & $12.6 \%$ & $20.2 \%$ & $7.6 \%$ & $2.5 \%$ & $0.8 \%$ & $18.5 \%$ & $8.4 \%$ \\
\hline \multirow[t]{2}{*}{ Total } & 92 & 131 & 207 & 223 & 213 & 114 & 160 & 26 & 15 & 157 & 140 \\
\hline & $6.2 \%$ & $8.9 \%$ & $14.0 \%$ & $15.1 \%$ & $14.4 \%$ & $7.7 \%$ & $10.8 \%$ & $1.8 \%$ & $1.0 \%$ & $\begin{array}{c}10.6 \\
\%\end{array}$ & $9.5 \%$ \\
\hline
\end{tabular}


The responses to participation related questions were converted to dichotomous variables for analytical purposes. Responses were coded as presented below:

Table 35. Coding of participation questions

\begin{tabular}{|c|c|c|}
\hline Question & $\begin{array}{l}\text { Number of } \\
\text { valid } \\
\text { responses }\end{array}$ & Coding \\
\hline $\begin{array}{l}\text { Have you ever heard of }\{\text { name }\} \\
\text { MPA? }\end{array}$ & 1190 & Yes (1); No (0) \\
\hline $\begin{array}{l}\text { Have you ever attended a } \\
\text { meeting about the MPA or } \\
\text { otherwise been involved? }\end{array}$ & 1394 & Yes (1); No (0) \\
\hline $\begin{array}{l}\text { Who do you know who is } \\
\text { responsible for managing the } \\
\text { MPA? } \\
\text { Re-coded to determine whether } \\
\text { the individuals named are } \\
\text { actually involved in managing } \\
\text { the MPA (Know Correct) }\end{array}$ & 1381 & $\begin{array}{l}\text { No (0): no one was named; person/group } \\
\text { named is not involved in MPA; can't name } \\
\text { a specific person or group (e.g. } \\
\text { government) } \\
\text { Yes (1): person/group named is involved } \\
\text { in managing MPA; some of the people } \\
\text { named are involved in management; } \\
\text { person named used to be involved in } \\
\text { management }\end{array}$ \\
\hline $\begin{array}{l}\text { Do you believe those responsible } \\
\text { for managing the MPA represent } \\
\text { your interests? (Interests } \\
\text { Represented) }\end{array}$ & 845 & $\begin{array}{l}\text { No (0): No; don't know } \\
\text { Yes (1): Yes; sometimes; they should }\end{array}$ \\
\hline
\end{tabular}

\section{Comparison of Responses by Occupation}

Occupation was selected as a potentially important factor in analyzing participation, as individuals employed in certain occupations are more likely to rely on the MPA for their livelihood, and may therefore be more important stakeholders to consider in co-management. The occupations provided by respondents were divided into one of eleven categories. Fisherman and tour guide were identified during fieldwork as the two occupation types potentially most affected by the MPA. Individuals working in tourism-related industries, including hotels, restaurants, car or 
bike rentals, etc. were also considered to be potentially important stakeholders, as their businesses may benefit from the presence of the MPA. These three occupation groups were determined to have the greatest interests in the MPAs, and are all identified as important stakeholders at each of the MPAs included in the study. All of the MPAs in the study have both a tourism industry and a fishing industry based within or nearby the MPA, although the relative importance of these two industries varies considerably by site (Table 4). Fishing and tourism interests are frequently at odds in many of the MPAs, and in situations where the MPA was created in order to promote tourism activities, fishermen have often been disenfranchised in the process.

The responses to certain questions by individuals employed in each of these occupation groups were compared to responses by the rest of respondents across the data set, using Chi-square analysis. Table 36 presents responses to three survey questions (Have you ever attended a meeting about the MPA?; Do you know anyone involved in management?; Do you believe your interests are represented by those involved in management?), cross-tabulated with occupation.

Table 36. Analysis of survey responses by occupation (Chi-squared analysis)

\begin{tabular}{|c|c|c|c|c|}
\hline Occupation & & $\begin{array}{l}\text { Participated } \\
\text { (attended } \\
\text { meeting) }\end{array}$ & $\begin{array}{l}\text { Can identify } \\
\text { someone involved } \\
\text { in management }\end{array}$ & $\begin{array}{l}\text { Believes interests } \\
\text { are represented } \\
\text { by management }\end{array}$ \\
\hline \multirow[t]{3}{*}{ Fisherman } & Fishermen & $38.4 \%$ & $72.1 \%$ & $57.5 \%$ \\
\hline & Others & $17.4 \%$ & $57.2 \%$ & $72.8 \%$ \\
\hline & & $\begin{array}{l}\chi^{2}=23.272 \\
\mathrm{df}=1, \mathrm{p}<0.001\end{array}$ & $\begin{array}{l}\chi^{2}=7.387, \mathrm{df}=1, \\
\mathrm{p}<0.01\end{array}$ & $\begin{array}{l}\chi^{2}=8.523, \mathrm{df}=1, \\
\mathrm{p}<0.01\end{array}$ \\
\hline \multirow[t]{3}{*}{ Tour Guide } & Tour Guide & $51.9 \%$ & $73.6 \%$ & $64.5 \%$ \\
\hline & Other & $15.3 \%$ & $49.0 \%$ & $43.3 \%$ \\
\hline & & $\begin{array}{l}\chi^{2}=103.184, \\
\mathrm{df}=1, \mathrm{p}<0.001\end{array}$ & $\begin{array}{l}\chi^{2}=28.329, \mathrm{df}=1, \\
\mathrm{p}<0.001\end{array}$ & $\begin{array}{l}\chi^{2}=19.283, \mathrm{df}=1, \\
\mathrm{p}<0.001\end{array}$ \\
\hline \multirow[t]{3}{*}{ Tourism } & Tourism & $26.7 \%$ & $55.5 \%$ & $66.7 \%$ \\
\hline & Other & $15.7 \%$ & $50.1 \%$ & $50.2 \%$ \\
\hline & & $\begin{array}{l}\chi^{2}=27.159, \\
\mathrm{df}=1, \mathrm{p}<0.001\end{array}$ & $\begin{array}{l}\chi^{2}=2.843, \mathrm{df}=1, \\
\mathrm{p}<0.1\end{array}$ & $\begin{array}{l}\chi^{2}=22.772, \mathrm{df}=1, \\
\mathrm{p}<0.001\end{array}$ \\
\hline
\end{tabular}


Results indicate that members of each of the three groups were statistically more likely to have attended a meeting. Tour guides and fishermen were more likely to be able to correctly identify someone in management than the rest of the group of respondents as a whole. In some cases these differences were drastic; for example, $51.9 \%$ of tour guides and $38.4 \%$ of fishermen had attended meetings as opposed to $15.3 \%$ and $17.4 \%$ respectively of the rest of the populations surveyed. Tour guides and others employed in tourism were significantly much more likely to believe their interests were being represented by those responsible for managing the MPA than the rest of the survey population. Fishermen, however, were statistically more likely to say their interests were not being represented; $42.5 \%$ of fishermen believed their interests were not being represented by management, as opposed to $27.2 \%$ of the rest of the population.

Table 37. Interests represented by occupation

\begin{tabular}{|l|c|c|c|}
\hline \multicolumn{1}{|c|}{ Occupation } & $\begin{array}{c}\text { Interests represented? } \\
\text { Yes }\end{array}$ & $\begin{array}{c}\text { Interests represented? } \\
\text { No }\end{array}$ & Not sure \\
\hline Fisherman & $41.3 \%$ & $42.5 \%$ & $16.2 \%$ \\
\hline Tour Guide & $64.5 \%$ & $17.4 \%$ & $18.2 \%$ \\
\hline $\begin{array}{l}\text { Construction/Manual } \\
\text { Labor }\end{array}$ & $39.0 \%$ & $35.6 \%$ & $25.3 \%$ \\
\hline Tourism & $49.8 \%$ & $25.0 \%$ & $16.8 \%$ \\
\hline All Occupations & $45.7 \%$ & $28.4 \%$ & $25.9 \%$ \\
\hline
\end{tabular}

Table 37 presents some of the same data as Table 36; here, percentages of responses for the question "Do you feel your interests are represented by those responsible for management" are broken down further by occupation, including the percentages of respondents who said they did not believe their interests were being represented, and percentages of respondents who were not sure. While the total percentage of individuals surveyed from all occupation categories who answered they 
were not sure whether their interests were represented is greater than $25 \%$, the percentage of 'not sure' responses for fishermen, tour guides, and individuals employed in tourism was much lower $\left(\chi^{2}=14.358, \mathrm{df}=1, \mathrm{p}<.001\right)$. Although, as stated above, fishermen were more likely to say their interests were not being represented, all three stakeholder groups were clearly more likely to have definitive opinions on whether their opinions were represented. This likely relates back to the fact that all three of these stakeholder groups were more likely to be able to name someone involved in management, and to have participated in a meeting.

One interesting outcome of breaking down the responses to this question by occupation is that individuals employed in construction or manual labor were the least likely to say their interests were being represented. Those individuals working in construction or other trades are not likely to be considered important stakeholders in the marine protected area, and as such do not generally have direct representation on any of the boards of directors of the various management organizations. Still, these individuals are residents of the communities where the surveys were conducted and should also be considered stakeholders in the marine protected areas.

Table 38. Participation data by socioeconomic variables.

\begin{tabular}{|l|l|l|l|l|l|}
\hline $\begin{array}{l}\text { Socioeconomic } \\
\text { variables }\end{array}$ & $\begin{array}{l}\text { Heard of } \\
\text { MPA }^{6}\end{array}$ & $\begin{array}{l}\text { Been to } \\
\text { meeting }\end{array}$ & $\begin{array}{l}\text { Can name } \\
\text { someone } \\
\text { involved in } \\
\text { MPA }\end{array}$ & $\begin{array}{l}\text { Interests are } \\
\text { represented }\end{array}$ \\
\hline $\begin{array}{l}\text { Gender }(\text { Chi- } \\
\text { squared) }\end{array}$ & Male & $87.4 \%$ & $23.3 \%$ & $52.3 \%$ & $70.5 \%$ \\
\cline { 2 - 6 } & Female & $80.3 \%$ & $11.9 \%$ & $51.3 \%$ & $74.5 \%$ \\
\cline { 2 - 6 } & & $\begin{array}{l}\chi^{2}=\mathbf{1 0 . 7 0 4}, \\
\mathbf{d f}=\mathbf{1}, \\
\mathbf{p}<\mathbf{0 . 0 1}\end{array}$ & $\begin{array}{l}\boldsymbol{\chi}^{2}=\mathbf{2 6 . 5 2 4}, \\
\mathbf{d f}=\mathbf{1}, \\
\mathbf{p}<\mathbf{0 . 0 0 1}\end{array}$ & $\begin{array}{l}\chi^{2}=.218, \\
\mathrm{df}=1, \mathrm{p}=.641\end{array}$ & $\begin{array}{l}\chi^{2}=1.451, \\
\mathrm{df}=1, \\
\mathrm{p}=.228\end{array}$ \\
\hline \multirow{2}{*}{ Age (t-test) } & Mean NO & 36.2 & 37.0 & 36.7 & 38.0 \\
\cline { 2 - 6 } & Mean YES & 35.9 & 39.6 & 38.3 & 34.5 \\
\hline
\end{tabular}

\footnotetext{
${ }^{6}$ This question excludes responses from Saba Marine Park and St. Eustatius National Marine Park

${ }^{7}$ This question excludes responses from Saba Marine Park and St. Eustatius National Marine Park
} 


\begin{tabular}{|c|c|c|c|c|c|}
\hline & & $\begin{array}{l}t=.272 \\
d f=1156 \\
p=.786\end{array}$ & $\begin{array}{l}t=-2.675 \\
d f=1352, \\
p<.01\end{array}$ & $\begin{array}{l}t=-2.017, \\
d f=1342, \\
p<.05\end{array}$ & $\begin{array}{l}t=3.549 \\
d f=828, \\
p<.001\end{array}$ \\
\hline \multirow{3}{*}{$\begin{array}{l}\text { Years of } \\
\text { Education } \\
(t \text {-test })\end{array}$} & Mean NO & 10.3 & 12.1 & 11.8 & 11.4 \\
\hline & Mean YES & 12.0 & 12.6 & 12.5 & 12.1 \\
\hline & & $\begin{array}{l}t=-5.271, \\
d f=1060, \\
p<.001\end{array}$ & $\begin{array}{l}t=-1.557 \\
d f=1272 \\
p=.120\end{array}$ & $\begin{array}{l}t=-3.034, \\
d f=1262, \\
p<.005\end{array}$ & $\begin{array}{l}t=-2.544, \\
d f=766, \\
p<.05\end{array}$ \\
\hline \multirow{3}{*}{$\begin{array}{l}\text { Years of } \\
\text { Residence (t- } \\
\text { test })^{8}\end{array}$} & Mean NO & 19.0 & 20.6 & 17.5 & 25.9 \\
\hline & Mean YES & 21.2 & 24.0 & 25.2 & 20.6 \\
\hline & & $\begin{array}{l}\mathrm{t}=-1.445 \\
\mathrm{df}=1102 \\
\mathrm{p}=.149\end{array}$ & $\begin{array}{l}t=-2.440, \\
d f=1015 \\
p<.01\end{array}$ & $\begin{array}{l}t=-7.314, \\
d f=1007 \\
p<.001\end{array}$ & $\begin{array}{l}t=4.128, \\
d f=791, \\
p<.001\end{array}$ \\
\hline
\end{tabular}

Table 8 shows the responses to the three questions listed above, as well as "Have you ever heard of the MPA?", compared according to gender, age, years of education, and years of residence. There was a significant difference between men and women as to whether the respondents had ever heard of the MPA or attended a meeting, with men more likely to have done both $(\mathrm{p}<.01 ; \mathrm{p}<.001$, respectively). Gender was not a significant factor in whether the respondents could name someone involved in the MPA, or in whether they felt their interests were represented by those responsible for management. The mean age of respondents was significantly different in both whether the respondent had attended a meeting and whether they were able to correctly name someone involved in the MPA (older respondents were more likely to do both). This is to be somewhat expected, as older respondents are also likely to have lived in the community longer, and as all of the MPAs included in the study have been in place for a number of years, older respondents would be more likely to have attended earlier meetings. Interestingly, however, younger residents were more likely to feel their interests are being represented by those responsible for managing the MPA.

\footnotetext{
${ }^{8}$ This question excludes responses from Saba Marine Park and St. Eustatius National Marine Park
} 
Also tested here was whether years of education was significantly different for any of these responses. Respondents who had heard of the MPA had more years of education on average than those respondents who had not. Respondents who could name someone involved in the MPA, as well as those who said they believed their interests were being represented, also had more years of education.

Average years of residence in the community was higher both for those who had attended a meeting and those who were able to name someone involved in the MPA. There was no significant difference in mean years of residence for those who had heard of the MPA compared with those who had not heard of the MPA. Another interesting result was that those who felt their interests were represented by those responsible for management had on average lived in the community fewer years than those who responded no to this question.

\section{Comparisons by site}

As all of the sites are very different, it is important to look more closely at statistics within each. Here the same types of analyses provided earlier for the full data set are provided for each individual MPA. This will assist in understanding which of the sites contribute most strongly to the earlier outcomes for the full data set, and to determine which of the sites contrast with findings presented earlier.

Table 39. Hol Chan Marine Reserve

\begin{tabular}{|l|l|l|l|l|}
\hline Occupation & & $\begin{array}{l}\text { Participated } \\
\text { (attended meeting) }\end{array}$ & $\begin{array}{l}\text { Can identify } \\
\text { someone involved } \\
\text { in management }\end{array}$ & $\begin{array}{l}\text { Believes interests } \\
\text { are represented by } \\
\text { management }\end{array}$ \\
\hline \multirow{3}{*}{ Tour Guide } & Tour Guide & $50.0 \%$ & $69.2 \%$ & $88.2 \%$ \\
\cline { 2 - 5 } & Other & $12.2 \%$ & $34.4 \%$ & $87.4 \%$ \\
\cline { 2 - 5 } & & $\chi^{2}=\mathbf{4 4 . 4 8 2 , ~ d f}=\mathbf{1}$, & $\chi^{2}=\mathbf{2 2 . 1 2 7}, \mathbf{d f}=\mathbf{1}$, & $\chi^{2}=.024, \mathrm{df}=1$, \\
\hline
\end{tabular}




\begin{tabular}{|c|c|c|c|c|}
\hline & & $\mathrm{p}<0.001$ & $\mathrm{p}<0.001$ & $\mathrm{p}=.877$ \\
\hline \multirow[t]{3}{*}{ Tourism } & Tourism & $27.4 \%$ & $27.9 \%$ & $92.7 \%$ \\
\hline & Other & $12.9 \%$ & $42.3 \%$ & $86.3 \%$ \\
\hline & & $\begin{array}{l}\chi^{2}=11.635, \mathrm{df}=1, \\
p<0.005\end{array}$ & $\begin{array}{l}\chi^{2}=4.886, \mathrm{df}=1, \\
p<0.05\end{array}$ & $\begin{array}{l}\chi^{2}=1.660, \mathrm{df}=1, \\
\mathrm{p}=.198\end{array}$ \\
\hline \multirow{3}{*}{$\begin{array}{l}\text { Years of } \\
\text { Residence }\end{array}$} & Mean YES & 20.02 & 21.13 & 16.59 \\
\hline & Mean NO & 15.34 & 12.67 & 21.10 \\
\hline & & $\begin{array}{l}t=-2.293, d f=347, \\
p<.05\end{array}$ & $\begin{array}{l}t=-5.502, \mathrm{df}=341, \\
p<.001\end{array}$ & $\begin{array}{l}t=1.666, d f=275 \\
p=.097^{\wedge}\end{array}$ \\
\hline
\end{tabular}

$\wedge^{\wedge}$ not normally distributed

Data for the Hol Chan Marine Reserve show that both those respondents who work as tour guides and other respondents who work in tourism were more likely to have attended a meeting than the rest of the respondents in the data set. This is consistent with the analysis of the data set as a whole, where the same occupation groups were found to be more likely to have attended meetings. Similarly, individuals from these two groups were more likely to be able to correctly name someone involved in the management of the MPA. However, whereas these stakeholder groups were also more likely to say their interests were represented when the complete data set was analyzed, there was no statistical difference in response for the Hol Chan Marine Reserve to this question. This is a reflection of the fact that the vast majority of all individuals said they believed their interests were represented by those involved in management, and thus there was no significant difference between groups.

Mean years of residence was also tested for the Hol Chan Marine Reserve. There was a significant difference in mean years of residence within the community for individuals who had participated in meetings; those who had attended meetings have lived in the community an average of 4.7 years longer than those who have not. Likewise, as could be expected, those who were able to correctly name someone involved in the MPA have lived in the community an average of 8.5 years longer than 
those who could not. Years of residence was not statistically significant in whether individuals felt their interests were represented.

Table 40. St. Eustatius National Marine Park

\begin{tabular}{|l|l|l|l|}
\hline Occupation & & $\begin{array}{l}\text { Participated } \\
\text { (attended meeting) }\end{array}$ & $\begin{array}{l}\text { Can identify someone } \\
\text { involved in } \\
\text { management }\end{array}$ \\
\hline \multirow{3}{*}{ Tourism } & Tourism & $16.7 \%$ & $60.0 \%$ \\
\cline { 2 - 4 } & Other & $15.4 \%$ & $60.8 \%$ \\
\cline { 2 - 4 } & & $\begin{array}{l}\chi^{2}=.013, \mathrm{df}=1, \\
\mathrm{p}=.909\end{array}$ & $\chi^{2}=.003, \mathrm{df}=1, \mathrm{p}=.960$ \\
\hline
\end{tabular}

For the St. Eustatius National Marine Park data, only individuals working in tourism were singled out for analysis, as there were few tour guides or fishermen in the data set $(<10)$. There was no significant difference for St. Eustatius between those working and tourism and the rest of the survey respondents.

Table 41. Scotts Head/Soufriere Marine Reserve

\begin{tabular}{|c|c|c|c|c|}
\hline Occupation & & $\begin{array}{l}\text { Participated } \\
\text { (attended } \\
\text { meeting) }\end{array}$ & $\begin{array}{l}\text { Can identify } \\
\text { someone involved } \\
\text { in management }\end{array}$ & $\begin{array}{l}\text { Believes interests } \\
\text { are represented } \\
\text { by management }\end{array}$ \\
\hline \multirow[t]{3}{*}{ Fisherman } & Fisherman & $42.2 \%$ & $77.8 \%$ & $50.0 \%$ \\
\hline & Other & $9.1 \%$ & $78.9 \%$ & $52.0 \%$ \\
\hline & & $\begin{array}{l}\chi^{2}=31.947, \mathrm{df}=1, \\
p<0.001\end{array}$ & $\begin{array}{l}\chi^{2}=.030, \mathrm{df}=1, \\
\mathrm{p}=.862\end{array}$ & $\begin{array}{l}\chi^{2}=.052, \mathrm{df}=1, \\
\mathrm{p}=.819\end{array}$ \\
\hline \multirow[t]{3}{*}{ Tour Guide } & Tour Guide & $47.1 \%$ & $100.0 \%$ & $73.3 \%$ \\
\hline & Other & $14.3 \%$ & $35.6 \%$ & $50.0 \%$ \\
\hline & & $\begin{array}{l}\chi^{2}=12.361, \mathrm{df}=1, \\
p<0.001\end{array}$ & $\begin{array}{l}\chi^{2}=5.908, \mathrm{df}=1, \\
\mathrm{p}<0.05\end{array}$ & $\begin{array}{l}\chi^{2}=3.042, \mathrm{df}=1, \\
\mathrm{p}=.081\end{array}$ \\
\hline \multirow[t]{3}{*}{ Tourism } & Tourism & $28.8 \%$ & $78.6 \%$ & $48.0 \%$ \\
\hline & Other & $13.3 \%$ & $73.9 \%$ & $42.7 \%$ \\
\hline & & $\begin{array}{l}\chi^{2}=4.582, \mathrm{df}=1, \\
\mathrm{p}<0.05\end{array}$ & $\begin{array}{l}\chi^{2}=.286, \mathrm{df}=1, \\
\mathrm{p}=.593\end{array}$ & $\begin{array}{l}\chi^{2}=.254, \mathrm{df}=1, \\
\mathrm{p}=.614\end{array}$ \\
\hline \multirow{3}{*}{$\begin{array}{l}\text { Years of } \\
\text { Residence }\end{array}$} & Mean YES & 33.57 & 32.50 & 31.93 \\
\hline & Mean NO & 33.01 & 34.88 & 32.29 \\
\hline & & $\begin{array}{l}\mathrm{t}=-.194, \mathrm{df}=224, \\
\mathrm{p}=.847\end{array}$ & $\begin{array}{l}t=.970, d f=224, \\
p=.333\end{array}$ & $\begin{array}{l}t=.170, d f=185, \\
p=.865\end{array}$ \\
\hline
\end{tabular}

Fishermen, tour guides, and those working in tourism industries in Dominica were all more likely than other respondents to have attended meetings. However, 
unlike in the analysis of the complete data set, there was no difference between these groups and the respondents for the SSMR as a whole as to whether or not they believe their interests are represented by management. There was also no difference in whether fishermen or those working in tourism were able to identify someone involved in the management of the MPA; all of the tour guides surveyed could name someone involved in management. Years of residence was not significantly related to any of the questions above.

Table 42. Saba National Marine Park

\begin{tabular}{|l|l|l|l|}
\hline Occupation & & $\begin{array}{l}\text { Participated } \\
\text { (attended meeting) }\end{array}$ & $\begin{array}{l}\text { Can identify someone } \\
\text { involved in } \\
\text { management }\end{array}$ \\
\hline \multirow{3}{*}{ Tourism } & Tourism & $45.4 \%$ & $83.3 \%$ \\
\cline { 2 - 4 } & Other & $25.2 \%$ & $68.2 \%$ \\
\cline { 2 - 4 } & & $\begin{array}{l}\chi^{2}=2.064, \mathrm{df}=1, \\
\mathrm{p}=.151\end{array}$ & $\chi^{2}=1.167, \mathrm{df}=1, \mathrm{p}=.280$ \\
\hline
\end{tabular}

For the Saba National Marine Park, only those individuals working in tourism were compared with the other respondents, and there was no significant difference in whether they had attended meetings or were able to identify someone involved in management.

Table 43. Laughing Bird Caye National Park

\begin{tabular}{|c|c|c|c|c|}
\hline Occupation & & $\begin{array}{l}\text { Participated } \\
\text { (attended } \\
\text { meeting) } \\
\end{array}$ & $\begin{array}{l}\text { Believes interests } \\
\text { are represented } \\
\text { by management }\end{array}$ & $\begin{array}{l}\text { Can identify } \\
\text { someone involved } \\
\text { in management }\end{array}$ \\
\hline \multirow[t]{3}{*}{ Fisherman } & Fisherman & $66.7 \%$ & $88.9 \%$ & $88.9 \%$ \\
\hline & Other & $25.1 \%$ & $87.5 \%$ & $54.0 \%$ \\
\hline & & $\begin{array}{l}\chi^{2}=7.566, \mathrm{df}=1, \\
\mathrm{p}<.01 \\
\text { Fishers Exact } \\
\text { sig<.05 }\end{array}$ & $\begin{array}{l}\chi^{2}=.015, \mathrm{df}=1 \\
\mathrm{p}=.902\end{array}$ & $\begin{array}{l}\chi^{2}=4.255, \mathrm{df}=1, \\
p<.05 \\
\text { Fishers Exact } \\
\text { sig<.05 }\end{array}$ \\
\hline \multirow[t]{3}{*}{ Tour Guide } & Tour Guide & $61.5 \%$ & $87.0 \%$ & $92.3 \%$ \\
\hline & Other & $22.0 \%$ & $87.7 \%$ & $50.0 \%$ \\
\hline & & $\begin{array}{l}\chi^{2}=18.101, \mathrm{df}=1, \\
p<0.001 \\
\text { Fishers Exact } \\
\mathrm{p}<.001\end{array}$ & $\chi^{2}=.010, p=.921$ & $\begin{array}{l}\chi^{2}=16.307, \mathrm{df}=1, \\
p<0.001 \\
\text { Fishers Exact } \\
p<.001\end{array}$ \\
\hline
\end{tabular}




\begin{tabular}{|c|c|c|c|c|}
\hline \multirow[t]{3}{*}{ Tourism } & Tourism & $13.2 \%$ & $77.5 \%$ & $51.9 \%$ \\
\hline & Other & $31.4 \%$ & $91.2 \%$ & $56.6 \%$ \\
\hline & & $\begin{array}{l}\chi^{2}=6.727, \mathrm{df}=1, \\
\text { p<.01 } \\
\text { Fishers Exact } \\
\text { p<.05 }\end{array}$ & $\begin{array}{l}\chi^{2}=5.061, \mathrm{df}=1, \\
p<.05 \\
\text { Fishers Exact } \\
p<.05\end{array}$ & $\begin{array}{l}\chi^{2}=.348, \mathrm{df}=1, \\
\mathrm{p}=.556\end{array}$ \\
\hline \multirow{3}{*}{$\begin{array}{l}\text { Years of } \\
\text { Residence }\end{array}$} & Mean YES & 22.41 & 18.69 & 19.81 \\
\hline & Mean NO & 13.84 & 18.89 & 15.36 \\
\hline & & $\mathrm{t}=-3.662, \mathrm{p}<.001$ & $\mathrm{t}=-1.157, \mathrm{p}=.249$ & $t=-4.003, p<.001$ \\
\hline
\end{tabular}

A comparison of data for the Laughing Bird Caye National Park found that fishermen and tour guides were more likely to have attended meetings and more likely to be able to name someone involved in managing the MPA. Interestingly, those working in tourism were significantly less likely to have attended a meeting or to believe their interests were being represented by those in management than other respondents from these communities. They were also less likely to be able to name someone involved in managing the MPA than other respondents, although this difference was not statistically significant. In this area in particular, many of the individuals working in tourism had come from other parts of Belize or other countries in Central America, which may explain these differences. Years of residence was found to be significant; individuals who had attended meetings and could identify someone involved in management had a statistically higher average years of residence within the community than those who answered no to these questions.

Table 44. Buccoo Reef Marine Park

\begin{tabular}{|l|l|l|l|l|}
\hline Occupation & & $\begin{array}{l}\text { Participated } \\
\text { (attended } \\
\text { meeting) }\end{array}$ & $\begin{array}{l}\text { Believes interests } \\
\text { are represented } \\
\text { by management }\end{array}$ & $\begin{array}{l}\text { Can identify } \\
\text { someone involved } \\
\text { in management }\end{array}$ \\
\hline \multirow{3}{*}{ Fisherman } & Fisherman & $15.0 \%$ & $25.0 \%$ & $50.0 \%$ \\
\cline { 2 - 5 } & Other & $13.1 \%$ & $62.1 \%$ & $29.0 \%$ \\
\cline { 2 - 5 } & & $\begin{array}{l}\chi^{2}=.056, \mathrm{df}=1, \\
\mathrm{p}=.814\end{array}$ & $\begin{array}{l}\chi^{2}=\mathbf{8 . 3 7 5}, \mathbf{d f}=\mathbf{1}, \\
\mathbf{p}<.005, \text { Fishers } \\
\text { Exact } \mathbf{p}<.01\end{array}$ & $\begin{array}{l}\chi^{2}=3.815, \mathrm{df}=1, \\
\mathrm{p}=.051\end{array}$ \\
\hline
\end{tabular}




\begin{tabular}{|l|l|l|l|l|}
\hline \multirow{5}{*}{ Tour Guide } & Tour Guide & $50.0 \%$ & $60.0 \%$ & $53.8 \%$ \\
\cline { 2 - 5 } & Other & $9.1 \%$ & $58.9 \%$ & $28.0 \%$ \\
\cline { 2 - 5 } & & $\begin{array}{l}\chi^{2}=\mathbf{3 3 . 8 7 7}, \mathbf{d f}=\mathbf{1}, \\
\mathbf{p}<.001 \\
\text { Fishers Exact } \\
\mathbf{p}<.001\end{array}$ & $\begin{array}{l}\chi^{2}=.010, \mathrm{df}=1, \\
\mathrm{p}=.919\end{array}$ & $\begin{array}{l}\chi^{2}=\mathbf{7 . 3 2 1}, \mathbf{d f}=\mathbf{1}, \\
\mathbf{p}<.01 \\
\text { Fishers Exact } \\
\mathbf{p}<.05\end{array}$ \\
\hline \multirow{5}{*}{ Tourism } & Tourism & $8.8 \%$ & $65.2 \%$ & $32.4 \%$ \\
\cline { 2 - 5 } & Other & $14.0 \%$ & $58.2 \%$ & $30.4 \%$ \\
\cline { 2 - 5 } & & $\begin{array}{l}\chi^{2}=.676, \mathrm{df}=1, \\
\mathrm{p}=.411\end{array}$ & $\begin{array}{l}\chi^{2}=.408, \mathrm{df}=1, \\
\mathrm{p}=.523\end{array}$ & $\begin{array}{l}\chi^{2}=.052, \mathrm{df}=1, \\
\mathrm{p}=.820\end{array}$ \\
\hline \multirow{2}{*}{$\begin{array}{l}\text { Years of } \\
\text { Residence }\end{array}$} & Mean YES & 23.02 & 21.48 & 23.99 \\
\cline { 2 - 5 } & Mean NO & 21.76 & 23.40 & 21.08 \\
\cline { 2 - 5 } & & $\mathrm{t}=-.389, \mathrm{p}=.698$ & $\mathrm{t}=.782, \mathrm{p}=.435$ & $\mathrm{t}=-1.208, \mathrm{p}=.228$ \\
\hline
\end{tabular}

In comparing data for the Buccoo Reef Marine Park, only tour guides were more likely to have attended meetings than other respondents. This difference was significant, with $50 \%$ of tour guides having attended a meeting or having been otherwise involved, as opposed to only $9.1 \%$ of other respondents. Tour guides were also more frequently able to name individuals involved in management of the MPA. The percentage of fishermen who had attended meetings was slightly higher than for other respondents, but the difference was not statistically significant. The percentage of fisherman who said their interests were being represented by management was statistically much lower than that of other respondents $(25.0 \%$ and $62.1 \%$, respectively; $p<.005)$. Years of residence was not significantly related to any of these questions for the Buccoo Reef Marine Park.

\section{Comparing Participation by Site}

The data relating to participation were then broken down by site, to compare how these responses differed among the six MPAs included in the study. Some of 
these results were also discussed in Chapter 4, in describing the co-management arrangement in place for each MPA.

Table 45. Participation data by MPA

\begin{tabular}{|l|l|l|l|l|l|l|l|l|}
\hline & \multicolumn{2}{|l|}{$\begin{array}{l}\text { Attended } \\
\text { meeting }\end{array}$} & \multicolumn{2}{l|}{$\begin{array}{l}\text { Can name } \\
\text { someone } \\
\text { involved }\end{array}$} & \multicolumn{2}{l|}{$\begin{array}{l}\text { Believes } \\
\text { interests are } \\
\text { represented }\end{array}$} & \multicolumn{2}{l|}{ Heard of MPA } \\
\cline { 2 - 9 } & Yes & No & Yes & No & Yes & No & Yes & No \\
\hline $\begin{array}{l}\text { Buccoo Reef } \\
\text { Marine Park }\end{array}$ & $12.5 \%$ & $87.5 \%$ & $28.4 \%$ & $71.6 \%$ & $58.8 \%$ & $41.2 \%$ & $72.3 \%$ & $27.7 \%$ \\
\hline $\begin{array}{l}\text { Hol Chan } \\
\text { Marine } \\
\text { Reserve }\end{array}$ & $16.6 \%$ & $83.4 \%$ & $36.2 \%$ & $63.8 \%$ & $87.6 \%$ & $12.4 \%$ & $93.5 \%$ & $6.5 \%$ \\
\hline $\begin{array}{l}\text { Laughing } \\
\text { Bird Caye } \\
\text { Nat. Park }\end{array}$ & $25.2 \%$ & $74.8 \%$ & $49.8 \%$ & $50.2 \%$ & $87.6 \%$ & $12.4 \%$ & $90.2 \%$ & $9.8 \%$ \\
\hline $\begin{array}{l}\text { Saba Marine } \\
\text { Park }\end{array}$ & $26.9 \%$ & $73.1 \%$ & $69.7 \%$ & $30.3 \%$ & $\mathrm{n} / \mathrm{a}$ & $\mathrm{n} / \mathrm{a}$ & $\mathrm{n} / \mathrm{a}$ & $\mathrm{n} / \mathrm{a}$ \\
\hline $\begin{array}{l}\text { St. Eustatius } \\
\text { Nat. Marine } \\
\text { Park }\end{array}$ & $15.5 \%$ & $84.5 \%$ & $60.4 \%$ & $39.6 \%$ & $\mathrm{n} / \mathrm{a}$ & $\mathrm{n} / \mathrm{a}$ & $\mathrm{n} / \mathrm{a}$ & $\mathrm{n} / \mathrm{a}$ \\
\hline $\begin{array}{l}\text { Scotts Head/ } \\
\text { Soufriere } \\
\text { Marine } \\
\text { Reserve }\end{array}$ & $14.3 \%$ & $85.7 \%$ & $65.7 \%$ & $34.3 \%$ & $48.4 \%$ & $51.6 \%$ & $81.3 \%$ & $18.7 \%$ \\
\hline
\end{tabular}

Table 45 shows some of the responses to the questions asked of community members, broken down by MPA. The MPAs with the highest rates of participation were the Saba National Marine Park and the Laughing Bird Caye National Marine Park, while the lowest were at the Buccoo Reef Marine Park and the Scotts Head/Soufriere Marine Reserve. Both the Saba Marine Park and the Laughing Bird Caye National Park are co-managed by local NGOs with boards of directors made up of a diverse selection of stakeholders from the local community. In both cases, the NGOs are very active in the local community, conducting outreach programs related to the MPA, and in both cases the communities where the MPAs are located are small. 
The Buccoo Reef Marine Park is co-managed primarily by representatives drawn from government agencies, few of whom are engaged directly with the local communities. The Scotts Head/Soufriere Marine Reserve also has a co-managing body made up of representatives from the local community; however, the group is not very active, and there are few management activities in which stakeholders can participate.

Saba National Marine Park also had the greatest number of respondents who could correctly name someone involved in the management. This site was followed closely by the Scotts Head/Soufriere Marine Reserve, where $65.7 \%$ of respondents correctly named an individual or individuals involved in managing the marine reserve. This site also had one of the lowest rates of participation; clearly those involved in management are visible to the community, but this has not translated to broader community involvement. The Buccoo Reef Marine Park had the lowest percentage of respondents who were able to name someone involved in the marine park, which was not surprising given the low levels of community involvement at this particular site. The Hol Chan Marine Reserve also had only $36.2 \%$ of respondents who named someone involved in managing the marine park; this particular community has a high level of knowledge of the MPA itself (93.5\% of respondents had heard of the MPA), but a lack of knowledge about the management of the MPA.

Interestingly, however, the Hol Chan Marine Reserve had the highest percentages of respondents who believed their interests were being represented (tied with the Laughing Bird Caye National Park), with the percentage of those respondents from the Hol Chan site who thought their interests were represented (87.6\%) more than twice the percentage of respondents who could name someone involved (36.2\%). 
Thus a large percentage of individuals believe their interests are represented, but do not know who it is representing their interests. (Again, this question was not asked for the St. Eustatius and Saba National Marine Parks, so data are not available for these sites). The residents in the communities adjacent to the Scotts Head/Soufriere Marine Reserve and the Buccoo Reef Marine Reserve had the fewest respondents indicating they believe their interests were being represented by those responsible for management of the MPA. These two sites also had the lowest percentages of respondents who had participated in the MPA. As discussed below, these two factors are related.

\section{Attending meetings and having one's interests represented}

Individuals who have attended a meeting overwhelmingly feel their interests are represented by those responsible for management, with $81.4 \%$ of those who have attended meetings saying they believed their interests were represented $\left(\chi^{2}=37.268\right.$, $\mathrm{p}<.001)$. These numbers imply a good deal about participation, although it is not possible to determine directionality by these results alone. Individuals who participate may come to feel their interests are being represented through the process of participating in management, or individuals who already feel their interests are being represented, or are inclined to do so because they support the goals of the MPA overall, are those likely to be involved in activities related to the MPA. Analyzing these data in another way, of those who believed their interests were represented, only 23.8\% had attended meetings. However, out of those who did not feel their interests were represented, only $13.9 \%$ had attended meetings $\left(\chi^{2}=9.941, \mathrm{p}<.01\right)$; this again 
supports the finding that participation is linked to community members feeling their interests are represented. The Phi coefficient was calculated for this chi-square test to determine effect size. In this case, the effect size was low (phi=.109, p<.005), meaning that while the percentages of those who have attended meetings who feel their interests are represented is high, there is not a large correlation between these two factors. It is difficult to determine definitively from this study whether participation can induce support and cause community members to feel their interests are represented, although this is one possible explanation for this outcome.

The relationship between meeting attendance and a feeling that one's interests are being represented also varies by site. There was a significant difference only for the SSMR as to whether those who had attended meetings believed their interests were represented; the percentage of respondents who had attended meetings and believed their interests were represented was higher, and significantly so, than the percentage of respondents who believed their interests were represented but had not attended meetings. The same relationship was not found, however, for any of the other three sites where this question was asked- the Hol Chan Marine Reserve, Laughing Bird Caye National Park, or the Buccoo Reef Marine Park (the question about whether respondents felt their interests were represented was not asked at the St. Eustatius National Marine Park or the Saba National Marine Park). In fact, at the Buccoo Reef Marine Park, respondents who had attended meetings were less likely to say their interests were represented, although the difference was not significant. While, again, an analysis of the complete data set did find a relationship between meeting attendance and belief that one's interests were being represented, variations in participation and 
co-management at the individual sites make it important to look at these data on the site level.

Table 46. Interests Represented and Meeting Attendance

\begin{tabular}{|l|l|l|l|l|}
\hline & Response & $\begin{array}{l}\text { Did not attend } \\
\text { meeting }\end{array}$ & $\begin{array}{l}\text { Attended } \\
\text { meeting }\end{array}$ & Total \\
\hline $\begin{array}{l}\text { Hol Chan } \\
\left(\chi^{2}=1.885, \mathrm{p}=.170\right)\end{array}$ & $\begin{array}{l}\text { Interests not } \\
\text { represented }\end{array}$ & $31(13.7 \%)$ & $4(7.0 \%)$ & 35 \\
\cline { 2 - 5 } & Interests represented & $195(82.3 \%)$ & $53(93.0 \%)$ & 248 \\
\hline & Total & 226 & 57 & 283 \\
\hline $\begin{array}{l}\text { Scotts } \\
\text { Head/Soufriere } \\
\left(\chi^{2}=\mathbf{4 . 8 0 6}, \mathbf{p}<.05\right)\end{array}$ & $\begin{array}{l}\text { Interests not } \\
\text { represented }\end{array}$ & $93(51.7 \%)$ & $11(31.4 \%)$ & 104 \\
\cline { 2 - 5 } & Interests represented & $87(48.3 \%)$ & $24(68.6 \%)$ & 111 \\
\hline \multirow{2}{*}{$\begin{array}{l}\text { LBC } \\
\left(\chi^{2}=1.618, p=.203\right)\end{array}$} & $\begin{array}{l}\text { Interests not } \\
\text { represented }\end{array}$ & 180 & 35 & 215 \\
\cline { 2 - 5 } & Interests represented & $86(85.1 \%)$ & $48(92.3 \%)$ & 134 \\
\hline & Total & 101 & 52 & 153 \\
\hline \multirow{2}{*}{$\begin{array}{l}\text { Buccoo Reef } \\
\left(\chi^{2}=.027, p=.870\right)\end{array}$} & $\begin{array}{l}\text { Interests not } \\
\text { represented }\end{array}$ & $65(40.9 \%)$ & $14(42.4 \%)$ & 79 \\
\cline { 2 - 5 } & Interests represented & $94(59.1 \%)$ & $19(57.6 \%)$ & 113 \\
\hline & Total & 159 & 33 & 192 \\
\hline
\end{tabular}

This relationship was also tested for occupational groups. Of fishermen who had attended meetings, $64.3 \%$ were likely to say their interests were represented, as opposed to $41.9 \%$ of fishermen who had not attended meetings. This difference was not so large as to be statistically significant at the $\mathrm{p}<.05$ level $\left(\chi^{2}=3.412, \mathrm{p}=.065\right)$.

Similarly, where $86.7 \%$ of tour guides who had attended meetings said their interests were represented, $72.2 \%$ of tour guides who had not attended meetings believed their interests were represented $\left(\chi^{2}=3.682, p=.055\right)$; again, this was not statistically significant at the $\mathrm{p}<.05$ level. 


\section{Logistic Regression to Predict Participation}

Several binary logistic regression analyses were then performed on the data to understand which of these variables were most important in predicting participation and other key factors.

A binary logistic regression analysis was conducted to determine whether certain individual variables would predict participation in a meeting or other activity. Logistic regression was selected as an appropriate test for the participation variable, which is a categorical variable (coded as either $1=$ YES or $0=\mathrm{NO}$ ). The logistic regression model is used to estimate factors that influence participation. Participation was used as the dependent variable, while occupation, correctly being able to name someone involved in MPA management (Know Correct), whether the respondent believed their interests were represented (Interests Represented), years of residence, sex, age, and years of education were used as the independent variables. Because Years of Residence and Interests Represented are not available for the Saba and St. Eustatius sites, they are not included in this analysis.

Of 1496 possible cases, 766 were rejected because of missing data (including all of the cases from St. Eustatius and Saba, and any respondents from the other sites who had not heard of the MPA); 730 were included in the analysis. The model was significant overall, with $\chi^{2}=148.181$, and $\mathrm{p}<.0001$. The Cox and Snell $\mathrm{R}^{2}$, a measure of shared variance, was .184, indicating the model predicted roughly $18.4 \%$ of the variance in stakeholder participation, while the Nagelkerke $\mathrm{R}^{2}$ measure was .287 , meaning the model predicted $28.7 \%$ of variance in stakeholder participation. While neither of these measures can be interpreted as the same as the $\mathrm{R}^{2}$ term, they provide 
an overall indication of the effect size of the model. Overall, the goodness of fit for the model was satisfactory.

Table 47. Results of Logistic Regression to predict Participation

\begin{tabular}{|l|l|l|l|l|l|l|l|}
\hline Variable & $\mathbf{B}$ & S.E. & Wald & Df & Sig & R & Exp(B) \\
\hline Years Res. & -.0091 & .0075 & 1.4831 & 1 & .2233 & .0000 & .9910 \\
\hline Gender $^{9}$ & .9300 & .2739 & 11.5286 & 1 & .0007 & .1129 & 2.5345 \\
\hline Occupation $^{10}$ & & & 52.9596 & 10 & .0000 & .2101 & \\
\hline $\begin{array}{l}\text { Occupation1 } \\
\text { (tour guide) }\end{array}$ & .2150 & .3704 & .3369 & 1 & .5616 & .0000 & 1.2399 \\
\hline $\begin{array}{l}\text { Occupation2 } \\
\text { (tourism) }\end{array}$ & -1.6259 & .4518 & 12.9532 & 1 & .0003 & -.1211 & .1937 \\
\hline $\begin{array}{l}\text { Occupation3 } \\
\text { (retail) }\end{array}$ & -1.3337 & .4412 & 9.1387 & 1 & .0025 & -.0978 & .2635 \\
\hline $\begin{array}{l}\text { Occupation4 } \\
\text { (construction) }\end{array}$ & -1.4087 & .4132 & 11.6242 & 1 & .0007 & -.1135 & .2445 \\
\hline $\begin{array}{l}\text { Occupation5 } \\
\text { (public } \\
\text { service) }\end{array}$ & -.5927 & .5144 & 1.3274 & 1 & .2493 & .0000 & .5528 \\
\hline $\begin{array}{l}\text { Occupation6 } \\
\text { (professional) }\end{array}$ & -1.3923 & .5108 & 7.4304 & 1 & .0064 & -.0853 & .2485 \\
\hline $\begin{array}{l}\text { Occupation7 } \\
\text { (student) }\end{array}$ & -1.0271 & .7605 & 1.8238 & 1 & .1769 & .0000 & .3580 \\
\hline $\begin{array}{l}\text { Occupation8 } \\
\text { (self- } \\
\text { employed) }\end{array}$ & -6.5826 & 11.5803 & .3231 & 1 & .5697 & .0000 & .0014 \\
\hline $\begin{array}{l}\text { Occupation9 } \\
\text { (unemployed) }\end{array}$ & -.4388 & .4780 & .8426 & 1 & .3587 & .0000 & .6448 \\
\hline $\begin{array}{l}\text { Occupation10 } \\
\text { (other) }\end{array}$ & -2.4336 & .6731 & 13.0737 & 1 & .0003 & -.1218 & .0877 \\
\hline Age & .0101 & .0092 & 1.1959 & 1 & .2741 & .0000 & 1.0101 \\
\hline Years of Ed. & .0200 & .0283 & .4965 & 1 & .4810 & .0000 & 1.0202 \\
\hline $\begin{array}{l}\text { Know } \\
\text { Correct }{ }^{11}\end{array}$ & 1.1305 & .2371 & 22.7370 & 1 & .0000 & .1666 & 3.0973 \\
\hline $\begin{array}{l}\text { Interests } \\
\text { Rep }{ }^{12}\end{array}$ & .8535 & .2667 & 10.2419 & 1 & .0014 & .1050 & 2.3478 \\
\hline Constant & -2.9252 & .6793 & 18.5445 & 1 & .0000 & & \\
\hline
\end{tabular}

Of the independent variables included in the model, Gender, Occupation, Know Correct (can correctly name someone involved in the MPA), and Interests

\footnotetext{
${ }^{9}$ Reference category for Gender is Female

${ }^{10}$ Reference category for occupation is Fisherman

${ }^{11}$ Reference category for Know Correct is no

${ }^{12}$ Reference category for Interests Represented is no
} 
Represented were all found to be predictors of participation, and were significant to at least the $p<.01$ level. All but Interests Represented were significant predictors of participation to the $\mathrm{p}<.001$ level. Within occupational categories, fisherman was used as the reference category, meaning all other occupations were compared as to whether they predicted respondents would be more or less likely to attend a meeting than someone employed as a fisherman. Many of these occupation categories were significant predictors and all but tour guide had a negative B value, meaning individuals in all income categories but tour guide are less likely to attend meetings than fishermen. The Wald $\chi^{2}$ value was highest for occupation (52.96) and for Know Correct (22.74), meaning these two variables were responsible for predicting the greatest amount of variance in the model.

According to the model, the odds of a community member attending a meeting are higher if the individual is male as opposed to female. Those who can correctly name someone involved in the MPA (Know Correct) are more likely to have attended a meeting. Similarly, someone who responded that their interests were represented by management (Interests Represented) would be more likely to have attended a meeting. Because fisherman is the reference category for occupation, all occupation categories can be compared to fishing. A fisherman is much more likely to have attended a meeting as someone employed in tourism or as someone whose occupation category is "other".

The model was run again to predict participation in the MPA, this time without the variables Interests Represented and Years of Residence, in order to incorporate respondents from the Saba and St. Eustatius MPAs. This new regression model 
included more cases; this time 1210 cases were included, and 286 were rejected because of missing data. This model was also significant $\left(\chi^{2}=203.475, \mathrm{df}=14\right.$, $\mathrm{p}<.0001)$. However, the Cox and Snell $\mathrm{R}^{2}$ for this model was only .155, and the Nagelkerke $\mathrm{R}^{2}$ was .253 , meaning the logistic regression model without the variables Interests Represented and Years of Residence explained less of the variance in participation than the earlier model.

The model was run again, this time removing the non-significant variables, and including only those found to be significant in the first model (gender, occupation, Know Correct, and Interests Represented). This time around, the Chi-Square value was higher $\left(\chi^{2}=162.419, \mathrm{p}<.0001\right)$, but the amount of variance predicted by the model was slightly less (Cox and Snell $\mathrm{R}^{2}=.177$, Nagelkerke $\mathrm{R}^{2}=.275$ ).

Another logistic regression model was run to predict participation using fisherman, tour guide, and tourism as separate, dichotomous variables rather than the occupation variable. Again, this model was statistically significant $\left(\chi^{2}=132.868, \mathrm{df}=9\right.$, $\mathrm{p}<.0001)$. The Cox and Snell $\mathrm{R}^{2}$ for this model was .166, and the Nagelkerke $\mathrm{R}^{2}$ was .260. Again, this model predicted less of the variability in participation than the original model with all occupations included. This model is worth exploring because it further illuminates the effect of these particular occupational categories.

In this model, both tour guide and fisherman are significant predictors of participation at the $p<.001$ level, along with gender, Know Correct, and Interests Represented (identified in the earlier model). When the variables are recoded and analyzed in this way, whether or not an individual is a tour guide becomes the most important predictor of whether or not they have attended a meeting, followed by 
whether or not they can name someone involved in the MPA. Someone employed as a tour guide is much more likely than someone who is not a tour guide to attend a meeting. A fisherman much more likely than someone employed in another occupation to attend a meeting.

Table 48. Results of Logistic Regression to predict Participation (with Fishermen, Tour Guide, and Tourism used as predictor variables)

\begin{tabular}{|l|l|l|l|l|l|l|l|}
\hline Variable & B & S.E. & Wald & Df & Sig & R & $\operatorname{Exp(B)}$ \\
\hline Years Res. & -.0090 & .0072 & 1.5656 & 1 & .2109 & .0000 & .9910 \\
\hline Gender & .8270 & .2579 & 10.2793 & 1 & .0013 & .1060 & 2.3425 \\
\hline Age & .0134 & .0088 & 2.3501 & 1 & .1253 & .0216 & 1.0135 \\
\hline $\begin{array}{l}\text { Years of } \\
\text { Ed. }\end{array}$ & .0348 & .0267 & 1.7018 & 1 & .1921 & .0000 & 1.0354 \\
\hline Tour Guide & 1.5033 & .2582 & 33.8860 & 1 & .0000 & .2066 & 4.4963 \\
\hline Fisherman & 1.2768 & .3362 & 14.4199 & 1 & .0001 & .1290 & 3.5851 \\
\hline Tourism & -.3732 & .3461 & 1.1633 & 1 & .2808 & .0000 & .6885 \\
\hline $\begin{array}{l}\text { Know } \\
\text { Correct }\end{array}$ & 1.1316 & .2340 & 23.3904 & 1 & .0000 & .1692 & 3.1005 \\
\hline $\begin{array}{l}\text { Interests } \\
\text { Rep. }\end{array}$ & .8512 & .2641 & 10.3914 & 1 & .0013 & .1060 & 2.3425 \\
\hline Constant & -4.4192 & .5777 & 58.5208 & 1 & .0000 & & \\
\hline
\end{tabular}

Finally, a logistic regression analysis was undertaken using the stepwise method of entry to predict participation, using all of the variables included in the first model described above. The first variable entered, that with the largest effect, was occupation, and this variable by itself made the model significant $\left(\chi^{2}=96.656, \mathrm{df}=10\right.$, $\mathrm{p}<.0001$, Cox and Snell $\mathrm{R}^{2}=.124$, Nagelkerke $\left.\mathrm{R}^{2}=.194\right)$. The next variable included was Know Correct, which increased the $\chi^{2}$ value by 23.800 to 120.457 (df=11, $\mathrm{p}<.0001$ ). The new Cox and Snell $\mathrm{R}^{2}$ is .152, and the Nagelkerke $\mathrm{R}^{2}$ is .237 . Gender was the next variable added to the model, increasing the $\chi^{2}$ value by 13.395 to 133.851 $(\mathrm{df}=12, \mathrm{p}<.0001)$, the Cox and Snell $\mathrm{R}^{2}$ to .168 , and the Nagelkerke $\mathrm{R}^{2}$ to .262 .

Interests Represented was the final variable to be added to the model, increasing the $\chi^{2}$ 
value by an additional 11.711 to $145.563(\mathrm{df}=13, \mathrm{p}<.0001)$. The new Cox and Snell $\mathrm{R}^{2}$ was now .181, and the new Nagelkerke $\mathrm{R}^{2}$ is .282. Age, years of education, and years of residence were not added to the model, as they are not significant and would not increase the prediction of the model to any considerable degree. While these results are virtually the same as the original model, this exercise serves to highlight the importance of certain variables - in particular Occupation, which by itself predicts between roughly 12 and 19 percent of the variance in participation, and Know Correct (being able to name someone involved in management).

A logistic regression was undertaken for each individual site, to evaluate whether the variables found to be significant determinants of participation in the combined data set were important at all MPAs or only at certain sites.

Overall, the results of the logistic regression models analyzed by site were much less informative than the analyses run encompassing the data from all sites. This is likely due in part to the skewed samples for some of the variables that come from very small numbers of some groups previously found to be influential in the model. For example, the test for significance of occupation categories uses fishermen as a reference category for consistency; however, at some of the sites, including Saba Marine Park and St. Eustatius Marine Park, there were very few fishermen included in the survey (two and three, respectively) so this is likely to skew these results. There were three variables that were significant predictors of participation for the Hol Chan Marine Reserve, more than for any of the other sites. Because this site has the largest number of respondents, the data from the Hol Chan Marine Reserve drive the results 
for the model overall to a considerable degree. The results of the logistic regression model for the Hol Chan Marine Reserve are presented here.

The logistic regression model for the Hol Chan Marine Reserve to predict participation is statistically significant $\left(\chi^{2}=71.820, \mathrm{df}=16, \mathrm{p}<.0001\right)$. The Cox and Snell and Nagelkerke $\mathrm{R}^{2}$ values indicate that 24.2 percent or 38.7 percent, respectively of the variation in participation for the Hol Chan Marine Reserve can be predicted by this model. These values are much higher than those for the model that included all sites. Of 384 possible cases, 125 were rejected because of missing data (including those who had never heard of the MPA), and 259 were included in the model.

For the Hol Chan Marine Reserve, Occupation, Know Correct, and Interests Represented were significant variables in predicting participation. Some of the variables that were found to be significant in the model used for all of the data were not significant for the Hol Chan Marine Reserve, including Gender and many of the individual occupation categories. The odds ratio for Know Correct is much higher for the Hol Chan Marine Reserve than for the full model; an individual who can correctly name someone involved in the marine reserve is much more likely to have attended a meeting than someone who cannot. Those respondents who said their interests were represented were also much more likely to have attended a meeting at the Hol Chan Marine Reserve than in the data set as a whole. Likewise, while tour guide was not significant for either the Hol Chan data or the full data set, tour guides were much more likely to have attended a meeting than fishermen for the Hol Chan Marine Reserve compared with that ratio for the complete data set. 
Table 49. Results of Logistic Regression to predict participation for Hol Chan Marine Reserve

\begin{tabular}{|l|l|l|l|l|l|l|l|}
\hline Variable & $\mathbf{B}$ & S.E. & Wald & Df & Sig & R & Exp(B) \\
\hline Years Res. $^{13}$ & -.0249 & .0163 & 2.3343 & 1 & .1266 & -.0363 & .9754 \\
\hline Gender $^{13}$ & .3519 & .4771 & .5442 & 1 & .4607 & .0000 & 1.4218 \\
\hline Occupation & & & 24.6707 & 10 & .0060 & .1356 & \\
\hline $\begin{array}{l}\text { Occupation1 } \\
\text { (tour guide) }\end{array}$ & .9796 & 1.3405 & .5340 & 1 & .4649 & .0000 & 2.6633 \\
\hline $\begin{array}{l}\text { Occupation2 } \\
\text { (tourism) }\end{array}$ & -.8210 & 1.4060 & .3409 & 1 & .5593 & .0000 & .4400 \\
\hline $\begin{array}{l}\text { Occupation3 } \\
\text { (retail) }\end{array}$ & -1.1832 & 1.4041 & .7101 & 1 & .3994 & .0000 & .3063 \\
\hline $\begin{array}{l}\text { Occupation4 } \\
\text { (construction) }\end{array}$ & -.8089 & 1.4432 & .3141 & 1 & .5751 & .0000 & .4454 \\
\hline $\begin{array}{l}\text { Occupation5 } \\
\text { (public } \\
\text { service) }\end{array}$ & .2493 & 1.7721 & .0198 & 1 & .8881 & .0000 & 1.2832 \\
\hline $\begin{array}{l}\text { Occupation6 } \\
\text { (professional) }\end{array}$ & -.9293 & 1.5056 & .3810 & 1 & .5371 & .0000 & .3948 \\
\hline $\begin{array}{l}\text { Occupation7 } \\
\text { (student) }\end{array}$ & -4.8779 & 36.6917 & .0177 & 1 & .8942 & .0000 & .0076 \\
\hline $\begin{array}{l}\text { Occupation8 } \\
\text { (self- } \\
\text { employed) }\end{array}$ & -6.4594 & 24.3342 & .0705 & 1 & .7907 & .0000 & .0016 \\
\hline $\begin{array}{l}\text { Occupation9 } \\
\text { (unemployed) }\end{array}$ & 1.4350 & 1.5574 & .8490 & 1 & .3568 & .0000 & 4.1995 \\
\hline $\begin{array}{l}\text { Occupation10 } \\
\text { (other) }\end{array}$ & -1.5496 & 1.7133 & .8181 & 1 & .3657 & .0000 & .2123 \\
\hline Age & .0227 & .0203 & 1.2530 & 1 & .2630 & .0000 & 1.0230 \\
\hline Years of Ed. & .0395 & .0554 & .5085 & 1 & .4758 & .0000 & 1.0403 \\
\hline Know Correct & 2.0347 & .4633 & 19.2858 & 1 & .0000 & .2608 & 7.6501 \\
\hline Interests Rep. & 1.8714 & .8402 & 4.9615 & 1 & .0259 & .1080 & .6476 \\
\hline Constant & -5.1445 & 1.9587 & 6.8985 & 1 & .0086 & & \\
\hline
\end{tabular}

While the logistic regression models for both the aggregated data set and each individual site were significant, that each has only a small to medium effect size points to the fact that site-level factors, rather than individual-level variables such as age and gender, would likely be as or more important in predicting the knowledge of and involvement in MPA management by community members. Factors such as how the MPA is co-managed, the inclusion of different sectors of society on the management

\footnotetext{
${ }^{13}$ Reference category for gender is male

${ }^{14}$ Reference category for occupation is Fisherman
} 
board or committee, the frequency of meetings, and the attempts of the MPA

management to involve community members are more likely to be important than personal level variables. This conclusion is not surprising, as the co-management arrangements at each site vary considerably, and as a result the level of participation at each site also differs significantly.

\section{Predictors of Naming Others Involved in Management}

A second logistical regression model analyzed the extent to which the variables were predictors of whether the respondents could correctly name someone involved in the MPA (Know Correct). This model was also statistically significant $\left(\chi^{2}=112.325\right.$, $\mathrm{df}=16, \mathrm{p}<.0001)$, and predicts somewhere between 14 and $19 \%$ of the variance in the dependent variable (Cox and Snell $\mathrm{R}^{2}=.143$, Nagelkerke $\left.\mathrm{R}^{2}=.191\right)$. In predicting whether a respondent could correctly name someone involved in the MPA, years of residence and participation were significant, both at the $\mathrm{p}<=.0001$ level. Years of education and occupation were significant at the $\mathrm{p}<.05$ level.

Table 50. Results of Logistic Regression to predict naming someone involved in the MPA

\begin{tabular}{|l|l|l|l|l|l|l|l|}
\hline Variable & B & S.E. & Wald & Df & Sig & R & Exp(B) \\
\hline Years Res & .0327 & .0059 & 30.3067 & 1 & .0000 & .1681 & 1.0332 \\
\hline Gender $^{15}$ & -.2612 & .1912 & 1.8668 & 1 & .1718 & .0000 & .7701 \\
\hline Occupation $^{16}$ & & & 18.4458 & 10 & .0479 & .0000 & \\
\hline $\begin{array}{l}\text { Occupation1 } \\
\text { (tour guide) }\end{array}$ & .4832 & .4062 & 1.4212 & 1 & .2332 & .0000 & 1.6229 \\
\hline $\begin{array}{l}\text { Occupation2 } \\
\text { (tourism) }\end{array}$ & -.5377 & .3859 & 1.9425 & 1 & .1634 & .0000 & .5841 \\
\hline $\begin{array}{l}\text { Occupation3 } \\
\text { (retail) }\end{array}$ & -.6388 & .3845 & 2.7603 & 1 & .0966 & -.0276 & .5280 \\
\hline $\begin{array}{l}\text { Occupation4 } \\
\text { (construction) }\end{array}$ & -.4299 & .3780 & 1.2931 & 1 & .2555 & .0000 & .6506 \\
\hline
\end{tabular}

\footnotetext{
${ }^{15}$ Reference category for gender is male

${ }^{16}$ Reference category for occupation is Fisherman
} 


\begin{tabular}{|l|l|l|l|l|l|l|l|}
\hline $\begin{array}{l}\text { Occupation5 } \\
\text { (public } \\
\text { service) }\end{array}$ & -.4590 & .4873 & .8874 & 1 & .3462 & .0000 & .6319 \\
\hline $\begin{array}{l}\text { Occupation6 } \\
\text { (professional) }\end{array}$ & -.2188 & .4264 & .2633 & 1 & .6079 & .0000 & .8035 \\
\hline $\begin{array}{l}\text { Occupation7 } \\
\text { (student) }\end{array}$ & .9404 & .7444 & 1.5961 & 1 & .2065 & .0000 & 2.5610 \\
\hline $\begin{array}{l}\text { Occupation8 } \\
\text { (self- } \\
\text { employed) }\end{array}$ & .2348 & .8020 & .0858 & 1 & .7696 & .0000 & 1.2647 \\
\hline $\begin{array}{l}\text { Occupation9 } \\
\text { (unemployed) }\end{array}$ & -.3368 & .4451 & .5725 & 1 & .4493 & .0000 & .7141 \\
\hline $\begin{array}{l}\text { Occupation10 } \\
\text { (other) }\end{array}$ & -.3347 & .4226 & .6272 & 1 & .4284 & .0000 & .7155 \\
\hline Age & -.0026 & .0073 & .1305 & 1 & .7179 & .0000 & .9974 \\
\hline Years of Ed. & .0591 & .0243 & 5.8960 & 1 & .0152 & .0624 & 1.0609 \\
\hline $\begin{array}{l}\text { Interests } \\
\text { Rep. }{ }^{17}\end{array}$ & .1307 & .1886 & .4805 & 1 & .4882 & .0000 & 1.1396 \\
\hline Participation & 1.1221 & .2326 & 22.5521 & 1 & .0000 & .1433 & 3.0712 \\
\hline Constant & -.9116 & .5589 & 2.6600 & 1 & .1029 & & \\
\hline
\end{tabular}

When Participation was taken out of the regression model, it predicted between 11 and 15 percent of the variance in whether respondents could name someone involved in the MPA (Cox and Snell $\mathrm{R}^{2}=.113$, Nagelkerke $\mathrm{R}^{2}=.152$ ) and was statistically significant $\left(\chi^{2}=87.992, \mathrm{df}=15, \mathrm{p}<.0001\right)$. Without participation in the model, years of residence and occupation were significant to the level of $p<.001$, and years of education was significant at the $\mathrm{p}<.01$ level in predicting whether a respondent could name someone involved in the MPA. Within occupation, both tourism and retail were statistically significant $(\mathrm{p}<.05)$ in that they were less likely to name someone involved in the MPA. While this model predicts less of the variance in the Know Correct variable, these results are important nonetheless. Whether or not a respondent could correctly name someone involved in the MPA (Know Correct) proved to be a significant predictor of whether or not someone had participated, both

\footnotetext{
${ }^{17}$ Reference category for Interests Represented is no

${ }^{18}$ Reference category for Participation is no
} 
for the full dataset and for most of the individual sites. Analyzing this variable by itself further reinforces what some of the other factors may be driving participation. Neither years of residence nor years of education were important in the model to predict participation for all sites, but these variables are important in predicting whether an individual knows someone involved in management. Because knowing someone involved in management is a strong predictor of participation, these variables may be of secondary importance in predicting participation.

\section{Predicting Interests Represented}

A third logistical regression analyzed Interests Represented as the dependent variable. This model was also significant $\left(\chi^{2}=53.426, \mathrm{df}=16, \mathrm{p}<.0001\right)$, but predicts only between 7 and 10 percent of the variance in whether respondents said their interests were represented, a small effect size (Cox and Snell $\mathrm{R}^{2}=.071$, Nagelkerke $\left.\mathrm{R}^{2}=.103\right)$. Only participation in a meeting was a significant predictor of whether someone felt their interests were represented by those responsible for managing the MPA, at the level of $\mathrm{p}<.005$. The relationship between these two variables was discussed earlier. Occupation itself was not a significant predictor of whether individuals would say their interests were being represented, but several individual occupation categories were, including tour guide, tourism, retail, construction, professionals, and "other" occupations. Individuals who had attended a meeting were more likely to say their interests were being represented by those responsible for management. All occupational categories with the exception of self-employed were more likely to say their interests were being represented than fisherman; those 
working in retail were more likely to say their interests were represented, and those working in tourism-related industries were more likely to say their interests were being represented by those responsible for managing the MPA.

Table 51. Results of Logistic Regression to predict whether respondents feel their interests are represented.

\begin{tabular}{|l|l|l|l|l|l|l|l|}
\hline Variable & $\mathbf{B}$ & S.E. & Wald & Df & Sig & R & Exp(B) \\
\hline Years Res. & -.0110 & .0062 & 3.1887 & 1 & .0741 & -.0375 & .9890 \\
\hline Gender $^{19}$ & -.0385 & .2134 & .0326 & 1 & .8567 & .0000 & .9622 \\
\hline Occupation & & & 17.8299 & 10 & .0579 & .0000 & \\
\hline $\begin{array}{l}\text { Occupation1 } \\
\text { (tour guide) }\end{array}$ & 1.0492 & .3854 & 7.4108 & 1 & .0065 & .0800 & 2.8554 \\
\hline $\begin{array}{l}\text { Occupation2 } \\
\text { (tourism) }\end{array}$ & 1.1771 & .3857 & 9.3159 & 1 & .0023 & .0930 & 3.2449 \\
\hline $\begin{array}{l}\text { Occupation3 } \\
\text { (retail) }\end{array}$ & 1.2339 & .3833 & 10.3650 & 1 & .0013 & .0995 & 3.4347 \\
\hline $\begin{array}{l}\text { Occupation4 } \\
\text { (construction) }\end{array}$ & .7383 & .3591 & 4.2266 & 1 & .0398 & .0513 & 2.0923 \\
\hline $\begin{array}{l}\text { Occupation5 } \\
\text { (public } \\
\text { service) }\end{array}$ & .7587 & .4924 & 2.3742 & 1 & .1234 & .0210 & 2.1355 \\
\hline $\begin{array}{l}\text { Occupation6 } \\
\text { (professional) }\end{array}$ & 1.0993 & .4414 & 6.2023 & 1 & .0128 & .0705 & 3.0020 \\
\hline $\begin{array}{l}\text { Occupation7 } \\
\text { (student) }\end{array}$ & .6024 & .6754 & .7955 & 1 & .3724 & .0000 & 1.8265 \\
\hline $\begin{array}{l}\text { Occupation8 } \\
\text { (self- } \\
\text { employed) }\end{array}$ & -.2786 & .7416 & .1412 & 1 & .7071 & .0000 & .7568 \\
\hline $\begin{array}{l}\text { Occupation9 } \\
\text { (unemployed) }\end{array}$ & .6086 & .4281 & 2.0206 & 1 & .1552 & .0049 & 1.8378 \\
\hline $\begin{array}{l}\text { Occupation10 } \\
\text { (other) }\end{array}$ & 1.0405 & .4173 & 6.2183 & 1 & .0126 & .0706 & 2.8306 \\
\hline Age & -.0123 & .0078 & 2.4738 & 1 & .1158 & -.0237 & .9878 \\
\hline Years of Ed. & .0406 & .0255 & 2.5377 & 1 & .1112 & .0252 & 1.0414 \\
\hline Participation ${ }^{21}$ & .8732 & .2648 & 10.8730 & 1 & .0010 & .1025 & 2.3947 \\
\hline $\begin{array}{l}\text { Know } \\
\text { Correct }\end{array}$ & .1135 & .1870 & .3683 & 1 & .5439 & .0000 & 1.1202 \\
\hline Constant & .1658 & .5625 & .0868 & 1 & .7682 & & \\
\hline
\end{tabular}

\footnotetext{
${ }^{19}$ Reference category for gender is male

${ }^{20}$ Reference category for occupation is Fisherman

${ }^{21}$ Reference category for participation is no

${ }^{22}$ Reference category for Know Correct is no
} 


\section{Predicting MPA Knowledge}

A fourth logistic regression analyzed a model to predict whether individuals had heard of the MPA. For this model, the only variables included were gender, age, years of education, and years of residence, in order to include respondents from all sites. Of the total number of cases, 444 were rejected because of missing data, meaning 1052 cases were included in this analysis. This model was also significant $\left(\chi^{2}=72.284, \mathrm{df}=13, \mathrm{p}<.0001\right)$, but predicts only between 6 and 12 percent of the variance in whether respondents said they had heard of the MPA, again a small effect size (Cox and Snell $\mathrm{R}^{2}=.066$, Nagelkerke $\left.\mathrm{R}^{2}=.120\right)$. Years of education $(\mathrm{p}<.0001)$, gender ( $\mathrm{p}<.01)$, and occupation $(\mathrm{p}<.05)$ were significant predictors of knowledge of the MPA. Occupation in construction was also significant at the $\mathrm{p}<.05$ level. Men are more likely than women to have heard of the MPA, and for every additional year of education a respondent has, their odds of having heard of the MPA increase.

Respondents working in construction are far less likely than fishermen to have heard of the MPA. Because the $\mathrm{R}^{2}$ terms for this model are so small, and because the percentage of respondents who had heard of the MPA varied so widely from site to site, it is likely that site-level factors specific to each community and each MPA are much more important in determining whether an individual has heard of the MPA.

Table 52. Results of Logistic Regression to predict awareness of MPA.

\begin{tabular}{|l|l|l|l|l|l|l|l|}
\hline Variable & B & S.E. & Wald & Df & Sig & R & $\operatorname{Exp(B)}$ \\
\hline Gender & .5918 & .2159 & 7.5101 & 1 & .0061 & .0808 & 1.8072 \\
\hline Occupation $^{23}$ & & & 18.9633 & 10 & .0407 & .0000 & \\
\hline $\begin{array}{l}\text { Occupation1 } \\
\text { (tour guide) }\end{array}$ & .8427 & .7880 & 1.1437 & 1 & .2849 & .0000 & 2.3227 \\
\hline $\begin{array}{l}\text { Occupation2 } \\
\text { (tourism) }\end{array}$ & -.9349 & .5775 & 2.6206 & 1 & .1055 & -.0271 & .3926 \\
\hline
\end{tabular}

\footnotetext{
${ }^{23}$ Reference category for occupation is Fisherman
} 


\begin{tabular}{|l|l|l|l|l|l|l|l|}
\hline $\begin{array}{l}\text { Occupation3 } \\
\text { (retail) }\end{array}$ & -.7985 & .5753 & 1.9265 & 1 & .1651 & .0000 & .4500 \\
\hline $\begin{array}{l}\text { Occupation4 } \\
\text { (construction) }\end{array}$ & -1.3654 & .5594 & 5.9573 & 1 & .0147 & -.0685 & .2553 \\
\hline $\begin{array}{l}\text { Occupation5 } \\
\text { (public } \\
\text { service) }\end{array}$ & -.7105 & .7107 & .9995 & 1 & .3174 & .0000 & .4914 \\
\hline $\begin{array}{l}\text { Occupation6 } \\
\text { (professional) }\end{array}$ & -.5403 & .6361 & .7213 & 1 & .3957 & .0000 & .5826 \\
\hline $\begin{array}{l}\text { Occupation7 } \\
\text { (student) }\end{array}$ & 4.5701 & 8.7858 & .2706 & 1 & .6029 & .0000 & 96.5582 \\
\hline $\begin{array}{l}\text { Occupation8 } \\
\text { (self- } \\
\text { employed) }\end{array}$ & -.2645 & 1.1753 & .0506 & 1 & .8220 & .0000 & .7676 \\
\hline $\begin{array}{l}\text { Occupation9 } \\
\text { (unemployed) }\end{array}$ & -.9613 & .6018 & 2.5521 & 1 & .1101 & -.0256 & .3824 \\
\hline $\begin{array}{l}\text { Occupation10 } \\
\text { (other) }\end{array}$ & -.8274 & .5947 & 1.9356 & 1 & .1641 & .0000 & .4372 \\
\hline Age & .0101 & .0075 & 1.7856 & 1 & .1815 & .0000 & 1.0101 \\
\hline Years of Ed. & .1369 & .0277 & 24.3791 & 1 & .0000 & .1629 & 1.1467 \\
\hline Constant & .3600 & .7158 & .2560 & 1 & .6150 & & \\
\hline
\end{tabular}

\section{Site-Level Statistics}

Non-parametric statistical tests of correlation (Kendall's tau-b and Spearman's rho) were conducted on site-level variables to compare each MPA based on the statistical measures arrived at from the network analysis. Because of the very small sample size (six sites), significant correlations could not be found between most network variables and measures of other data collected. While the networks are clearly different, as discussed in Chapter 5, these differences are not generally significant enough to be correlated with any site-level statistics. However, a few of these tests are discussed below.

The network centralization measure was positively correlated with the percentage of respondents at each site who can correctly name someone involved in the MPA (Spearman's rho=.943, p<.005); however, this strong correlation can be 
expected, as network centralization is defined by respondents naming others connected within the network. Another important result from comparing statistics at the network level was a lack of correlation between network centralization and the population size of the relevant community (Spearman's rho=-.543, $\mathrm{p}=.266$ ). It could be hypothesized that as population increases, centralization would be smaller, because respondents might be less likely to personally know or know of individuals involved in the MPA. That these two variables are not correlated is indicative of the fact that other factors in addition to population size, such as the co-management structure and efforts at informing and including the community in management decisions, contribute to network centrality.

Network centralization was also not found to be correlated with the percentage of respondents who had participated in meetings at a particular MPA (Spearman's $\mathrm{rho}=.543, \mathrm{p}=.266$ ). Again, because the sample size is so small, it is difficult to detect any statistical differences between these variables. 


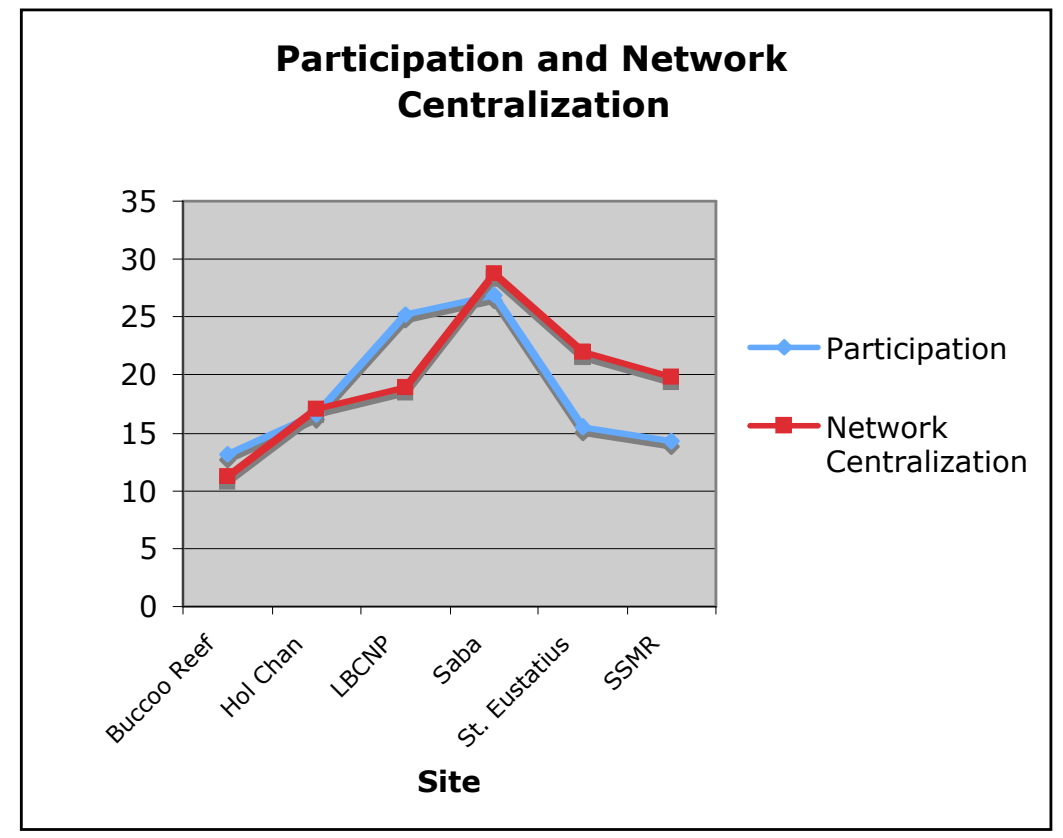

Figure 11. Participation rate and network centralization measure by site

The above graph compares participation and network centralization for each of the sites. While the sample size is too small to reliably find a correlation between these two variables, the graph clearly shows that these two variables co-vary to some degree. The trends of the two lines are mostly similar. Buccoo Reef Marine Park and the Hol Chan Marine Reserve are both low on both measures, and the Saba Marine Park is high on both.

Variables from this data set were also compared with variables from the NSFsponsored MPA study (Dalton et al.) using the Spearman's rho correlation coefficient. Again, these analyses were of a very small dataset (six sites), so finding sufficiently large, meaningful relationships between the variables proved difficult. There was no correlation found between participation in the MPA and the mean level of compliance reported for each site (Spearman's rho=.486, sig=.329), between participation in the MPA and the percent of respondents in the MPA study who said the MPA was 
successful (Spearman's rho=.486, sig=.329) or between participation and the mean number of fish found in the reserve (Spearman's rho=.257, sig=.623).

\section{Comparison of Survey Data with Network Data}

In a final stage for analyzing these data, network measures were created for each individual respondent based on their position within the social networks, or their number of linkages and distance from the most central actors, as described in Chapter 5. These measures were then analyzed using the participation data to investigate the connection between an individual's position within a network and the likelihood that they might attend a meeting.

Betweenness centrality is a measure of how frequently each actor lies on the path connecting two other actors; in other words, how many actors must pass through them in order to reach another actor. Betweenness centrality is important for considering the flow of information within the network. Those actors with the highest betweenness centrality often serve as intermediaries between the most central actors and the rest of the actors in the network. This itself is a very powerful position, as they can control what resources, including information, flow through the network. An actor's normalized betweenness is a percentage of the maximum possible betweenness they could have had considering all actors and relations within the network (Hanneman and Riddle 2005). In many cases, the actors with the highest degree centrality will be the actors with the highest betweenness centrality, but this is not always the case. 
Degree is simply the number of connections each actor has to other actors within the network, and is a measure of prominence within the network. It can be hypothesized that the higher the degree and betweenness centrality of an actor, the more likely it is that they have attended a meeting.

Table 53. Analysis of individual network measures

\begin{tabular}{|c|c|c|c|c|}
\hline & \multicolumn{2}{|c|}{$\begin{array}{l}\text { Attended } \\
\text { Meeting }\end{array}$} & \multicolumn{2}{|c|}{$\begin{array}{l}\text { Interests } \\
\text { represented }\end{array}$} \\
\hline & Yes & $\mathrm{No}$ & Yes & $\mathrm{No}$ \\
\hline \multirow[t]{2}{*}{ Mean Degree } & 4.06 & 1.08 & 1.52 & .96 \\
\hline & \multicolumn{2}{|c|}{$\begin{array}{l}\mathrm{t}=-6.537 * \\
\mathrm{df}=375.6 \\
p<.001\end{array}$} & \multicolumn{2}{|c|}{$\begin{array}{l}\mathrm{t}=-2.061^{*}, \\
\mathrm{df}=597.8, p<.05\end{array}$} \\
\hline \multirow{2}{*}{$\begin{array}{l}\text { Betweenness } \\
\text { centrality }\end{array}$} & 545.6 & 100.9 & 184.4 & 51.6 \\
\hline & \multicolumn{2}{|c|}{$\begin{array}{l}\mathrm{t}=-5.169 * \\
\mathrm{df}=432.2, \\
p<.001\end{array}$} & \multicolumn{2}{|c|}{$\begin{array}{l}\mathrm{t}=-2.064^{*}, \\
\mathrm{df}=546.2, p<.05\end{array}$} \\
\hline
\end{tabular}

*Equal variances not assumed

As indicated in Table 53, those individuals who had attended meetings had a significantly higher degree and betweenness centrality than those who had not. Again, this relates to the discussion above, about how individuals are likely to know someone involved in the MPA because they have attended a meeting. Those who have attended meetings have more connections to others within the network. They are also likely to have a higher level of betweenness centrality, meaning they can serve as intermediaries for others in the network, a connection to those ultimately in power.

Those respondents who said their interests were represented are also more likely to have a higher degree (more connections within the network) and a higher betweenness centrality. Those who believe their interests are represented are more likely to be connected directly or indirectly with those making decisions about the MPA, and thus able to have their interests heard. 
These network measures were also compared for occupation groups, using an analysis of variance (ANOVA) to compare the degree and betweenness centrality of fishermen, tour guides, those employed in tourism, and other occupations. A highly significant correlation between occupation and betweenness was found $(F=5.942$, $\mathrm{df}=3, \mathrm{p}<.001$ ), and in a Bonferroni post-hoc test, tour guides had a statistically higher mean degree and betweenness centrality when compared with all other groups. There were no statistically significant differences between the other three groups. This means that throughout the data set, tour guides are the most likely to serve as intermediaries within the network, to be on a path to those in charge.

Likewise, a significant relationship was found between degree and occupation $(\mathrm{F}=6.838, \mathrm{df}=3, \mathrm{p}<.001)$. In a post hoc test, the mean differences between tour guides and those employed in tourism, and tour guides and other occupations, were found to be significant. However, the mean difference in degree between tour guides and fishermen was not significant. Thus tour guides and fishermen have equally as many connections within the networks, but tour guides are more likely to serve intermediary roles, and may therefore be more connected to those in power. Tour guides are thus likely to have the most power when compared with other occupational groups within the various co-management regimes.

\section{Comparing individual network measures by site}

Table 54. Mean degree and betweenness centrality by meeting attendance for individual sites

\begin{tabular}{|l|l|l|l|l|l|l|l|l|l|l|l|l|}
\hline $\begin{array}{l}\text { Attended } \\
\text { Meeting }\end{array}$ & \multicolumn{3}{|l|}{ Hol Chan } & \multicolumn{2}{l|}{ SSMR } & \multicolumn{2}{l|}{$\begin{array}{l}\text { St. } \\
\text { Eustatius }\end{array}$} & \multicolumn{2}{l|}{ Saba } & \multicolumn{2}{l|}{$\begin{array}{l}\text { Laughing } \\
\text { Bird Caye }\end{array}$} & \multicolumn{2}{l|}{$\begin{array}{l}\text { Buccoo } \\
\text { Reef }\end{array}$} \\
\cline { 2 - 10 } & Yes & No & Yes & No & Yes & No & Yes & No & Yes & No & Yes & No \\
\hline
\end{tabular}




\begin{tabular}{|c|c|c|c|c|c|c|c|c|c|c|c|c|}
\hline \multirow{2}{*}{$\begin{array}{l}\text { Mean } \\
\text { Degree }\end{array}$} & 1.43 & 1.77 & 5.50 & .77 & 6.27 & .92 & 3.86 & 1.20 & 4.55 & .92 & 4.28 & .73 \\
\hline & \multicolumn{2}{|c|}{$\begin{array}{l}t=.496 \\
d f=375 \\
p=.620\end{array}$} & \multicolumn{2}{|c|}{$\begin{array}{l}\mathrm{t}=-2.904^{*}, \\
\mathrm{df}=51.1, \\
p<.01\end{array}$} & \multicolumn{2}{|c|}{$\begin{array}{l}\mathrm{t}=-3.405^{*}, \\
\mathrm{df}=44.1, \\
p<.005\end{array}$} & \multicolumn{2}{|c|}{$\begin{array}{l}\mathrm{t}=-2.203^{*}, \\
\mathrm{df}=43.4, \\
p<.05\end{array}$} & \multicolumn{2}{|c|}{$\begin{array}{l}\mathrm{t}=-3.475^{*}, \\
\mathrm{df}=73.5 \\
p<.005\end{array}$} & \multicolumn{2}{|c|}{$\begin{array}{l}\mathrm{t}=-3.700^{*}, \\
\mathrm{df}=53.3 \\
p<.005\end{array}$} \\
\hline \multirow{2}{*}{$\begin{array}{l}\text { Betweenness } \\
\text { Centrality }\end{array}$} & 325.0 & 129.7 & 1017.9 & 35.8 & \begin{tabular}{|l|}
602.2 \\
\end{tabular} & 5.3 & 266.0 & 45.0 & 525.9 & 25.1 & 917.0 & 33.3 \\
\hline & \multicolumn{2}{|c|}{$\begin{array}{l}t=.905 \\
d f=375 \\
p=.366\end{array}$} & \multicolumn{2}{|c|}{$\begin{array}{l}\mathrm{t}=-2.881^{*} \\
\mathrm{df}=51.1 \\
p<.01\end{array}$} & \multicolumn{2}{|c|}{$\begin{array}{l}\mathrm{t}=-2.937^{*} \\
\mathrm{df}=44.0 \\
p<.01\end{array}$} & \multicolumn{2}{|c|}{$\begin{array}{l}\mathrm{t}=-2.055^{*} \\
\mathrm{df}=44.3 \\
p<.05\end{array}$} & \multicolumn{2}{|c|}{$\begin{array}{l}\mathrm{t}=-3.196^{*} \\
\mathrm{df}=73.9 \\
p<.005\end{array}$} & \multicolumn{2}{|c|}{$\begin{array}{l}\mathrm{t}=-3.221^{*}, \\
\mathrm{df}=53.2 \\
p<.005\end{array}$} \\
\hline
\end{tabular}

*Equal variances not assumed

Table 55. Mean degree and betweenness centrality by interests represented for individual sites

\begin{tabular}{|c|c|c|c|c|c|c|c|c|}
\hline \multirow[t]{2}{*}{$\begin{array}{l}\text { Interests } \\
\text { represented }\end{array}$} & \multicolumn{2}{|c|}{ Hol Chan } & \multicolumn{2}{|c|}{ SSMR } & \multicolumn{2}{|c|}{$\begin{array}{l}\text { Laughing } \\
\text { Bird Caye }\end{array}$} & \multicolumn{2}{|c|}{$\begin{array}{l}\text { Buccoo } \\
\text { Reef }\end{array}$} \\
\hline & Yes & $\mathrm{No}$ & Yes & $\mathrm{No}$ & Yes & No & Yes & $\mathrm{No}$ \\
\hline \multirow{2}{*}{$\begin{array}{l}\text { Mean } \\
\text { Degree }\end{array}$} & 1.93 & 1.34 & 1.21 & .85 & 1.31 & 1.35 & 1.13 & .84 \\
\hline & \multicolumn{2}{|c|}{$\begin{array}{l}t=-.516, \\
d f=246, \\
p=.607\end{array}$} & \multicolumn{2}{|c|}{$\begin{array}{l}t=-3.175, \\
d f=202, \\
p<.005\end{array}$} & \multicolumn{2}{|c|}{$\begin{array}{l}\mathrm{t}=.142, \\
\mathrm{df}=131, \\
\mathrm{p}=.887\end{array}$} & \multicolumn{2}{|c|}{$\begin{array}{l}\mathrm{t}=-1.896, \\
\mathrm{df}=163, \\
\mathrm{p}=.06\end{array}$} \\
\hline \multirow{2}{*}{$\begin{array}{l}\text { Betweenness } \\
\text { Centrality }\end{array}$} & 347.7 & 49.9 & 58.1 & 57.8 & 53.9 & 46.5 & 97.8 & 45.7 \\
\hline & \multicolumn{2}{|c|}{$\begin{array}{l}t=-.849, \\
d f=246, \\
p=.347\end{array}$} & \multicolumn{2}{|c|}{$\begin{array}{l}\mathrm{t}=-.009, \\
\mathrm{df}=202, \\
\mathrm{p}=.992\end{array}$} & \multicolumn{2}{|c|}{$\begin{array}{l}\mathrm{t}=-.140, \\
\mathrm{df}=131, \\
\mathrm{p}=.889\end{array}$} & \multicolumn{2}{|c|}{$\begin{array}{l}\mathrm{t}=-1.152, \\
\mathrm{df}=163 \\
\mathrm{p}=.251\end{array}$} \\
\hline
\end{tabular}

As Tables 54 and 55 demonstrate, the relationship between the two network measures (mean degree and betweenness centrality) and meeting attendance and whether a respondent felt their interests were represented becomes a bit murkier when data for the individual sites are analyzed. For the question of whether these network measures related to meeting attendance, there was a significant relationship for all sites but Hol Chan. However, there was no significant relationship between the network measures and whether respondents felt their interests were represented for any site but the Scotts Head/Soufriere Marine Reserve, where there was a relationship between mean degree and whether respondents felt their interests were represented. 


\section{Discussion}

Overall, analysis of this data set found significant differences between MPAs in the participation by community members in meetings and other activities related to the MPA, as well as significant differences between stakeholder groups in participation and in whether they felt their interests were represented. While occupation is a generalized and crude proxy of whether an individual should be considered a stakeholder in the MPA, fieldwork confirmed that both fishing and tourism interests stand to benefit from or lose out to the presence of an MPA, and their interests should be considered. Another result of this analysis is that women are less likely to be aware of the MPA or to have attended meetings than men; women may represent an important stakeholder group being excluded from the process. While some authors have found females to frequently be participants in fisheries meetings in other parts of the world, in the Caribbean females appear to have less of a role in fishing, often having an occupation of their own. Brown (2001) noted that poverty in the Caribbean is often associated with female-headed households, making gender an important variable for analysis as a stand-in for poverty in some cases. Likewise, fishing in the Caribbean is often associated with chronic or seasonal poverty (Brown 2001), underscoring the importance of analyzing these data by occupational category.

Years of residence in a community had emerged in fieldwork as a potentially important variable to predict participation, especially at the two sites in Belize, where there were clear discrepancies between those who had recently arrived in the community and those who had lived there for a number of years. This variable was found to be significant to predict both participation and one's ability to identify 
someone involved in management, and reflects the potential importance of a longterm, stable population in implementing co-management. However, when tested by site, this relationship was important only for those two sites in Belize, and not for the others. Additionally, those who had resided in the community longer were less likely to believe their interests were being represented, perhaps because, as long-term residents, they have a greater stake in the MPA, or because they are frustrated as a result of previous experiences.

Analysis of the network variables found positive relationships between both meeting attendance and the belief that one's interests were represented, and one's position within the network. These findings speak to the importance of a social network, or social capital in general, in stakeholder participation and issues of representation.

While analysis of the data found many significant relationships to predict participation in the MPA, it is important to note that the effect size of the logistic regression models was relatively small, and that the demographic factors and small number of questions analyzed cannot come close to providing a complete picture of why individuals choose to participate in activities related to an MPA.

One potentially relevant finding of these analyses is the importance of whether or not an individual can name someone involved in the MPA in predicting their participation in activities related to the MPA. While this finding is somewhat obvious, in that those who have been at meetings can probably name the people in charge of the meetings, this result corroborates the findings of the chapter on network analysis, and 
highlights the importance of personal contacts and community linkages in community participation.

By analyzing data on participation for each MPA alongside the qualitative data on each individual co-management arrangement, it becomes apparent that the greater the diversity of stakeholders involved in the co-management process and the more active the management bodies are within the local community, the more likely individuals are to attend meetings or be otherwise engaged in the MPA. Engagement in the MPA leads stakeholders to feel their interests are represented by the process. This research points to the conclusion that not all co-management arrangements are created equal; different stakeholder groups must be identified and engaged in order to ensure equitable management. 


\section{CHAPTER 7. DISCUSSION AND RECOMMENDATIONS}

\section{Introduction}

The primary objective of this dissertation is to evaluate co-management arrangements at several sites in the Caribbean by comparing participation by individuals and groups in meetings and management activities. An underlying assumption of this research is that successful co-management, at least from a governance perspective, is that which encourages participation by stakeholders, and encompasses a wide range of stakeholder perspectives in decision-making processes.

A secondary objective of this dissertation is to use network analysis to understand the underlying social network for stakeholders in communities with MPAs to determine what impact this underlying structure has on the co-management arrangement and participation. Network analysis is used here as a tool to expand thinking about stakeholder participation, to increase our understanding of why it is that individuals choose to participate in management activities.

The previous chapters provide the foundation to answer the following questions: 1) How do social networks affect participation?; 2) What is the relationship between successful co-management and social networks?; 3) What does successful comanagement look like? The responses to these questions will be summarized in this chapter. Additionally, management recommendations to improve co-management processes for each of the sites studied in this dissertation are included. 


\section{How do social networks affect participation?}

As indicated in the earlier chapters, there is a strong correlation between whether community members participate and who they know. Those individuals who named people involved in co-management of the MPA as those who they would go to with a question or to make their opinion known about the MPA are more likely to have attended meetings or participated in management. Similarly, this research found strong correlations between one's position within the social network and the likelihood that one has attended a meeting. The more connections one has to others already involved in the MPA, the more likely one is to attend meetings, as well as to believe one's interests are represented by those in charge. There also appears to be a fairly consistent connection between the percentage of people who have attended meetings within a community and the centralization measure for the particular social network. Typically, where the network was more centralized, meaning more respondents were connected to key actors at the center of the network, the greater the percentage of community members participating.

While some of these conclusions may seem self-evident, they are important in the larger context of measuring social capital. Individuals are likely to become familiar with those in charge through attending meetings, even if they did not know those individuals in positions of power previously; participation and network position are mutually reinforcing. The social networks overall, and the social capital they represent, will also be reinforced as individuals participate in meetings. The more often individuals attend, the more key actors in positions of power they are likely to know, and the more important they themselves become within the network through 
increasing the number of ties they have to others, and their ability to serve as an intermediary.

At each of the MPAs included in the study, fishermen and tourism stakeholders have been involved in the co-management process through attending meetings, serving on boards, and participating in other activities such as clean ups, mooring maintenance, trainings, etc. Tour guides and fishermen were also found to have more connections within the social networks, although their network positions were different (tour guides were more likely to play an intermediary role). Those working in tourism did not have more connections within the networks than other occupation groups. As demonstrated in Chapter 5, tour guides and fishermen in particular are also likely to have links to similar individuals involved in co-management. This may be advantageous in that they may be represented by others with similar interests in the co-management structure, but can have disadvantages if these groups are only connected to a limited portion of the social network, and thus may be limited in the information they receive through the network.

Each of the co-management arrangements has succeeded in involving stakeholders from various sectors in some capacity; however, the extent of participation and the difference this might make varies. Participating in MPA activities does not necessarily mean these stakeholders are able to influence the process. While tour guides and others involved in tourism for the most part believed their interests were represented, the majority of fishermen did not feel their interests were being represented in the co-management process. As analysis of the network data demonstrates, fishermen on average have more connections within the network than 
other occupations, but do not necessarily hold more centralized positions, and are not necessarily linked directly to those doing the decision-making. Participation does not necessarily translate to the ability to direct the outcome of management.

However, overall, those who have been involved generally do feel their interests are being represented; increasing involvement in the MPA, particularly by key stakeholder groups, is likely to increase support of management activities and of the MPA overall. While, once again, it could be that support induces participation, rather than the other way around, those fishermen who participated were more likely to say their interests were represented. It is more likely that support and participation can be viewed as a two-way street, with each inducing the other, rather than viewing the relationship between the two as simply in one direction or the other.

\section{What is the relationship between successful co-management and social networks?}

From the perspective of this paper, successful co-management is that which results in participation by a large and diverse group of stakeholders, and in the ability of stakeholders to meaningfully exert influence over management. As discussed above, network position is strongly correlated with participation. As Bodin and Crona note: "possessing a central position in a network is linked to a greater ability to exert influence in power, as well as coordinating action" (2009, 2766, from Burt 2003). The social networks presented in Chapter 5 represent only connections related to the MPA, and are just a fraction of the existing underlying social networks within a community. Nevertheless, it has been pointed out by numerous authors that social capital is 
important for any sort of cooperative natural resource management, including comanagement.

Generally, within the social networks presented in Chapter 5, most of the highly central actors in the networks are to some degree involved in the comanagement of the related MPA. However, the overlap between those actors who are the most central to the network and the individuals who are most influential in the comanagement of the MPA varies between sites. At the sites that are arguably the most successfully co-managed (i.e. Saba and St. Eustatius National Marine Parks, and the Laughing Bird Caye National Park), the network analysis demonstrated the greatest overlap between those individuals responsible for co-managing the MPA and the most prominent actors within the networks. This is because respondents frequently named the individuals who are those doing the co-managing, demonstrating a familiarity with both the individuals involved in management and a general transparency of the comanagement process. At the Buccoo Reef Marine Park and the Scotts Head/Soufriere Marine Reserve, where it can be argued the co-management arrangements are less successful based on lower participation rates and less agreement that those in charge represent the interests of stakeholders, the most central actors named in the network corresponded less well with the key actors in co-management. As discussed in Chapter 5 , those networks representing the most successful co-management arrangements were the most centralized, because there are more stakeholders with direct connections to individuals making decisions about the MPA. These networks are also more evenly distributed, in that community members reported seeking out a variety of individuals, 
providing a greater diversity of opinions and more even representation of different stakeholder interests within the co-management body.

When the data set as a whole was analyzed, tour guides were found to have more connected positions within the networks than other stakeholder groups. Each MPA has a tourism component, and tour guides are an important stakeholder group benefiting from the MPAs. For each of the MPAs, tour guides and/or the dive industry are represented on the co-management board, either formally, through a representative from a formal association, or informally. At all sites, there was some kind of tour guide or dive industry association, which allows individuals working in this industry to be organized and to be informed about the MPA through the association. This connection permits those working as tour guides to have access to the decision-making processes, and to make their needs understood to those responsible for co-managing the MPA.

On the other hand, "in those stakeholder groups that are poorly organized, the inability to develop a coherent message and deliver it to the appropriate agency is in effect exclusion" (Tomkins et al. 2002, 1106). Few other stakeholders were formally organized, and thus risk exclusion from the decision-making process. Typically, for a group to be organized they require a leader of some type. Those individuals who are marginalized in co-management typically named someone at a higher level than themselves, such as someone within the government, or, frequently, named no one at all and appear as isolates within the networks. This may be representative of the fact that there is no organization, whether formal or informal, among those marginalized in the process, and therefore no one whom they might view as their representative in 
matters related to the marine reserve. One such group is women, who, as discussed in Chapter 6, are less likely than men to know of the MPA or to attend meetings related to the MPA. Women were not frequently employed as fishermen or tour guides, and are therefore not likely to be formally represented in co-management. However, many of the women surveyed did work in tourism, and thus may have a direct or indirect interest in the management of the MPA, but no representation.

The exception to this rule may be fishermen who, while often marginalized in many societies, do sometimes form a somewhat cohesive group. When an effort has been made to include fishermen in meetings and in management for the marine reserves to some extent, de facto leaders among the fishermen have emerged through this process. At some sites, fishermen were formally organized into a cooperative which is represented on the board of directors (Hol Chan, Laughing Bird Caye), while at the rest of the sites, fishermen are not formally organized and are also not directly represented in the co-management of the MPA.

Mean years of residence emerged as a potentially important variable in predicting participation and support for the MPA, with apparent differences uncovered in fieldwork between newcomers to the community and those who had lived there their entire lives. Ostrom (1990) has noted in her work that one of the factors that may predict successful and enduring common property institutions is the stability of populations in a location over a long period of time. Years of residence is a variable that is linked to social networks - the longer an individual has lived in a community, the more community members they are likely to know, and the more likely they are to appear within the MPA social network. 
In my work, years of residence in the community was found to correlate with participation in the co-management of the MPA; individuals who had been in the community longer were more likely to have participated. There was, however, a negative relationship between years of residence and belief that one's interests were represented. Also interesting is the fact that the mean years of residence within the community was higher for those MPAs with the least support. The mean years of residence in Scotts Head and Soufriere was 33.6 years, and in the communities surrounding Buccoo Reef it was 22.1 years. San Pedro (Hol Chan) and the communities associated with Laughing Bird Caye had mean years of residence of 15.3 and 15.0, respectively (data on years of residence was not collected for the Saba and St. Eustatius marine parks). The two Belize sites had shorter mean residence periods largely because of a significant influx of people in the communities from the tourism industry. While this seems to contradict Ostrom's assertion that the stability of populations will lead to success in common property management (although, to be sure, this sample size is too small to make any such statement), the correlation between years of residence and participation indicates that it is the long-term, stable residents in these communities who are participating in management. Fieldwork confirmed that many of the recent migrants to the communities were uninvolved in the MPA, and in some cases represent a group lacking representation in the decision making process.

Community size is another factor that cannot be ignored in considering the relationship between social networks and successful co-management. The smallest and most insular community included in the study - the island of Saba - also had the 
highest network centralization and the most respondents who could correctly name someone involved in the MPA. St. Eustatius and Scotts Head/Soufriere also have small, geographically isolated populations, and high network centralization as a result. Communities with a smaller population are likely to have a stronger existing social network that can be capitalized upon in advancing a co-management scheme, whereas larger communities may require additional effort to forge social capital around a comanaged MPA.

\section{What does successful co-management look like?}

As stated above, successful co-management is assumed to be made up of an arrangement where the interests of a variety of stakeholders are represented, and where a large number of stakeholders are participating in co-management in some way, either through attending meetings or being involved in other activities. This research found the more successfully co-managed MPAs to be the ones where more community members felt their interests were represented by those in charge, seemingly a good measure of success. Another important factor is representation, and here the results were mixed; while one important stakeholder group, tour guides, felt their interests were represented, fishermen, another important group, were more likely to state that their interests were not being represented by those in charge. As stated in Chapter 2, there are always winners and losers from a co-management arrangement, and while fishermen are often participating in meetings and other activities, they do not necessarily feel their interests are fairly represented. However, a relationship between meeting attendance and believing one's interests are represented was found 
for fishermen; those participating in meetings were more likely to say their interests are represented. This finding has simple yet important management implications; increasing participation by fishermen, as well as other stakeholders, can increase their support. If stakeholders attending meetings are allowed to contribute in a meaningful way, then their interests are being represented.

When the data collected for these sites on participation are compared with the network analysis measures such as centralization, it begins to tell a story about the success of co-management at each site. This can then be compared with data collected by Dalton et al. on perceptions of success for each of these marine reserves. In this study, respondents were asked whether or not they believed the MPA to be successful. While these were different respondents surveyed at a different time, their responses create a more complete picture of the co-management of these particular sites.

\begin{tabular}{|l|l|l|l|l|}
\hline Site & $\begin{array}{l}\text { Percentage } \\
\text { participation }\end{array}$ & $\begin{array}{l}\text { Believes } \\
\text { interests are } \\
\text { represented }\end{array}$ & $\begin{array}{l}\text { Network } \\
\text { centralization }\end{array}$ & $\begin{array}{l}\text { Percentage of } \\
\text { respondents who } \\
\text { believed the MPA } \\
\text { was successful } \\
\text { (Dalton et al. study) }\end{array}$ \\
\hline $\begin{array}{l}\text { Buccoo Reef } \\
\text { Marine Park }\end{array}$ & $12.5 \%$ & $58.8 \%$ & $11.22 \%$ & $74 \%$ \\
\hline $\begin{array}{l}\text { Hol Chan Marine } \\
\text { Reserve }\end{array}$ & $16.6 \%$ & $87.6 \%$ & $17.00 \%$ & $93 \%$ \\
\hline $\begin{array}{l}\text { Laughing Bird } \\
\text { Caye Nat. Park }\end{array}$ & $25.2 \%$ & $87.6 \%$ & $18.89 \%$ & $86 \%$ \\
\hline $\begin{array}{l}\text { Saba Nat. Marine } \\
\text { Park }\end{array}$ & $26.9 \%$ & $\mathrm{n} / \mathrm{a}$ & $28.76 \%$ & $88 \%$ \\
\hline $\begin{array}{l}\text { St. Eustatius Nat. } \\
\text { Marine Park }\end{array}$ & $15.5 \%$ & $\mathrm{n} / \mathrm{a}$ & $21.94 \%$ & $91 \%$ \\
\hline $\begin{array}{l}\text { Scotts Head/ } \\
\text { Soufriere Marine } \\
\text { Reserve }\end{array}$ & $14.3 \%$ & $48.4 \%$ & $19.76 \%$ & $63 \%$ \\
\hline
\end{tabular}


For each site, more than $50 \%$ of respondents believed the MPA to be successful, and it is important to note that respondents were evaluating the MPA as a whole, rather than just the governance of the MPA. However, these numbers still support the results of this study, and peoples' perceptions of success are likely to be related to the success of the co-management arrangement. The Buccoo Reef Marine Park and the Scotts Head/Soufriere Marine Reserve had the lowest perceived rates of success in the Dalton et al. study. Similarly, these two had the lowest rates of participation, and the fewest respondents who believed their interests were represented by management. In fact, these two MPAs stand out from the other four fairly dramatically on all measures used in this research. In particular, the SSMR, which had the fewest respondents believing their interests were represented, also had the fewest respondents stating they believe the MPA was successful. While, again, the sample size of MPAs is small for this study, it is evident that participation and social capital, as measured through network analysis, are important elements of success.

By comparison, the other sites, with high levels of participation and higher network centralization, had more respondents stating they believed the MPA was successful, although, interestingly, those sites with the highest participation levels Saba Marine Park and Laughing Bird Caye - had fewer respondents stating the MPAs were successful than at the Hol Chan Marine Reserve and the St. Eustatius National Marine Park. The Hol Chan Marine Reserve had the highest percentage of respondents stating they believed the MPA was successful out of this group; this site also had the most respondents who thought their interests were represented by management. Clearly there is a strong link between these two measures. 
The data analysis here combined with observations in the field ultimately found the keys to successful co-management for the case studies here to consist of two important ingredients. One is a well-known and highly visible staff to manage the MPA. The four sites with the greatest levels of participation and the highest levels of success share in common a staff of individuals who are well known to the community, and a physical location (an office and/or a visitors' center) where the community had physical access to the staff. The staff and board must not only be known to the community, but also accessible. At the Scotts Head/Soufriere Marine Reserve, the chairman of the board was well known to the community, but inaccessible - he is much wealthier and more educated than the rest of the community, and is seen as an elitist by the rest of the community. The marine reserve manager is also almost completely inaccessible, as he lives on another island (in an entirely different country) much of the time. These factors do not engender trust between the community and the management of the MPA, and while there is a co-management structure in place, these two individuals dominate the decision-making process.

Another important factor these sites have in common is a staff and a board of directors or advisory group made up of individuals who reflect important stakeholders and the make-up of the community. Where the co-management group has individuals who represent important stakeholder groups, such as the tour guide association, participation and decision-making processes seem to be more accessible to those stakeholders. Beem (2007) notes in her analysis of fisheries co-management the important role that policy entrepreneurs play in developing co-management, and the necessity of a strong relationship between this individual and the fishing community. 
Likewise, it is evident from this research that successful co-management is highly dependent upon a strong relationship between the key actors and the key stakeholder groups. The co-management structure of the Laughing Bird Caye National Park can be held up as a model in this respect; not only are many different stakeholder groups represented on the board of Friends of Nature (including fishermen, tour guides, dive guides, the tourism industry, and business), but also each of the surrounding communities is represented. This structure has led to a high rate of participation (more than $25 \%$ ), and to the greatest number of stakeholders believing their interests are represented by management.

It is important, however, to remember the participation paradox as described by Suárez de Vivero et al. (2008), where an increasing number of actors leads to decreasing prominence of traditional interest groups. While this danger exists, it is also important to consider that MPAs have a great number of stakeholder groups, some traditional and some less so, with an interest in a well-functioning, wellgoverned MPA. At the sites included in this study, there are a number of user groups as well as non-users in the communities with an interest in the MPA in addition to fishermen and other traditional groups. This does not necessarily mean that all groups will participate to the same level, mostly because of varying interest, and comanagement should err on the side of being overly inclusive as a precaution against excluding important interests from the governance process.

Network analysis can have practical applications for managers trying to improve the involvement of community members in the co-management process. In using network analysis to identify influential individuals within the community, one is 
not dependent solely on experts' perceptions of who these influential people are (Bodin and Crona 2008). This is useful for management purposes, because it is possible to identify some of the key individuals within the community who may not be cited by those involved in management as being important and playing a role. These may be individuals who can serve an important role as a bridge to components of the community who are not being included, to develop a more equitable process.

It is important to note that support for the MPA, and similarly, participation in management activities, will change over time. While co-management and the potential benefits to be derived from it, such as more support for management and an increase in equity among stakeholders, are often assumed to increase with the life of the project, often this is not the case. In the case of the Saba National Marine Park, for example, when the MPA was first started, there was considerable interest on the part of the community. Now that the MPA has been in place and stable for many years, participation by community members has dropped off.

\section{Site Recommendations}

Co-management should be an adaptive management process, and not all of the following recommendations may be appropriate at the present time. However, while all of these MPAs should be commended for their current efforts to include stakeholders in management through the co-management process, each has room for improvement. 


\section{Hol Chan Marine Reserve}

This site is well accepted within the community, but suffers from a fairly low participation rate. While meetings are sometimes held within the community, there appears to be little opportunity for direct input from the public. Participation is significant among tour guides, who successfully pushed to increase the size of the reserve in 2007. On the other hand, community members not originally from San Pedro, of which there are many, frequently indicated that they felt excluded from decision-making related to the reserve. As many of these recent migrants to the island are involved in the tourism industry, more effort should be made to notify them of opportunities to participate at the very least.

There were concerns cited within the community about the financial accountability and transparency of the marine reserve and some of its staff. The reserve should hold regular meetings on at least a yearly basis where they present to the public a summary of the past year, and should include a financial summary to assuage the concerns of the public. There should also be opportunity for direct input from community members at these meetings.

\section{Scotts Head/Soufriere Marine Reserve}

This site suffers from distrust of the management authority (LAMA) and of the individual who chairs the management authority. An effort should be made to include more stakeholder interests on LAMA, perhaps by allowing the public to nominate a couple of additional members. At present, fishermen are not represented on LAMA, which seems a significant oversight, considering that fishing is a major activity within 
these two communities, and a major component of the reserve. A fisherman, or perhaps multiple fishermen of different gear types, should be nominated to the board to represent fishing interests in the community as soon as possible. Network analysis could be helpful in selecting the most influential fishermen in the communities, who perhaps should be those with a seat on LAMA. As this research found, most fishermen in these communities do not feel their interests are represented by LAMA, and as they are the stakeholders whom this reserve was created to protect, it is imperative they feel their interests are taken into consideration. Additionally, because there is concern within the community about the LAMA chair, provisions should be made to rotate the chairperson on a regular basis.

While LAMA and the Fisheries Department were attempting to hold meetings with fishermen, LAMA should also hold regular, informational meetings with the general public. An open and transparent process, or at least a venue to provide the public with general information and a forum to ask questions, may alleviate some of the distrust that currently plagues this site.

\section{St. Eustatius National Marine Park}

St. Eustatius appears to have a strong public presence through its outreach program, even if the rate of participation is relatively low. As discussed in Chapter 4, many of the residents of the island are employed in occupations that are not affected by the marine reserve, so the desire to participate may be low amongst many of the residents. The only significant source of conflict over the marine park is with fishermen, as some poaching continues to take place. There is a spot on the board 
available for a fisherman, so a key fisherman who is willing to serve on the board of directors should be identified for inclusion in this group.

\section{Saba National Marine Park}

There was a sense of some participation fatigue for the Saba National Marine Park, where many people had attended meetings in the past, but current meetings are sparsely attended by the same individuals each year. Some people felt the park staff was not doing a sufficient job of engaging the public, and it is clear that Sabans are less engaged than the expat community. An effort should be made to re-engage the local Saban community, both through formal meetings and perhaps less formally simply through speaking with community members about their concerns. Sabans are underrepresented on the board of directors and among the staff; an effort should also be made to include more Sabans in these decision-making roles, and this may lead to more engagement by the community as a whole.

\section{Laughing Bird Caye National Park}

While other authors have cited concerns about transparency in decisionmaking and financial matters for the Friends of Nature (e.g. Pomeroy et al.2004), this was not evident from my fieldwork. I heard few complaints about the management of the park. However, as this area is highly diverse, with migrants coming from other parts of Belize and Central America, as well as two indigenous groups - the Mayans and the Garifuna - found in the region, these various groups are underrepresented both 
in the management structure and in participatory activities. There is a significant population in Placencia in particular of individuals who have come from elsewhere to work in tourism and have never heard of the marine park. More effort should be made to inform these newcomers to the community about the marine park and to seek their attendance at meetings.

\section{Buccoo Reef Marine Park}

The Buccoo Reef Marine Park, at the time of fieldwork, had only an advisory board that was not delegated with any authority over management, so the first step for this marine park would be to provide legal authority to this group as a co-management body. Secondly, more stakeholder groups should be included on this board, rather than just formal government departments and NGOs. Fishermen are not directly represented on this board; this should be remedied, particularly because a sizable number of fishermen pass through the marine park to fish each day. More stakeholders dependent upon the marine reserve to make a living should be represented. Currently there is a glass bottom boat operator on the board; dive operators, who do not typically dive in the park but do take snorkeling trips in the park, as well as vendors who operate in the land adjacent to the park and are dependent upon tourism from the park, should also be considered.

The advisory board should also hold meetings for the general public, something that has not been done for the Buccoo Reef Marine Park. As this area is heavily reliant on tourism, and is used for recreation by residents of the local 
communities, there are many community members with a direct interest in the comanagement of this marine park.

\section{Conclusions and Next Steps}

The findings of this study highlight the importance of social networks in encouraging the participation of stakeholders in management activities related to a marine protected area. This conclusion has implications beyond marine protected areas, and should be considered in other coastal management areas. Social networks, and the social capital that results from these connections, are essential in promoting cooperation among stakeholders, and to creating successful co-management of resources. This research also found a significant relationship between whether stakeholders had attended meetings about the marine protected area, and whether or not they believed their interests were represented by the management of the marine protected area. This finding highlights the importance of encouraging participation by a broad range of stakeholders to account for their interests, and to encourage their support for not only existing management activities but potential future coastal management projects.

There are many next steps for further research that could be taken to bolster the findings here and to further elucidate the factors influencing participation. One important next step would be to ground truth the network analysis. This could be done by selecting individuals within the network, providing them with information, and detecting whether that information did in fact travel through the network in the way that could be predicted by the network analysis. Because social networks related to the 
MPA and participation are likely to be mutually enforcing, a longitudinal study could be conducted to observe how individuals' positions within the network change with increased participation and attendance at meetings. Similarly, an important next step would involve more detailed surveys of individual support for those involved in management, and the extent to which they believed their interests were represented, before and after participating in management activities to more conclusively determine how well one variable can influence the other.

Co-management should be viewed as a highly desirable approach to natural resource management, and encouraging co-management arrangements that are highly representative of the interests of stakeholders should be viewed as an important objective of academics and policy makers. This research serves as a step in the evolution of a more nuanced and critical understanding of what makes co-management and its underlying participatory processes successful in the realm of coastal management. 


\section{LITERATURE CITED}

Adger, W. N., K. Brown, and E. L. Tompkins. 2005. The political economy of cross scale networks in resource co-management. Ecology and Society, 10(2).

Agrawal, A.; Gibson, C.C. 1999. Enchantment and disenchantment: the role of community in natural resource conservation. World Development, 27 (4). 629-649.

Alamilla, M. Hol Chan Marine Reserve, personal communication, December 4, 2008.

Armstrong, H. Buccoo Reef Trust, personal communication, February 2, 2009.

Arnstein, S.R. 1969. A Ladder of Citizen Participation. Journal of the American Institute of Planners 35 (1969), p 216.

Beem, B. 2007. Co-management from the top? The role of policy entrepreneurs and distributive conflict in developing co-management arrangements. Marine Policy, 31; 540-549.

Berkes, F. 2000. Cross-scale institutional linkages: Perspectives from the bottom-up. Proceedings of the NAS/NRC Panel on Institutions for Managing the Commons IASCP 2000 Conference.

Berkes, F. 2004. Rethinking community-based conservation. Conservation Biology, 18 (3): 621-630.

Bernard, R.H. 2002. Research Methods in Anthropology: Qualitative and Quantitative Methods, third edition. Walnut Creek, CA: AltaMira Press.

Bodin, O.; Crona, B. 2008. Management of Natural Resources at the Community Level: Exploring the Role of Social Capital and Leadership in a Rural Fishing Community. World Development, 36(12): 2763-2779.

Bodin, O.; Crona, B. 2009. The role of social networks in natural resource governance: What relational patterns make a difference? Global Environmental Change, 19: 366-374.

Borgatti, S.P.; Everett, M.G. 1999. Models of core/periphery structures. Social Networks, 21: 375-395.

Brown, D.N.; Pomeroy, R.S. 1999. Co-management of Caribbean Community (CARICOM) fisheries. Marine Policy, 23 (6). 549-570. 
Brown, K.; Adger, W.N.; Tompkins, E.; Bacon, P.; Shim, D.; Young, K. 2001. Tradeoff analysis for marine protected area management. Ecological Economics, 37: 417434.

Buccoo Reef Trust. N.d. Coastal \& Marine Management and Education in the Southeastern Caribbean. Online at: http://www.buccooreef.org/icran.html. Accessed November 30, 2010.

Carlsson, L.; Berkes, F. 2005. Co-management: concepts and methodological implications. Journal of Environmental Management, 75: 65-76.

Cho, L. 2005. Marine protected areas: a tool for integrated coastal management in Belize. Ocean and Coastal Management, 48: 932-947.

Choguill, M.B.G. 1996. A ladder of community participation for underdeveloped countries. Habitat International, 20 (3): 431-444.

Costenbader, E.; Valente, T.W. 2003. The stability of centrality measures when networks are sampled. Social Networks, 25: 283-307.

Crona , B.; Bodin, O. 2006. What you know is who you know? Communication patterns among users as a prerequisite for co-management. Ecology and Society 11(2): 7.

Degenne, A.; Forse, M. 1999. Introducing Social Networks. London: Sage Publications.

Dilrosun, F. 2004. Inventory of the Fishery sector of St. Eustatius. Island Territory of CURAÇAO, Department of Agriculture, Animal Husbandry and Fisheries.

Ernston, H.; Sorlin, S.; Elmqvist, T. 2008. Social Movements and Ecosystem Services: the Role of Social Network Structure in Protecting and Managing Urban Green Areas in Stockholm. Ecology and Society, 13 (2): 39.

Esteban, N. STENAPA, personal communication, June 25, 2008.

Freeman, L. 1979. Centrality in social networks: Conceptual clarification. Social Networks, 1: 215-39.

Garaway, C.; Esteban, N. 2002. The impact of marine protected areas on poorer communities living in and around them: institutional opportunities and constraints: Appendix 3 - case study of Hol Chan Marine Reserve, Belize. DFID Natural Resources Systems Programme. December 2002.

Geoghegan, T.; Renard, Y. 2002. Beyond community involvement: lessons from the insular Caribbean. Parks, 12 (2). 16-25. 
Geoghegan, T.; Smith, A.H.; Thacker, K. 2001. Characterization of Caribbean Marine Protected Areas: An Analysis of Ecological, Organizational, and Socioeconomic Factors. Caribbean Natural Resources Institute. CANARI Technical Report No. 27.

Google Earth. 2010. Accessed April 18, 2010 from: www.google.com/earth

Hanneman, R.A.; Riddle, M. 2005. Introduction to social network methods. Riverside, CA: University of California, Riverside (published in digital form at http://faculty.ucr.edu/ hanneman/)

Hardin, G. 1968. The tragedy of the commons. Science, 162: 1243-1248.

James, C.; McConney, P.; Pomeroy, R. 2006. Case study analysis of coastal resources Jentoft, S. 2000. Legitimacy and disappointment in fisheries management. Marine Policy, 24. 141-148.

Jentoft, S. 2005. Fisheries co-management as empowerment. Marine Policy, 29. 1-7.

Jentoft, S.; McCay, B.; Wilson, D.C. 1998. Social theory and fisheries comanagement. Marine Policy, 22, 423-436.

Kelleher, G. 1999. Guidelines for Marine Protected Areas. Gland, Switzerland: International Union for the Conservation of Nature and Natural Resources.

Lawrence, N. Dominica Fisheries Department. personal communication, November 27,2008

Loucks, L., J. A. Wilson, and Ginter, Jay J. C. 2004. Experiences with fisheries comanagement in North America. Pages 153-169 in D. C. Wilson, J. R. Nielsen, and P. Degnbol, editors. The fisheries co-management experience: Accomplishments, challenges, and prospects. Kluwer Academic Publishers, Boston.

McCay, B.; Acheson, J.M., eds. 1987. The Question of the Commons: The Culture and Ecology of Communal Resources. Tucson: The University of Arizona Press.

McConney, P., R. Pomeroy and R. Mahon. 2003. Guidelines for coastal resource comanagement in the Caribbean: Communicating the concepts and conditions that favour success. Caribbean Coastal Co-management Guidelines Project. Caribbean Conservation Association, Barbados. 56pp.

McShane, T.O. and M.P. Wells (eds.) (2004) Getting Biodiversity Projects to Work: Toward More Effective Conservation and Development. New York: Columbia University Press. 
National Research Council (NRC). 2001. Marine Protected Areas: Tools for Sustaining Ocean Ecosystems. Washington, DC: National Academies Press.

Noble, B.F. 2000. Institutional criteria for co-management. Marine Policy, 24. 69-77.

Ostrom, E. 1990. Governing the Commons: The Evolution of Institutions for Collective Action. New York: Cambridge University Press.

Ostrom, E. 2005. Understanding Institutional Diversity. Princeton University Press, Bloomington.

Parsram, K.; McConney, P. 2004. Belize Case Study: Marine Protected Areas CoManaged by Friends of Nature. A Summary of Lessons Learnt. Caribbean Conservation Association, Barbados. 9 pp.

Pinkerton, E. (ed.) 1989. Co-operative Management of Local Fisheries. Vancouver: University of British Columbia Press.

Plummer, R., FitzGibbon, J., 2004. Some observations on the terminology in cooperative environmental management. Journal of Environmental Management, 70: 63-72.

Pomeroy, R. S. 2001. Devolution and fisheries co-management. Pages 108-145 in R. Meinzen-Dick, A. Knox, and M. Di Gregorio, editors. Collective action, property rights, and devolution of natural resource management: Exchange of knowledge and implications for policy. DSE/ZEL, Feldafing, Germany.

Pomeroy, R. S., and R. Rivera-Guieb. 2006. Fishery co-management: A practical handbook. International Development Research Center, CABI Publishing, Cambridge, MA.

Pomeroy, R.S.; Berkes, F. 1997. Two to tango: the role of government in fisheries comanagement. Marine Policy, 21 (5). 465-480.

Pomeroy, R.S.; McConney, P.; Mahon, R. 2004. Comparative analysis of coastal resource co-management in the Caribbean. Ocean and Coastal Management, 47: 429447.

Pretty, J. 1995. Participatory learning for sustainable agriculture. World Development, 23 (8): 1247-1263.

Pretty, J.; Smith, D. 2004. Social capital in biodiversity conservation and management. Conservation Biology, 18 (3): 631-638.

Pretty, J.; Ward, H. 2001. Social capital and the environment. World Development, 29 
(2): 209-227.

Roberts, C.M. 2000. Selecting marine reserve locations: optimality versus opportunism. Bulletin of Marine Science, 66 (3): 581-592(2).

Roberts, C.M.; Hawkins, J.P. 2000. Fully Protected Marine Reserves: A Guide. Washington, DC: WWF Endangered Seas Campaign.

Rogers, E.; Kincaid, D. L. 1981. Communication networks: A paradigm for new research. New York: Free Press.

Rogers, E.M. 1983. Diffusion of Innovations. New York: Free Press.

Rosenberg, J.; Korsmo, F.L. 2001. Local participation, international politics, and the environment: The World Bank and the Grenada dove. Journal of Environmental Management, 62. 283-300.

Saba Conservation Foundation. 1999. Management Plan: Saba Marine Park.

Sandersen, H.T.; Koester, S. 2000. Co-management of tropical coastal zones: the case of the Soufriere Marine Management Area, St. Lucia, WI. Coastal Management, 28. 87-97.

Scholz, J.T.; Wang, C.L. 2006. Cooptation or Transformation? Local Policy Networks and Federal Regulatory Enforcement. American Journal of Political Science, 50 (1): 81-97.

Sen, S., and J. R. Nielsen. 1996. Fisheries co-management: A comparative analysis. Marine Policy 20(5):405-405-418.

SIDSnet. N.d. Soufriere/Scotts Head Marine Reserve. Small Island Developing States Network. Accessed from: http://www.sidsnet.org/successtories/14.html

Sobel, J.; Dahlgren, C. 2004. Marine Reserves: A Guide to Science, Design, and Use. Washington, DC: Island Press.

STENAPA. 2007. St. Eustatius Marine Park Management Plan 2007.

Suárez de Vivero, J.L.; Rodriguez Mateos, J.C.; del Corral, D.F. 2008. The paradox of public participation in fisheries governance. The rising number of actors and the devolution process. Marine Policy, 23 (3): 319-325.

Tompkins, E., W. N. Adger, et al. 2002. Institutional networks for inclusive coastal management in Trinidad and Tobago. Environment and Planning A, 34(6): 1095-1111. 
Tritter, J.Q.; McCallum, A. 2006. The snakes and ladders of user involvement: moving beyond Arnstein. Health Policy, 76: 156-168.

Wasserman, S; Faust, K. 1994. Social Network Analysis: Methods and Applications. New York: Cambridge University Press.

Wellman, B. 1983. Network analysis: Some basic principles. Sociological Theory, 1: 155-200. 